\title{
Comunidades de Trichoptera en ríos patagónicos \\ sometidos a diferentes \\ usos de la tierra
}

\section{Lic. Cecilia Brand}

Trabajo de tesis para optar al titulo de Doctor en Ciencias Naturales

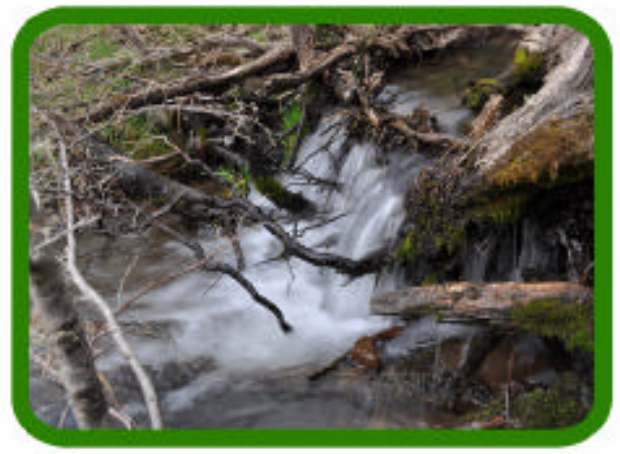

Directora de tesis: Dra. Maria L. Miserendino

Co-directora de tesis: Dra. Liliana Fernández
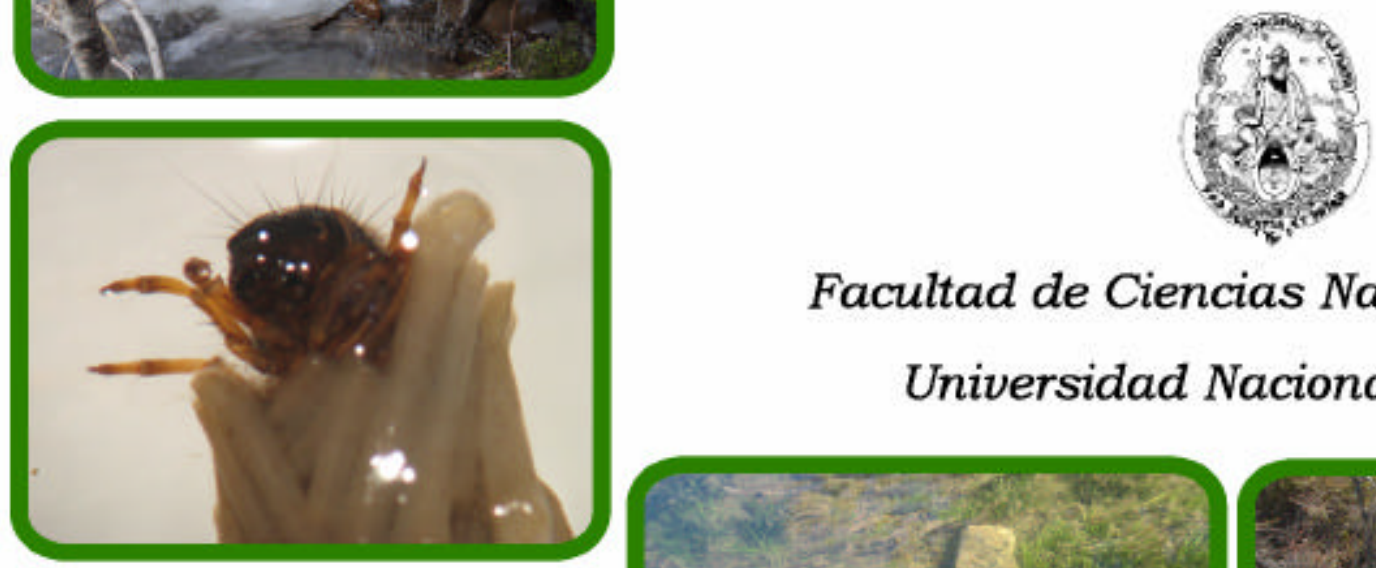

Facultad de Ciencias Naturales y Museo Universidad Nacional de La Plata
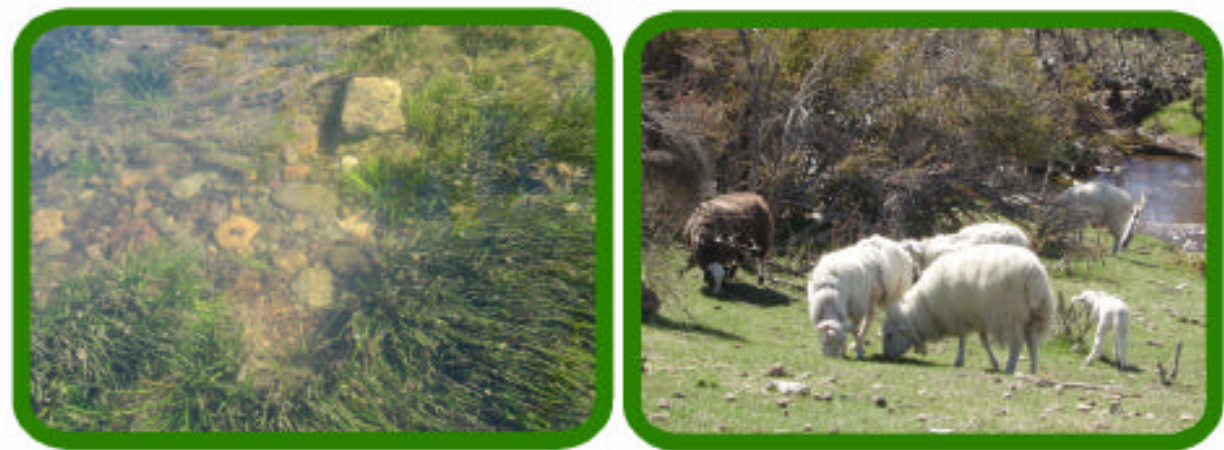


\section{ÍNDICE GENERAL}

\section{AGRADECIMIENTOS}

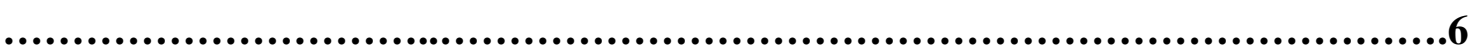

\section{RESUMEN}

\section{8}

\section{ABSTRACT}

\section{INTRODUCCIÓN}

1.1. Características biológicas y rasgos del Orden Trichoptera................17

1.2. Los Trichoptera como indicadores de la calidad del agua.................18

1.3. Los efectos del uso de la tierra.......................................20

1.3.1. Las urbanizaciones......................................21

1.3.2. Las pasturas...........................................23

1.3.3. Las prácticas forestales...................................25

1.3.4. Efecto de los usos de la tierra a escala de cuenca.................27

1.4. Justificación......................................................28

\section{HIPÓTESIS}

\section{OBJETIVOS}

3.1. Objetivos generales............................................... 31

3.2. Objetivos específicos............................................. 31

\section{4. ÁREA DE ESTUDIO}

4.1. Selección de sitios. 
4.2. Sitios urbanos .36

4.3. Sitios sometidos a actividades silvopastoriles .40

\section{MATERIALES Y MÉTODOS}

5.1. Caracterización geográfica...........................................52

5.1.1. Cálculo de las coberturas de usos por cuenca...................52

5.2. Características fisicoquímicas.....................................52

5.3. Caracterización de la vegetación terrestre y acuática......................55

5.4. Caracterización del hábitat...........................................55

5.4.1. Índice de calidad de ribera patagónico (QBRp)..................55

5.4.2. Índice de valoración de hábitat (HA) ........................57

5.5. Caracterización biológica........................................6 60

5.5.1. Análisis de materia orgánica autóctona y alóctona.................61

5.5.2. Análisis de datos.........................................62

5.5.3. Grupos funcionales alimentarios............................63

4.6. Análisis estadístico.................................................63

5.6.1. Comparaciones entre usos.................................63

5.6.2. Relaciones especie ambiente.............................64

5.6.3. Cobertura de cuencas y modelos predictivos..................66

\section{RESULTADOS}

6.1. Análisis de la biocenosis...........................................68

6.2. Uso urbano....................................................... 87

6.2.1. Descriptores de la cuenca y del tramo.........................87

6.2.2. Análisis de la materia orgánica..............................91

6.2.3. Vegetación acuática.......................................92

6.2.4. Caracterización del hábitat...................................99

6.2.5. Composición de la comunidad de tricópteros.....................93

6.2.6. Estructura funcional de la comunidad de tricópteros.............96

6.2.7. Distribución temporal de tricópteros en relación a las principales variables ambientales...........................................97

6.3. Usos de la tierra asociados a prácticas silvopastoriles....................100 
6.3.1. Descriptores de la cuenca................................100

6.3.2. Descriptores ambientales del tramo..........................100

6.3.3. Clorofila epilítica............................................ 104

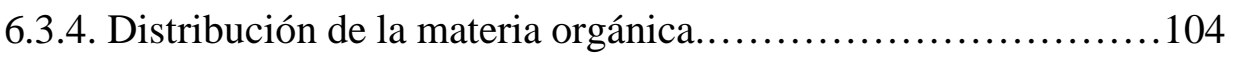

6.3.5. Ordenamiento de los sitios en base a características

ambientales....................................................... 105

6.3.6. Vegetación acuática......................................106

6.3.7. Caracterización del hábitat..................................107

6.3.8. Composición de la comunidad de tricópteros....................109

6.3.9. Estructura funcional de la comunidad de tricópteros............114

6.3.10. Relaciones estacionales especie-ambiente..................117

6.3.11. Atributos de la comunidad de Trichoptera a escala de hábitat..121

6.4. Comunidades de tricópteros y uso de la tierra a una escala de paisaje......122

\section{DISCUSIÓN}

\section{CONCLUSIONES}

\section{BIBLIOGRAFÍA}

\section{ANEXOS}

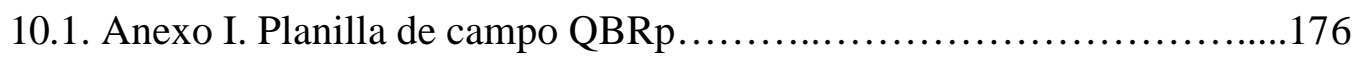

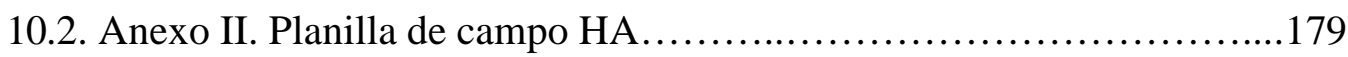


Brand, C. 2012 Comunidades de Trichoptera en ríos patagónicos sometidos a diferentes usos de la tierra

\section{Para Sofi,}

\section{I shin den shin.}




\section{Agradecimientos}

En primer lugar quiero agradecer profundamente a mi directora, Dra. María Laura Miserendino, por haberme dado la oportunidad y las herramientas para encaminarme en esta profesión y por todo el apoyo, la contención y sobre todo el cariño que puso en esta tarea (y por lograr que sea un poco menos mojarrita).

A mis padres, Pitu y Diego darme las raíces y las alas que me trajeron hasta acá. A Sofía, por ser mi inspiración todos los días y a mis hermanos Sancho, Juli, Joaco, Tomi y Fran (los quiero enanos!).

A mi gran y colorida familia, a mis abuelos, tíos, tías, primas, primos y allegados por todo el cariño y por estar siempre cerca cuando lo necesité. Y claro que a Marcelo Rossi, Analia Bosch y Cecilia Garzonio. A Camila Suárez por su asistencia, sin la cual las cosas me hubieran sido mucho más complicadas.

Gracias a mi familia adoptiva del LIESA, Dra. Laura Miserendino, Dra. Cecilia Di Prinzio, Dr. Miguel Archangelsky, Lic. Luis Epele, Lic. Guillermo Omad, Ing. Magdalena Aguirre, Dr. Pablo Pessacq, Dr. Ricardo Casaux y Eloísa Romero, no sólo por la impecable asistencia profesional, también por la calidez, la alegría y la compañía de todos los días (diseño, mates, terapia, música, películas, comida y posterazos!).

A Sebas, por el camino recorrido juntos, y a su familia por el cariño que me brindó durante tanto tiempo.

A la Dra. Liliana Fernández, muchas gracias por su paciencia, tiempo y dedicación.

Gracias a la Lic. Eugenia Hollmann por toda la ayuda y la compañía durante muchos años, a la Lic. Carolina Masi, por la asistencia en el campo, por la separación de muestras y por el trabajo compartido, a la Dra. Adriana Kutschker por las determinaciones de las plantuchis.

Mil gracias a la Dra. Elisa Angrisano, Dra. Julieta Sganga y a la Lic. Alejandra Valverde, por la asistencia y el entrenamiento en la determinación de Tricópteros, con tanta paciencia!

Gracias al Ing. Horacio Claverie y la gente de la Dirección General de Bosques y Parques, por la ayuda con el procesamiento de imágenes satelitales. Dirección de Pesca Continental de la Provincia de Chubut, por el préstamo de la sonda multiparamétrica durante las salidas de campo. 
A Don Cirilo Nancual y los pobladores que gentilmente nos cedieron el acceso a los sitios de muestreo.

Este trabajo de tesis se llevó a cabo con el financiamiento del Proyecto Plurianual PIP 5733 (CONICET): "LOS EFECTOS DEL USO DE LA TIERRA SOBRE AMBIENTES LOTICOS DE LA CORDILLERA PATAGÓNICA”, ha recibido financiación por parte de la Project AWARE FOUNDATION (California USA, P-001036, titular: Dra. María Laura Miserendino, 2005-2006) y ha sido declarado de interés provincial por la Dirección de Pesca Continental de la Provincia de Chubut (Res. 037/2003). 


\section{Resumen}

Las prácticas asociadas a los usos de la tierra afectan la integridad y la conservación de los ecosistemas acuáticos y se destacan como problemas emergentes en la cordillera Patagónica. Entre las comunidades acuáticas mejor representadas en cursos de agua cordilleranos se encuentran los Trichoptera. Las especies de este orden exhiben diferentes respuestas a los disturbios y a las perturbaciones ambientales antropogénicas, por lo que son consideradas potencialmente buenas indicadoras del estado ecológico de los sistemas lóticos.

El objetivo general de este trabajo fue determinar las variaciones de las comunidades de tricópteros en 18 sitios de arroyos de la cordillera patagónica sometidos a diferentes usos. En el diseño se compararon arroyos en urbanizaciones vs. sitios de referencia y para usos silvopastoriles se contrastaron arroyos ubicados en pasturas, plantaciones de pino, bosques de ñire nativo con extracción de madera vs. arroyos en bosque nativo de referencia. Para cada tipo de uso y sus respectivos testigos se seleccionaron tres ríos $(n=3)$, todos ubicados en el NO de la provincia del Chubut (entre $41^{\circ} 59^{\prime} 33^{\prime \prime}$ y $\left.43^{\circ} 44^{\prime} 09^{\prime \prime} \mathrm{S}\right)$. Los sitios se visitaron trimestralmente durante el período de un año (mayo 2005-marzo 2006).

Se realizó una caracterización de los usos predominantes en la cuenca aguas arriba de cada sitio seleccionado (tipo de vegetación y porcentaje de cobertura) mediante imágenes LandSat ETM (años 2000 y 2001. 15 m de resolución) utilizando un sistema de información geográfica (GIS) (Software Arc Wiew 3,3). En cada oportunidad se registraron los principales parámetros fisicoquímicos (ancho del lecho seco y mojado, profundidad, velocidad, caudal, composición granulométrica del sustrato, temperatura del agua y del aire, $\mathrm{pH}$, conductividad, oxígeno disuelto, turbidez y salinidad) y se tomaron muestras de agua para obtener valores de nutrientes (nitritos + nitratos, amonio, fósforo reactivo soluble) y del total de sólidos en suspensión. Durante el estiaje se midió la clorofila $a$ epilítica y se realizó una caracterización de la vegetación acuática y terrestre. El estado de conservación y estructura de la cobertura vegetal ribereña se evaluó mediante el índice de calidad de bosque de ribera patagónico (QBRp). La calificación del estado del hábitat físico se realizó mediante el índice de valoración de hábitat para ríos-arroyos en zonas de alto gradiente (HA).

Se tomaron en cada sitio y en cada ocasión muestras bénticas, tres réplicas en rápidos y tres en pozones, las que se colectaron con red Surber modificada ( $250 \mu \mathrm{m}$ de 
poro y $0,09 \mathrm{~m}^{2}$ ) totalizando $n=432$ muestras. Las muestras se fijaron in situ (formaldehído $10 \% \mathrm{v} / \mathrm{v}$ ) y una vez en laboratorio los tricópteros fueron separados manualmente bajo lupa (aumento 5X) y conservados en alcohol (70\%). La identificación de los individuos se realizó utilizando claves disponibles para la zona. De cada réplica se realizó una cuantificación visual de los componentes del detrito.

Se calculó la densidad total de individuos $\left(\right.$ ind. $\mathrm{m}^{-2}$ ) y la densidad media total para cada sitio, se registró la riqueza media estacional, media total y la riqueza acumulada de especies. Se obtuvieron los índices de diversidad de Shannon-Weaver y de equitatividad de Pielou. Cada especie fue asignada a un grupo funcional de acuerdo a la observación de las piezas bucales, el análisis de contenido estomacal y a la bibliografía existente, se calculó la abundancia y abundancia relativa de cada grupo funcional.

Se evaluaron las diferencias entre las características ambientales y los atributos estructurales y funcionales de la comunidad mediante un análisis ANOVA no paramétrico por rangos de Kruskal-Wallis y test de Mann-Whitney. Se realizó un Análisis de Componentes Principales (PCA) para estimar la variación de los parámetros físicos y químicos entre los sitios correspondientes a los usos silvopastoriles. Se identificaron las principales variables ambientales determinantes de los ensambles de especies de tricópteros en los sitios urbanos y preurbanos en los distintos momentos del año mediante un Análisis de Redundancias (RDA). La relación entre la densidad de especies de Trichoptera y las principales variables ambientales en los sitios sometidos a usos silvopastoriles se interpretó mediante un Análisis de Correspondencias Canónicas (CCA).

Se obtuvieron modelos de dispersión entre los distintos atributos de la comunidad de Trichoptera (variable dependiente) y los porcentajes de cobertura de la cuenca afectados por un determinado uso (variable independiente). Se seleccionaron aquellos modelos de mejor ajuste, los que se examinaron para visualizar un valor umbral en el porcentaje de cobertura de la cuenca a partir del cual los cambios en los atributos de la comunidad de Trichoptera indicaran una declinación rápida en la calidad del agua.

En el estudio se registraron 37 taxa, agrupados en 26 géneros y 13 familias. La densidad media por sitio estuvo comprendida entre 0 (Esquel, urbano) y 3305 ind.m ${ }^{-2}$ (Nant y Fall, pasturas). Los sitios sometidos a usos urbanos produjeron los impactos más severos sobre las comunidades de tricópteros. En ellos se observó que la falta o 
fuerte modificación del corredor ribereño, el incremento del total de sólidos en suspensión, el aumento en los sedimentos finos fueron las más importantes causas de deterioro. La incorporación de nutrientes al curso de agua tanto por fuentes puntuales como por las difusas determinó la fuerte polución orgánica documentada en el tramo correspondiente a la ciudad de Esquel, donde los valores medios de la conductividad (313 $\left.\mu \mathrm{S} \mathrm{cm}{ }^{-1}\right)$, los nutrientes amonio $\left(103,6 \mu \mathrm{g} . \mathrm{l}^{-1}\right)$, nitratos $\left(42,7 \mu \mathrm{g} . \mathrm{l}^{-1}\right)$ y fósforo reactivo soluble $\left(13,6 \mu \mathrm{g} . \mathrm{l}^{-1}\right)$ fueron significativamente mayores en el tramo urbano respecto al de referencia. Estas condiciones resultaron en la extinción local de los Trichoptera. En la localidad de Cholila los disturbios sobre el arroyo las Minas fueron principalmente debido al dragado y a la remoción de la vegetación de ribera los que determinaron cambios de la estructura trófica de la comunidad.

En cuanto a los usos silvopastoriles todos los sitios presentaron significativamente mayor temperatura del agua que los de bosque nativo de referencia. Los sitios de uso pasturas tuvieron un detrimento de la calidad del hábitat y del bosque de ribera, sin embargo no se incrementaron los valores de nutrientes respecto a los sitios de referencia. Se observaron cambios significativos en la comunidad de tricópteros en los sitios de uso de pasturas siendo la densidad, la diversidad y la equitatividad los estimadores más sensibles. Asimismo se produjo un significativo aumento de los colectores-filtradores posiblemente como resultado de un mayor aporte de material fino proveniente del lixiviado y escorrentía superficial de la cuenca.

La buena calidad de los tramos de bosque nativo de referencia se evidenció en el Análisis de Componentes Principales, tanto por las características fisicoquímicas como por los valores de los índices de calidad de hábitat y calidad de bosque de ribera que fueron los óptimos. Los sitios de referencia también presentaron una cantidad significativamente mayor de raspadores con respecto a los sitios de otros usos, sugiriendo que los cambios ambientales resultantes de las prácticas silvopastoriles podrían alterar la estructura funcional en las cuencas de bajo orden.

La asociaciones de tricópteros típicas de los sitios de bosque nativo fueron: Parasericostoma cristatum, Mastigoptila sp., Metrichia neotropicalis, Austrocosmoecus hirsutus, Smicridea sp. 2, Monocosmoecus sp. y Austrocentrus valgiformis. Este grupo de taxa sensibles caracterizaría los ensambles de tricópteros de los sitios sin polución química ni degradación física en ambientes de cabecera de montaña patagónicos. Por otra parte, los taxa Parasericostoma ovale, Metachorema griseum, Oxyethira bidentata, Hudsonema flaminii, Brachysetodes quadrifidus, 
Rheochorema lobuliferum, Smicridea annulicornis, Cailloma pumida y Verger sp, caracterizaron las comunidades de tricópteros de pasturas. De este grupo las especies $S$. annulicornis, H. flaminii y B. quadrifidus también se registraron en sitios urbanos moderadamente disturbados.

Con respecto al análisis de cobertura de cuenca se observó una relación negativa entre riqueza taxonómica y diversidad de tricópteros y el área de la cuenca urbanizada y convertida a pasturas, en coincidencia con trabajos previos de otras regiones de áreas templadas del planeta. Se reconoció un valor umbral de 8-10\% a partir del cual se evidenció una pérdida significativa en la riqueza $(60 \%)$ y diversidad $(78 \%)$ de esta comunidad. Asimismo se observó una relación positiva significativa entre la riqueza taxonómica y el porcentaje de la cuenca cubierto de bosque nativo.

En este trabajo se reconocieron los efectos favorables del mantenimiento de la vegetación ribereña sobre las condiciones ambientales y el funcionamiento de los ríos de cabecera patagónicos y su capacidad de atenuar los efectos del desarrollo pastoril y de las actividades de extracción de madera del bosque. El sombreo, el aporte de material orgánico para las larvas, el hábitat adecuado para los adultos y la mayor estabilidad de las riberas serían los beneficios más importantes que aportaría un corredor ribereño sano.

Como resultado de un enfoque integral, fue posible detectar que los cambios más significativos en ecosistemas lóticos que incluyeron características físicas, químicas, condición del hábitat, de la ribera y comunidad de Trichoptera, se produjeron en los sitios urbanos. Un estado intermedio se encontró en usos pasturas, seguido de bosque manejado y bosque de pino. Los sitios de bosque nativo presentaron la mayor integridad ecológica con las mejores condiciones ambientales, en los cuales se encontró una comunidad de tricópteros rica, diversificada y con mayor cantidad de representantes endémicos. El presente trabajo resalta la vulnerabilidad de estos ambientes frente a los disturbios antrópicos y el rol de las comunidades de Trichoptera en los ecosistemas de cabecera patagónicos. 


\section{Abstract}

Land-use practices affect the integrity and conservation of aquatic ecosystems; this is considered as an emerging issue in Patagonian Cordillera. Trichoptera are a well represented community on patagonian Mountain streams, and their species exhibit a wide array of responses to disturbances and to anthropogenic changes; for this reason they are considered potentially good indicators of the ecological status of lotic systems.

The main objective of this study was to determine variations in Trichoptera communities at 18 sites of the patagonian cordillera subjected to different land uses. Urbanizations were compared with pre-urban reference sites, and the selected agricultural land uses included pastures, pine plantations and harvested forest, which were compared to native forest reference sites. Three sites on rivers affected by each determined land use were selected, all located in NW Chubut Province (41 ${ }^{\circ} 59^{\prime} 33^{\prime \prime}$ and $43^{\circ} 44^{\prime} 09^{\prime}$ 'S). Each site was visited every three months during a one year period (May 2005 - March 2006).

To characterize the main vegetation types and land use coverage, a set of Land Sat ETM images (2000 and 2001. $15 \mathrm{~m}$ ) were analyzed using a geographic information system (GIS) (Software Arc Wiew 3.3). At each visit, dry and wet width, depth, current speed, discharge, substrate composition, water and air temperature, $\mathrm{pH}$, conductivity, dissolved oxygen, turbidity and salinity and total suspended solids were measured. Water samples were taken to obtain nutrient values (nitrate plus nitrite nitrogen, ammonia, soluble reactive phosphorus). During the low water period aquatic and terrestrial vegetation was characterized and epilithic chlorophyll $a$ was measured. Patagonian Riparian Quality Index (QBRp) was used to assess the status of conservation of the riparian corridor and vegetation cover. Habitat quality was analyzed following the procedure of the habitat assessment index for high gradient streams with the (HA).

Six benthic samples were taken at each site and visit, three in riffles and three in pools $(n=432)$ with a modified Surber net $\left(250 \mu \mathrm{m}\right.$ pore and $\left.0.09 \mathrm{~m}^{2}\right)$. Samples were fixed in situ (formaldehide10\%), individuals were sorted under at least 5x magnification and preserved in $70 \%$ alcohol. Species identification was made using available keys for the region. In each sample a visual quantification of detrital components was performed.

Total density (ind. $\mathrm{m}^{-2}$ ), mean total density, mean richness, seasonal mean richness and cumulative species richness was estimated. Shannon-Weaver's diversity 
index and Pielou's equitability index were estimated. Each species was assigned to a functional feeding group according to mouthpart morphology, gut content analysis and literature; both absolute abundance and relative abundance of each functional feeding group were calculated.

Differences among environmental features and caddisfly structural and functional attributes were assessed using a non-parametric ANOVA test using KruskalWallis and Mann-Whitney U-test. Principal Component Analysis (PCA) was performed in order to estimate variation among physicochemical parameters of agricultural land uses. The main environmental variables determining caddisfly assemblages on urban and reference sites of different seasons were identified using a Redundancy Analysis (RDA). The relationship between caddisfly species density and the main environmental variables in agricultural land-uses was interpreted using a Canonical Correspondence Analysis (CCA).

Single regression models of Trichoptera community attributes (dependent variable) and percentage of land cover for each use (independent variable) were obtained. Only best fitting models were selected and analyzed to determine the threshold at which changes in the community attributes indicate a strong decrease on water quality.

A total of 37 taxa were recorded, grouped in 26 genera and 13 families. Mean density per site ranged between 0 (Esquel, urban) and 3306 ind.m ${ }^{-2}$ (Nant y Fall, pasture). The most severe impact on Trichoptera community was observed at urban sites. The lack or strong modification of the riparian corridor, the increase in total suspended solids, and the augment of fine sediment inputs were the main causes of impairment. Moreover, at Esquel city, a strong organic pollution was documented. Different pollutant sources produced significant differences in the mean values of conductivity (313 $\left.\mu \mathrm{S} \mathrm{cm}^{-1}\right)$, and nutrients such as ammonia $\left(103.6 \mu \mathrm{g} . \mathrm{l}^{-1}\right)$, nitrates $\left(42.7 \mu \mathrm{g} . \mathrm{l}^{-1}\right)$ and soluble reactive phosphorus $\left(13.6 \mu \mathrm{g} . \mathrm{I}^{-1}\right)$ which were significantly higher at impacted reaches than at the reference one. These conditions resulted in the local extinction of caddisfly species. At Cholila town Trichoptera trophic structure changed, probably in response to dredging and clearing of the riparian vegetation.

Regarding agricultural land use practices, all sites had significantly higher water temperature than the reference reaches. At pasture sites a reduction in habitat conditions and riparian forest quality was documented, however no increase in nutrient levels was observed compared to reference sites. Major changes in caddisfly community were 
observed at pasture sites, being density, diversity and equitability the most sensitive estimators. In this sense, a higher density of collector-filterers was detected, possibly as a result of the large inputs of fine particulate organic matter from surface runoff.

The optimum quality of the native forest sites was evidenced by the Principal Component Analysis, in this sense, physicochemical parameters, in-stream habitat, and riparian forest showed the best possible condition at these reaches. Moreover, scrapers density was significantly higher at reference sites, when compared to agricultural uses; this suggests that environmental changes resulting from these practices could disrupt the functional structure at low order stream Patagonian catchments.

Typical caddisfly assemblages at reference sites were composed by Parasericostoma cristatum, Mastigoptila sp., Metrichia neotropicalis, Austrocosmoecus hirsutus, Smicridea sp. 2, Monocosmoecus sp. and Austrocentrus valgiformis. This sensitive group characterized unpolluted headwater streams in Patagonian Mountains. On the other hand, the species Parasericostoma ovale, Metachorema griseum, Oxyethira bidentata, Hudsonema flaminii, Brachysetodes quadrifidus, Rheochorema lobuliferum, Smicridea annulicornis, Cailloma pumida and Verger sp., were identified as common species at pasture streams. Among these, $S$. annulicornis, H. flaminii and B. quadrifidus were also recorded at urban, moderately disturbed sites.

Coincidently with previous works, land cover analysis exposed a negative relationship among community features (taxonomic richness and caddisfly diversity) and the increase of basin area converted to pastures and urban land-uses. The presence of a disturbance threshold between 8 and $10 \%$ of the catchment either as pasture or as urban areas was identified where a significant loss on richness (60\%) and diversity (78 $\%$ ) on caddisfly community was evident. A positive correlation was detected between taxonomic richness and percentage of native forest cover.

The present work highlighted the ability of riparian corridors to improve the instream conditions and the functioning of patagonian headwater streams, and also to ameliorate the effects of pastoral development and forest harvesting practices. The shading, suitable habitat for adult stages and bank stability would be the main benefits provided by a healthy riparian corridor.

As a result of this integral approach, we infer that the most relevant changes on lotic ecosystems, involving physicochemical characteristics, in-stream condition, riparian quality and caddisfly community occurred in urban streams. An intermediate 
effect was produced by pastures, followed by harvested forest and pine plantations. Native forested sites had the highest ecological integrity, with the best possible environmental conditions, which in turn resulted in a rich, diversified and highly endemic caddisfly community. The present study highlighted the vulnerability of these pristine environments facing anthropogenic disturbances and the role of Trichoptera communities on headwater Patagonian streams. 


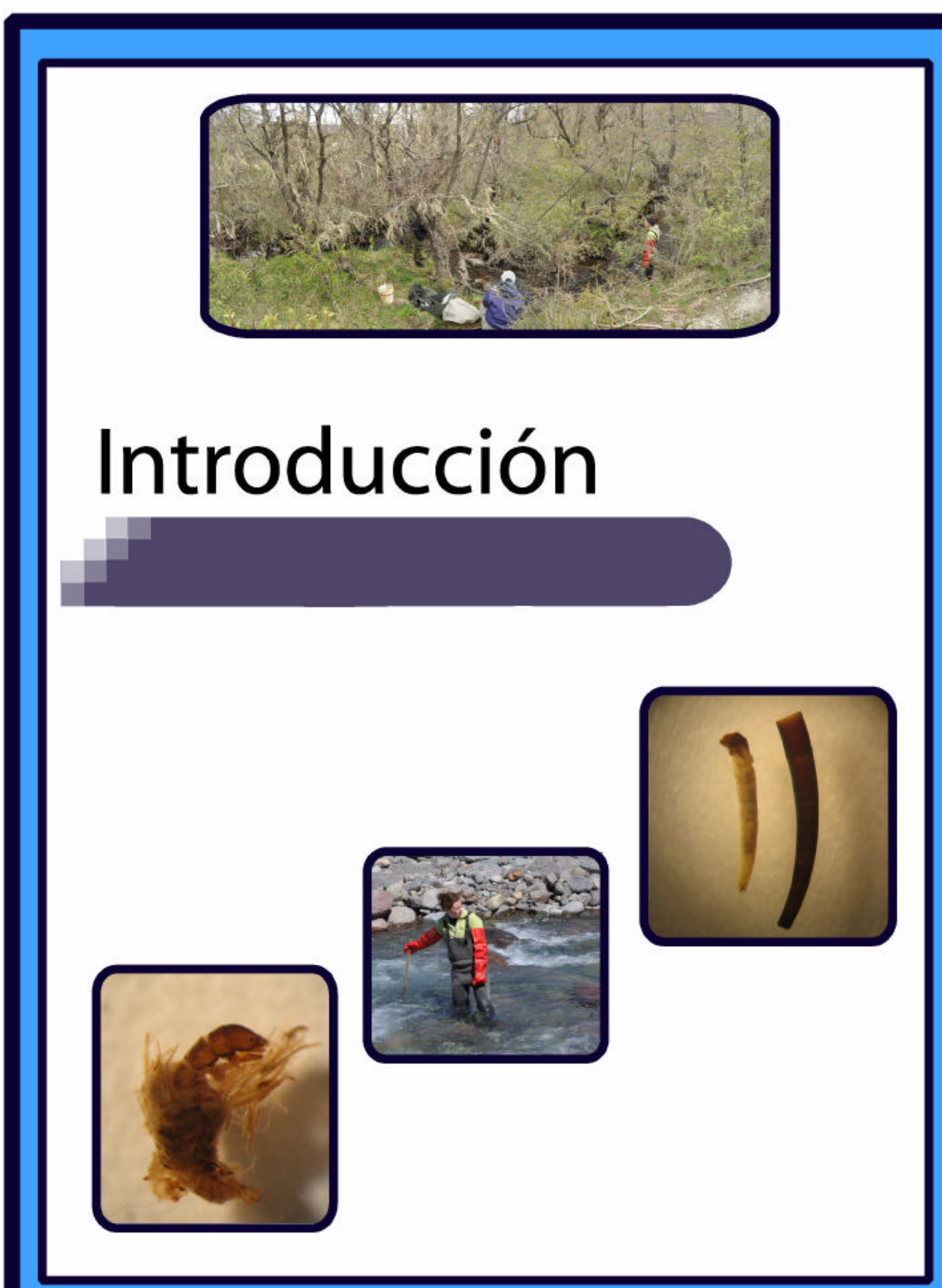




\section{INTRODUCCION}

\subsection{Características bioecológicas y rasgos del Orden Trichoptera}

El orden Trichoptera comprende un grupo de insectos holometábolos cercanamente emparentados con el orden Lepidoptera. Ambos órdenes constituyen el superorden Amphiesmenoptera. Los tricópteros adultos son insectos similares a las polillas, con alas cubiertas de pelos, no de escamas como ocurre con las mariposas, poseen antenas prominentes que en algunas familias pueden llegar a duplicar el largo de las alas. También poseen palpos labiales y maxilares bien desarrollados, pero carecen de la probóscide que caracteriza a los Lepidoptera adultos.

Este orden es considerado uno de los más diversificados en hábitats de agua dulce. Podemos encontrarlos en todas las regiones del mundo y muchas de sus familias son cosmopolitas. Sin embargo a nivel de especie la mayoría son endémicas o presentan distribuciones geográficas bastante estrechas (Wiggins 1998, 2004; Flint et al. 1999; Merrit et al. 2008).

Las larvas, todas acuáticas, se pueden encontrar tanto en ambientes lénticos como lóticos, siendo más abundantes y diversas en éstos últimos. Los estadíos larvales se han adaptado a utilizar los recursos de un amplio rango de hábitats de agua dulce: surgentes frías, arroyos, lagunas, pantanos, el litoral y las profundidades de los lagos e incluso charcos temporarios. Además intervienen en la transferencia de energía y de los nutrientes a través de los niveles tróficos de las redes alimenticias dulceacuícolas (Wiggins 1998).

Todas poseen glándulas secretoras de seda, la cual es en gran medida responsable de la amplia plasticidad del grupo ya que les ha permitido desarrollar diversas adaptaciones para ocupar distintos nichos ecológicos. La seda es utilizada para construir refugios transportables con distintos materiales cementados entre sí (piedras de distintos tamaños, trozos de hojas o de ramitas, etc.), redes fijas al sustrato que utilizan para atrapar su alimento y también los capullos pupales. En consecuencia han desarrollado mecanismos alimenticios muy diversos y altamente específicos (Ward 1992).

De las más de 1100 especies citadas en América del Sur unas 300 están presentes en la Argentina (Angrisano \& Sganga 2009). Esto no es llamativo dado que en 
el área confluyen dos tipos de fauna distintas: la de la subregión brasileña, altamente diversificada y la de la subregión chilena, rica en endemismos (Angrisano \& Sganga 2009). Esta última que abarcaría la Patagonia presenta además elementos compartidos con Oceanía.

En una serie de trabajos muy recientes han aumentado el número de contribuciones mejorando el conocimiento de los estadios preimaginales de los Trichoptera de Patagonia. En estos estudios se han incorporado nuevas herramientas que facilitan los trabajos ecológicos como son claves de identificación y datos de distribución geográfica (Angrisano 1995a, b, 1997; Valverde 1996; Valverde \& Miserendino 1997, 1998; Valverde \& Albariño 1999; Bravo \& Angrisano 2003; Angrisano \& Sganga 2005, 2009; Sganga \& Fontanarrosa 2006).

Algunas de las especies de Trichoptera presentan una gran abundancia y biomasa en ciertos ambientes, de esta manera adquieren protagonismo en la ecología y funcionamiento de los ecosistemas acuáticos. Junto con Ephemeroptera y Chironomidae constituyen los grupos de insectos más productivos en los ríos (Wiberg-Larsen et al. 2000). En los cursos de agua de la Patagonia constituyen un componente altamente relevante de las comunidades bentónicas, tanto en los arroyos de cabecera como en ríos de mayor jerarquía (Valverde \& Miserendino 1997; Miserendino 1999; Miserendino \& Brand 2007).

\subsection{Los Trichoptera como indicadores de calidad del agua}

La utilización de las comunidades de macroinvertebrados acuáticos particularmente de los grupos más sensibles como Ephemeroptera, Plecoptera y Trichoptera en el monitoreo de la calidad de aguas ha sido frecuente (Hynes 1970; Armitage et al. 1983; Hellawell 1986; Pautasso \& Fontaneto 2008). En diversas regiones del mundo se han confeccionado índices que combinan riqueza taxonómica y ocasionalmente la abundancia absoluta o abundancia relativa de macroinvertebrados, con la tolerancia conocida de cada taxón a un determinado nivel de polución o disturbio (Stark 1985, 1993, 1998; Rosenberg \& Resh 1993; Chessman 1995; Prat 1997; Barbour et al. 1999; Prat et al. 1999). Estos índices son relativamente fáciles de aplicar y presentan una gran sensibilidad ante las alteraciones del medio particularmente cuando se trata de evaluar los efectos de la degradación física del hábitat (Winterbourn 1981). 
Dada la elevada proporción de especies endémicas, cada índice debe ser adaptado a la región en particular, no siendo aplicables los índices extranjeros o de otras regiones de manera directa (Miserendino \& Pizzolón 1999). En la Argentina, la utilización de estas comunidades como indicadores es relativamente reciente (Gualdoni \& Corigliano 1991; Gualdoni et al. 1994; Domínguez \& Fernández 1998; Corigliano 1999; Miserendino \& Pizzolón 1999; Rodrigues Capítulo et al. 2001; Pavé \& Marchese 2005; Marchese \& Ezcurra de Drago 2006; Miserendino et al. 2008).

En la zona andino patagónica han sido adaptados dos índices de calidad de agua: el Índice Andino Patagónico (IAP) que considera unidades sistemáticas a nivel género o familia, dependiendo del caso (Miserendino \& Pizzolón 1992) y el Monitoreo Biótico de Arroyos Patagónicos (BMPS) que se basa principalmente en familias de invertebrados acuáticos (Miserendino \& Pizzolón 1999). No obstante, diversos estudios afirman que para lograr predicciones ecológicas más acertadas deben hacerse identificaciones a nivel de especie (de Moor 1999). Una de las críticas más frecuentes a los métodos de bioindicación basados en la presencia/ausencia de familias es que pueden ocasionar interpretaciones erróneas y hasta carecer de sensibilidad suficiente. Por estos motivos frecuentemente se realizan estudios enfocados en un orden en particular que resulte suficientemente representado en el área, que a la vez sea altamente sensible y que además refleje correctamente las alteraciones del medio (Dohet 2002; Bonada et al. 2004; Chakona et al. 2009).

Las larvas de Trichoptera resultan altamente apropiadas a los efectos de monitorear la calidad del agua por diversos motivos, en primer lugar, por su amplia distribución geográfica que abarca todas las ecoregiones del mundo, encontrándose representantes del orden en una amplia variedad de ecosistemas acuáticos (Holzenthal et al. 2007; de Moor \& Ivanov 2008). Por otra parte exhiben un amplio rango de rasgos ecológicos y biológicos, entre ellos una movilidad limitada, su ciclo de vida es relativamente largo y cada especie presenta requerimientos ambientales bien definidos (Dohet 2002; Bonada et al. 2004; de Moor 2007; Graf et al. 2008; Hering et al. 2009). Asimismo, presentan diferentes respuestas ante perturbaciones ambientales antropogénicas y grados de polución tanto químicos como físicos, por lo que diversos estudios concluyen que son potencialmente buenos indicadores del estado ecológico de los sistemas lóticos (Quintero \& Rojas de Hernández 1990; Ballesteros Navia et al. 1997; Collier et al. 1997; Sykora et al. 1997; Dohet 2002; Waringer \& Graf 2002; Blinn \& Ruiter 2006, Chakona et al. 2009, Gombeer et al. 2011). 
En los últimos diez años, en la Argentina, se ha investigado cómo las comunidades de Trichoptera han sido afectadas por distintos tipos de disturbios tales como embalses, urbanizaciones y deforestaciones (Mangeaud 1996; Vallania et al. 1998; Miserendino 1999; Miserendino \& Brand 2007; Miserendino et al. 2008).

Si bien en otras regiones la taxonomía del grupo está adecuadamente descripta, en la Patagonia los estadíos larvales de muchas especies son aún desconocidos. Esta situación se da especialmente en sitios de cabecera de las cuencas andinas donde la diversidad es mayor. Los nuevos estudios intensivos en áreas aún no exploradas aumentan considerablemente la cantidad de citas, ya sea por la descripción de nuevas especies, asociaciones de larvas y adultos, como así también por ampliación de la distribución de las ya descriptas (Angrisano 1995a; Angrisano \& Korob 2001; Angrisano \& Sganga 2009; Brand 2009).

\subsection{Los efectos del uso de la tierra}

Las vías de interacción entre ecosistemas acuáticos y terrestres son múltiples (Vanotte et al. 1980; Ward 1989). Se ha demostrado que el uso de la tierra influye sobre la calidad del agua y el hábitat físico de los ríos y esto impacta a las comunidades de invertebrados bentónicos (Cummins 1972; Harding \& Winterbourn 1995; Quinn et al. 1997). Los efectos de las distintas actividades humanas sobre la cuenca generan una multiplicidad de perturbaciones cuyo grado de impacto sobre los ecosistemas acuáticos es muy variable según la escala y la intensidad. Los distintos estudios sobre requerimientos de los estadíos larvales y rangos de tolerancia de determinadas especies nos permiten tener un mejor entendimiento de los mecanismos de acción de estos impactos (Collier et al. 1997; Bonada et al. 2004).

El corredor ribereño es la tierra adyacente que rodea un canal natural o artificial y es un área de influencias recíprocas entre los componentes acuático y terrestre, su ancho es variable y depende de diversos factores como el clima, la topografía, la ubicación dentro de la cuenca y el uso de la tierra (Miserendino 2005a; Richardson \& Danehy 2007). Los corredores ribereños no sólo son un eslabón esencial entre el ecosistema acuático y terrestre sino que además constituyen una unidad única y distintiva dentro del paisaje, con características propias. 
Esta zona de ribera proporciona importantes beneficios al ambiente acuático, fundamentalmente, actúa como filtro de determinados factores externos. La vegetación del corredor consolida el suelo y reduce la velocidad del agua, atenuando el incremento de caudal durante las crecidas y reduciendo al mínimo el daño causado por las mismas y previniendo la erosión de las riberas. Asimismo, actúa como filtro de sedimentos y nutrientes de la escorrentía superficial evitando que éstos ingresen al ecosistema acuático (Sabater et al. 2000).

Por otra parte, un bosque de ribera donde la cobertura arbórea es cerrada o en dosel produce un importante efecto de sombreo especialmente en arroyos, lo que genera un microclima, disminuyendo la amplitud térmica. Estas condiciones generalmente favorecen a las especies intolerantes a amplios rangos térmicos. La vegetación ribereña también aporta gran cantidad de energía en la forma de detrito o material vegetal e invertebrados terrestres, que sirve de alimento a un gran número de consumidores acuáticos (Haggerty et al. 2002; Richardson \& Danehy 2009).

\subsubsection{Urbanizaciones}

Las urbanizaciones son un tipo persistente y creciente de uso de la tierra, representan un impacto complejo para los cursos de agua que incluye tanto modificaciones hidráulicas, geomorfológicas como químicas y ecológicas (Paul \& Meyer 2001). Históricamente la necesidad de agua llevó a los hombres a construir sus asentamientos cerca de ríos y lagos, sin embargo esto siempre representó un problema dado que estos ecosistemas acuáticos son entidades en continuo cambio. Los períodos de mayor caudal, sumados a la creciente demanda de espacio para las poblaciones en crecimiento propiciaron una mayor intervención del hombre sobre los cursos de agua (Mason 1991; Rosenberg \& Resh 1993).

Los principales efectos de las urbanizaciones sobre la hidrología se deben principalmente al incremento en las superficies impermeables, que impiden la infiltración del agua en distintos puntos de la cuenca y aumentan la escorrentía superficial (Dunne \& Leoppold 1978), como resultado, los picos de crecidas son mayores y ocurren en menor tiempo que en cuencas boscosas (Paul \& Meyer 2001). Esto trae consigo una marcada disminución en el tiempo de retención del agua en la cuenca, por lo que una mayor proporción del agua precipitada se escurre superficialmente, esto reduce la recarga de los acuíferos y aumenta las crecidas por tormentas (Barringer et al. 1994). 
Frente al fenómeno de la urbanización las principales intervenciones humanas son la alteración del régimen hidrológico y las obras de realineamiento y redirección del cauce natural, lo que sucede generalmente con el objeto de mejorar el drenaje del agua en períodos de caudal alto (Blakely \& Harding 2005). Estas actividades conllevan otro tipo de impactos potenciales, como la modificación de la vegetación ribereña, la pérdida de sustrato, la remoción de troncos y raíces que permiten una mayor firmeza de las márgenes, y la disrupción de la secuencia de pozones y rápidos con la consecuente pérdida de microhábitats y refugio eventual para distintas especies (Brookes 1988).

En casos extremos, se construyen refuerzos de madera o concreto para detener la erosión de las márgenes, lo cual incrementa la velocidad del agua e impide la infiltración hacia y desde los terrenos adyacentes. En estos casos la reducción de la heterogeneidad espacial provoca una abrupta disminución en los taxa más sensibles (como por ejemplo especies del grupo EPT: Ephemeroptera, Plecoptera y Trichoptera), permitiendo solo la supervivencia de especies con ciclos de vida cortos y estrategias de reproducción oportunistas (Chessman 1995, Ballesteros Navía et al. 1997; Prat et al. 1999; Barbour et al. 1999). Generalmente solo especies muy pequeñas, como las de Chironomidae pueden habitar ríos canalizados ya que por su tamaño reducido son los únicos que pueden evitar ser arrastrados por la corriente y gracias a su ciclo de vida corto pueden tolerar períodos de descargas extremas (Wilding 1996; Suren 2000).

Muchos de los efectos de las urbanizaciones tienen incidencia sobre la temperatura y los patrones térmicos, entre ellos la remoción de la vegetación ribereña, la disminución en el aporte de agua subterránea y el efecto de calentamiento que ofrecen las superficies de las áreas urbanizadas. Estas acciones modifican los diferentes procesos ecológicos y el ciclo de vida de los organismos que habitan el curso de agua (Sweeney 1984; Webster \& Benfield 1986).

Por otra parte, es común que en estos ríos se observe una importante contaminación orgánica, que en gran medida se debe al vertido de efluentes. En estos casos, el incremento en la demanda bioquímica de oxígeno y la disminución del oxígeno disuelto provocan la degradación del hábitat acuático y un severo empobrecimiento de la biota (Hellawel 1978; Mason 1991; Mangeaud 1999). En casos extremos la presencia de metales pesados en los sedimentos resulta altamente tóxico para la biota y dificulta las tareas de restauración del sistema (Hickey 2000; Blakely \& Harding 2005; Miserendino \& Brand 2009). 
En nuestra región se han realizado estudios sobre la calidad de las aguas en ríos urbanos. Tanto en el sistema Esquel-Percy (Miserendino 1999; Miserendino \& Pizzolón 2000) como en el arroyo Las Minas (ciudad de Cholila, cuenca del arroyo Blanco) (Pizzolón et al. 1997) se encontró una fuerte evidencia de polución orgánica proveniente de los efluentes domésticos. Se registró una fuerte alteración en las condiciones fisicoquímicas del agua y un reemplazo de las especies de la comunidad macrozoobéntica (principalmente del grupo EPT) típicas de ambientes sin contaminación y aguas con altos niveles de oxígeno disuelto, por otras más tolerantes a bajos tenores de oxígeno y alta carga de nutrientes.

\subsubsection{Las pasturas}

La conversión de bosques nativos a pasturas afecta las cuencas de drenaje y esto repercute en las condiciones características de cada río. Una de las principales consecuencias de la ganadería es el pastoreo, normalmente las áreas más afectadas son las riberas de los ríos. Estos sectores sufren pérdida de vegetación lo que se traduce en una disminución del sombreo y del aporte de materia orgánica gruesa (Ward 1992; Merrit \& Cummins 1996). La entrada de detritos provenientes del bosque ribereño proporciona alimento para los organismos desmenuzadores, además el aporte de troncos y ramas favorecen la creación de microhábitats aumentando la heterogeneidad espacial (Wallace \& Webster 1996). Además, la vegetación de ribera es un ambiente adecuado para el desarrollo de los estados adultos durante el período de vuelo (Wiberg-Larsen et al. 2000), ésta se considera como zona de amortiguación o protección y es un área de enlace y transición acuático-terrestre (Quinn et al. 1993, Collier 1995; Collier et al. 2000; Sponseller et al. 2001). Sin esta protección, el régimen térmico se altera por aumento tanto de las temperaturas máximas diurnas como del intervalo térmico, a valores que no son tolerados por muchas especies (Rutherford et al. 1997; Gombeer et al. 2011). La capacidad de amortiguar incrementos de caudal en ríos alimentados por lluvias también disminuye drásticamente con la pérdida de la cobertura vegetal (Collier \& Quinn 2003).

El pisoteo y ramoneo del ganado degrada la cubierta vegetal terrestre, como consecuencia los procesos de infiltración y evapotranspiración se alteran, la erosión del terreno aumenta y se incrementan los sedimentos y sólidos en suspensión en los cursos de agua. Este tipo de polución física provoca cambios en el ecosistema que repercuten en la biota (Quinn et al. 1997). El efecto abrasivo de los sólidos en suspensión puede 
eliminar biofilms, algas y materia orgánica particulada (POM), resultando en un empobrecimiento de los recursos alimenticios disponibles (Wantzen 1998). Estas partículas también pueden distorsionar las condiciones ópticas del medio acuático interfiriendo en la producción de algas epilíticas (Davies-Colley et al. 1992) y la capacidad de las especies predadoras de capturar sus presas (Brunton 1985). Además pueden obstruir las redes de filtrado de algunas especies de Trichoptera (Wantzen 2006). El aumento en la deposición de partículas finas sobre el lecho del río puede impedir el acceso a determinados recursos alimenticios como depósitos de hojarasca y biofilms (Herbst 1980; Mayack et al. 1989; Masi \& Miserendino 2009), o bien reducir la diversidad de hábitats (Allan 2004; Mol \& Ouboter 2004; Song et al. 2009).

En arroyos de Nueva Zelanda con desarrollo pastoril (Allen 1959) se reportó como consecuencia de la degradación de la vegetación de ribera, un marcado incremento en algas filamentosas y disminución en la biomasa de algas epilíticas. Esto a su vez resultó en un reemplazo de especies de Trichoptera y Ephemeroptera por otras especies de invertebrados que se alimentan de estas algas, tales como larvas de Elmidae, Gasteropoda, Chironomidae y Ostracoda.

Niyogi et al. (2007) observaron que en ríos afectados por prácticas agrícologanaderas se produjo un incremento inicial en los nutrientes, lo que estimuló la producción primaria (e.g. biomasa algal) y esto se tradujo en una mayor densidad y biomasa de invertebrados. Sin embargo, como consecuencia del estrés ambiental producido por el uso de la tierra se documentó una disminución en la biodiversidad, particularmente de los taxa sensibles (EPT). Similarmente, Camargo et al. (2004), demostraron que este tipo de actividades en ríos mediterráneos afectaron principalmente los ensambles de tricópteros, siendo las especies de este grupo unas de las primeras en desaparecer.

En otros casos de ríos que atraviesan pasturas, se han registrado fuertes aumentos en la densidad total de invertebrados, una marcada disminución en la abundancia de las especies del grupo EPT (30 a 60\%) acompañado por una dramática caída en la proporción de desmenuzadores (Quinn et al. 1997). En general ante un aumento de la proporción de la cuenca modificada hacia pasturas, la fauna acuática distintiva de la región se pierde y es progresivamente menor la cantidad de especies endémicas encontradas (Harding et al. 1997; Weijters et al. 2009). Cabe destacar que en la mayoría de los casos se registra una atenuación de los efectos antes mencionados cuando se conserva un porcentaje de la vegetación ribereña en buenas condiciones 
(zonas buffer o de amortiguación) (Ward 1985; Storey \& Cowley 1997; Scarsbrook \& Halliday 1999; Vondracek et al. 2005; Song et al. 2009).

\subsubsection{Las prácticas forestales}

Existe una amplia variedad de actividades relacionadas con el uso del bosque nativo, entre ellas las más difundidas incluyen la extracción de ejemplares maderables, el raleo y la tala para extracción de leña y la tala seguida de implantación de especies exóticas con importancia económica como es el caso de las coníferas del hemisferio norte en nuestra región. El impacto que pueden tener las actividades forestales en ríos y arroyos dependerá principalmente del tipo de acciones que se lleven a cabo y de la magnitud y metodología de explotación (tala rasa, por bosquetes, por bandas) (Harding et al. 2000; Carabelli \& Scoz 2008).

Las principales causantes de estrés en la comunidad béntica durante el desarrollo de actividades forestales son: la plantación, el mantenimiento y la tala o raleo. Éstas pueden resultar en serias modificaciones sobre los ecosistemas. La tala y el desmonte previos a una plantación o la extracción de la madera degradan los suelos de las laderas adyacentes al curso de agua y esto puede provocar un aumento significativo en el ingreso de sedimentos (Collier et al. 2000; Richardson 2008; Richardson \& Thompson 2009). Se ha sugerido que los cambios en los procesos de sedimentación y en la temperatura se ven amortiguados en ríos de mayor tamaño que en ríos pequeños de cabecera. En éstos últimos, que presentan menor caudal, los sedimentos se acumularán más rápidamente colmatando el lecho y serán desalojados más lentamente alterando así el régimen hídrico (Death et al. 2003).

Asimismo, es común que luego de la cosecha, queden residuos como hojas, ramas y troncos de descarte en las márgenes o cubriendo el lecho de los ríos (Collier et al. 1997), la presencia de tal cantidad de madera ramas u hojas puede alterar seriamente tanto el hábitat físico como el alimento disponible de los invertebrados y ocasionar cambios tanto en la morfología del canal, como en la corriente y la secuencia de rápidos y pozones (Davies-Colley \& Quinn 1998; Baillie \& Davies 2002). La descomposición de este material también puede provocar una disminución de los niveles de oxígeno disuelto y la lixiviación de materiales solubles, lo que puede traducirse en un aumento de las concentraciones de carbono orgánico y nutrientes aguas abajo (Graynoth 1979; Collier et al. 1997, 1998; Baillie et al. 2005). 
Por otra parte, la remoción de la vegetación ribereña debido a éstas prácticas, propicia una mayor entrada de luz incrementando tanto los valores medios de temperatura como la amplitud térmica del agua (Masi \& Miserendino 2009). Como consecuencia del aumento de luminosidad, la base de la cadena trófica del ecosistema acuático se ve dramáticamente afectada y se produce un cambio en el recurso energético dominante, desde un sistema basado en el aporte alóctono (hojarasca) hacia una producción autóctona (mayormente algas) (Collier et al. 1997; Kiffney et al. 2003; Melody \& Richardson 2007).

En general la comunidad bentónica reacciona a estos disturbios con una disminución en los grupos EPT, muy sensibles al estrés provocado por la colmatación del lecho por sedimentos y el cambio en la temperatura. A su vez suele observarse un aumento en los grupos de dípteros, anélidos y moluscos, que resultan más tolerantes a tales condiciones. Se ha detectado en estos casos un cambio en la relación de los gremios tróficos, dado que la falta de aportes de materia orgánica particulada gruesa y el aumento en la biomasa epilítica resultante de la entrada de luz repercute en la abundancia relativa de desmenuzadores y raspadores (Graynoth 1979; Baillie et al. 2005).

Death et al. (2003) sugieren que las prácticas forestales pueden ser consideradas como pulsos de disturbios, en los que el ecosistema tenderá a evolucionar hacia un conjunto de especies de invertebrados bentónicos más similar al encontrado en ríos de pasturas que al que habitaba previamente el bosque preexistente. Cabe destacar que en la mayoría de los casos, ante estos impactos, se registra una atenuación de los efectos si se conserva una franja de vegetación ribereña nativa de 18 a 20 metros de ancho a cada lado (Ward 1985; Harding \& Winterbourn 1995).

Otra de las prácticas de manejo del bosque es la implantación de especies exóticas con fines comerciales. En relación al efecto que pueden tener los bosques de pinos implantados sobre los ecosistemas lóticos, se han llevado a cabo diversos estudios, especialmente en Nueva Zelanda (Harding \& Winterbourn 1995; Friberg \& Winterbourn 1997; Harding et al. 1997). Estos concluyen que se observan pocas diferencias en riqueza taxonómica y composición de Trichoptera entre bosque nativo y pinares, cuando las evaluaciones se basan en los estadíos larvales. Sin embargo cuando se analizan los estadíos adultos (aéreos) de Trichoptera, la riqueza parece ser menor en los arroyos localizados en pinares respecto de los de bosque nativo (Collier \& Smith 1995). Probablemente la falta de refugio expondría los estadíos alados a una mayor 
presión de predación (Sweeney 1993; Baas \& Mennen 1996). Sin embargo se sugiere que algunas larvas no alcanzarían el estadío pupal o no lograrían emerger lo que podría relacionarse con un aumento de la turbidez y de sedimentos inorgánicos en los ríos que atraviesan pinares implantados (Quinn et al. 1997). Por otra parte, no se registran cambios importantes en las relaciones de predominio de los grupos funcionales lo que sugeriría poco impacto en la estructura trófica del bentos en los ríos que sufrieron conversión de bosque nativo a implantado (Collier et al. 1997). En trabajos experimentales, Albariño y Balseiro (2002) encontraron que el procesamiento del detrito se vio afectado como consecuencia de la sustitución de bosque nativo de Nothofagus por plantaciones de pino exóticas en ambientes patagónicos. Recientemente, Miserendino y Masi (2010) documentaron una disminución significativa en el gremio desmenuzadores en bosques de pinares de exóticas respecto a bosque nativo sin manejo.

\subsubsection{Efecto de los usos de la tierra a escala de cuenca}

Los patrones observados en las comunidades de invertebrados acuáticos son el resultado de una serie de procesos actuando a distintas escalas espaciales. Es así que la ocurrencia de las especies se debe a un efecto combinado de las características locales y factores a gran escala geográfica (Allan 2004; Mykrä et al. 2007).

Mientras algunos estudios identifican los factores a nivel de paisaje como las principales variables predictivas de los indicadores biológicos, otros argumentan que no hay relaciones a niveles mayores que el local o ribereño (García et al. 2006; Wasson et al. 2010). Hasta el momento encontrar la relación entre un determinado uso a escala de cuenca y el impacto que produce en la biota acuática es un desafío, dado que el patrón de actividades humanas y las diferencias en las respuestas ecológicas de acuerdo a las características naturales del tipo de río pueden confundirse con patrones regionales (Wasson et al. 2010). En este sentido, el análisis de la respuesta de la comunidad de macroinvertebrados a la cobertura de determinado uso de la tierra es relativamente reciente (Hall et al. 2001; Utz et al. 2009).

Death y Collier (2010), señalaron que el porcentaje de bosque nativo a nivel de cuenca en Nueva Zelanda, se correlacionó positivamente y más fuertemente con la diversidad taxonómica y la condición ecológica, que las variables a nivel de segmento o hábitat. Se ha demostrado que la remoción de la vegetación de la cuenca altera las características del flujo y la cantidad de sedimentos que se incorporan a los cursos de agua, al mismo tiempo que disminuye la infiltración y eleva los niveles de escorrentía 
superficial (Walling \& Fang 2003; Miserendino et al. 2011). Paul y Meyer (2001) relevaron que en aquellas cuencas cuyas urbanizaciones afectaran entre 8 y $10 \%$ del área de la cuenca se producían dramáticos cambios en la integridad biótica, riqueza, diversidad de macroinvertebrados. Lussier et al. (2008) documentaron que a medida que el porcentaje de áreas residenciales en la cuenca se incrementaba se observó un notorio cambio de una fauna sensible a una tolerante en arroyos de Rhode Island (Estados Unidos). Por otra parte, Maloney y Feminella (2006) encontraron un valor umbral de 10 $\%$ correspondiente a coberturas de superficies impermeables en la cuenca (e.g. rutas, construcciones) a partir del cual se observaron alteraciones significativas en las comunidades de macroinvertebrados, evidenciadas por una disminución en los grupos sensibles (EPT) y los valores de los índices bióticos.

La percepción de los impactos a escala de cuenca ha sido definitivamente favorecida por el advenimiento de herramientas de informática y los sistemas de información geográfica (Utz et al. 2009), esto ha estimulado y facilitado el trabajo de los ecólogos del paisaje permitiendo nuevas interpretaciones y abordajes de los fenómenos a esta escala.

\subsection{Justificación}

En la cordillera patagónica, las actividades humanas más frecuentes han sido la ganadería, la extracción de madera, las plantaciones de pinos y las urbanizaciones (Pizzolón et al. 1997; Miserendino 2005a; Miserendino \& Brand 2009, 2011a; Miserendino et al. 2011). Estas actividades se han llevado a cabo desde hace más de un siglo en nuestra región impactando en distinto grado sobre estos ecosistemas. Actualmente la presión de producción sobre las cuencas de la región se incrementa y esto requiere de la implementación de nuevas normas que contemplen el avance científico-tecnológico de producción, pero que garanticen la conservación del equilibrio ecológico de los ambientes dulceacuícolas.

En la Patagonia, los estudios regionales referidos a comunidades macrobénticas de ambientes de cabecera y piedemonte son escasos (Miserendino \& Pizzolón 2003, 2004; Miserendino 2001, 2007), pero han sido útiles para evidenciar distintos tipos de impacto en la región (desertificación, introducción de vegetación exótica, pastoreo). Específicamente en relación a los Trichoptera existen pocos trabajos ecológicos en 
Patagonia: entre ellos se analiza la distribución altitudinal de especies en la subcuenca Esquel-Percy (Miserendino, 1999) y los patrones de distribución en relación a características ambientales en la cuenca del Río Chubut (Miserendino \& Brand 2007). Estos trabajos evidencian el amplio rango de distribución que los Trichoptera exhiben en la región, encontrándose representados desde los ambientes de cabecera hasta los tramos medios a bajos de los ríos patagónicos. Este rasgo es muy valioso a la hora de explorar los patrones de distribución de las especies del grupo en relación a las diferentes presiones ambientales.

Actualmente la restauración de ecosistemas acuáticos es objetivo comunitario creciente a nivel global, sin embargo parece haber poca consideración sobre dónde deberían dirigirse los esfuerzos para maximizar la respuesta ecológica (Johnson et al. 2007). Se ha considerado el ancho óptimo de las zonas ribereñas, la influencia de los fragmentos de bosque nativo, pero aún debe resolverse si el manejo de la cuenca, del tramo o de las condiciones locales es lo más efectivo (Death \& Collier 2010).

Los estudios intensivos y sistemáticos en regiones aún no exploradas resultan vitales para conocer la biodiversidad y el funcionamiento de tales ecosistemas. Los inventarios faunísticos son una herramienta fundamental para evaluar cambios en los ecosistemas, la pérdida de la biodiversidad o la degradación de los ambientes. Por esta razón, el presente trabajo, además de brindar una visión más amplia y completa del orden Trichoptera en la región, intentará proveer una base de datos que asista en la creación de pautas de manejo y monitoreo de las diferentes actividades económicas humanas sobre este tipo de ecosistemas. 


\section{HIPÓTESIS}

- Una mayor intensidad de uso de la tierra en ríos de bajo orden de la Cordillera Patagónica tendrá efectos negativos en la calidad del agua, del hábitat, la condición de la ribera y la comunidad de tricópteros.

- La riqueza y diversidad específica de tricópteros es indicativa de la calidad ambiental por lo tanto los mayores valores se registrarán en los sitios de referencia respecto a los usos silvopastoriles y urbanos.

- Las relaciones de predominio de los grupos funcionales de tricópteros será diferente según los usos de la tierra en respuesta a bs cambios de calidad y cantidad de los recursos alimenticios disponibles, por lo tanto la densidad de colectores-filtradores se incrementará en los sitios de pasturas y bosque nativo manejado, y la densidad de desmenuzadores disminuirá en las plantaciones de pinos.

- Los rápidos en los ríos de cordillera son hábitats funcionalmente heterogéneos por lo tanto la riqueza y la densidad de tricópteros será mayor en estos ambientes respecto a los pozones. 


\section{OBJETIVOS}

\subsection{Objetivos generales:}

- Determinar las variaciones de las comunidades de tricópteros en 18 ríos de la cordillera patagónica sometidos a diferentes usos (urbanizaciones, pasturas, plantaciones de pino, bosques de ñire nativo con extracción de madera, bosques de ñire nativo sin explotación).

\subsection{Objetivos específicos:}

- Describir las asociaciones de Trichoptera en ríos que atraviesan zonas con distintas actividades antrópicas (pastoreo, plantaciones exóticas, extracción de leña y urbanizaciones) y comparar dichas asociaciones con las encontradas en sitios no disturbados.

- Establecer las relaciones entre las especies de Trichoptera con las distintas variables ambientales (físicas, químicas y biológicas).

- Evaluar la distribución temporal de las especies estudiadas contrastando cuatro momentos estacionales a lo largo de un año.

- Analizar la segregación espacial a una escala de hábitat comparando los ambientes de rápidos y pozones.

- Establecer en qué medida los atributos de las comunidades de Trichoptera reflejan los disturbios relacionados con el uso de la tierra.

- Ampliar el conocimiento taxonómico y ecológico de las especies de Trichoptera patagónicos. 


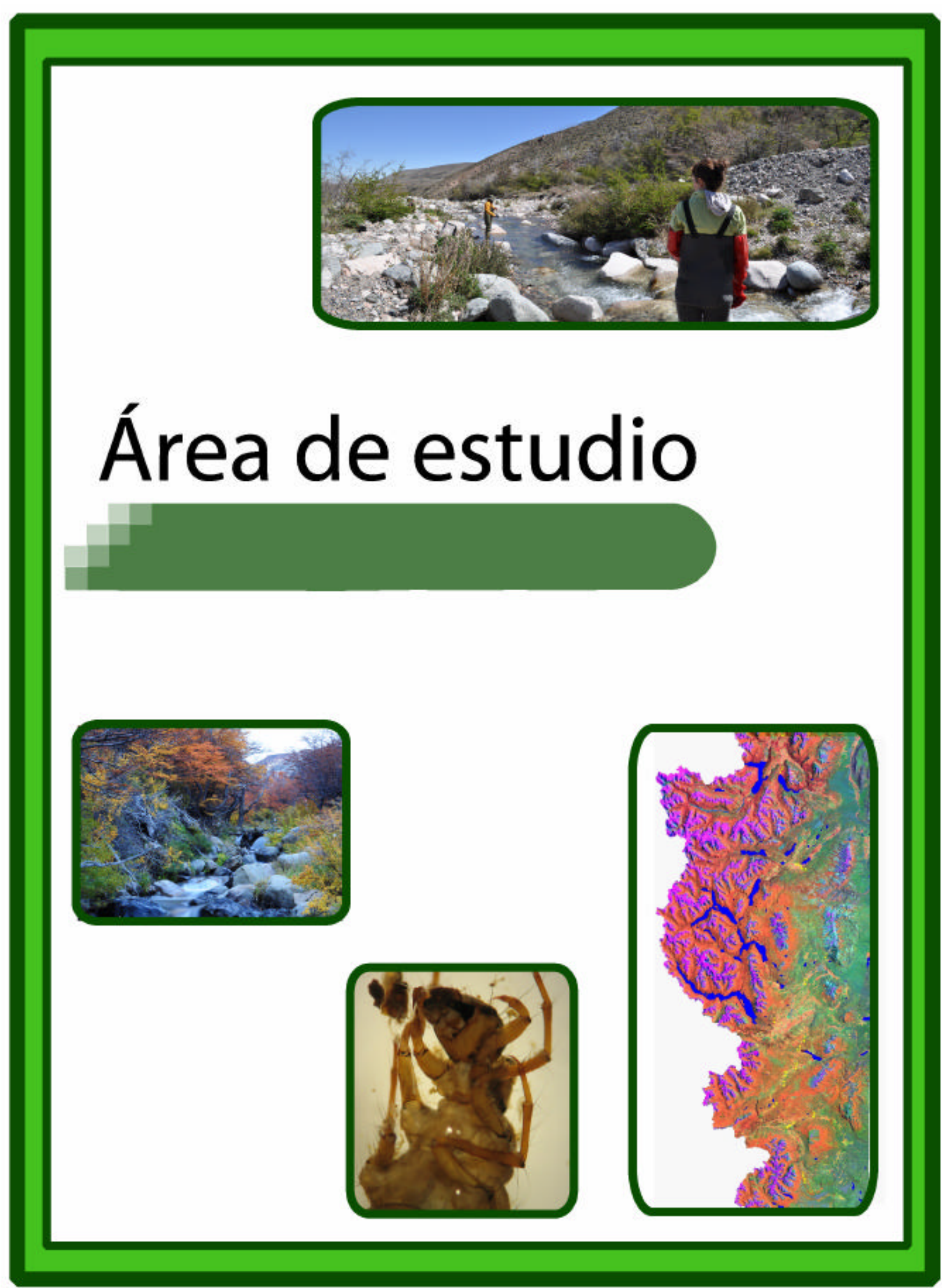




\section{4. ÁREA DE ESTUDIO:}

Los ríos seleccionados para el estudio se localizan en el noroeste de la provincia del Chubut (Figura 1). El área de estudio comprende dos zonas geográficas principales, la cordillera de los Andes Patagónicos y el ecotono cordillera-meseta Patagónica. El clima se clasifica como templado frío y las precipitaciones decrecen desde las montañas, con $3000 \mathrm{~mm}$ caídos por año, hacia la meseta del este donde se registran precipitaciones anuales inferiores a $150 \mathrm{~mm}$. Los ríos de la cordillera se alimentan principalmente de las precipitaciones pluviales y nivales del oeste. El régimen hidrológico muestra dos picos máximos en el año, el primero debido a las fuertes precipitaciones invernales y el segundo causado por el derretimiento de hielo y nieve en las montañas (Coronato \& del Valle 1988).

Las provincias fitogeográficas que corresponden al área de estudio son: el bosque deciduo subantártico y el ecotono bosque-estepa (Paruelo et al. 1998). El primero caracterizado por especies perennes (Austrocedrus chilensis, Nothofagus dombeyi y Maytenus boaria) y deciduas (Nothofagus pumilio, N. antarctica). La lenga (N. pumilio) rodea especialmente los cursos de agua de bajo orden, mientras que los cursos de agua bajos están caracterizados por la presencia de las especies de sauce exótico (Salix fragilis y S. nigra). En el ecotono, a medida que el bosque desaparece y se hace más importante la estepa arbustiva, se registran especies herbáceas con diversas formas xerófitas: Mulinum spinosum, Stipa spp., Senecio spp., Discaria articulata, Adesmia sp., Fabiana imbricata y Poa sp. (Tell et al. 1997).

\subsection{Selección de sitios}

Los sitios se han elegido representando diferentes usos. En primer lugar se seleccionaron tres ríos que atraviesan centros urbanos de importancia, localizando en cada uno, un sitio testigo o de referencia aguas arriba $(n=3)$ y un punto de muestreo aguas abajo de la urbanización (sitio disturbado) $(n=3)$. Los sitios fueron elegidos en función de su accesibilidad y en base a la existencia de información ambiental previa.

Para evaluar los efectos de otras actividades antrópicas, relacionadas a usos agriculturales, se seleccionaron tres ríos en:

- plantaciones de pino $(n=3)$ 
- bosque nativo sometido a extracción de leña $(n=3)$

- pastoreo vacuno/ovino $(n=3)$

Además, se seleccionaron tres sitios testigo localizados en bosque nativo sin disturbios antrópicos $(n=3)$ o sin modificaciones evidentes de su estado natural.

En la tabla 1 se detallan las ubicaciones y altura de los sitios seleccionados para este estudio, ordenados por tipo de uso.

Tabla 1. Características descriptivas de los 18 sitios de muestreo, nombre asignado, código de identificación, latitud, longitud, altura y uso principal de la cuenca.

\begin{tabular}{|c|c|c|c|c|c|c|}
\hline Nombre & Código & Latitud & Longitud & $\begin{array}{c}\text { Altura } \\
\text { (msnm) }\end{array}$ & $\begin{array}{l}\text { Orden } \\
\text { lótico }\end{array}$ & Uso \\
\hline Esquel arriba & EU & $42^{\circ} 52^{\prime} 13^{\prime \prime}$ & $71^{\circ} 17^{\prime} 30^{\prime \prime}$ & 721 & 3 & $\begin{array}{c}\text { Referencia } \\
\text { urbano }\end{array}$ \\
\hline Las Minas arriba & LMU & $42^{\circ} 31^{\prime} 03^{\prime \prime}$ & $71^{\circ} 25^{\prime} 13^{\prime \prime}$ & 573 & 2 & $\begin{array}{c}\text { Referencia } \\
\text { urbano }\end{array}$ \\
\hline Carbón arriba & $\mathrm{CU}$ & $43^{\circ} 32^{\prime} 07^{\prime \prime}$ & $71^{\circ} 28^{\prime} 11^{\prime \prime}$ & 415 & 3 & $\begin{array}{c}\text { Referencia } \\
\text { urbano }\end{array}$ \\
\hline Esquel abajo & ED & $42^{\circ} 58^{\prime} 32^{\prime \prime}$ & $71^{\circ} 23^{\prime} 47^{\prime \prime}$ & 491 & 4 & Urbano \\
\hline Las Minas abajo & LMD & $42^{\circ} 30^{\prime} 32^{\prime \prime}$ & $71^{\circ} 25^{\prime} 34^{\prime \prime}$ & 555 & 2 & Urbano \\
\hline Carbón abajo & $\mathrm{CD}$ & $43^{\circ} 32^{\prime} 11^{\prime \prime}$ & $71^{\circ} 28^{\prime} 21^{\prime \prime}$ & 403 & 3 & Urbano \\
\hline Patriada & PAT & $42^{\circ} 08^{\prime} 17^{\prime \prime}$ & $71^{\circ} 31^{\prime} 56^{\prime \prime}$ & 495 & 1 & Pinar \\
\hline Ifona & IFO & $43^{\circ} 0738^{\prime \prime}$ & 71³3’30” & 368 & 3 & Pinar \\
\hline Golondrinas & GOL & $41^{\circ} 59^{\prime} 33^{\prime \prime}$ & $71^{\circ} 33^{\prime} 25^{\prime \prime}$ & 361 & 2 & Pinar \\
\hline Los Nires & $\mathrm{EN}$ & $43^{\circ} 29^{\prime} 56^{\prime \prime}$ & $71^{\circ} 20^{\prime} 22^{\prime \prime}$ & 667 & 4 & Pasturas \\
\hline Manguera & MG & $43^{\circ} 18^{\prime} 33^{\prime \prime}$ & $71^{\circ} 26^{\prime} 36^{\prime \prime}$ & 699 & 3 & Pasturas \\
\hline Nant y Fall & $\mathrm{NyF}$ & $43^{\circ} 13^{\prime} 24^{\prime \prime}$ & $71^{\circ} 25^{\prime} 17^{\prime \prime}$ & 690 & 3 & Pasturas \\
\hline Cabeza de vaca & $\mathrm{CDV}$ & $43^{\circ} 29^{\prime} 58^{\prime \prime}$ & $71^{\circ} 20^{\prime} 51^{\prime \prime}$ & 699 & 2 & $\begin{array}{l}\text { Bosque } \\
\text { manejado }\end{array}$ \\
\hline Pipo & PIP & $43^{\circ} 12^{\prime} 02^{\prime \prime}$ & $71^{\circ} 24^{\prime} 01^{\prime \prime}$ & 728 & 2 & $\begin{array}{l}\text { Bosque } \\
\text { manejado }\end{array}$ \\
\hline Glyn & GLY & $43^{\circ} 27^{\prime} 34^{\prime \prime}$ & $71^{\circ} 33^{\prime} 25^{\prime \prime}$ & 615 & 2 & $\begin{array}{l}\text { Bosque } \\
\text { manejado }\end{array}$ \\
\hline Comisario & $\mathrm{COM}$ & $43^{\circ} 44^{\prime} 45^{\prime \prime}$ & $71^{\circ} 23^{\prime} 32^{\prime \prime}$ & 770 & 3 & Bosque ñire \\
\hline Loro & ALO & $43^{\circ} 44^{\prime} 09^{\prime \prime}$ & $71^{\circ} 23^{\prime} 58^{\prime \prime}$ & 820 & 2 & Bosque ñire \\
\hline Chiquito & $\mathrm{CHI}$ & $43^{\circ} 21^{\prime} 43^{\prime \prime}$ & $71^{\circ} 30^{\prime} 22^{\prime \prime}$ & 670 & 2 & Bosque ñire \\
\hline
\end{tabular}




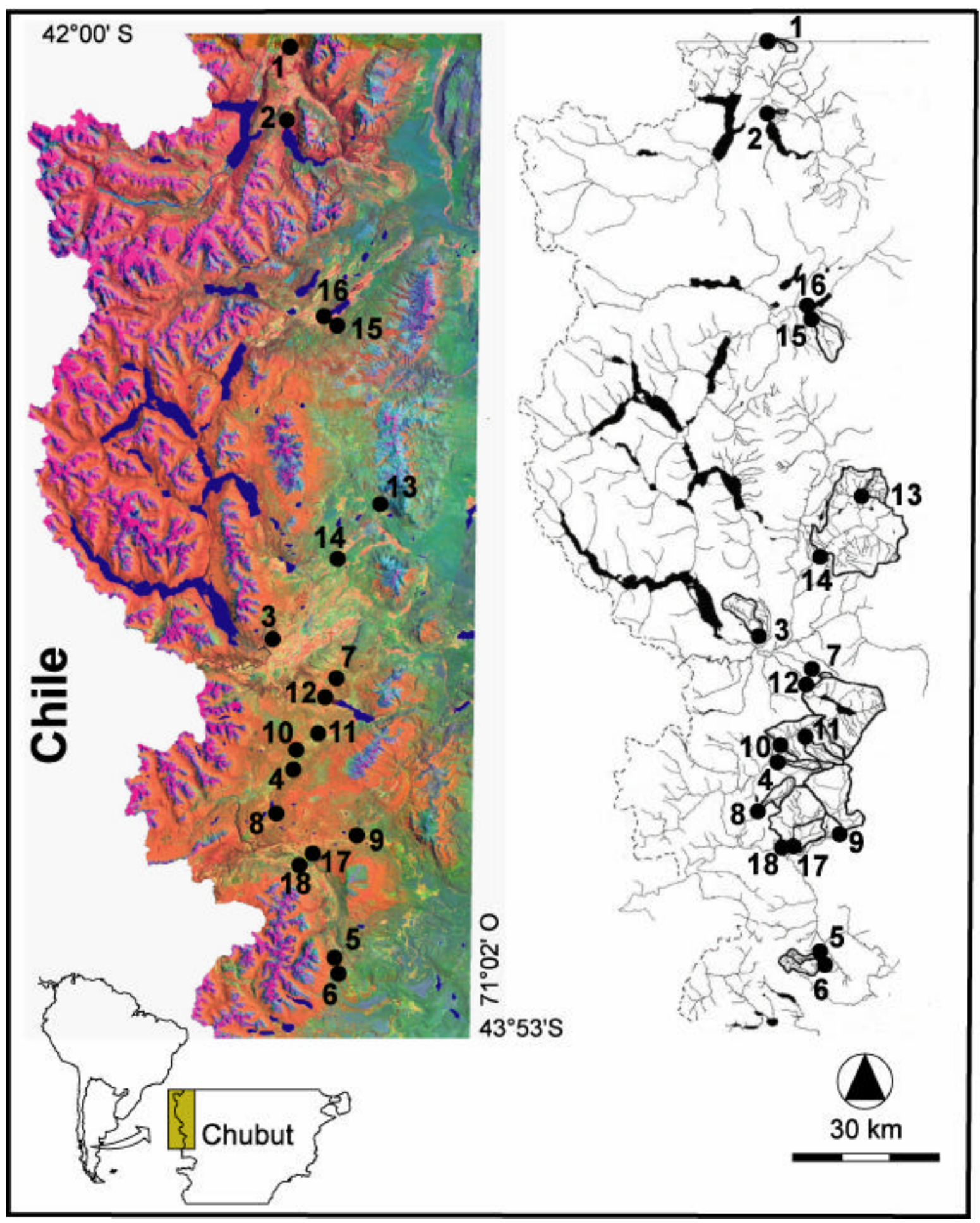

Figura 1. Imagen satelital Landsat y mapa hidrográfico de la zona de muestreo. Los puntos indicados en la imagen corresponden a los 18 sitios de muestreo. Referencias: 1: Golondrinas; 2: Patriada; 3: Ifona; 4: Chiquito; 5: Arroyo Loro; 6: Comisario; 7: Pipo; 8: Glyn; 9: Cabeza de Vaca; 10: Los Ñires; 11: Manguera; 12: Nant y Fall; 13: Esquel arriba; 14: Esquel abajo; 15: Las Minas arriba; 16: Las Minas abajo; 17: Carbón arriba; 18: Carbón abajo. 


\subsection{Sitios urbanos}

Para evaluar el efecto de las urbanizaciones en los ambientes lóticos, se seleccionaron tres localidades del noroeste de la provincia del Chubut atravesadas por cursos de agua: la de mayores dimensiones, la ciudad de Esquel (30.977 habitantes), seguida de Cholila (2.190 habitantes) y Corcovado (1.848 habitantes). En los tres casos se seleccionó un sitio aguas abajo de la urbanización y como testigo un sitio aguas arriba. Los sitios de referencia presentaron relictos de bosques de especies nativas y exóticas, ausencia de asentamientos poblacionales y escasa o nula actividad humana. En todos los sitios preurbanos el cauce y las márgenes se encontraron en buen estado con poca modificación por parte del hombre y los tres estratos de vegetación estuvieron bien representados.

Arroyo Esquel: el arroyo Esquel atraviesa la ciudad del mismo nombre, ésta es la ciudad de mayor cantidad de habitantes en el Oeste de la provincia del Chubut. Este curso de agua de orden lótico 3, es parte de la cuenca del Futaleufú-Yelcho, y antes de ingresar a la ciudad recibe el aporte del arroyo Valle Chico.

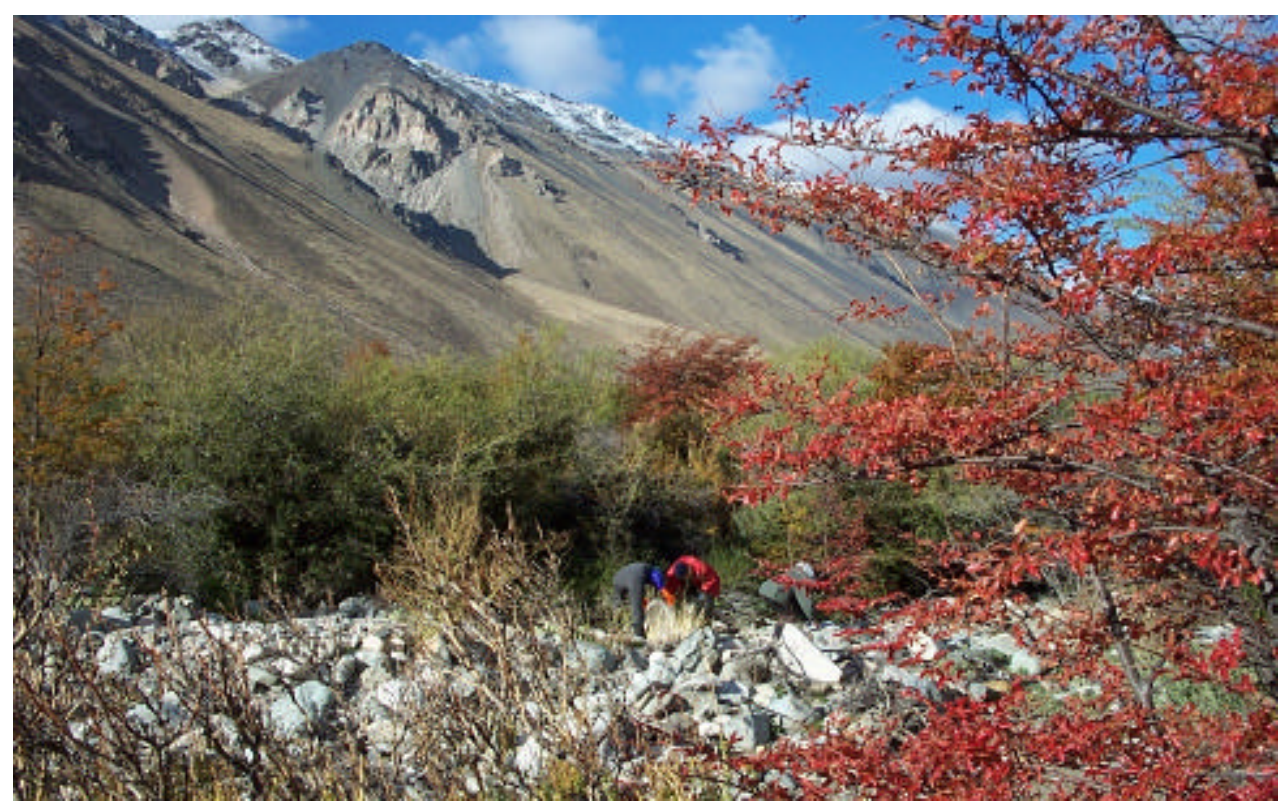

Figura 2. Entorno del Arroyo Esquel, cuenca del Futaleufú-Yelcho, aguas arriba de la ciudad de Esquel, provincia de Chubut, durante el mes de mayo de 2005.

El estrato arbóreo en el sitio de referencia EU (Figura 2) exhibió una importante presencia de especies nativas como ñire (Nothofagus antarctica) y coihue (Nothofagus dombeyi), las especies arbustivas más comunes fueron calafate (Berberis buxifolia y $B$. 
heterophylla), mamuel choique (Adesmia volckmanni), huautro (Baccharis obovata), laura (Schinus patagonica) y chacay (Discaria chacaye y Ochetophila trinervis).

En contraste, el sitio urbanizado ED (Figura 3) ubicado a $15.9 \mathrm{~km}$ de Esquel, aguas abajo de la planta de tratamiento de líquidos cloacales, presentó como única especie arbórea el sauce, desarrollando buena cobertura.

La planta de tratamiento de líquidos cloacales se sitúa tres kilómetros al sur de la localidad de Esquel, consta de una primera sección para el tratamiento primario (retención de sólidos) y el tratamiento secundario (reducción principalmente de la carga orgánica) se realiza en estanques de macrófitas emergentes (carrizo, Phragmites australis). La planta consta de dos sectores modulares de tratamiento secundario, el primero incluye 27 módulos y comenzó a funcionar en el año 2001 y el segundo con 17 módulos adicionales comenzó a funcionar en el año 2009. Ambos sectores de módulos descargan independientemente al arroyo Esquel (Bauer 2010).

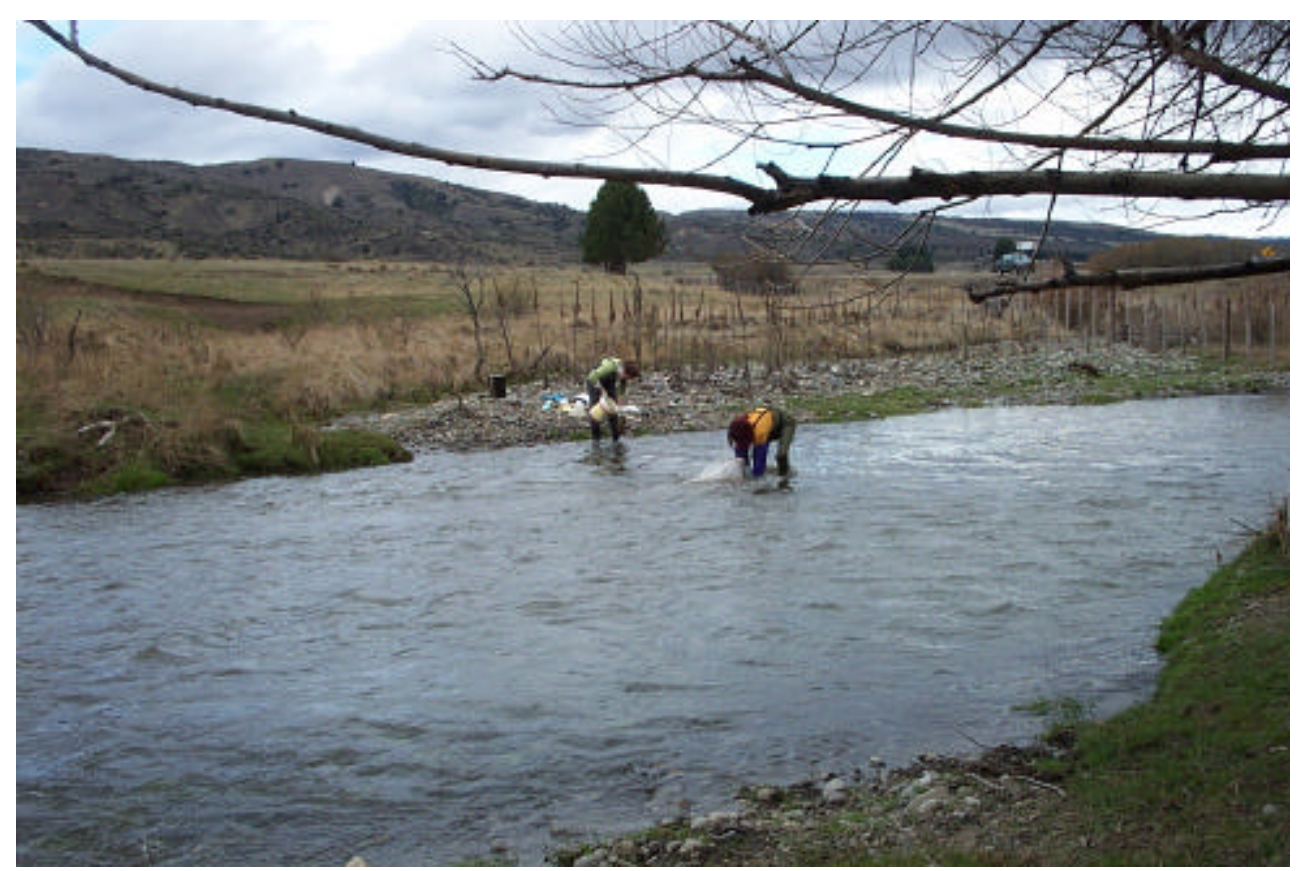

Figura 3. Arroyo Esquel cuenca del Futaleufú-Yelcho, aguas abajo de la cuidad de Esquel, provincia de Chubut, mes de septiembre de 2005.

Arroyo Las Minas: El sitio de referencia sobre el Arroyo las Minas (LMU) (Figura 4), presentó una importante cobertura de especies arbóreas nativas, ñire (Nothofagus antarctica) y coihue (Nothofagus dombeyi). Entre las especies arbustivas presentes estuvieron calafate (Berberis buxifolia y B. heterophylla), mamuel choique (Adesmia volckmanni), huautro (Baccharis obovata), laura (Schinus patagonica) y 
chacay (Discaria chacaye y D. trinervis), así como también la exótica rosa mosqueta

\section{(Rosa rubiginosa).}

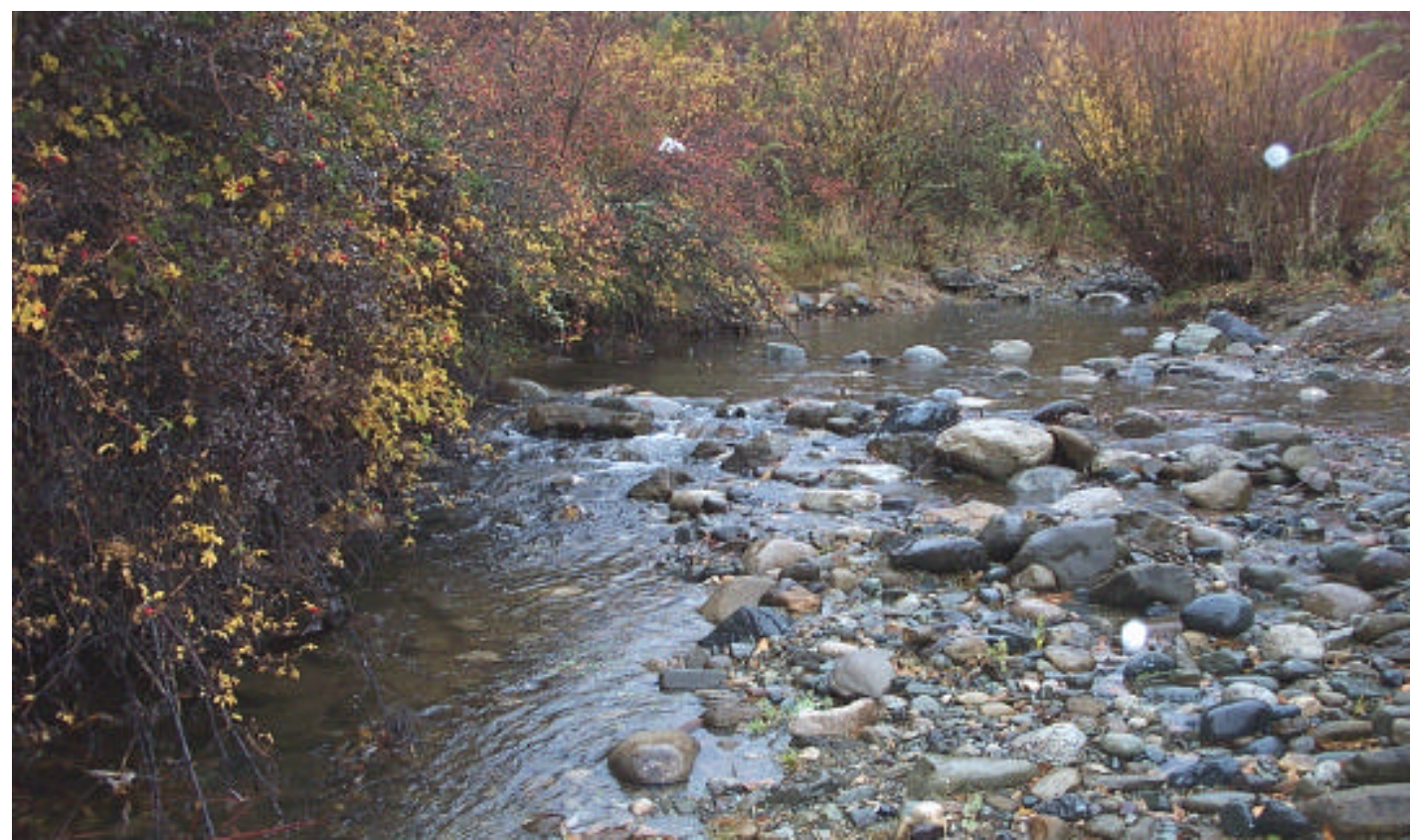

Figura 4. Arroyo Las Minas, cuenca de Futaleufú-Yelcho, aguas arriba de la localidad de Cholila, provincia de Chubut, mes de mayo de 2005.

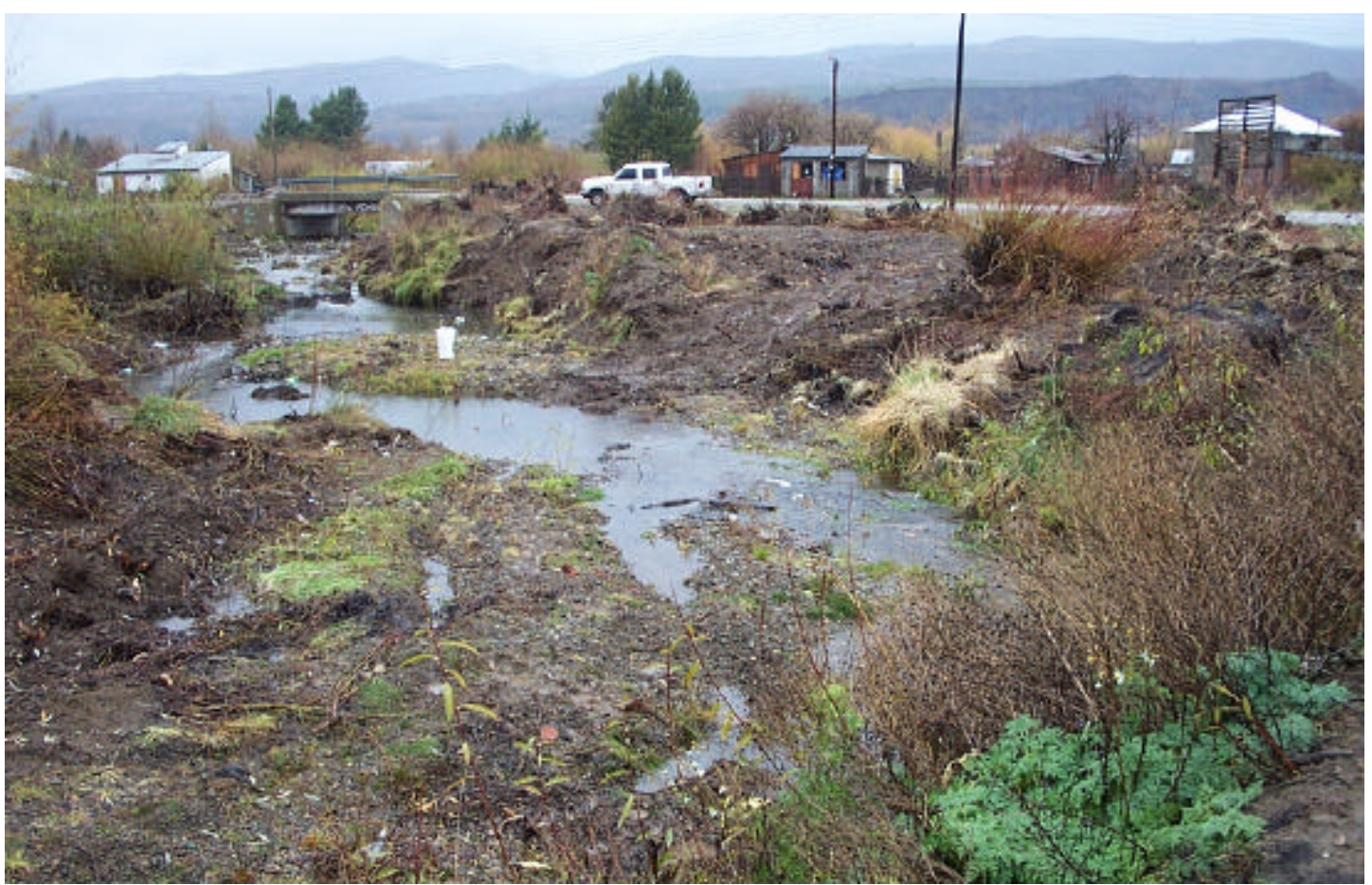

Figura 5. Arroyo Las Minas, cuenca del Futaleufú-Yelcho, sitio de muestreo localizado en la localidad de Cholila, provincia de Chubut, durante el mes de mayo de 2005. 
El sitio urbanizado LMD (Figura 5, en el pueblo de Cholila), se encontró fuertemente modificado por maquinarias, tanto en su cauce como en las márgenes, en consecuencia la vegetación sólo se compuso de especies herbáceas y algunos renovales pequeños de sauce.

Arroyo Carbón: En el sitio de referencia CU (Figura 6), el estrato arbóreo estuvo dominado por especies exóticas como sauces (Salix sp.) y álamos (Populus nigra y $P$. $a l b a)$, mientras que en el estrato arbustivo las especies que se encontraron fueron retama (Cytisus scoparia), cicuta (Conium maculatum) y rosa mosqueta (Rosa rubiginosa). No hubo especies nativas ni en el estrato arbóreo ni en el arbustivo.

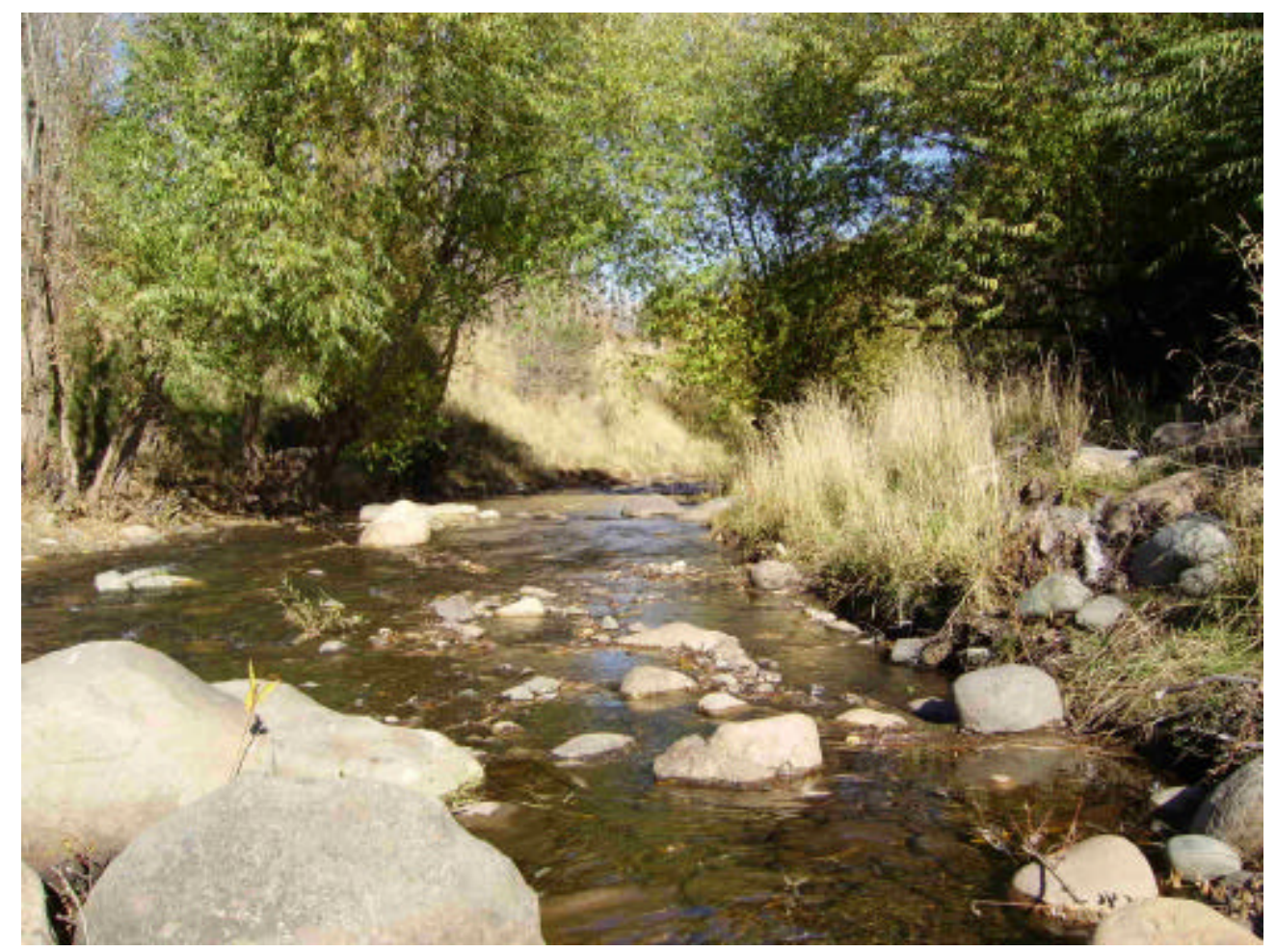

Figura 6. Punto de muestreo preurbano sobre el Arroyo Carbón, cuenca del Corcovado, aguas arriba la localidad de Corcovado, provincia de Chubut, mes de mayo de 2006.

En el tramo urbanizado (Figura 7), el sauce fue la única especie arbórea. El estrato arbustivo presentó especies exóticas, retama (Cytisus scoparia), ajenjo (Artemisia absinthium), rosa mosqueta (Rosa rubiginosa), cicuta (Conium maculatum), y ejemplares aislados de maqui (Aristotelia chilensis) y laura (Schinus patagonica), de bajo porte. 


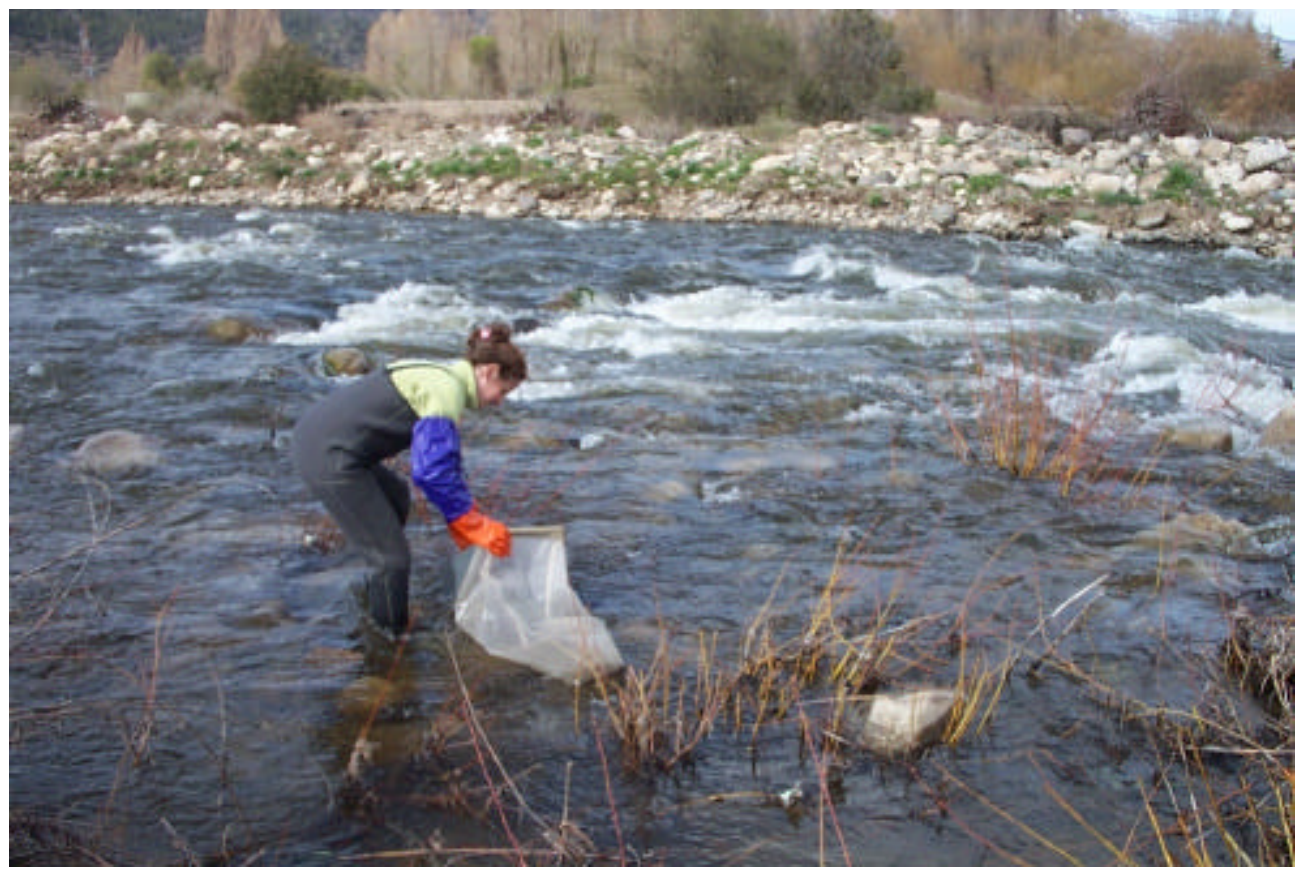

Figura 7. Arroyo Carbón, cuenca del Corcovado, aguas abajo del pueblo de Corcovado, mes de diciembre de 2005.

\subsection{Sitios sometidos a actividades silvopastoriles}

El manejo silvopastoril en Patagonia incluye la explotación de árboles, ganado y pastos de manera integrada a través de técnicas de introducción o mejoramiento deliberado de forraje y producción de maderas o productos forestales. De esta manera, en la región de la cordillera patagónica las actividades silvopastoriles más difundidas son la extracción de madera de los bosques nativos de Nothofagus spp. (para su uso en carpintería o bien para su utilización como combustible), en las áreas clareadas es común la cría de ganado extensiva o la implantación de especies de coníferas exóticas para extracción de madera.

Pinares. La elección de los sitios para este tipo de uso se realizó empleando la base de datos provista por la Dirección General de Bosques y Parques (DGBP), se tuvo especial consideración en que los sitios atravesaran plantaciones maduras con una cobertura arbórea del $100 \%$ o ligeramente inferior. En todos los casos, las plantaciones seleccionadas se situaron en cuencas previamente ocupadas por bosque nativo y reemplazadas por bosque exótico maderable de pino oregón (Pseudotsuga menziesii) mayormente (Carabelli \& Scoz 2008). Las plantaciones maduras promedian los 50 años, por lo tanto, el efecto producido por las tareas de poda del bosque preexistente y plantación no afectan actualmente dichos cursos de agua. Los sitios localizados en 
pinares son Patriada (Figura 8), en la cuenca del Lago Epuyén, Golondrinas, en la cuenca del Lago Puelo (Figura 9) e IFONA (Figura 10), cuenca del Futaleufú-Yelcho.

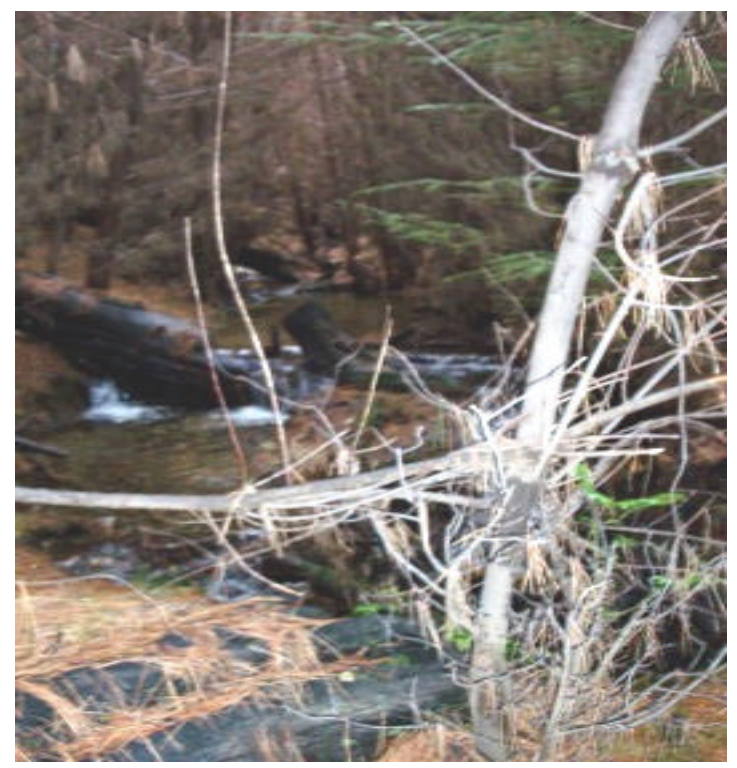

Figura 8. Sitio Patriada, cuenca del lago Epuyén, provincia de Chubut, mes de diciembre de 2005.

En el caso de Patriada, que hasta la fecha del estudio no tuvo manejo (poda, raleo, limpieza), el bosque encontrado fue monoespecífico, sin sotobosque ni herbáceas presentes y con muy poca entrada de luz al curso de agua. Tanto el suelo como el lecho del arroyo se encontraron cubiertos por una densa capa de acículas. En el arroyo Golondrinas (cuenca del Lago Puelo) la canopia fue muy cerrada, además de pino oregón también se registraron ejemplares de pino murrayana (Pinus contorta var. latifolia) y de álamo, mientras que el sotobosque ralo, estuvo compuesto principalmente por rosa mosqueta. 


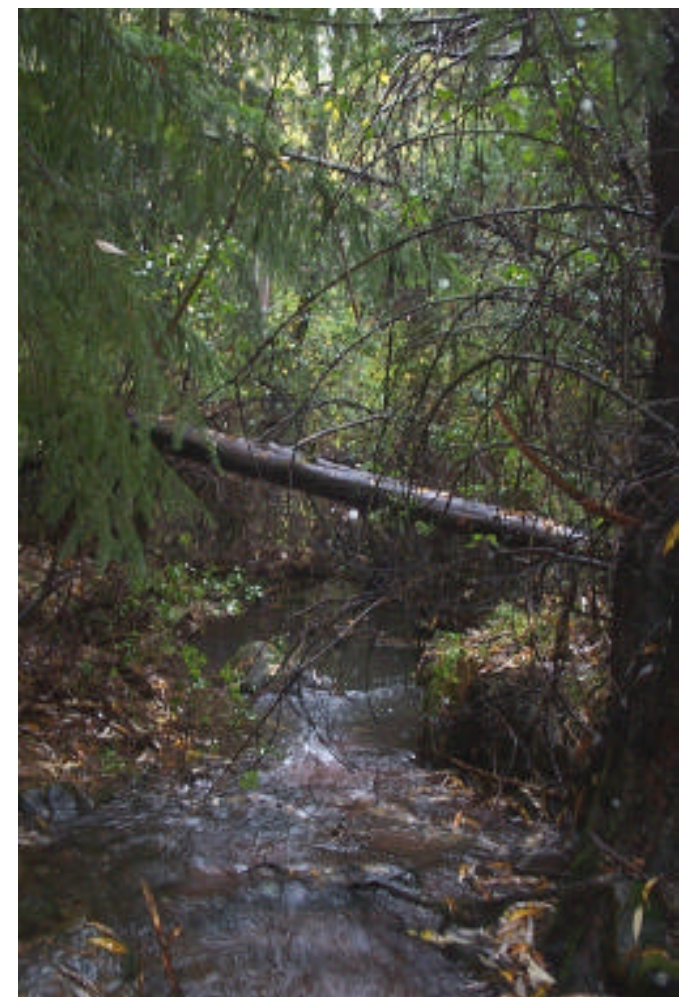

Figura 9. Arroyo Golondrinas, pinar, mes de mayo de 2005.

En el sitio IFONA (A. Blanco, cuenca del Futaleufú-Yelcho), aunque los árboles eran de gran porte no cubrían todo el lecho (canopia parcialmente abierta). La vegetación en este sitio fue más variada que en los anteriores, comprendiendo además del pino oregón, pino ponderosa (Pinus ponderosa), sauces, coihues y algunos ejemplares de álamo. El sotobosque, estuvo representado por ejemplares de laura y caña colihue (Chusquea culeou) entre las nativas, y rosa mosqueta, retama y lupinos (Lupinus polyphyllus) entre las exóticas. 


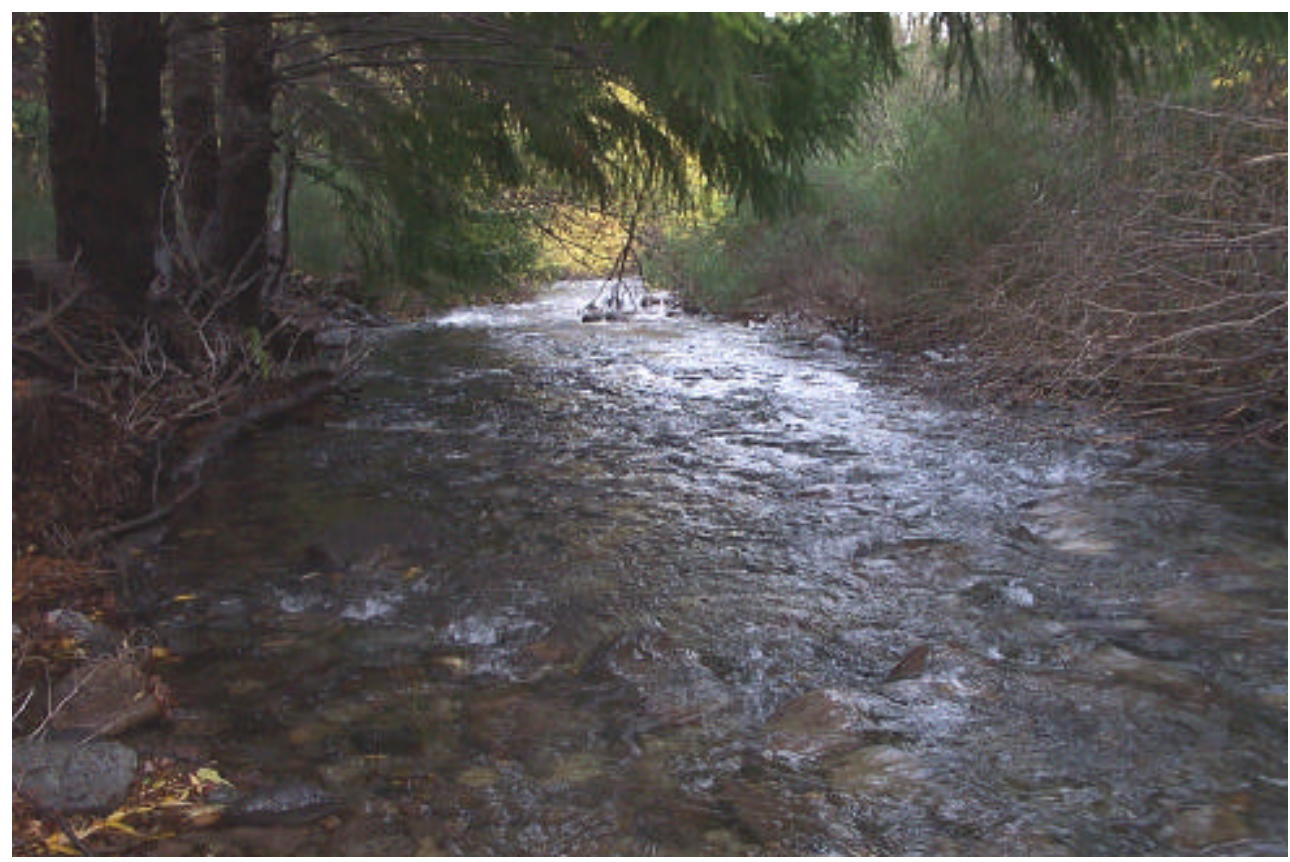

Figura 10. Arroyo Blanco, cuenca del Futaleufú-Yelcho, pinar, en el sitio IFONA, mes de mayo de 2005.

Pasturas. Para la selección de los sitios en pasturas se consideraron áreas en las que el bosque de ñire nativo fue clareado entre 60 a 70 años atrás. Posiblemente mediante quemas que eran las prácticas comunes en ese entonces para uso ganadero (Carabelli \& Scoz 2008). Las especies eliminadas, características del bosque, fueron progresivamente reemplazadas por otras de crecimiento rápido, resistentes al pastoreo y pisoteo del ganado, mayormente herbáceas. En los tres sitios, el ganado fue mayormente vacuno con presencia de ganado ovino (Figura 11).

El sitio Los Ñires (Figura 11. Río Frío, cuenca del Corcovado) presentó un bosque ribereño remanente del bosque originario, bastante ralo y alejado del curso de agua. Por lo tanto no proporcionó ni sombreo ni sujeción para las márgenes. Una de las márgenes se encontró fuertemente erosionada por la corriente, mientras que en la opuesta se formó una amplia playa de material depositado colonizado por especies como lupinos, cardo (Carduus thoermeri) y manzanillón (Tripleurospermum perforatum). En los sectores pastoreados aparecieron gramíneas, diente de león (Taraxacum officinale), llantén (Plantago lanceolata), vinagrillo (Rumex acetosella), Crepis capillaris, trébol blanco (Trifolium repens), cepa caballo de mallín (Acaena magellanica), Ranunculus repens, y junquillo (Juncus arcticus) en contacto con el río. Entre las macrófitas y acuáticas se registraron juncáceas, ciperáceas (Eleocharis sp.), 
Veronica serpyllifolia y algas filamentosas. También se observaron algunos sauces aislados.

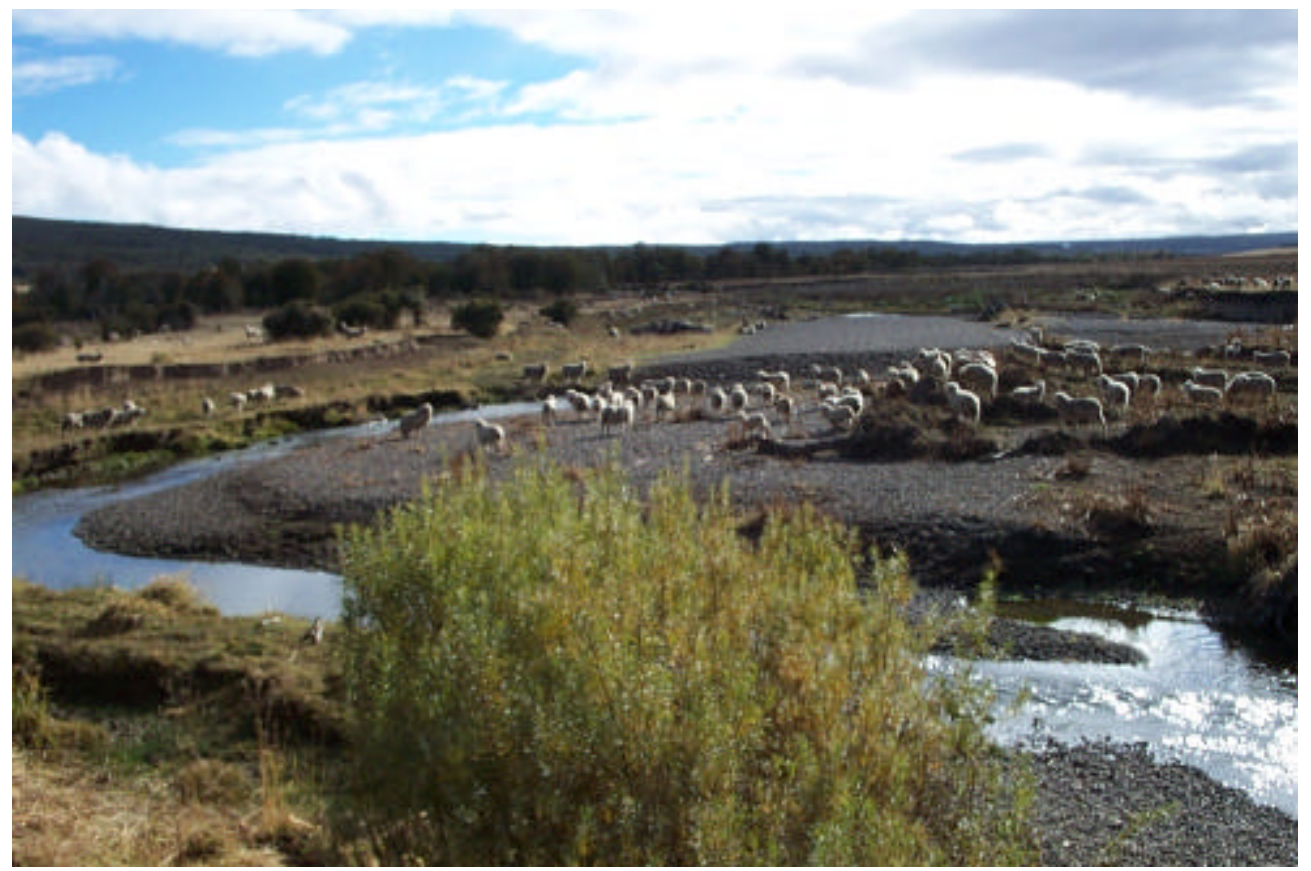

Figura 11. Sitio Los Nires, sobre el Río Frío, cuenca del Corcovado. Mes de marzo de 2006.

El sitio Manguera (Figura 12), tributario del Río Frío, aunque conservó bosque de ñire en su cabecera, el tramo seleccionado para el estudio se encontró con un alto grado de impacto.

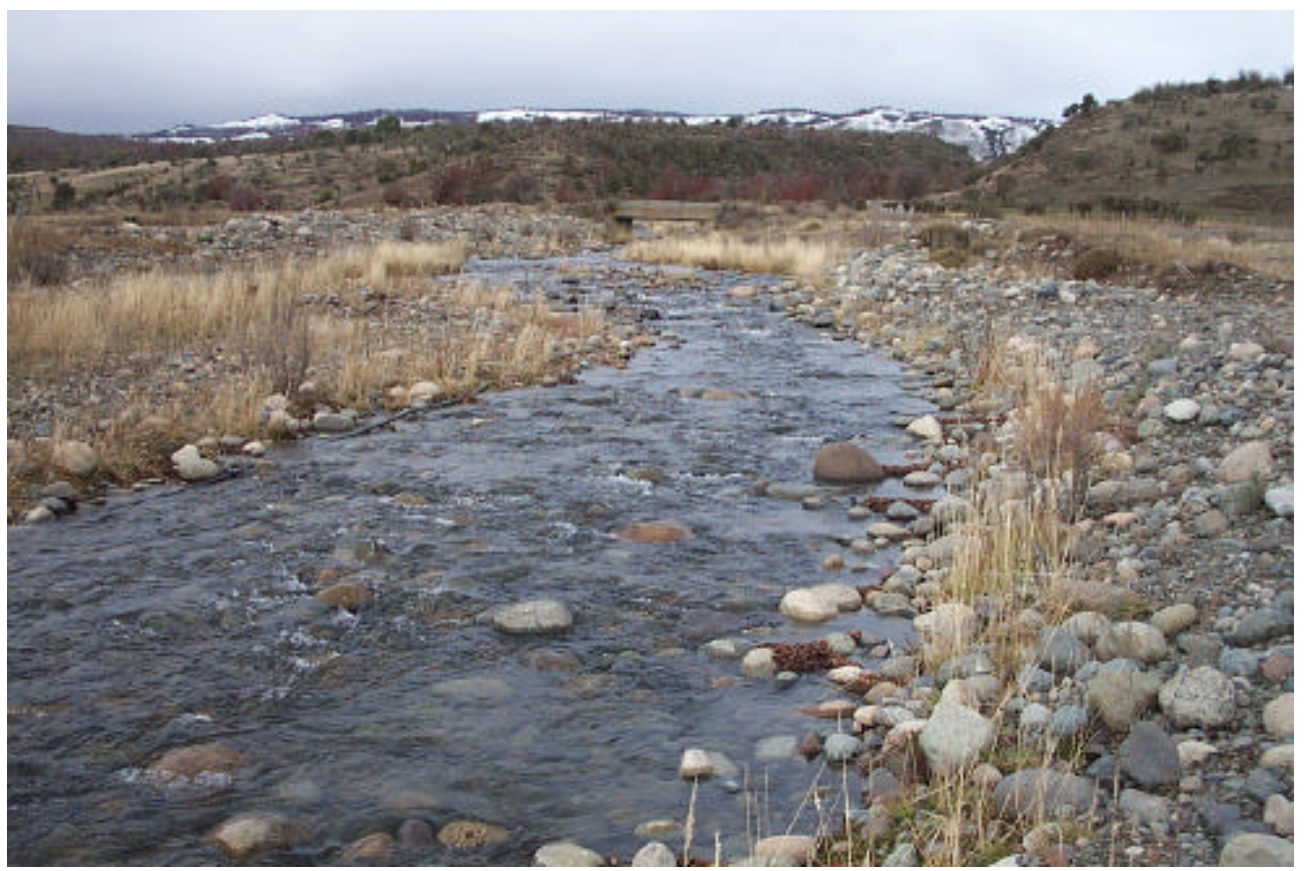

Figura 12. Sitio Manguera, pastura, sobre un tributario del Río Frío, cuenca del Corcovado. Mes de mayo de 2005. 
La vegetación fue muy escasa (30\% cobertura), generalmente compuesta por especies exóticas: llantén, vinagrillo, ajenjo (Artemisia absinthium), trébol blanco (Trifolium repens), Hypochaeris sp., diente de león, Crepis capillaris, alfilerillo (Erodium cicutarium). Entre las nativas se registraron pimpinela (Acaena pinnatifida), Senecio sp., pichoga (Euphorbia collina), manca caballo (Discaria articulata), y calafate, en forma aislada.

El sitio Nant y Fall (Figura 13, cuenca del Futaleufú-Yelcho), se ubica pocos metros debajo del bosque de ñire, en el tramo estudiado se aprecia la alteración producida por la presencia de ganado. Se observaron ejemplares de las especies nativas ñire, laura y calafate. Las herbáceas (cobertura de 60 a 70\%) estuvieron representadas por gramíneas y exóticas como llantén, trébol blanco, troicachu (Cerastium arvense), diente de león, vinagrillo, ajenjo, alfilerillo, lupulina (Medicago lupulina), manzanilla (Matricaria recutita). Algunas nativas son pichoga, cepa caballo (Acaena splendens) y pimpinela. Hay importantes sectores de mallín, con especies como junquillo, Pratia repens, Ranunculus sp. También se observa gran cobertura de vegetación acuática, con especies como cola de zorro (Myriophyllum quitense), Limosella australis, Eleocharis sp., Callitriche lechleri.

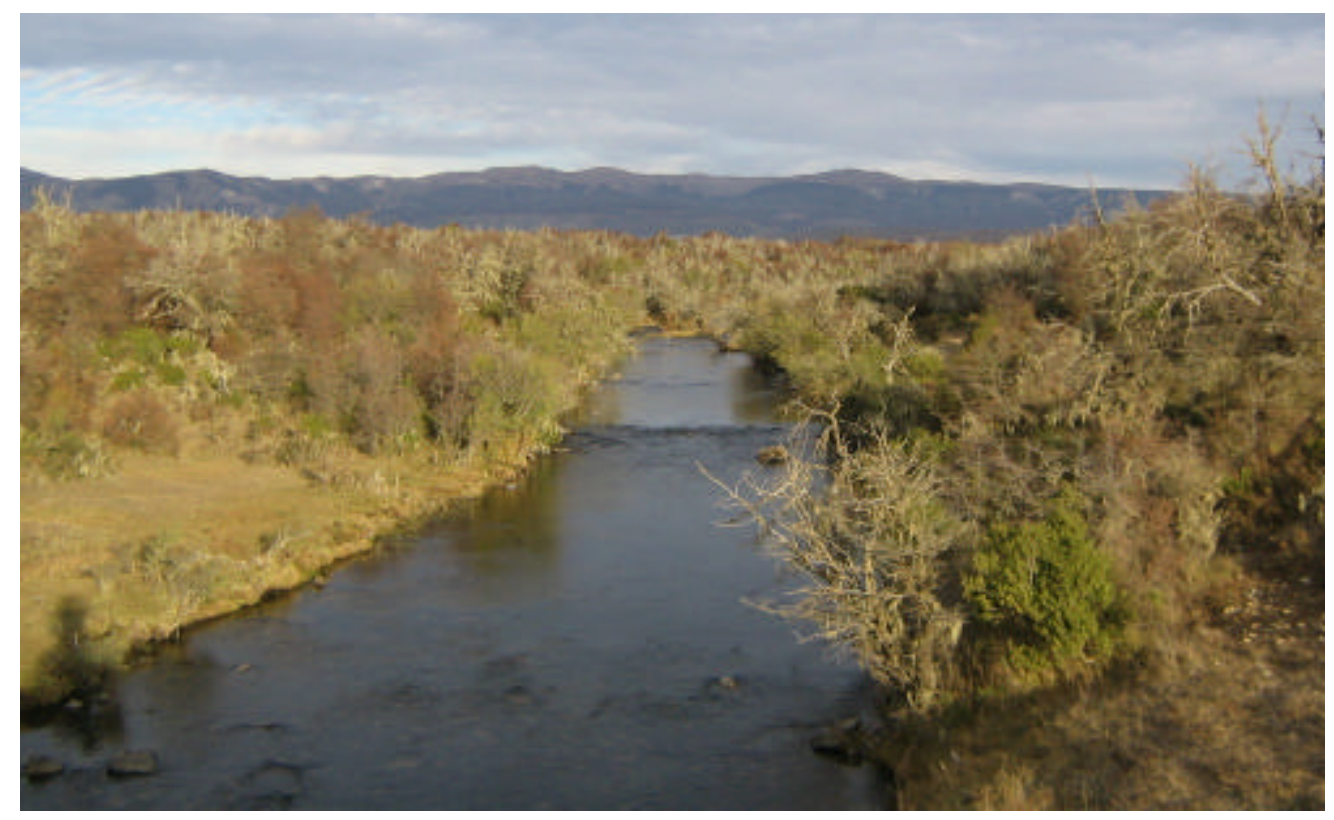

Figura 13. Vista panorámica Río Nant y Fall, cuenca del Futaleufú-Yelcho, pastura, durante el mes de mayo de 2005.

Bosque manejado. Los sitios correspondientes a este tipo de uso, se localizan en áreas donde el bosque nativo típico de ñire se encuentra sometido a distintas actividades de 
extracción comercial de madera. Esta actividad es una de los más difundidas en la región cordillerana y consiste en la poda y corta selectiva de ciertos individuos jóvenes y maduros para leña. Este clareo no afecta más del $50 \%$ del área pero permite la inclusión de ganado para pastoreo. Si bien el raleo del bosque debe excluir la zona de protección ribereña, y los operarios deben disponer apropiadamente el material de descarte para que el mismo no ingrese al curso de agua, es frecuente que las podas afecten la franja de bosque de protección e incluso grandes cantidades de material obstruyen el cauce natural del arroyo. En el sitio Cabeza de Vaca (Figura 14, cuenca del Corcovado), el estrato arbóreo se compuso principalmente de sauces con una cobertura de $80 \%$ y algunos ejemplares aislados de ñire. El estrato arbustivo está caracterizado por laura, neneo (Mulinum spinosum), parrillita (Ribes cucullatum), calafate, chaurilla (Maytenus chubutensis); en los sectores con mayor cobertura de ñires se desarrolla un sotobosque importante conformado por las especies anteriormente citadas.

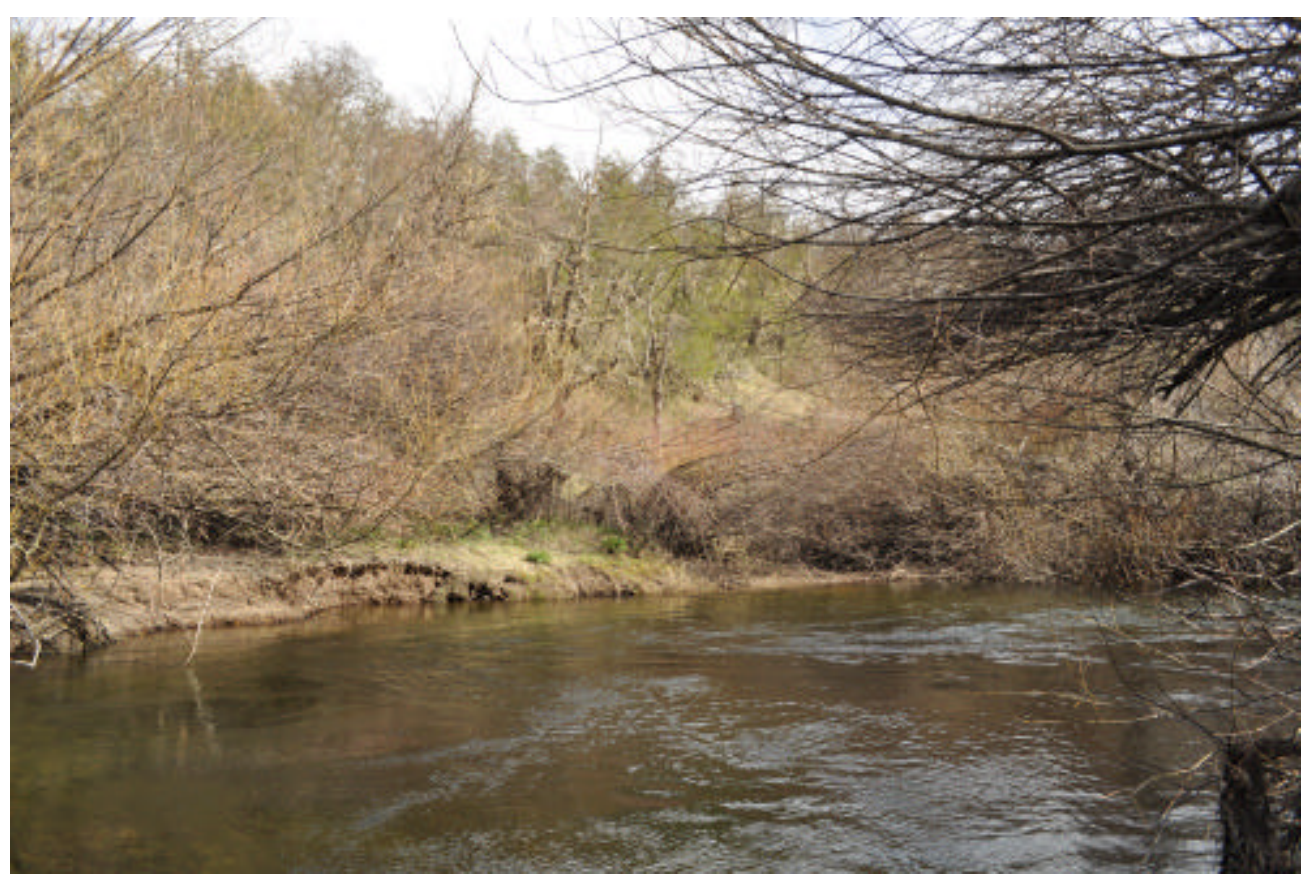

Figura 14. Arroyo Cabeza de Vaca, cuenca del Corcovado durante el mes de septiembre de 2005.

El sitio Glyn (Figura 15, cuenca Corcovado) con fuertes pendientes en sus márgenes, presentó una cobertura de ñires de alrededor de $30 \%$. El sotobosque cubrió aproximadamente $40 \%$ del terreno y estuvo representado por especies como calafate, laura, chaurilla, parrillita, pillo-pillo (Ovidia andina) y caña colihue. También se observaron signos de presencia de ganado ovino. 


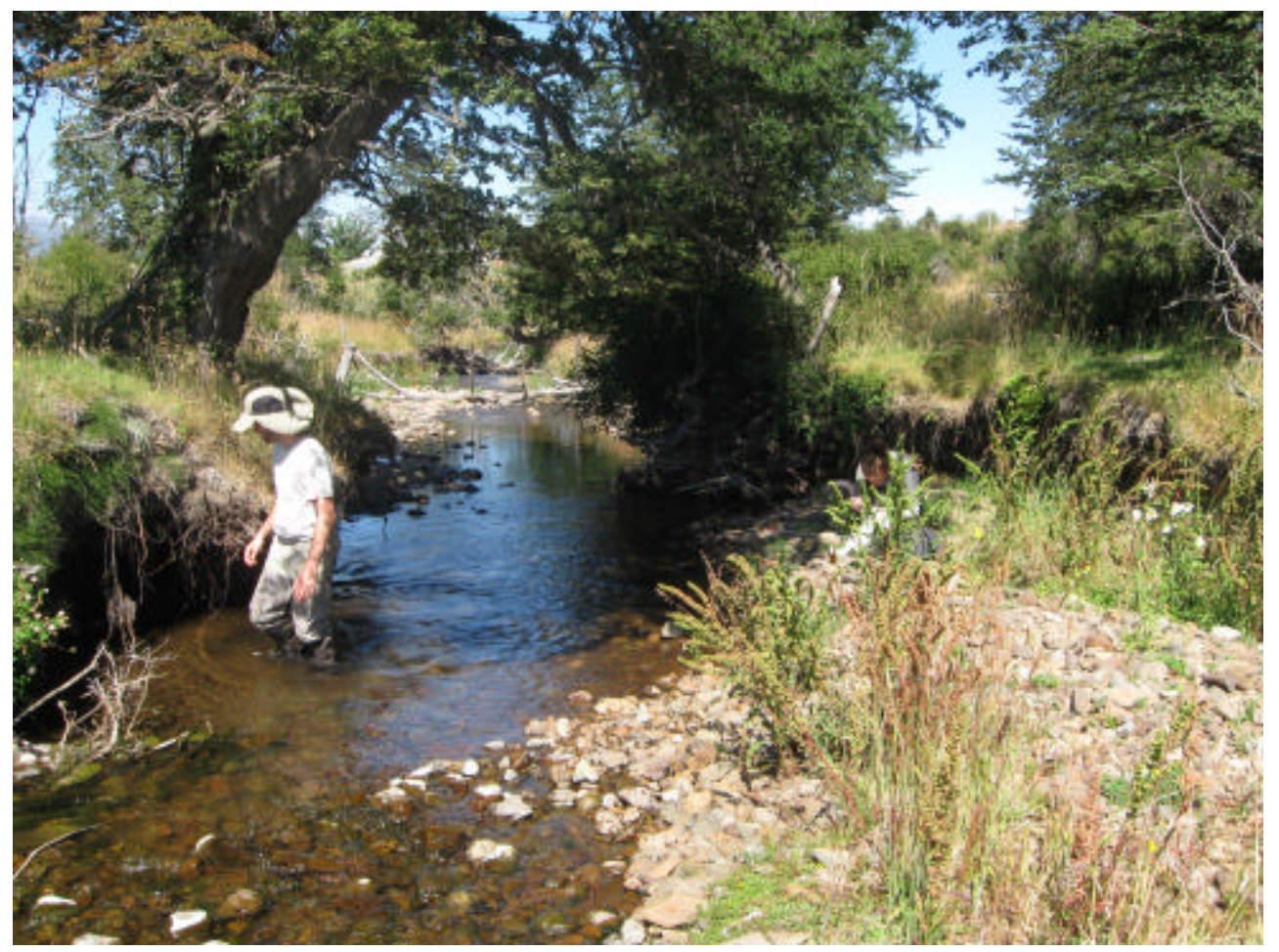

Figura 15. El Arroyo Glyn, cuenca del Corcovado, durante el mes de febrero de 2010.

El sitio Pipo (Figura 16), es un arroyo de orden 1, que atraviesa un área donde, además de realizarse extracción de madera para leña, hay pastoreo de ganado vacuno. El estrato arbóreo estuvo representado por ñire exclusivamente con una cobertura superior al $80 \%$. El sotobosque, bien definido, con una cobertura de 40 a $60 \%$, se compuso de: laura, virreina (Mutisia spinosa), parrilla (Ribes magellanicum), parrillita, chaurilla, calafate, michay (B. darwinii). En este sitio los efectos de la extracción fueron más evidentes, ya que parte del material de descarte (hojas, ramas, etc.) fueron arrojadas al arroyo, impidiendo el flujo natural del agua. 


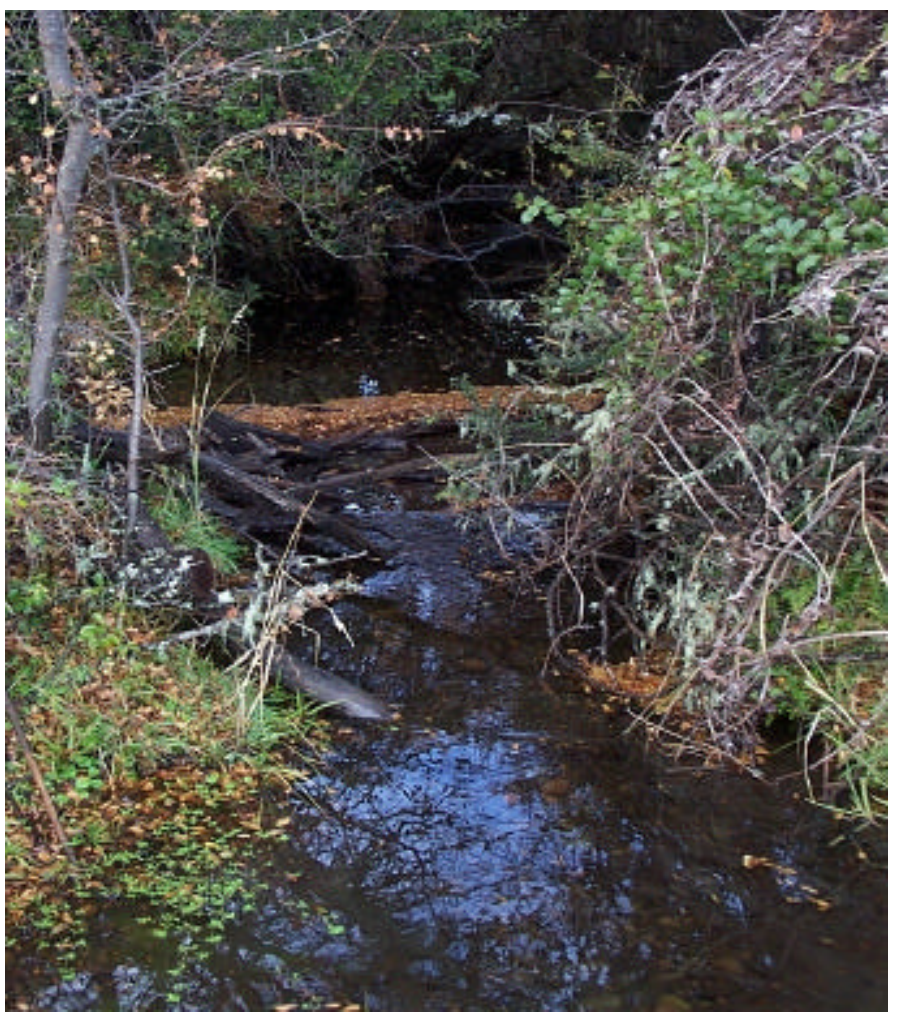

Figura 16. Sitio Pipo, sobre un tributario del río Nant y Fall, cuenca del Futaleufú-Yelcho, mes de mayo de 2005.

Bosque nativo. Los tres sitios seleccionados como testigo, se sitúan en bosque de ñire sin ningún tipo de disturbio.

Los ríos Loro (Figura 17) y Comisario (Figura 18), pertenecen a la cuenca del río Corcovado, ambos presentaron un estrato arbóreo compuesto por ñire y lenga, cubriendo entre el 50 y $60 \%$. El sotobosque, en ambos casos estuvo bien desarrollado, representado por chaurilla, chaura (Gaultheria sp.), laura, parrillita, calafate, calafatillo (B. empetrifolia), mosaiquillo (Baccharis magellanica), neneo, Senecio sp., radal (Lomatia hirsuta), huautro, romerillo (Chiliotrichum rosmarinifolium), palo piche (Fabiana imbricata), notro (Embothrium coccineum) y la enredadera reina (Mutisia decurrens). 


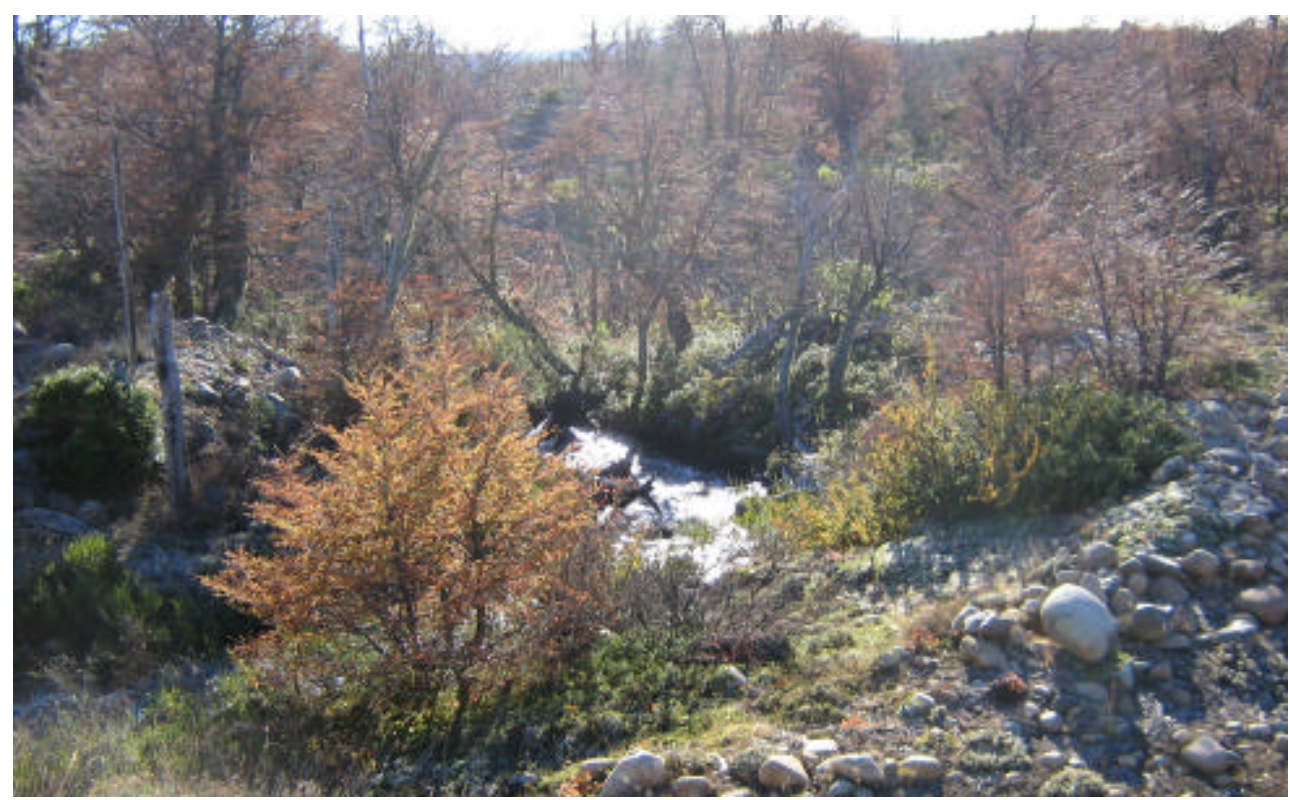

Figura 17. Arroyo Loro, cuenca del Corcovado, durante el mes de mayo de 2006.

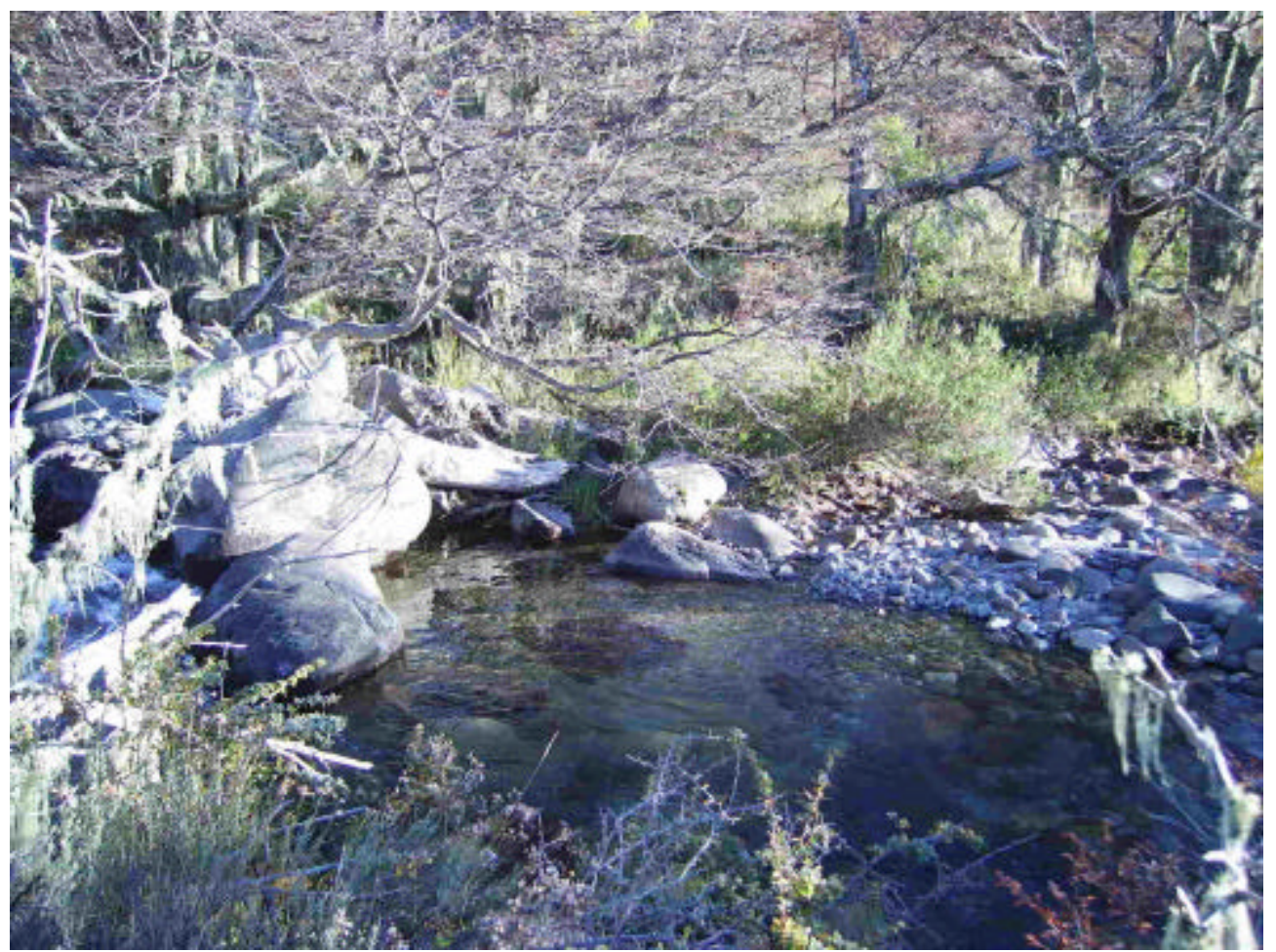

Figura 18. Arroyo Comisario, cuenca del Corcovado, bosque nativo de referencia, mes de mayo de 2006.

El sitio Chiquito (Figura 19, cuenca del Río Frío) se encuentra en un arroyo permanente de bajo orden. Si bien la cobertura en la zona ribereña es de $90 \%$ de bosque de ñire en buen estado, a metros de la franja ribereña hacia la margen izquierda se encontró una plantación de pino ponderosa y hacia la derecha un pastizal. El bosque 
nativo conservó un sotobosque denso con especies como parrillita, chacay de la cordillera, laura, chaurilla y calafate.

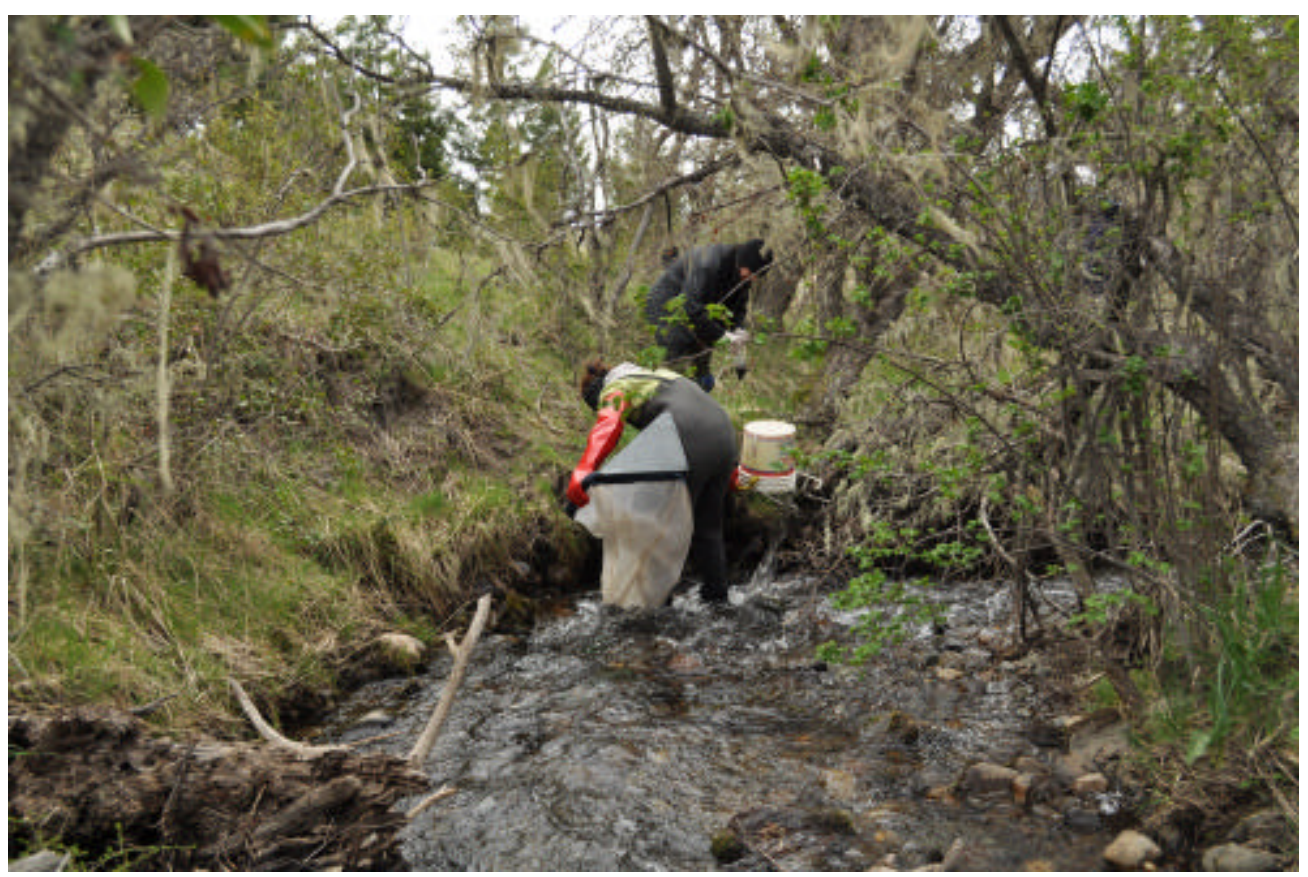

Figura 19. Sitio Chiquito, sobre un tributario sin nombre del Río Frío, cuenca del Corcovado. Localizado en bosque nativo de referencia, mes de octubre de 2009. 


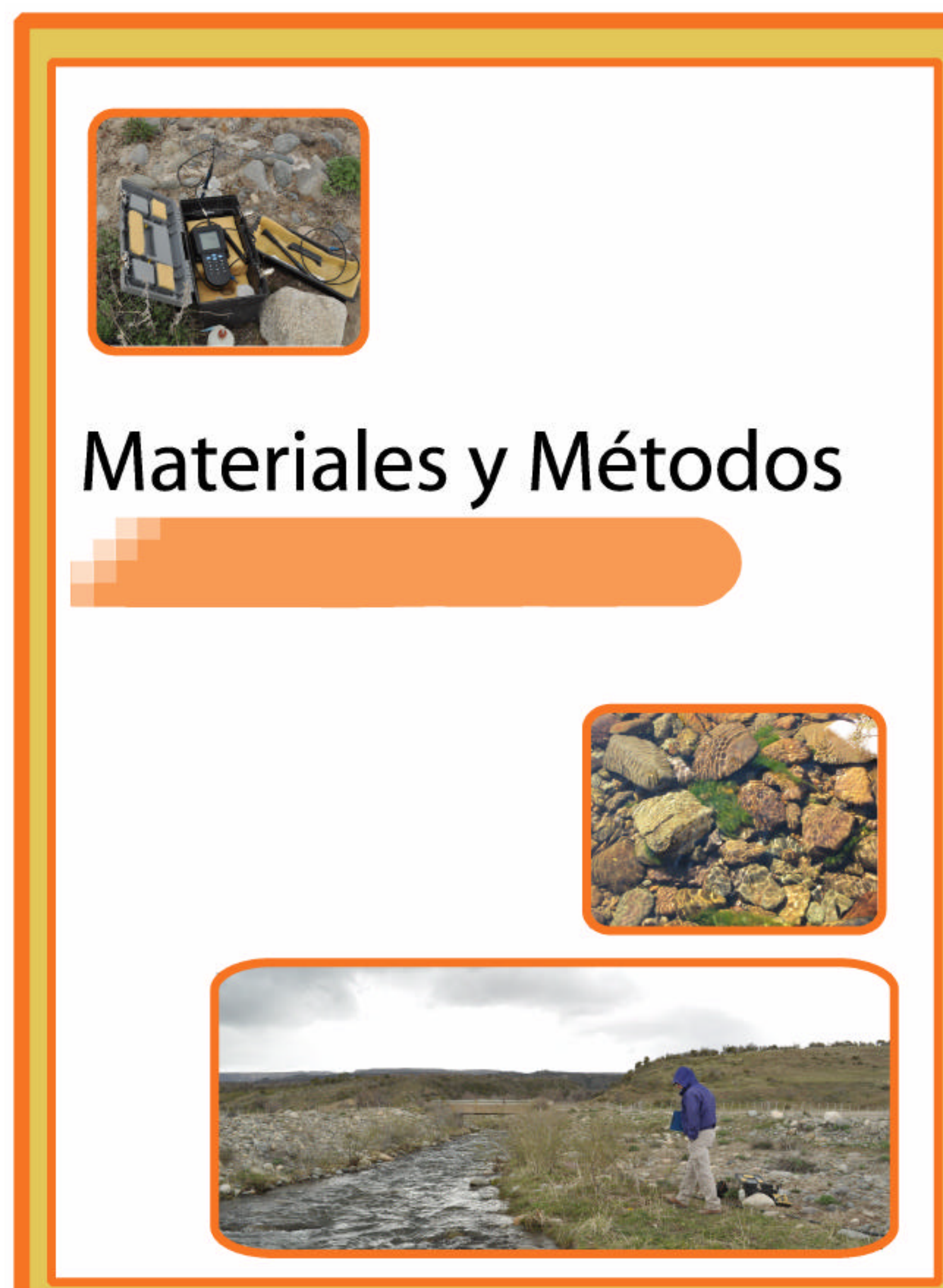

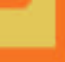




\section{MATERIALES Y METODOS}

\subsection{Caracterización geográfica}

En cada uno de los sitios muestreados, se registró la latitud, longitud y la elevación sobre el nivel del mar, mediante la utilización de posicionador satelital Legend - Etrex (Garmin). También se determinó el orden lótico de cada uno de los arroyos según Strahler (1957). Los tres sitios seleccionados para cada uso de la tierra son relativamente comparables tanto en jerarquía, régimen hidrológico y elevación sobre nivel del mar (Tabla 1).

\subsubsection{Cálculo de las coberturas de usos por cuenca}

También se realizó una caracterización de los usos predominantes de la cuenca y sus principales rasgos, tipo de vegetación y cobertura (porcentajes y superficies). Para esto se utilizó un set de imágenes Land Sat ETM de los años 2000 y 2001, de 15 m de resolución, clasificadas y procesadas utilizando un sistema de información geográfica (GIS) (Software Arc Wiew 3,3) de cada cuenca y subcuenca provisto por la Dirección de Bosques y Parques (DGBP) de la Provincia del Chubut. Para cada sitio de muestreo se obtuvo el área de la subcuenca aguas arriba y el porcentaje de cobertura de de vegetación nativa y exótica, pasturas y áreas urbanas. Asimismo se cuantificaron las áreas caracterizadas por humedales, lagos, y altas cumbres. Estas tareas se llevaron a cabo con la colaboración de Área de procesamiento y análisis de imágenes satelitales de la DGBP.

\subsection{Características fisicoquímicas}

Para la determinación de los parámetros físicos y químicos más relevantes del ambiente, en cada sitio de muestreo y en cada ocasión se registraron en planilla de campo el ancho del lecho seco (m) (como el ancho máximo que cubre el agua durante las crecidas máximas), el ancho del lecho mojado (m) (como el ancho del río en el momento de muestreo), tres perfiles de profundidad con varilla graduada $(\mathrm{cm})$ y se estimó la velocidad de la corriente, como un promedio de tres mediciones con flotador $\left(\mathrm{m} . \mathrm{s}^{-1}\right)$ (Gordon et al. 2004). Estos tres valores fueron utilizados para estimar el valor de caudal 
$\left(\mathrm{m}^{-3} . \mathrm{s}\right)$ (Gordon et al. 2004). En la primera visita, como única vez se estimó la proporción relativa de los distintos componentes del sustrato. Para ello se utilizó una grilla de $1 \mathrm{~m}^{2}$, dividida en cuadrados de $20 \mathrm{~cm}$ de lado, la misma se colocó sobre el sustrato y se fotografió (Figura 20). Dentro de cada celda se estimó luego la cobertura de cada categoría de sustrato. El área media de cobertura para una categoría fue calculada como el número de celdas de esa categoría dividida por el número total. Los rangos de tamaño de partícula se basaron en la escala de Wentworth. Dependiendo de la longitud de la dimensión mayor de la partícula (DM) se clasificaron en: bloque (DM>25 $\mathrm{cm})$, guijón $(12,8 \mathrm{~cm}<\mathrm{DM}<25 \mathrm{~cm})$, guijarro $(6 \mathrm{~cm}<\mathrm{DM}<12,8 \mathrm{~cm})$, grava $(0,2 \mathrm{~cm}<$ $\mathrm{DM}<6 \mathrm{~cm}$ ), y sedimentos finos (DM $<0,2 \mathrm{~cm})$ que incluye mayormente arena (Gordon et al. 2004).

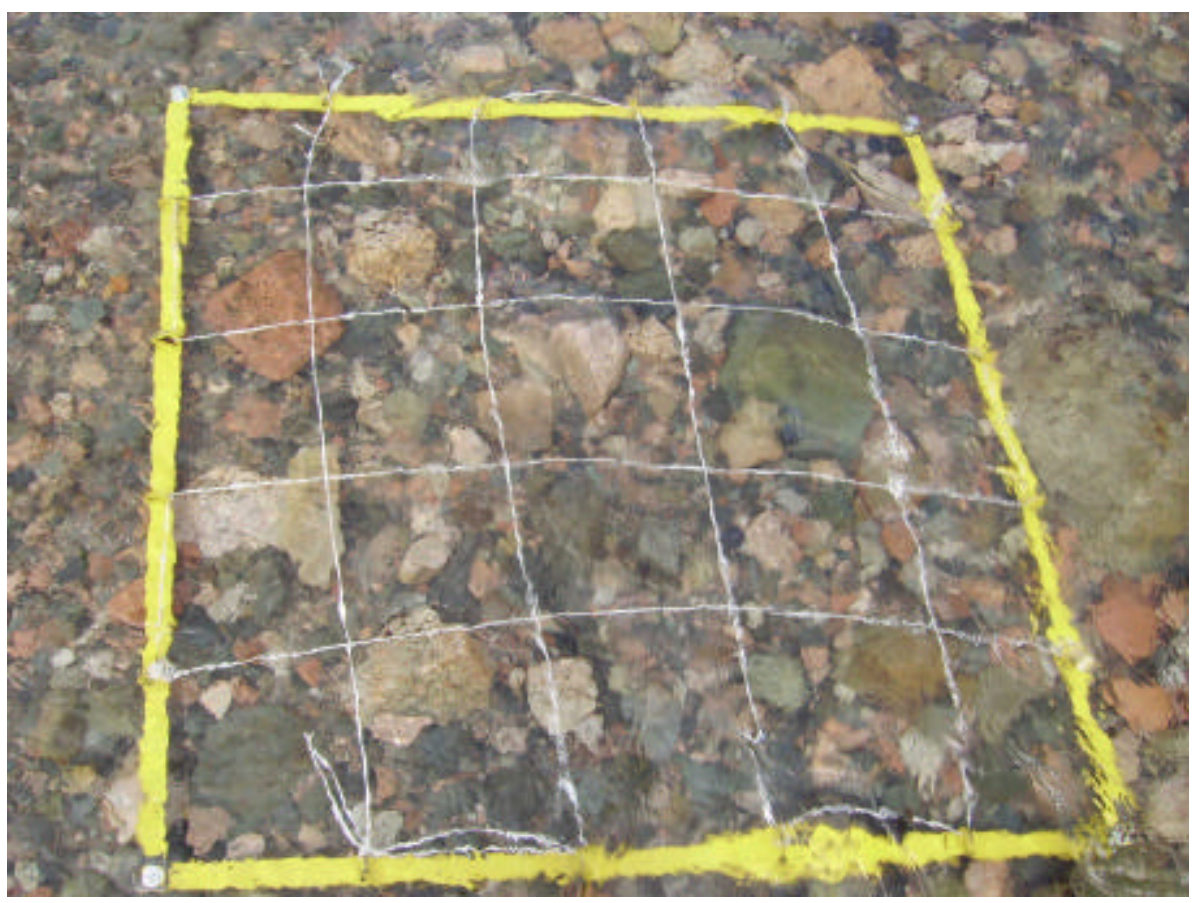

Figura 20: Fotografía de la grilla $\left(1 \mathrm{~m}^{2}\right)$ colocada en la sección muestreada en el mes de mayo de 2005. Cada celda mide aproximadamente $20 \times 20 \mathrm{~cm}$.

La temperatura del aire $\left({ }^{\circ} \mathrm{C}\right)$ se midió con termómetro de mercurio. La temperatura del agua $\left({ }^{\circ} \mathrm{C}\right), \mathrm{pH}$, conductividad $\left(\mu \mathrm{S}_{20} \mathrm{~cm}^{-1}\right)$, concentración de oxígeno disuelto $\left(\mathrm{mg} \mathrm{O}_{2} \mathrm{l}^{-1}\right)$, turbidez (NTU) y la salinidad (\%) se midieron con una sonda multiparamétrica Horiba U10 de inmersión, alimentada por una batería 6F22, en cada muestreo.

En cada uno de los sitios se tomaron muestras de agua superficial, las cuales fueron preservadas a $4{ }^{\circ} \mathrm{C}$ para un posterior análisis de nutrientes. En laboratorio, se 
determinaron las concentraciones de nitritos + nitratos $\left(\mathrm{NO}_{3}{ }^{-}-\mathrm{NO}_{2}{ }^{-}\right)$, amonio $\left(\mathrm{NH}_{4}{ }^{+}\right)$, fósforo reactivo soluble (PRS) (+/- 0,01 $\left.\mu \mathrm{gl}^{-1}\right)$ y total de sólidos en suspensión (TSS) (+/- 0,1 $\left.\mathrm{mg} \mathrm{l}^{-1}\right)$ (APHA 1999).

Para la determinación del amonio se utilizó el método colorimétrico por reacción con fenol, nitroprusiato y reactivo oxidante (Método del Fenato, 417-C Standard Methods (1980)). La lectura se realizó con un espectrofotómetro Hewlett Packard modelo 8452A a una longitud de onda de $640 \mathrm{~nm}$. En el análisis de la concentración de nitrito + nitrato se utilizó el método colorimétrico por reacción con naftil-etilendiamina y sulfanilamida (Método de reducción en columna de cadmio, 418F Standard Methods) (APHA 1980). Previo a la coloración, la muestra atravesó una columna reductora de cobre-cadmio. La lectura se realizó con autoanalizador “Autoanalyzer" a una longitud de onda de $540 \mathrm{~nm}$. La concentración de fósforo reactivo soluble se obtuvo mediante método colorimétrico por reacción con Molibdato de amonio, ácido sulfúrico diluido, ácido ascórbico y tartrato antimonio de potasio (Método del Ácido Ascórbico (424-F Standard Methods) (APHA 1980). Las lecturas se realizaron con espectrofotómetro Agilent 8452, a una longitud de onda de $885 \mathrm{~nm}$. En todos los casos se han utilizado reactivos de calidad Analítica (PRO-ANALYSIS).

La clorofila $a$ epilítica se midió únicamente durante el muestreo de marzo (verano). Para esto se cepillaron y lavaron 5 rocas del lecho de cada río muestreado. El producto extraído se transportó en frascos color caramelo de $120 \mathrm{ml}$, refrigerados al laboratorio. A las rocas involucradas en el procedimiento se les tomaron las medidas de ancho y largo con regla para calcular el área de cobertura de la comunidad algal expresando los valores en miligramo por metro cuadrado. Para el análisis de clorofila $a$ se filtraron, mediante una bomba de vacío, dos alícuotas de $25 \mathrm{ml}$ de la muestra compuesta de perifiton, en filtros de fibra de vidrio Whatman GFC $47 \mathrm{~mm}$. Los filtros fueron envueltos en papel aluminio, rotulados y congelados (crio-lisis) durante un tiempo mínimo de 24 hs. Posteriormente se trituraron utilizando un mortero con el agregado de $4 \mathrm{ml}$ de acetona al 90\% (90\% de acetona $+10 \%$ de solución saturada de carbonato de Magnesio). Las soluciones preparadas se refrigeraron $\left(4^{\circ} \mathrm{C}-24 \mathrm{~h}\right)$, para permitir que la acetona extrajera la clorofila, luego los tubos se centrifugaron (500 rpm 2 minutos). El sobrenadante fue retirado y transferido a una cubeta de vidrio para la lectura espectrofotométrica.

La concentración de clorofila $a$ se determinó leyendo la muestra a longitudes de onda de 664, 647, 630 y $750 \mathrm{~nm}$. Las medidas de cada longitud de onda fueron 
corregidas mediante sustracción de la lectura a $750 \mathrm{~nm}$ sobre las absorciones de 664, 647 y $630 \mathrm{~nm}$ (APHA - AWWA - WPCF 1989). Los valores de clorofila $a$ fueron expresados en mg.m ${ }^{-2}$ (Wetzel \& Likens 1991).

\subsection{Caracterización de la vegetación terrestre y acuática en los sitios de estudio}

Se realizó una recopilación de información sobre las especies vegetales presentes. Se herborizaron las especies principales y luego fueron determinadas en gabinete. Se tomaron fotografías panorámicas de los sitios con el objeto de caracterizar a posteriori la estructura vertical y el porcentaje de cobertura vegetal en el tramo estudiado (Dimitri 1977; Correa 1978-1999; Lopretto \& Tell 1995).

\subsection{Caracterización del hábitat}

\subsection{1. Índice de calidad de ribera (QBRp)}

Para evaluar el estado de conservación y estructura de la cobertura vegetal ribereña se calculó el índice de calidad de bosque de ribera patagónico (QBRp) (Kutschker et al. 2009). Éste es una adaptación del índice QBR propuesto por Munné y colaboradores (Prat et al. 1999; Munné et al. 2003) a los ambientes de cordillera patagónica. Esta herramienta permite valorar de forma rápida y sencilla las riberas, mediante la integración de aspectos estructurales de la vegetación, morfología de la ribera y el grado de intervención antrópica en el terreno. Su aplicación es amplia en ríos españoles y portugueses (González del Tánago \& Antón 1998, 2000; Prat et al. 1999; Carrascosa \& Munné 2000; Suárez \& Vidal-Abarca 2000; Suárez et al. 2002), en Argentina se ha adaptado para su uso en cursos de agua de la provincia de Tucumán (Sirombra et al. 2006).

Para la determinación del valor del QBRp se debe completar la planilla (Anexo 1) para cada sitio, teniendo en cuenta la zona entre el tramo delimitado por el mínimo de flujo permanente y el de máximas crecidas. La puntuación del índice varía entre 0 y 100 y es la suma de cuatro apartados basados en cuatro aspectos de calidad ribereña. A continuación se presenta un resumen de la metodología aplicada para el cálculo de cada uno de los apartados. 
Grado de cubierta de la zona de ribera: este apartado califica según el porcentaje de cobertura vegetal teniendo en cuenta tanto el área ribereña como el canal e incluye árboles, arbustos, plantas o helófitas. De esta cuantificación se excluyen las herbáceas anuales dado que su cobertura puede variar ampliamente a lo largo del año y las condiciones hidrológicas. En esta instancia se evalúa también la conectividad entre el bosque de ribera y el ecosistema forestal adyacente, este es un punto clave en la preservación de la biodiversidad. Se adicionan puntos si la conectividad es total o mayor al $50 \%$ y se restan 2 o 5 puntos en caso de que la conectividad esté entre 25 y $50 \%$ o si es inferior al $25 \%$, respectivamente.

Estructura de la cubierta: se analiza la complejidad estructural del ambiente ribereño. El puntaje inicial está dado por la cobertura de especies arbóreas, sin embargo este puede luego aumentar por la presencia de helófitas en una cobertura superior al 25 o al $50 \%$ o bien, por la presencia de sotobosque arbustivo. Asimismo, si los árboles se distribuyen en arreglos lineares, como ocurre en plantaciones, o en parches el puntaje disminuye.

Calidad de la cubierta: previamente a la evaluación de este apartado, debe asignarse el tipo morfológico de ribera (ver final planilla de campo, Anexo I). Se evalúan ambos márgenes independientemente y sus valores se suman. Si existen islas o bardas de arena, se restan puntos al total, dado que estos aumentan la disponibilidad de sustrato colonizable por distintas especies. De esta manera, al sustraerle puntos al tipo morfológico, debido a la presencia de islas, el tipo de ribera puede pasar de una categoría a la siguiente inferior, aumentando el número óptimo de especies nativas necesarias para alcanzar el máximo puntaje en el bloque.

De acuerdo al valor obtenido para el tipo morfológico de ribera se procede a la calificación del apartado 3, este apartado evalúa si el tramo estudiado presenta el número óptimo de especies arbóreas nativas, si el número es inferior o si no presenta ninguna especie arbórea nativa. Se asignan puntos extra en caso de que la comunidad presente una alta continuidad o bien, en caso de que exista un determinado número de especies arbustivas en el sotobosque. Se quitan puntos en caso de que existan especies arbóreas y/o arbustivas aisladas o formando comunidades. En la sección final de la planilla de campo (Anexo I) se provee una lista de especies arbóreas/arbustivas nativas y exóticas para la región de cordillera patagónica.

Grado de naturalidad del canal fluvial: en este apartado se asigna un puntaje de acuerdo al grado de alteración antrópica registrada en el tramo analizado. Asignándose 
un máximo de 25 puntos en caso de que no se registre ninguna modificación y mínimo para los tramos que se encuentran canalizados en su totalidad. Se registran modificaciones de las terrazas adyacentes al curso de agua en las que no se reduce el canal, modificaciones que producen una reducción del canal y presencia de distintas estructuras transversales o dentro del canal.

La puntuación final del índice resulta sumando el puntaje obtenido en cada uno de los apartados. El rango obtenido (0-100) puntos se divide en cinco clases o niveles de calidad (Tabla 2).

Tabla 2. Niveles de calidad y clasificación por color de acuerdo al puntaje final obtenido en el QBRp (Kutschker et al. 2009).

\begin{tabular}{lcc}
\hline Nivel de calidad & QBRp & Color \\
\hline Bosque de ribera sin alteraciones, calidad muy buena, estado & $>90$ & Azul \\
natural & $>70-90$ & Verde \\
Bosque ligeramente perturbado, calidad buena & $>50-70$ & Amarillo \\
Inicio de alteración importante, calidad intermedia & $>25-50$ & Naranja \\
Alteración fuerte, calidad mala & $<$ ó $=25$ & Rojo \\
Degradación extrema, calidad pésima & \\
\hline
\end{tabular}

\subsection{2. Índice de valoración de hábitat (HA)}

Para obtener una calificación del estado del hábitat físico en cada sitio de muestreo se aplicó el método de índice de valoración de hábitat para ríos-arroyos en zonas de alto gradiente, HA (Barbour et al. 1999). El método fue propuesto por primera vez para arroyos norteamericanos (Barbour \& Stribling 1991, 1994) y luego fue aplicado exitosamente en arroyos de bajo orden de la cordillera patagónica (Miserendino 2005 a). El índice HA evalúa la disponibilidad de hábitats para la fauna en los arroyos, dando una medida de la heterogeneidad espacial del arroyo (Castela et al. 2008).

Este método se realiza mediante la estimación visual de diez parámetros para todo el tramo estudiado, cada uno de los parámetros se califica en una escala de 0 a 20 puntos, correspondiendo 20 a la condición óptima esperable, asimismo el rango se divide en cuatro categorías continuas (óptima, subóptima, marginal y pobre). A continuación se detallan los diez parámetros y la delimitación de las categorías de calidad de acuerdo al puntaje total obtenido. 
Parámetro 1. Sustrato disponible epifaunal: incluye la cantidad relativa y variedad de estructuras naturales en el lecho del arroyo, tales como bloques (en los rápidos), árboles caídos, troncos, ramas disponibles como sitios de refugio, alimentación y oviposición de la macrofauna acuática. Una amplia variedad o abundancia de estructuras sumergidas en el arroyo proveen tanto a los macroinvertebrados como a los peces una gran combinación de nichos, incrementando la diversidad de hábitats.

Parámetro 2. Grado de enterramiento: Este parámetro hace referencia al grado en el cual las rocas (bloques, guijones, guijarros) están cubiertas o hundidas en arcilla, arena o barro. Generalmente el grado de enterramiento disminuye la superficie disponible para macroinvertebrados (refugio, oviposición, incubación de huevos). El enterramiento resulta del movimiento de sedimentos a gran escala y su deposición en rápidos y correderas.

Parámetro 3. Régimen de velocidad/profundidad. Las combinaciones de velocidad y profundidad son una característica importante en la determinación de la diversidad de hábitats.

La mejor condición deberá tener los cuatro patrones presentes: 1) lento-profundo; 2) lento-superficial; 3) rápido-profundo y 4) rápido-superficial. El parámetro estimado es $0,5 \mathrm{~m}$ para separar superficial de profundo y $0,3 \mathrm{~m} \cdot \mathrm{s}^{-1}$ para separar rápido de lento.

Parámetro 4. Deposición de sedimentos: Este parámetro estima la cantidad de sedimentos que se han acumulado en pozones y los cambios que han ocurrido en el lecho, como resultado de esta deposición. Este fenómeno ocurre por movimiento de sedimentos a gran escala y puede dar lugar a la formación de islas, bardas o resultar en la colmatación de correderas y pozones. Altos niveles de deposición de sedimentos es síntoma de que el ambiente se muestra continuamente cambiante e inestable, siendo por lo tanto poco adecuado para muchos organismos.

Parámetro 5. Estatus del flujo del canal: este parámetro evalúa el grado en que el canal está cubierto por agua. El estatus de flujo puede cambiar conforme el canal se ensancha o el flujo disminuye como resultado de diques, obstrucciones, extracción de agua para riego o sequías. Cuando una fracción del lecho queda expuesta, la cantidad de sustrato apropiado para los organismos acuáticos se ve limitada.

Parámetro 6. Alteraciones del canal: da una idea de los cambios a gran escala en la morfología del cauce. Muchos arroyos en áreas rurales y urbanas han sido realineados, dragados o derivados en canales de concreto, ya sea para control de 
inundaciones o irrigaciones. En estos casos, los hábitats disponibles para la biota acuática son escasos o mínimos.

Parámetro 7. Frecuencia de rápidos o curvas: esta frecuencia da una idea de la heterogeneidad en el arroyo. Los rápidos son una fuente de hábitat de alta calidad y diversidad de fauna y por lo tanto una alta ocurrencia de rápidos mejora la diversidad de la comunidad acuática. En zonas de alto gradiente, donde los rápidos bien diferenciados no son comunes, puede calcularse la relación rápidos/curvas. La absorción de energía por estas curvas protege el canal de la erosión excesiva en eventos de alta descarga.

Parámetro 8. Estabilidad de las márgenes: evalúa si las márgenes se encuentran erosionadas, o si son potencialmente erosionables. Las márgenes con mayor pendiente, son más propensas a colapsar y erosionarse. Los signos visibles de la erosión son derrumbes, márgenes desprovistas de vegetación, raíces de árboles y suelo expuestos. Las márgenes erosionadas sugieren escasez de cobertura vegetal y aporte orgánico al curso de agua. Ambas márgenes se evalúan separadamente, el valor de este parámetro es la suma de los valores de ambas márgenes.

Parámetro 9. Protección vegetal: mide la cantidad de protección vegetal que presenta la ribera. Esta protección vegetal representa una mayor fijación del suelo, por parte del sistema radicular, que repercute en una alta resistencia a procesos erosivos, pero también aumenta la retención de nutrientes y materia orgánica que de otra manera ingresarían al curso de agua, así como también el sombreo en caso de los cursos de agua debajo orden y hábitat para gran parte de la fauna. Este parámetro se estima para cada margen individualmente y el puntaje final de ambos se suma para dar el valor del parámetro.

Parámetro 10. Ancho de la zona ribereña: mide el ancho natural de la vegetación desde el borde del curso de agua. La vegetación ribereña sirve de amortiguador de crecidas, controla la erosión y provee hábitat y nutrientes al curso de agua. Rutas, zonas de estacionamiento, roca desnuda o construcciones afectan el ancho de la zona ribereña, mientras que sendas, de menor tamaño no se consideran de mayor impacto. El ancho óptimo estimado se calcula como cuatro veces el ancho del lecho mojado del arroyo en el tramo estudiado. Cada margen se calcula por separado y el puntaje final del parámetro esta dado por la suma de ambos valores.

Calificación final: las calificaciones de cada parámetro se sumaron, un puntaje total de 200 corresponde a un tramo prístino y en la mejor condición esperable. El rango 
150-200 categoría óptimo, incluye sitios con las mejores condiciones esperables; 100150: subóptimo; 50-100: marginal; 0-50: pobre (Anexo II).

\subsection{Caracterización biológica}

\section{Análisis estacional}

Para evaluar el aspecto estacional en el desarrollo de este plan, se realizaron muestreos cada tres meses en cada uno de los 18 sitios seleccionados, entre mayo de 2005 y marzo de 2006 (primavera, verano, otoño e invierno).

\section{Análisis espacial a escala de hábitat}

Para conocer las diferencias de distribución y abundancia de las especies de Trichoptera se trabajó en áreas deposicionales y de rápidos. En cada muestreo se tomaron tres réplicas en rápidos y tres réplicas en pozones $(n=6)$. Por lo tanto se analizaron una totalidad de 432 muestras $(\mathrm{N}=18 \times 4 \times 6=432)$.

\section{Colecta e identificación de especímenes}

Las muestras bénticas se colectaron con red Surber modificada (Winget \& Magnum 1979) de $250 \mu \mathrm{m}$ de poro y $0.09 \mathrm{~m}^{2}$ de superficie. Las fijación de muestras re realizó in situ con formaldehído al $10 \%(\mathrm{v} / \mathrm{v})$, las muestras se almacenaron en bolsas acondicionadas y fueron trasladadas al laboratorio.

Una vez en laboratorio las muestras se lavaron en tamiz de $250 \mu \mathrm{m}$ de malla, para eliminar el formol restante. Los individuos fueron separados manualmente bajo lupa manual (de aumento 5X). Los organismos encontrados se separaron del resto de la muestra y se conservaron en alcohol (70\%). La identificación y recuento de individuos se realizó utilizando lupas binoculares (Zeiss, Stemi DV4 y Leica MZ6) mediante claves disponibles para la zona y publicaciones actuales sobre el tema (Flint 1973, 1997; Holzenthal 1986a, 1986b; Angrisano 1995 a, b; Valverde 1996; Angrisano 1997; Valverde \& Miserendino 1997, 1998; Valverde \& Albariño 1999; Angrisano \& Korob 2001; Bravo \& Angrisano 2003, 2004; Angrisano \& Sganga 2005, 2009; Sganga \& Fontanarrosa 2006).

Para lograr un mayor grado de precisión en la identificación de las larvas se realizaron capturas de adultos durante los meses de primavera y verano con trampas de luz blanca. Las mismas se colocaron durante la noche dejándose activas por un lapso de 
tres horas. En los casos en los que no fue posible identificar las larvas por ausencia de descripciones de los estadíos inmaduros, se colectó material vivo (larvas y pupas). Parte del material fue fijado in situ, y el restante fue transportado al laboratorio para su cría hasta obtener el estadío adulto.

La cría de las larvas se realizó en una cámara refrigerada, mantenida a una temperatura menor de $10{ }^{\circ} \mathrm{C}$. Las mismas se colocaron en recipientes individuales con zonas de intercambio con malla plástica de $0,5 \mathrm{~mm}$, dentro de contenedores con agua, en los que se dispusieron las larvas aisladas con piedras pequeñas, ramas y hojas en el fondo. Los contenedores se revisaron diariamente a los fines de mantener la calidad del agua, hasta la emergencia del adulto (Sganga \& Fontanarrosa 2006). La identificación específica del resto de las larvas se realizó utilizando el método del metamorfotipo (Milne 1938). Se denomina metamorfotipo al conjunto formado por el capullo pupal cerrado, que contiene en su interior al adulto, recubierto por la autícula pupal, y los escleritos larvales desprendidos en la última muda, que permanecen en el extremo posterior del estuche. Usando esta estructura se pueden asociar todos los estados de una misma especie sin posibilidades de error, ya que todos se encuentran encerrados en un mismo capullo (Angrisano \& Sganga 2009).

\subsubsection{Análisis de materia orgánica autóctona y alóctona}

Se realizó una valoración visual de la cantidad y calidad del detrito y productores primarios existentes en cada réplica extraída con red Surber, estimando el porcentaje de las distintas clases materia orgánica autóctona y alóctona. De esta manera en la fracción autóctona se determinaron las clases: algas filamentosas (comprendiendo mayormente Cladophora spp.), cianobacterias mucilaginosas (Nostoc spp. en su totalidad), macrófitas (excluyendo briófitas) y briófitas. Por otra parte el detrito alóctono en cada muestra se separó en las clases: hojarasca entera, hojarasca fragmentada, material leñoso, frutos y semillas, y otros. El porcentaje de materia orgánica particulada béntica (MOPB) se estimó como la suma de todas las fracciones alóctonas (Voelz \& Ward 1990). Siempre que fue posible se identificaron las especies vegetales presentes. Se completó una tabla para cada sitio en cada muestreo (Tabla 3). 
Tabla 3. Tabla utilizada para evaluar los datos de cantidad de materia orgánica y porcentajes de cada fracción en las muestras bénticas colectadas con red Surber, en las tres réplicas de rápidos y pozones en cada uno de los sitios de estudio durante el período mayo 2005 a marzo 2006. A, $\mathrm{B}$ y $\mathrm{C}$ identifican las distintas réplicas tomadas en el mismo sitio, hábitat y para la misma fecha.

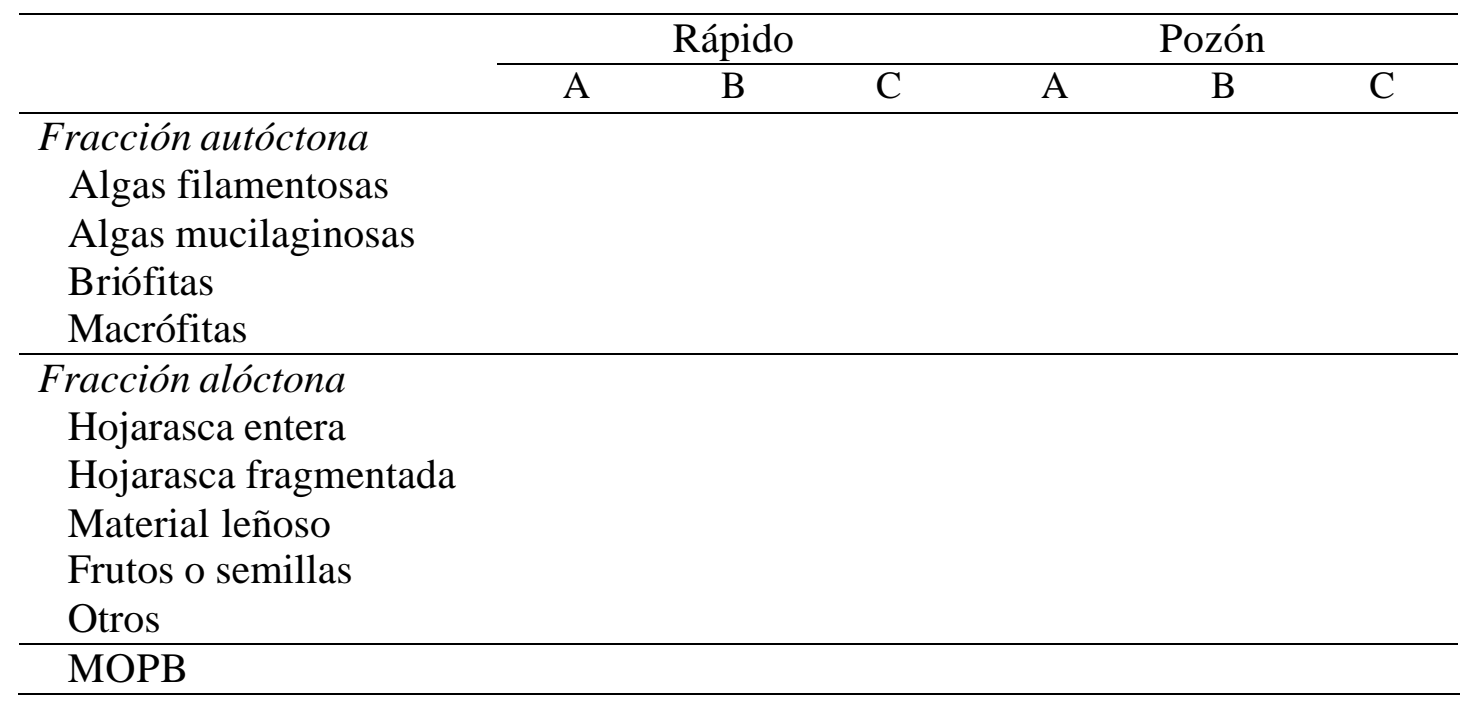

\subsubsection{Análisis de datos}

Para cada sitio, tipo de uso y fecha se confeccionaron listas de especies. Se calculó la densidad (ind. $\mathrm{m}^{-2}$ ) total de individuos para cada muestra y la densidad media total para cada sitio. Se registró la riqueza media estacional, media total y la riqueza acumulada de especies del grupo. Se estimó la abundancia relativa para cada familia representada, por sitio y por tipo de uso.

Con el objeto de analizar la estructura de la comunidad de Trichoptera, se aplicó el índice de diversidad de Shannon-Weaver y el índice de Equitatividad de Pielou.

Índice de Diversidad de Shannon-Weaver $\left(H^{\prime}\right)$ : se aplica con el fin de comparar las distintas relaciones especie-abundancia entre los sitios en estudio y es uno de los índices más utilizados en ecología (Ludwig \& Reynolds 1988).

$$
H^{\prime}=-\sum_{i=1}^{s}\left(p_{i} \ln p_{i}\right)
$$

En la fórmula $\mathrm{H}^{\prime}$ mide el grado promedio de incertidumbre para predecir la especie a la que pertenece un individuo dado, elegido al azar dentro de una comunidad de $\mathrm{S}$ especies. Las proporciones de abundancias se estiman para cada especie $\mathrm{p}_{1}, \mathrm{p}_{2}, \mathrm{p}_{3}, \ldots . ., \mathrm{p}_{\mathrm{s}}$. $\mathrm{p}_{\mathrm{i}}=$ proporción de la especie $\mathrm{i}$ en la muestra dada por $\mathrm{ni} / \mathrm{S}$, donde $\mathrm{n}_{\mathrm{i}}=$ número de individuos de la especie i. 
$\mathrm{S}=$ número de especies en la muestra

Índice de Equitatividad: analiza con que grado de igualdad están representadas las especies presentes en una muestra, cuando las abundancias son similares, el valor arrojado por el índice es máximo, mientras que cuando son muy diferentes el valor del índice se acerca a cero. El índice de Pielou es uno de los más aplicados.

$$
\mathrm{E}=\frac{\mathrm{H}^{\prime}}{\ln (\mathrm{S})}=\frac{\ln \left(\mathrm{N}_{1}\right)}{\ln \left(\mathrm{N}_{0}\right)}
$$

Donde: $\mathrm{H}^{\prime}$ es la diversidad Shannon-Weaver y $\mathrm{S}$ es el número de especies.

\subsubsection{Grupos funcionales alimentarios (GFA)}

Se obtuvieron datos de abundancia y abundancia relativa de grupos funcionales. Previo a esto se realizó una categorización funcional utilizando bibliografía (Albariño \& Valverde 1999; Angrisano \& Korob 2001; Merritt et al. 2008) y mediante observaciones en laboratorio. Se analizó la primera porción del tubo digestivo de al menos 10 especímenes. El contenido estomacal se disgregó en portaobjetos con una gota de glicerina y se observó en el microscopio. Se determinaron los porcentajes de los distintos componentes en cinco campos por cada muestra: fragmentos vegetales, diatomeas, hongos, detrito inorgánico y restos de invertebrados (Palmer et al. 1993). Los fragmentos se clasificaron por rangos de tamaño: hasta $50 \mu \mathrm{m}$, desde $50-1 \mathrm{~mm}$ y $>1$ mm (Cummins \& Klug 1979). Se consignó la abundancia relativa de cada ítem por campo, luego se promediaron los valores para todos los campos de un mismo individuo. Los organismos se clasificaron en: desmenuzadores, raspadores, colectores-recolectores, colectores-filtradores y depredadores (Merritt et al. 2008).

\subsection{Análisis estadístico}

\subsubsection{Comparaciones entre usos}

Métodos no paramétricos. Para evaluar si existieron diferencias entre las características ambientales de los sitios urbanos respecto a los urbanos de referencia se realizaron análisis ANOVA no paramétricos por rangos de Kruskal Wallis, seguidos de test a posteriori (Tukey test $\mathrm{P}<0.05$ ) cuando dichas diferencias fueron significativas (Sokal \& 
Rohlf 1995). De esta manera los ríos sujetos a cierto tipo de uso fueron "casos" en los modelos $(n=3)$. Adicionalmente los muestreos estacionales fueron usados para mejorar la significación de los análisis en las comparaciones, lo cual es aceptable en orden de contrastar múltiples muestras independientes (Sokal \& Rohlf 1995).

Para examinar las diferencias entre las variables fisicoquímicas y en los atributos de la comunidad (densidad, riqueza, diversidad Shannon-Weaver y equitatividad) por los usos silvopastoriles (pinares, pasturas, bosque manejado y bosque de ñire) se ponderaron los valores promedios por pares utilizando el test de Mann Whitney $(\mathrm{p}<0,05)$. Asimismo se evaluaron las diferencias de abundancia total de cada grupo funcional entre estos usos utilizando el mismo test (Ludwing \& Reynolds 1988).

Para estos análisis no paramétricos se utilizó el programa Statistica 6.0 (19842001. Número de serie: 31415926535897$)$.

\subsubsection{Relaciones especie ambiente}

Modelos multivariados. La variación de los parámetros físicos y químicos entre los sitios correspondientes a los usos silvopastoriles, se analizó mediante un Análisis de Componentes Principales (PCA). Este es un método lineal que particiona una matriz de correlación en un set de ejes ortogonales. Cuando este método se utiliza dentro de los límites establecidos es un procedimiento válido para detectar la estructura en las relaciones entre variables (Ludwig \& Reynolds 1988), asimismo es un método eficaz para detectar gradientes ambientales. El ordenamiento se presentó gráficamente, las flechas indican la dirección de cambio de la variable representada.

Como métodos de ordenamiento multivariado para establecer relaciones entre especies y el ambiente se utilizaron modelos de análisis directo de gradientes (programa CANOCO 4.0. Número de serie: 6009). Previo al ordenamiento se evaluó si el comportamiento de las especies era mejor explicado por métodos lineares o unimodales (ter Braak \& Smilauer 1998) y se utilizaron alternativamente análisis de redundancias o de correspondencias canónicas. Estos métodos permiten identificar la base ambiental que determina o afecta la distribución de la comunidad (ter Braak 1986). Para la aplicación de estos ordenamientos se confeccionaron separadamente matrices de datos ambientales y matrices de abundancia de especies de Trichoptera por época del año. Todos los análisis multivariados se realizaron sobre matrices estandarizadas, es decir las variables ambientales (exceptuando $\mathrm{pH}$ ) y los datos de densidad de especies de Trichoptera se transformaron como el $\log (x+1)$. Esta es una transformación habitual 
en las matrices de datos biológicos que se realiza con el objeto de normalizar la distribución de los datos y resolver el problema de la ausencia de valores.

RDA. Para identificar las principales variables ambientales determinantes de los ensambles de especies de tricópteros en los sitios urbanos y preurbanos en los distintos momentos del año, se realizó un Análisis de Redundancias (RDA). Se construyeron dos matrices, una con datos de abundancia por especie por época del año (20 especies X 24 muestreos) y su correspondiente matriz ambiental (23 variables ambientales X 24 muestreos). Este análisis permitió determinar las combinaciones lineales de variables ambientales que mejor explicaron los patrones de abundancia de especies. La elección de este análisis multivariado se debió a que se observó que los patrones de abundancia mostraron una tendencia lineal más que unimodal, evidenciado por el largo del gradiente (primer eje: 1,73) (ter Braak \& Smilauer 1998). Para extraer un set reducido de variables ambientales se excluyeron las que presentaron un factor de inflación de la varianza superior a 10. La significación de los ejes obtenidos se determinó mediante el test de Monte Carlo (9999 permutaciones) (ter Braak \& Smilauer 1999). El ordenamiento se presentó gráficamente donde las flechas indican la dirección de cambio de la variable representada.

CCA. Para establecer la relación entre la densidad de especies de Trichoptera y las principales variables ambientales en los sitios sometidos a usos silvopastoriles, se realizó un Análisis de Correspondencias Canónicas (CCA). Este es un análisis directo de gradientes y es muy útil para gradientes ambientales largos, dado que combina de forma simultánea ordenamiento y análisis de regresión múltiple (ter Braak 1986). Se construyeron dos matrices, una con datos de abundancia por especie por época del año (36 especies X 48 muestreos) y su correspondiente matriz ambiental (25 variables ambientales X 48 muestreos). Posteriormente se seleccionaron las variables que presentaron un factor de inflación de la varianza menor a 10, dado que un mayor valor estaría indicando colinearidad entre variables (ter Braak \& Smilauer 1998). Se graficó el ordenamiento los sitios de muestreo simultáneamente con las variables ambientales seleccionadas, sobre los dos primeros ejes del CCA. Las variables ambientales se representan como flechas cuya longitud y cercanía a los ejes representa un mayor grado de correlación y tasa de cambio. En el biplot del CCA, los dos primeros ejes representan los dos más importantes gradientes ambientales, a lo largo de los cuales las 
especies y los sitios están distribuidos. La significación de los ejes obtenidos se evaluó mediante la prueba de Monte Carlo (9999 permutaciones). Éste es un test de permutaciones que permite determinar la significación estadística de la relación entre las especies y el total del grupo de variables ambientales medidas aún cuando hay covariables. El enfoque del test se basa en un remuestreo aleatorio donde se admiten la mayor cantidad de permutaciones posibles. En el programa CANOCO ya sea en análisis de redundancias como de correspondencias canónicas permite establecer la significación (valor de $p$ ) tanto del primer eje como de todos los ejes en los ordenamientos realizados. (ter Braak \& Smilauer 1999).

\subsubsection{Cobertura de cuencas y modelos predictivos}

Modelos de regresión simple. Se utilizaron modelos de dispersión en los que los métricos basados en los atributos de la comunidad de Trichoptera constituyeron la variable dependiente y los porcentajes de cobertura de la cuenca la variable independiente (Ludwing \& Reynolds 1999). Se seleccionaron aquellos modelos de mejor ajuste, los que se examinaron para visualizar un valor umbral en el porcentaje de cobertura de la cuenca a partir del cual los cambios en los atributos de la comunidad de Trichoptera indicaran una declinación rápida en la calidad del agua (Paul \& Meyer 2001; Roy et al. 2003; Maloney \& Feminella 2006). Entre los atributos considerados de la comunidad de tricópteros se examinaron los valores medios anuales de la riqueza taxonómica, diversidad de Shannon-Weaver, porcentaje de tricópteros en la comunidad de macroinvertebrados, porcentaje de la familia Hydropsychidae y densidad por sitio como variables dependientes en el modelo. Las regresiones se construyeron utilizando los porcentajes de cobertura de la cuenca según los usos urbano, exóticas, pasturas y bosque nativo. Para estos análisis se utilizó el programa Statistica 6.0 (1984-2001. Número de serie: 31415926535897$)$. 


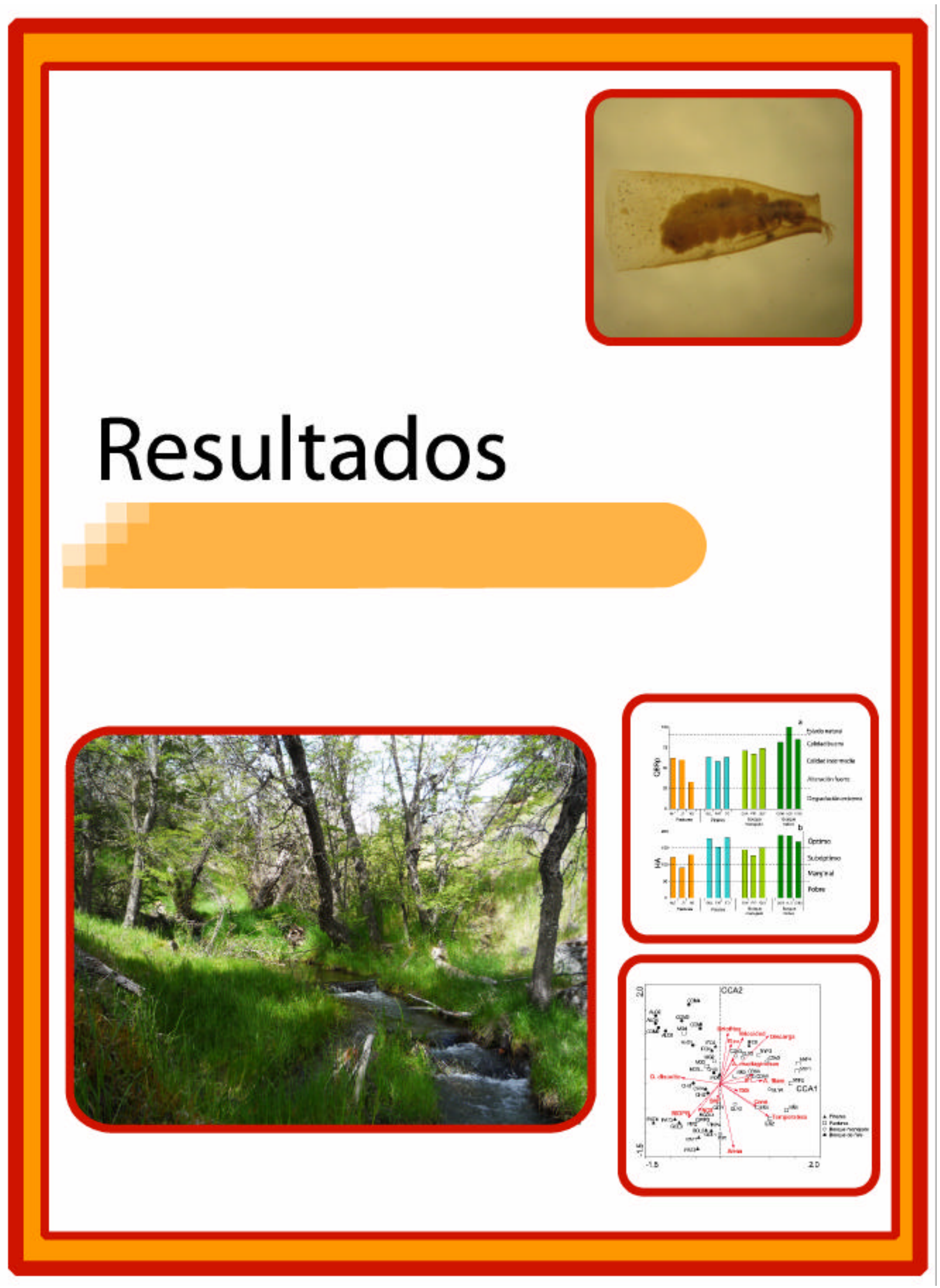




\section{Resultados}

\subsection{Análisis de la biocenosis}

Se registraron un total de 37 taxa en todo el estudio, distribuidos en 13 familias (Tabla 4). Se detallan a continuación los principales datos de distribución de cada taxón, por familia, en el estudio, se describen algunos datos morfológicos y caracteres diagnósticos y se documentan observaciones ecológicas.

\section{Familia Calamoceratidae}

Esta familia es cosmopolita, se compone de 8 géneros 2 de los cuales se encuentran en la región Neotropical: Banyallarga y Phylloicus. Ambos géneros están presentes desde América Central hasta el sur de Argentina. En nuestro estudio el único registro para esta familia lo constituyó una larva del género Phylloicus, hallada en el sitio GOL (pinares), el más septentrional del estudio. Las larvas de esta familia son fácilmente identificables debido a que el pronoto presenta prolongaciones anterolaterales y el trocantín tiene el ápice en forma de gancho (Figura 21a). Los especímenes observados de Phylloicus presentaron refugios tubulares aplanados dorso-ventralmente, compuestos enteramente de fragmentos ovales de hojas que no incluyeron acículas de pino (Figura 21b).

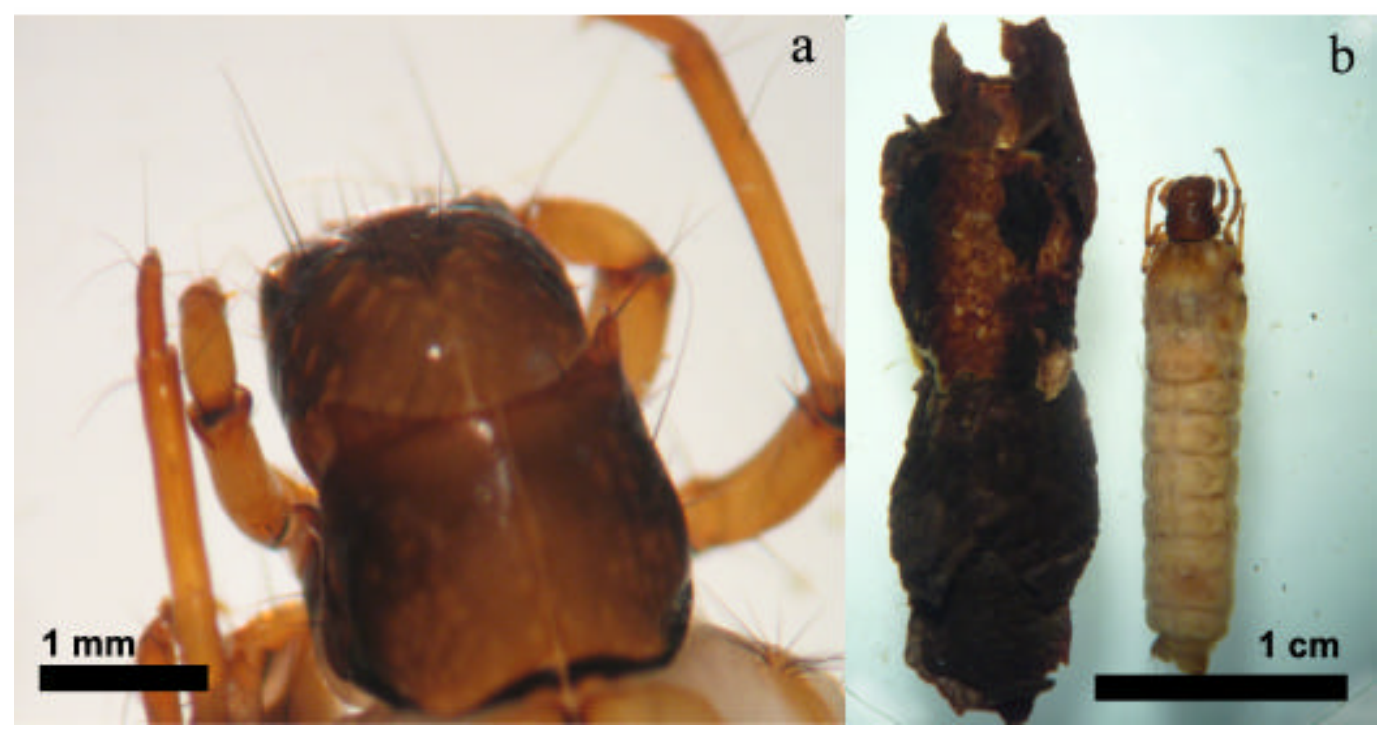

Figura 21. a. Detalle de la cabeza y pronoto y b. hábito y refugio de la larva de Phylloicus sp. colectada en el sitio Golondrinas, durante el período de estudio. 
Tabla 4. Grupos funcionales alimenticios (GFA) y presencia-ausencia de los taxa de Trichoptera registrados entre mayo 2005 y marzo 2006 en los 18 sitios del noroeste de la provincia del Chubut, Cordillera Patagónica. Códigos de sitios, ver Tabla 1. Usos: R-ur: referencia urbanos; Ur: urbanos; Pas: pasturas; HNF: bosque nativo manejado; NF: bosque nativo. CF: colector-filtrador, PA: perforador de algas, D: desmenuzador, P: predador, R: raspador.

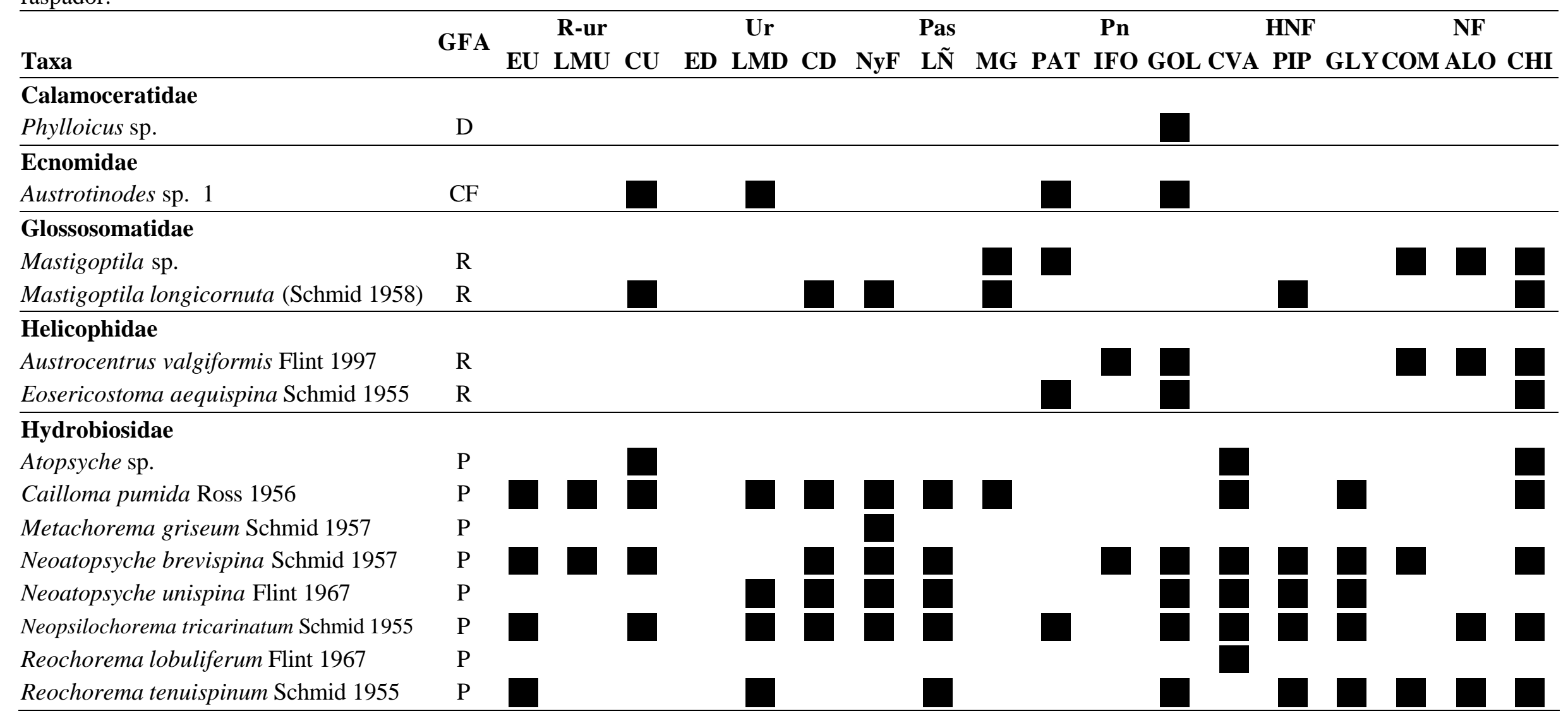


Tabla 4. Continuación.

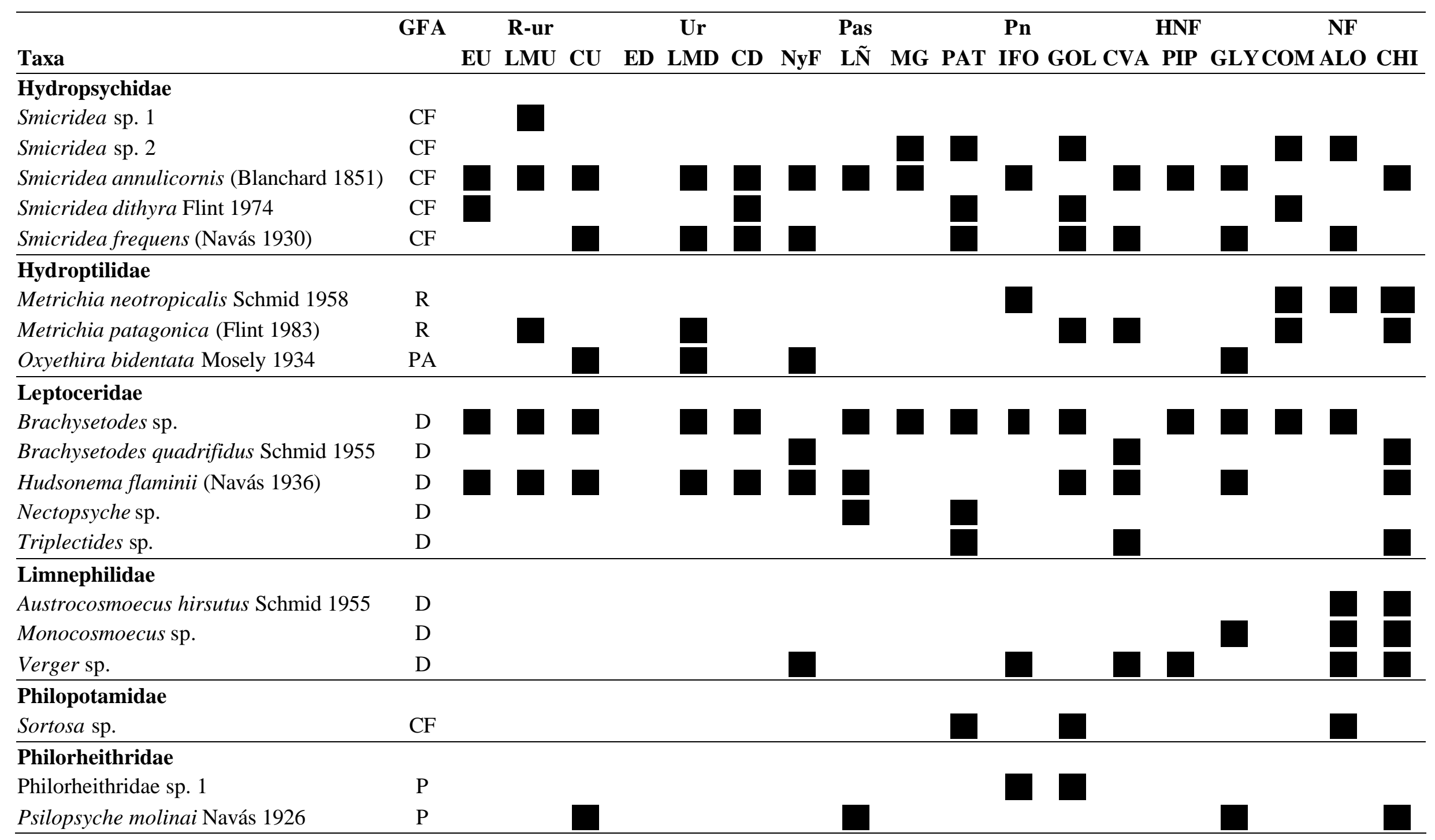


Tabla 4. Continuación.

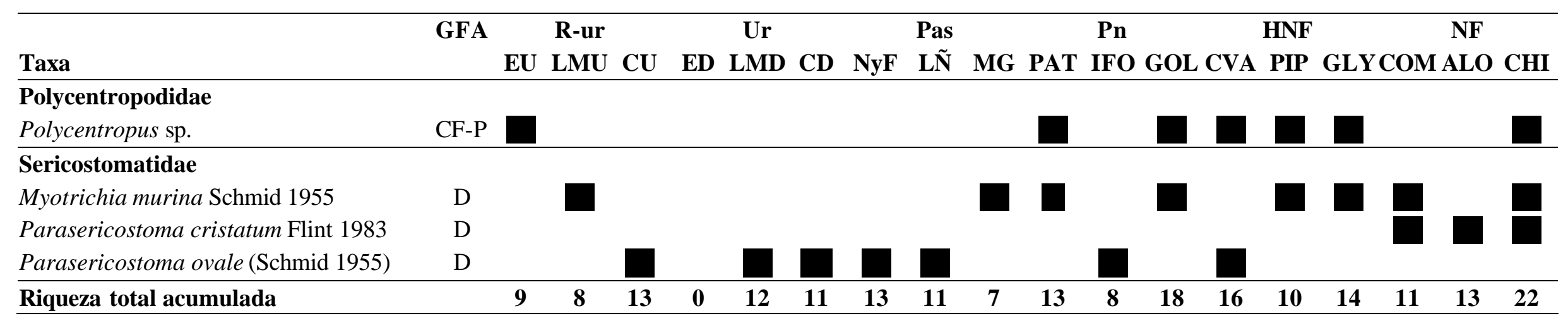




\section{Familia Ecnomidae}

Se atribuyen más de 1000 especies a esta familia y es posible encontrar representantes de la misma en todos los continentes. En América del Sur sólo se citan dos géneros: Austrotinodes, el mejor representado y Chilocentropus, un género poco conocido con una sola especie. En este estudio, se registraron larvas de Austrotinodes en los sitios CU (urbano de referencia), LMD (urbano), PAT y GOL (pinares). Todas las larvas observadas correspondieron a una misma morfoespecie. Sin embargo dado que no se dispuso de suficiente material para realizar una asociación larva adulto, no se logró una identificación a nivel de especie. Las larvas de Austrotinodes presentan la cabeza alargada con carena a ambos lados. Los tres segmentos del tórax están esclerotizados, no poseen branquias en el abdomen. El trocantín del primer segmento toráxico es muy prominente y se extiende hacia adelante en forma de lóbulo alargado (Figura 22).

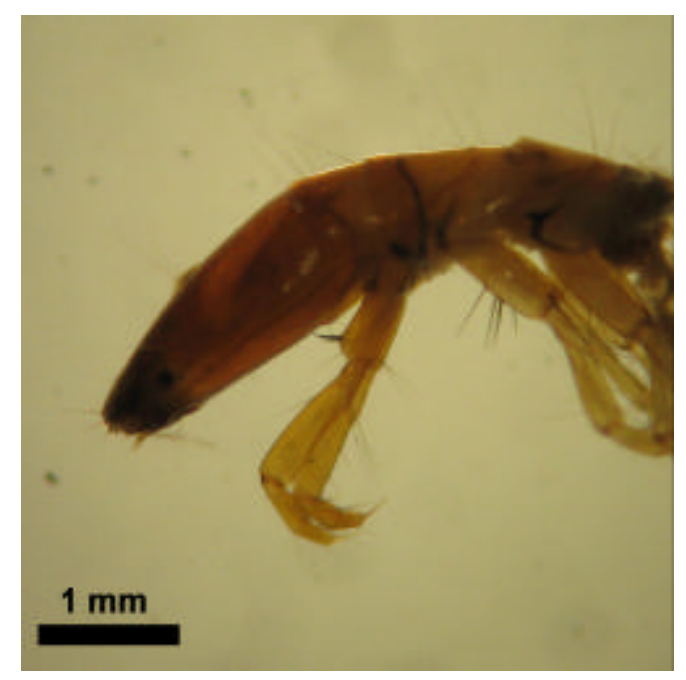

Figura 22. Detalle de la cabeza, tórax y primer par de patas, de Austrotinodes sp. colectada en el sitio Patriada, durante el período de estudio.

En este estudio las larvas se colectaron en refugios temporales adheridos con seda al sustrato, extendiendo la parte anterior del tubo a modo de red, en concordancia con un hábito alimentario colector filtrador, es decir de detrito fino en transporte.

\section{Familia Glossosomatidae}

Esta familia cuenta con representantes en casi todas las regiones del mundo. Hasta el momento se conocen más de 400 especies, agrupadas en tres subfamilias. Tres géneros, Mastigoptila, Scotiotrichia y Tolhuaca han sido citados para nuestra región y/o Chile sin embargo el conocimiento de los estadíos larvales es aún escaso y sólo se han 
descrito larvas de algunas especies del género Mastigoptila. En este estudio los registros de esta familia correspondieron únicamente al género Mastigoptila y ocurrieron en los sitios NyF, MG, PAT, PIP, COM, ALO, CHI. Las especies fueron Mastigoptila longicornuta y una larva del mismo género que aún no pudo ser asociada a ningún adulto conocido. Este morfotipo se caracterizó por presentar un menor tamaño y diferencias en el número de pelos terminales en el esclerito del IX segmento abdominal.

Las larvas del género Mastigoptila son relativamente pequeñas, generalmente de 1,5 a $5 \mathrm{~mm}$. La cabeza y el pronoto se encuentran totalmente esclerotizados, el mesonoto presenta tres placas esclerotizadas de menor tamaño y el metanoto posee sólo dos pequeños escleritos. El abdomen no presenta branquias y se ensancha considerablemente en relación al tórax. Las pseudopatas anales son cortas y robustas (Figura 23 a y b).

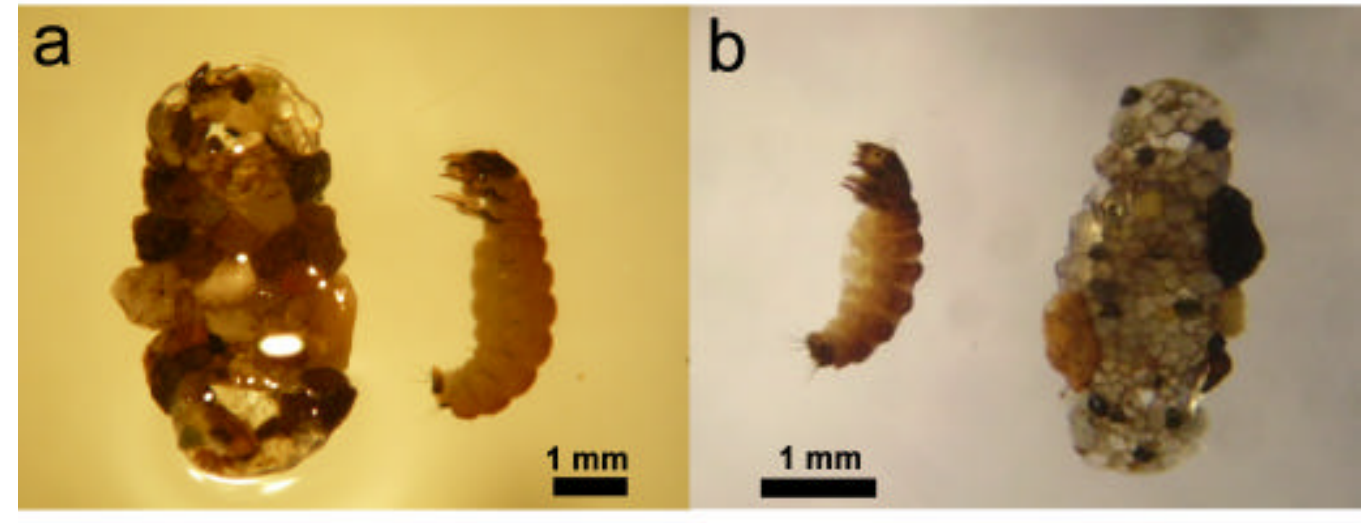

Figura 23. Hábito y capullo de las larvas de a. Mastigoptila longicornuta y b. Mastigoptila sp., colectadas durante el período de estudio.

Las construcciones larvales de Mastigoptila fueron capullos de piedras de diversos tamaños, con forma de caparazón de tortuga y dos aberturas en la zona ventral, fue común la colocación de piedras de mayor tamaño a modo de balastos especialmente en Mastigoptila sp. (Figura 23b). El análisis del contenido estomacal de las larvas de $M$. longicornuta capturadas en el sitio $\mathrm{NyF}$, reveló gran participación de fragmentos de hojas (54\%) y detrito fino (38\%) y en menor medida los ítems diatomeas (6\%) (Figura 24) y detrito inorgánico (2\%). Aunque la fracción dominante fue el detrito esta familia se asignó al grupo funcional raspador. 


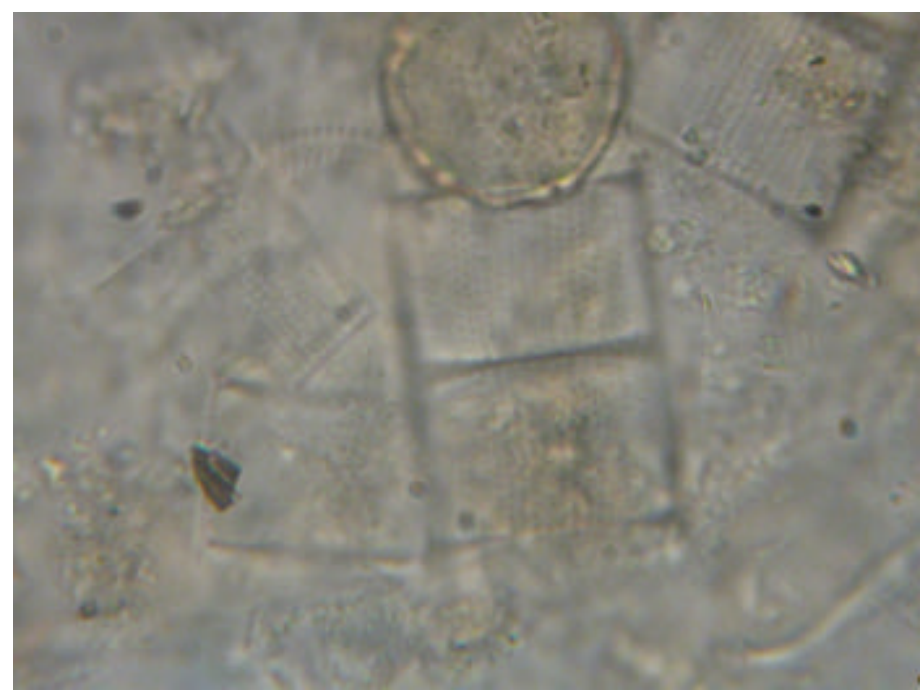

Figura 24. Diatomeas encontradas en el contenido estomacal de larvas de Mastigoptila longicornuta, colectadas en el sitio Nant y Fall, durante el período de muestreo. Imágenes tomadas de microscopio $(1000 \mathrm{X})$, con aceite de inmersión.

\section{Familia Helicophidae}

Los representantes de esta familia se encuentran restringidos al hemisferio sur. Cuatro géneros se conocen en Australia y Nueva Zelanda y cinco en América del Sur, de los cuales hasta el momento sólo dos se han citado para la Patagonia Argentina: Austrocentrus y Eosericostoma.

En este estudio se colectaron larvas de dos especies pertenecientes a ambos géneros citados para la Patagonia, Austrocentrus valgiformis y Eosericostoma aequispina. Los registros de estas especies sólo tuvieron lugar en los sitios con buena cobertura arbórea, tanto de pinares, como de bosque nativo (PAT, IFO, GOL, ALO, COM y CHI). En el caso de E. aequispina, la determinación se realizó mediante cría de larvas, colectadas en el sitio CHI.

Las especies de esta familia presentan el pronoto totalmente esclerotizado, cubriendo la parte trasera de la cabeza, el mesonoto esclerotizado sólo anteriormente y membranoso en la parte posterior, el metanoto sólo tiene un par de escleritos. El abdomen no presenta branquias y las pseudopatas anales son cortas y robustas fusionadas al noveno segmento.

Los capullos larvales de las especies encontradas fueron refugios transportables de granos de arena pequeños. En el caso de A. valgiformis, presentaron la forma típica de tubo arqueado con la porción terminal en forma de gancho (Figura 25a). Eosericostoma aequispina, sin embargo presentó capullos tubulares con una proyección dorsal hacia los lados, que se ensancha hacia la parte delantera (Figura 25b). Si bien no 
se reunió una gran cantidad de ejemplares que permitieran realizar análisis de contenidos estomacales, de las observaciones de las piezas bucales y las características de su hábitat (bloques), se dedujo que las especies serían raspadoras de perifiton.

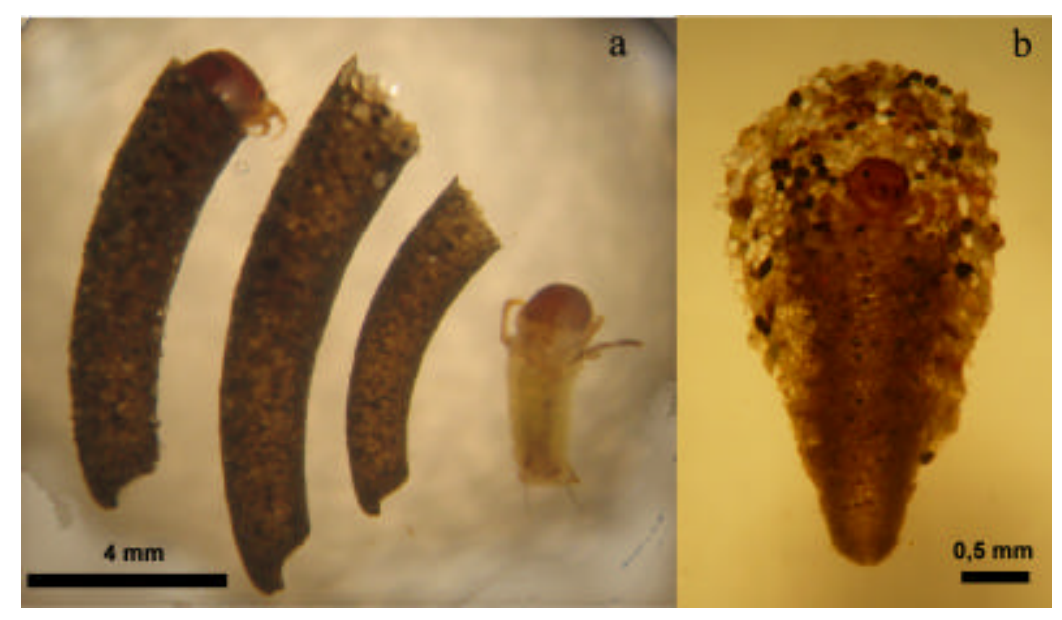

Figura 25. a. Hábito y capullos cónicos con la terminación característica de Austrocentrus valgiformis. b. Larva y capullo típico del último estadío de Eosericostoma aequispina. Larvas colectadas durante el período de muestreo en los sitios COM y CHI, respectivamente.

\section{Familia Hydrobiosidae}

Hydrobiosidae fue la familia con mayor cantidad de especies registradas en el estudio. Se encuentra muy bien representada en América del Sur, Australasia y este de Rusia. En el nuevo mundo se reconocen 22 géneros, de los cuales Atopsyche, Amphicorema, Cailloma, Metachorema, Neoatopsyche, Neopsilochorema, Rheochorema y Schajovskoya, son los que hasta el momento han sido citados para la Patagonia Argentina. En el presente estudio se registraron representantes de seis géneros (Atopsyche, Cailloma, Metachorema, Neoatopsyche, Neopsilochorema y Rheochorema), siendo Metachorema griseum y Rheochorema lobuliferum, especies colectadas en un único sitio ( $\mathrm{NyF}$ y $\mathrm{CVA}$, respectivamente). Por otra parte, Neoatopsyche brevispina (Figura 26a) y Neopsilochorema tricarinatum, fueron las más ampliamente distribuidas (Tabla 4).

Las larvas de ésta familia presentan la cabeza y el pronoto bien esclerotizados, mientras que el meso y metanoto son totalmente membranosos, no poseen branquias en el abdomen, éste suele tener una coloración verdosa, que se pierde una vez fijado en alcohol. La característica morfológica más importante es la modificación del primer par de patas, estas son raptoras (queladas), con tibia y tarso plegados a modo de pinza sobre el fémur, rasgo típico del hábito alimentario predador (Figura 26 b). 


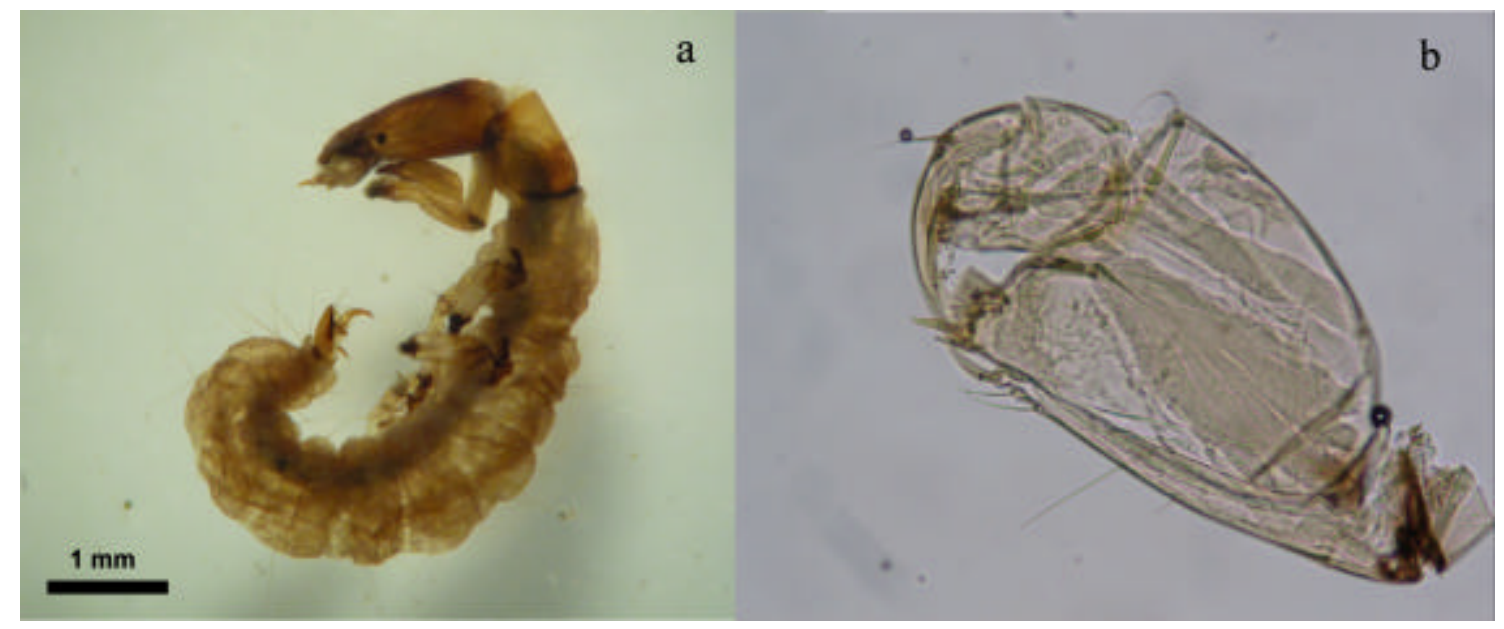

Figura 26. a. Hábito de la larva de Neoatopsyche brevispina y b. detalle de la pata I de la larva de Rheochorema tenuispinum (100 X), ambas colectadas durante el período de muestreo.

El análisis de contenido estomacal de las larvas de $N$. brevispina y $N$. tricarinatum colectadas en el sitio $\mathrm{NyF}$, evidenció una dieta compuesta casi en su totalidad $(98 \%)$ de otros invertebrados. La porción restante correspondió a fragmentos de hojas en el caso de $N$. brevispina y a detrito inorgánico en el caso de $N$. tricarinatum. En ambas especies estas observaciones se corresponderían con un hábito exclusivamente predador.

\section{Familia Hydropsychidae}

Las Hydropsychidae tienen una distribución mundial. En la región Neotropical se registran 9 géneros, sin embargo el único que ha sido citado para la Patagonia es el género Smicridea. En este estudio se colectaron cinco taxa correspondientes a este género, siendo S. annulicornis (Figura 27 a) y S. frequens (Figura 27 b), las que presentaron mayor densidad y frecuencia. Se registraron larvas de $S$. dithyra en sitios de los usos urbanos, referencia de sitios urbanos, pinares y bosque nativo.

Asimismo se colectaron dos tipos de larvas pertenecientes al mismo género pero que no pudieron ser identificadas a nivel de especie. La primera, Smicridea sp. 1, fue registrada únicamente en el sitio LMU, mientras que Smicridea sp. 2 fue común en los sitios MG (pasturas), GOL, PAT (pinares), COM y ALO (bosque nativo).

Las larvas de Hydropsychidae son relativamente grandes, pudiendo medir hasta $30 \mathrm{~mm}$, poseen el pro, meso y metanoto bien esclerotizados. Todos los segmentos del abdomen poseen branquias muy notorias. Las pseudopatas anales presentan un mechón de setas largas. 
Las larvas del género Smicridea colectadas construyeron redes filtradoras de seda en forma de embudo, en concordancia a su hábito alimentario de colectores filtradores. Este tipo de redes permiten capturar las partículas del seston derivante en la columna de agua (Figura 27b). La mayor fracción de su alimento lo constituyeron diversos tipos de plantas (diatomeas, Cladophora spp. y hojarasca fragmentada), zooplancton (rotíferos) y algunos invertebrados pequeños como larvas de dípteros. El análisis del contenido estomacal de larvas de S. annulicornis y S. frequens del sitio NyF, mostró una contribución alta de fragmentos de hojas (40,5 y 43,77 \% respectivamente), junto con detrito fino (43,7 y 30,2 \% respectivamente), acompañado de algas, diatomeas y detrito orgánico en fracciones inferiores a $10 \%$. En el caso de S. frequens también se observó una participación importante de rotíferos e invertebrados bentónicos (10,9 y 6 $\%$ respectivamente) (Figura $27 \mathrm{c}$ ), indicando cierta preferencia por el zooplancton derivante.

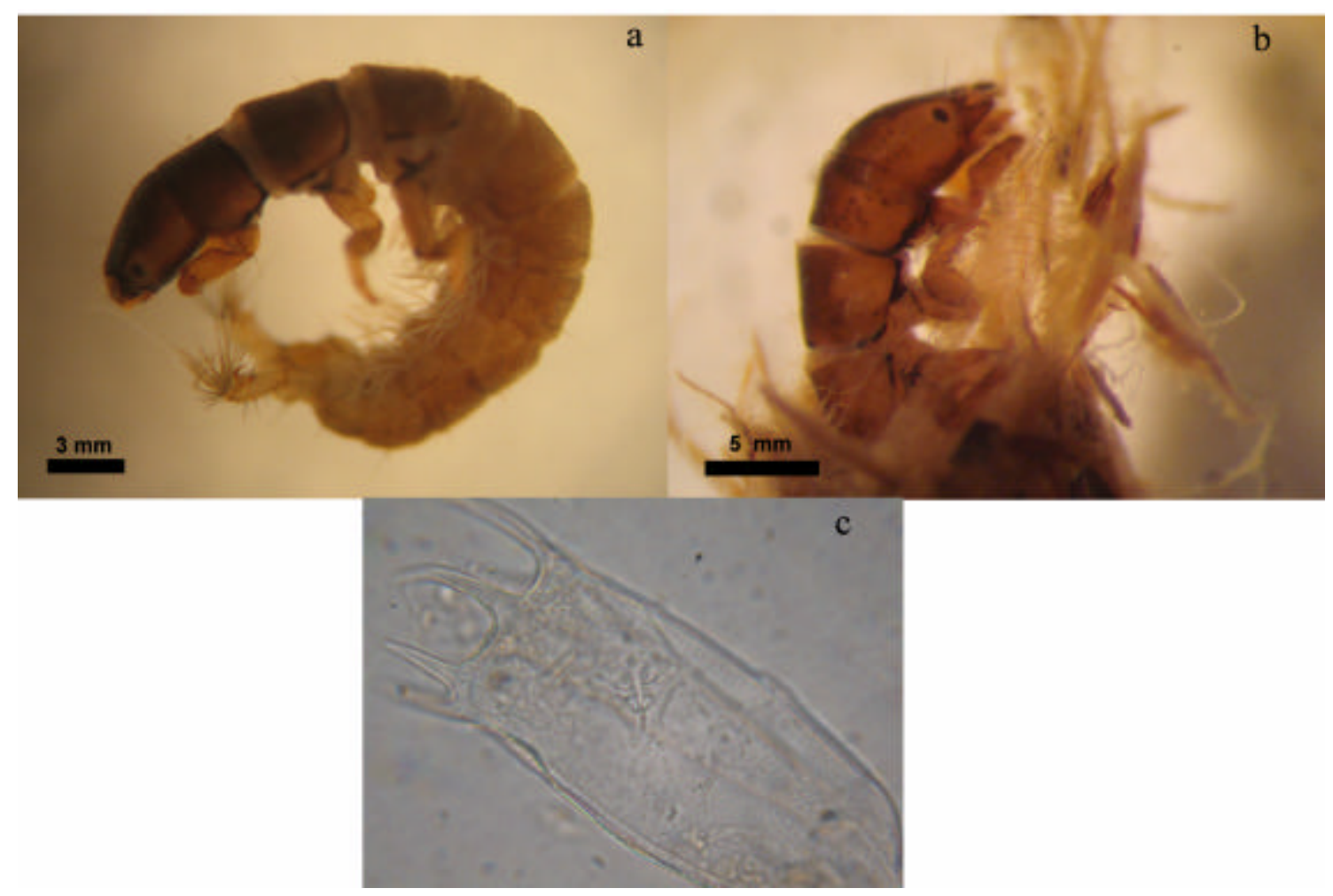

Figura 27. a. Smicridea annulicornis, hábito. b. Detalle de Smicridea frequens, donde se observa la estructura de la malla con la que forma el refugio fijo al sustrato. c. detalle de Keratella thomassoni, Rotifera, observado en el contenido estomacal de $S$. frequens (400 X).

\section{Familia Hydroptilidae}

Esta es una numerosa familia representada en todas las ecoregiones del mundo. Aunque se reconocen dos subfamilias, únicamente Hydroptilinae cuenta con representantes en la 
Neotrópica. En los 18 sitios de estudio se registraron tres especies de Hydroptilidae o micro-tricópteros, esta familia incluye los tricópteros más pequeños (inferiores a los 3 $\mathrm{mm}$ ). La especie con mayor cantidad de registros fue Metrichia patagonica (seis sitios), mientras que $M$. neotropicalis y Oxyethira bidentata se reportaron en cuatro de los sitios. Metrichia neotropicalis sólo se registró en sitios con canopia más cerrada (IFO, COM, ALO y CHI), mientras que las colectas de Oxyethira bidentata correspondieron a sitios urbanos, de pasturas y de bosque manejado (Tabla 4).

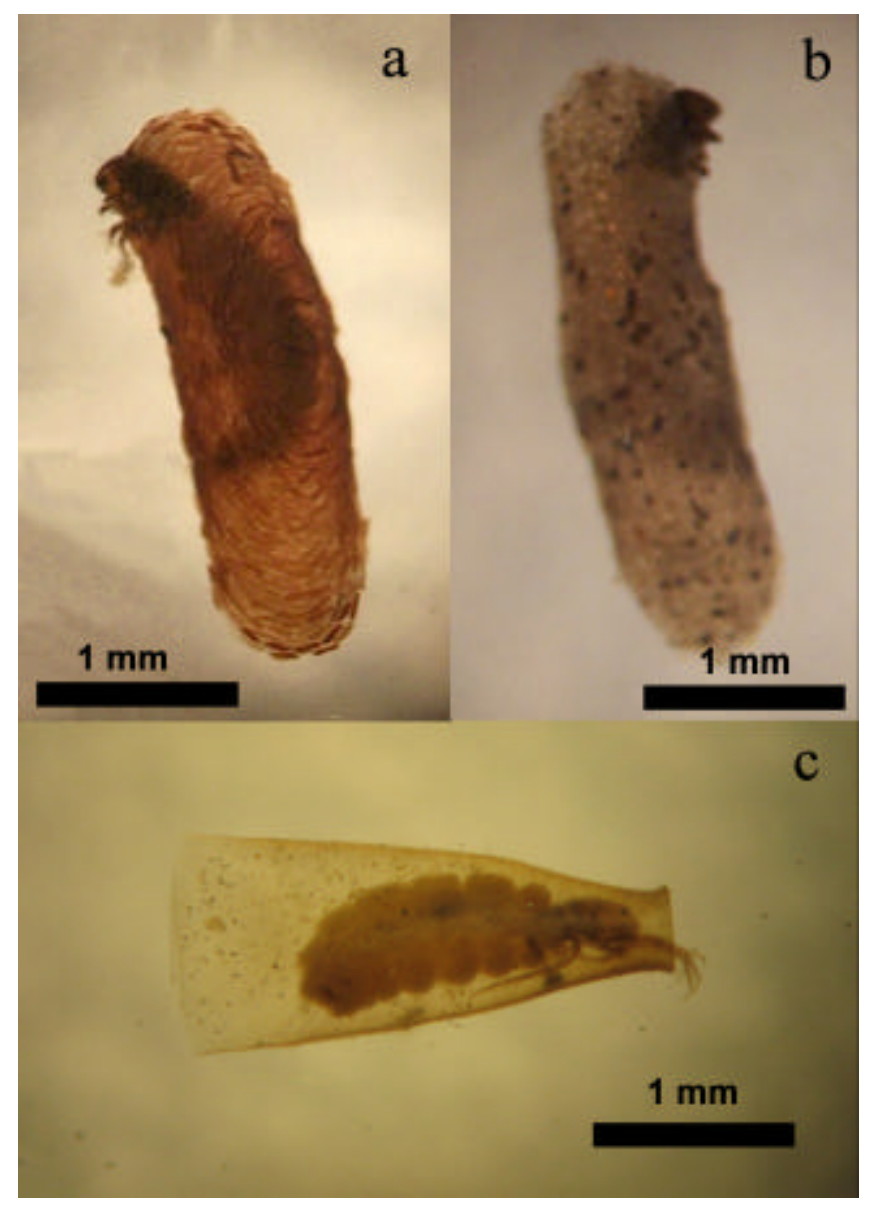

Figura 28. Larvas de a. Metrichia neotropicalis, b. Metrichia patagonica y c. Oxyethira bidentata, en sus capullos, colectadas durante el período de estudio en arroyos del Noroeste de la provincia de Chubut, cordillera Patagónica, Argentina.

Las larvas poseen los tres segmentos torácicos esclerotizados, sus patas son cortas y robustas y el abdomen muy ensanchado con respecto al tórax y sin branquias. Sólo construyen un capullo transportable en el último estadío, éste puede incluir diversos materiales y presentar distintos diseños. En éste estudio se observaron capullos aplanados lateralmente, de fragmentos de algas dispuestos en círculos concéntricos para M. neotropicalis (Figura 28a) y de arena en el caso de M. patagonica (Figura 28b), 
mientras que los capullos construidos por $O$. bidentata presentaron una forma de botella, transparente y enteramente de seda (Figura $28 \mathrm{c}$ ).

Se observó que las dos especies de Metrichia estuvieron asociadas a sustratos tipo bloque y guijón y a briófitas, mientras que las larvas de $O$. bidentata se asociaron a sitios con macrófitas.

\section{Familia Leptoceridae}

La familia Leptoceridae, es una de las más ampliamente distribuidas a nivel mundial, se reconocen hasta el momento más de 1300 especies y cerca de 50 géneros. En Patagonia se encuentran citados los géneros Brachysetodes, Hudsonema, Nectopsyche y Triplectides, los cuatro estuvieron representados en este estudio.

Brachysetodes estuvo presente en todos los sitios, con excepción de ED, donde no se colectó ningún tricóptero. Las larvas de Brachysetodes en tres sitios pudieron ser asociadas al adulto mediante cría, correspondiendo todas a larvas de B. quadrifidus. En el resto de los casos se trató como una morfoespecie distinta. En el caso de Triplectides y Nectopsyche tampoco fue posible la determinación específica, aunque los ejemplares correspondieron en cada caso a una sola morfoespecie.

Las larvas pertenecientes a esta familia tienen un aspecto delgado y delicado, su tercer par de patas es largo y se extiende hacia adelante sobrepasando los dos primeros y la cabeza (Figura 29 a). Los dos primeros segmentos del tórax están bien esclerotizados, en algunos géneros el tercero presenta algunos pequeños escleritos. El abdomen es delgado, sin coloración particular y generalmente sin branquias. El primer segmento abdominal presenta a ambos lados una protuberancia más o menos notoria con algún esclerito, la forma y tamaño del mismo varía en los distintos géneros.

Las larvas de Brachysetodes exhibieron refugios construidos con fragmentos minerales pequeños, siguiendo la forma típica de tubo cónico y recto. La misma forma se observó en el caso de $H$. flaminii, que utilizó fragmentos vegetales alargados y mezclados con una pequeña porción de arena en las larvas de los primeros estadíos. Los refugios en los últimos estadíos presentaron fragmentos de hojas recortadas en forma oval o circular y sin constituyentes minerales (Figura 29 a).

Los registros de Nectopsyche fueron escasos y no fue posible en este estudio observar sus construcciones. Las larvas de Triplectides se encontraron habitando ramitas o palitos ahuecados (Figura 29 b) y ocasionalmente acondicionados en su extremo anterior, con seda uniendo pequeños fragmentos de madera. En pocos casos se 
encontraron larvas de Triplectides habitando casas de seda, construidas por larvas de sericostomátidos, acondicionadas de la misma manera en la porción delantera.

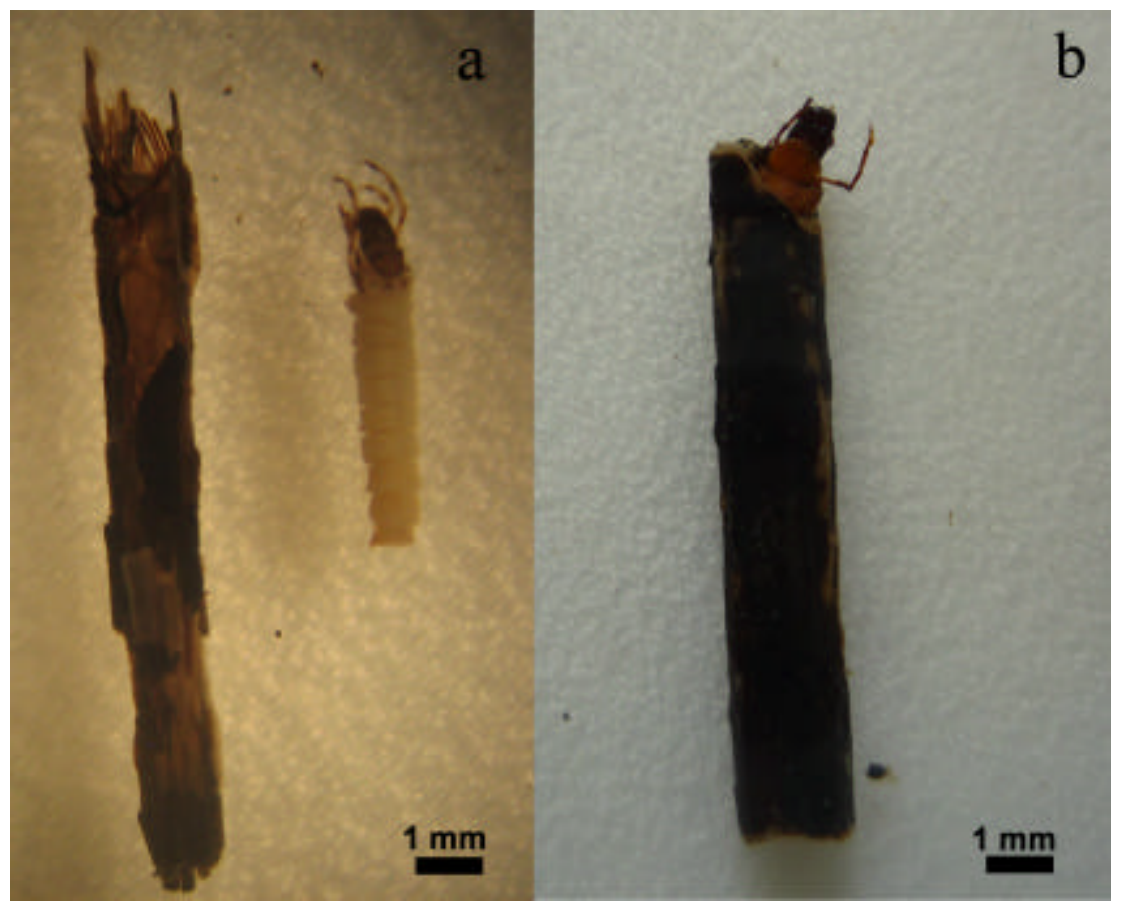

Figura 29. a. Detalle de la casa construida con materiales vegetales de Hudsonema flaminii, junto a la larva y b. larva de Triplectides sp. dentro del refugio.

En el análisis de contenidos estomacales se observó que las larvas de $B$. quadrifidus colectadas en NyF, presentaron un $98 \%$ de hojarasca fragmentada en el rango $100 \mu \mathrm{m}$ a $250 \mu \mathrm{m}$ por lo que corresponderían al grupo funcional desmenuzador.

\section{Familia Limnephilidae}

Si bien esta familia está representada en muchas regiones del mundo, en América del Sur está limitada a siete géneros que se hallan muy asociados a ambientes cordilleranos. Tres géneros se han citado para la Patagonia Argentina, Austrocosmoecus (género monotípico), Monocosmoecus y Verger, siendo éste último el que presenta mayor cantidad de especies en la región. En el estudio actual se colectaron especímenes de los tres géneros, sin embargo en los casos de Monocosmoecus y Verger no fue posible asociarlos a especie. Los registros de Austrocosmoecus hirsutus sólo tuvieron lugar en los sitios de bosque nativo, ALO y CHI. Monocosmoecus sp. sólo se colectó en los sitios GLY (bosque nativo manejado), ALO y CHI (bosque nativo). Por otra parte Verger sp. se encontró en sitios de pasturas ( $\mathrm{NyF}$ ), pinares (IFO), bosque nativo manejado (CVA y PIP) y bosque nativo (ALO y CHI) (Tabla 4). 
Las larvas son de gran tamaño, pudiendo superar los $30 \mathrm{~mm}$ en su último estadío, siendo las más grandes entre los tricópteros de la región Patagónica. La cabeza y partes esclerotizadas del tórax suelen tener una coloración marrón rojiza o marrón oscura, con pelos robustos y notorios. El pronoto y mesonoto son totalmente esclerotizados, mientras que el metanoto puede presentar diverso grado de esclerotización, pero nunca formando una placa grande. Todas las especies de esta familia exhiben un cuerno prosternal esclerotizado que en algunos casos tiene una coloración diferencial. El abdomen presenta branquias (generalmente agrupadas en ramilletes) en todos los segmentos (Figura 30b).

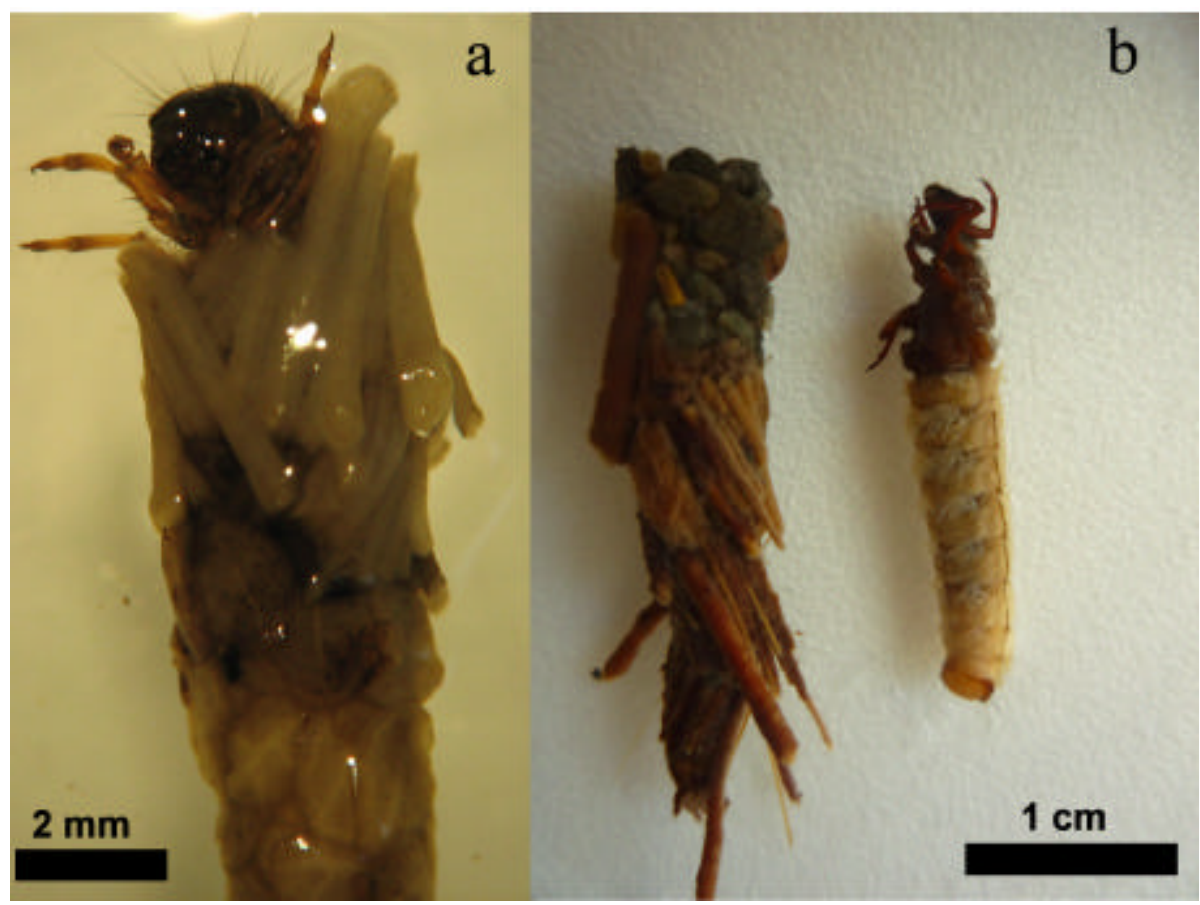

Figura 30. Larvas de a. Verger sp. dentro del capullo construido con fragmentos vegetales y b. Monocosmoecus sp. junto al refugio construido con granos de arena y fragmentos vegetales.

En los especímenes colectados se observaron diferentes tipos de refugios desde fragmentos minerales, madera y distintos tipos de hojas (Figuras 30 a y b). Dado que el estuche puede variar a lo largo del desarrollo de la larva siempre fue necesaria la observación directa del ejemplar.

Con respecto a los hábitos alimenticios, el análisis del contenido estomacal de ejemplares del género Monocosmoecus, colectados en el sitio CHI, mostró dominancia (>90 \%) de hojarasca fragmentada, por lo que se asignó al grupo funcional desmenuzador. 


\section{Familia Philopotamidae}

Esta familia de distribución mundial presenta su mayor diversidad en las regiones más cálidas, sin embargo en la región Andino Patagónica podemos encontrar dos géneros, Chimarra y Sortosa, siendo éste último el mejor representado. Las especies identificadas en el presente estudio correspondieron a este último género, sin embargo los registros fueron escasos y limitados únicamente a los sitios PAT, GOL (pinares) y ALO (bosque nativo) (Tabla4). Dado que no hay descripciones de las larvas de las distintas especies del género y no fue posible criarlas exitosamente en laboratorio, no se logró una identificación hasta el nivel específico.

Las larvas de Philopotamidae presentan una coloración marrón rojiza en la cabeza y el pronoto, que contrasta con el blanco cremoso del resto del cuerpo. Sólo la cabeza y el pronoto están esclerotizados y una banda negra muy característica se extiende transversalmente en la parte posterior del pronoto. Las pseudopatas anales son largas. No poseen branquias en el abdomen pero las especies de la región Andino Patagónica tienen en la región terminal un penacho de branquias, entre las patas anales.

\section{Familia Philorheithridae}

Esta familia está representada en la región Neotropical por dos géneros, Mystacopsyche y Psilopsyche y cinco especies, todas endémicas de la región cordillerana de sur de Chile y Argentina. Por otra parte, otros seis géneros se describen para Oceanía. La principal característica de las larvas de esta familia son el primer y segundo par de patas semiraptoras, y la fusión de la tibia y tarso de las patas medias.

Las larvas colectadas en los sitios CU, LÑ, GLY y CHI fueron asociadas al adulto mediante el método de cría y análisis del metamorfotipo, por lo cual se identificaron como Psilopsyche molinai (Figura 31). Por el contrario, larvas colectadas en los sitios de pinares IFO y GOL presentaron claras diferencias con respecto a las de la especie antes mencionada, fundamentalmente en la forma del esclerito del IX segmento abdominal, sin embargo no fue posible mantener el material vivo en laboratorio y quedó pendiente la determinación específica. 


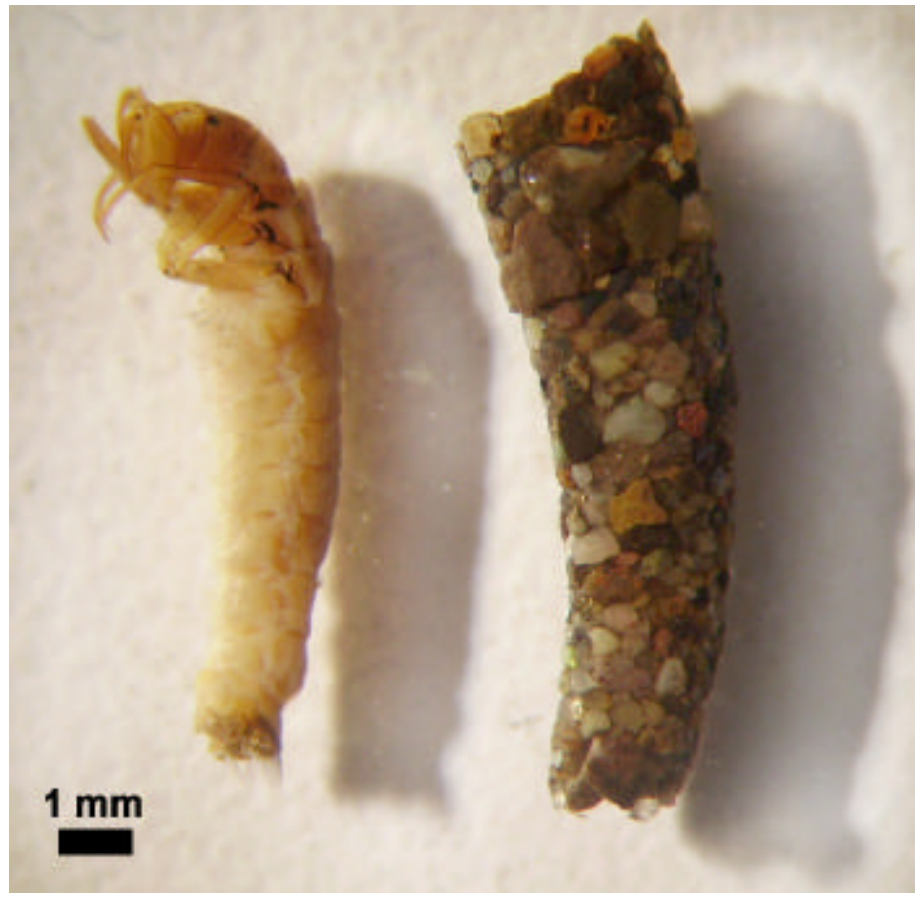

Figura 31. Larva de Psilopsyche molinai, junto al refugio de arena que construyen. Larva colectada en el sitio Glyn (noroeste de la provincia del Chubut, Patagonia Argentina), durante el período de estudio.

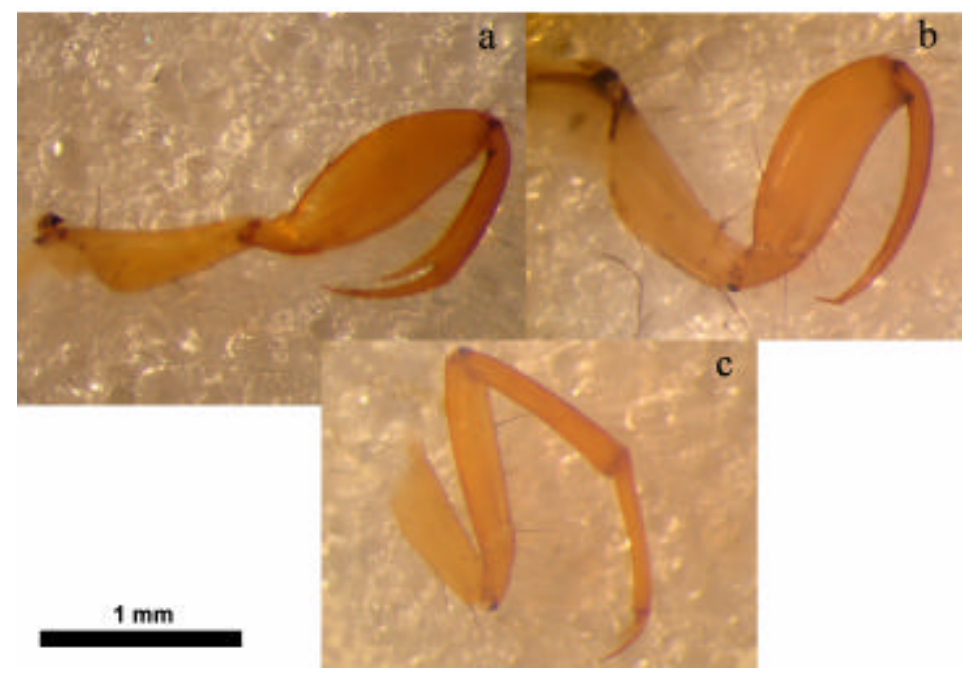

Figura 32. a. b. y c. Patas I a III de Psilopsyche molinai, colectada en el sitio Glyn, durante el período de estudio.

El análisis de las piezas bucales, así como la presencia de patas anteriores y medias subqueladas o semiraptoras (Figura 32 a y b) indicaron que esta especie sería primariamente de hábitos predadores. 


\section{Familia Polycentropodidae}

Esta familia es diversa y está representada en todas las regiones biogeográficas del mundo, con excepción de las regiones polares y las islas oceánicas más remotas. Es probable que únicamente el género Polycentropus se encuentre en la región Andino Patagónica, pero aún es escaso el conocimiento de esta familia en nuestro país. Los registros de este trabajo correspondieron a sitios urbanos (EU), pinares (PAT y GOL), bosque nativo manejado (CVA, PIP y GLY) y bosque nativo (CHI) (Tabla 4).

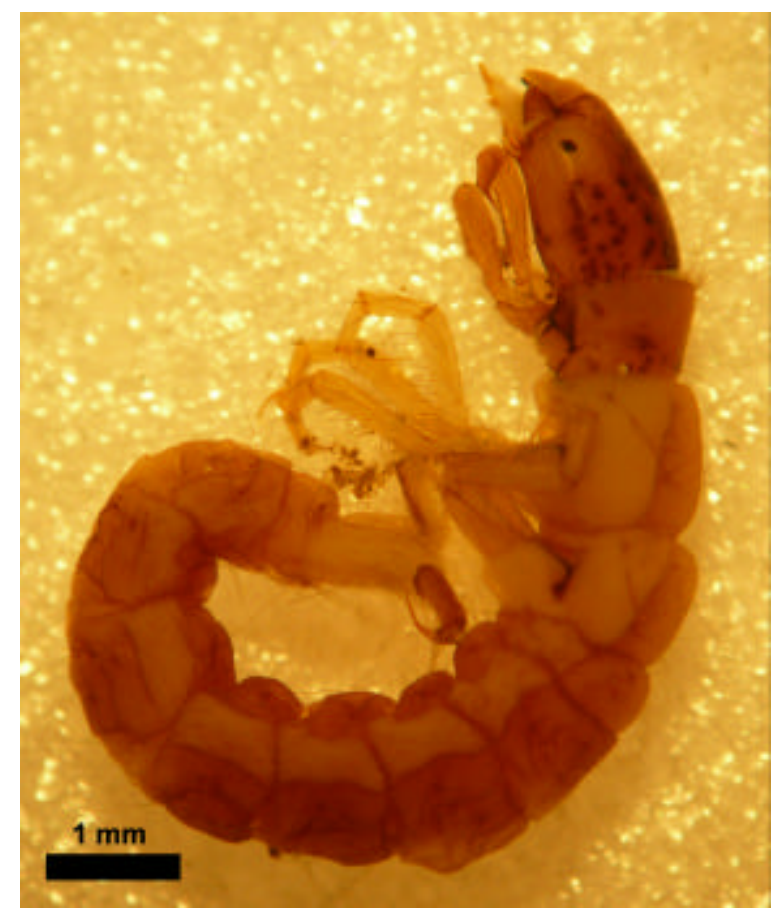

Figura 33. Larva de Polycentropus sp. colectada en el sitio Pipo (noroeste de la provincia del Chubut, Patagonia, Argentina), durante el período de muestreo.

Las larvas presentan una cabeza más o menos alargada y únicamente el pronoto está esclerotizado, las regiones esclerotizadas presentan una coloración amarillo pálida con manchas musculares marrones bien notorias. Las patas no son raptoras. El abdomen no presenta branquias y las propatas anales son largas y prominentes (Figura 33). Las larvas fueron frecuentes tanto en pozones como en rápidos. No fue posible observar los refugios de esta especie.

\section{Familia Sericostomatidae}

Esta familia comprende 25 géneros, que se distribuyen en Europa, Oriente de Asia, África y América del Sur, sólo seis se encuentran citados para nuestro continente y tres de ellos en la región Patagónica: Chiloecia, Myotrichia y Parasericostoma. 
Se registraron tres especies de esta familia, Myotrichia murina, Parasericostoma cristatum y Parasericostoma ovale. La mejor representada fue $M$. murina (siete registros), sin embargo $P$. ovale (cuatro registros) fue generalmente más abundante. Por el contrario $P$. cristatum se encontró restringida a sitios de bosque nativo (COM, ALO y $\mathrm{CHI})$.

Las larvas de esta familia tienen el protórax bien esclerotizado, que suele cubrir parte de la cabeza, el mesotórax esclerotizado sólo en la primera mitad y el metatórax totalmente membranoso. Las patas son cortas y robustas, el abdomen no presenta branquias y las pseudopatas anales son cortas y están fijas a los lados del noveno segmento (Figura 34).

Los refugios transportables construidos por M. murina y $P$. ovale presentaron una forma cónica curvada y se compusieron exclusivamente de seda, por lo que éstas presentaron una coloración marrón oscura, con la inclusión de algunas pequeñas líneas de arena. Por otra parte, Parasericostoma cristatum construyó su refugio enteramente con fragmentos minerales de tamaño mediano.

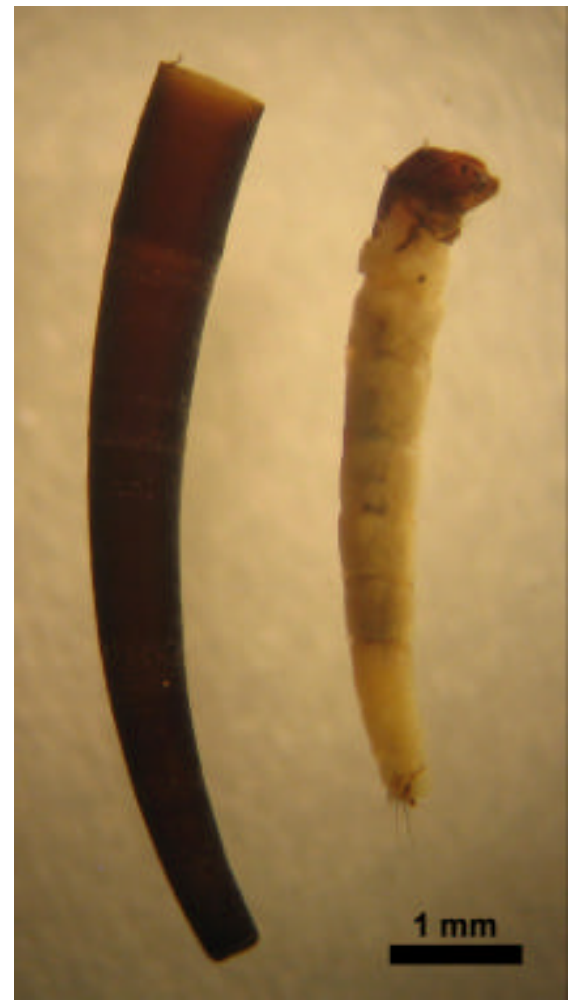

Figura 34. Larva de Parasericostoma ovale, junto a su refugio transportable construido con seda y pequeñas incrustaciones de granos de arena. Especímen colectado en el sitio Nant y Fall (noroeste de la provincia del Chubut, Patagonia Argentina), durante el período de estudio. 
El análisis de contenido estomacal realizado en las larvas de $P$. ovale colectadas en el sitio de pasturas $\mathrm{NyF}$, mostró que el $51 \%$ de la dieta estuvo compuesto por fragmentos de hojas, y un 41,1\% de detrito fino, aunque un 3,75\% correspondió a diatomeas, sugiriendo que esta especie podría pertenecer al grupo desmenuzador sin embargo en algunos casos podría presentar hábitos de consumidor oportunista aprovechando otros recursos (e.g. perifiton). 


\subsection{Uso Urbano}

\subsubsection{Descriptores de la cuenca y del tramo}

Los sitios seleccionados para el estudio estuvieron comprendidos entre las latitudes $42^{\circ}$ $30^{\prime} y 43^{\circ} 32^{\prime} \mathrm{S}$ (Figura 35).

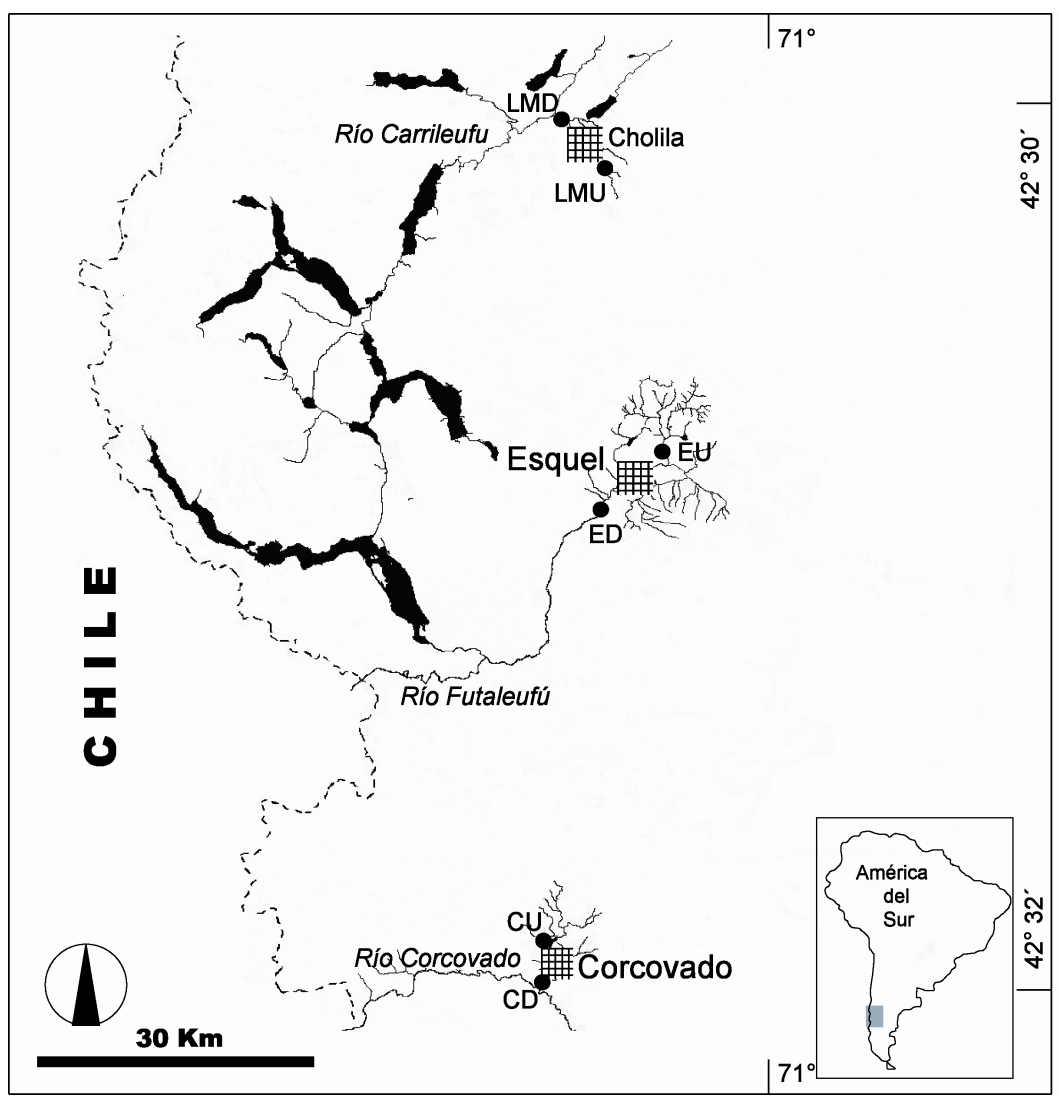

Figura 35. Área de estudio con la ubicación de las tres localidades y los sitios de muestreo urbanos y de referencia. Noroeste de la Provincia de Chubut, Argentina.

Los valores de los descriptores morfológicos (ancho del lecho seco, ancho del lecho mojado, profundidad promedio, velocidad y caudal) fueron mayores en los sitios urbanos que en los de referencia, con excepción de la profundidad promedio en el arroyo Las Minas, que fue mayor en el sitio de referencia que en urbano (Tabla 5).

El sustrato encontrado en los tres sitios de referencia estuvo compuesto mayormente por bloques y guijón. En los sitios urbanos se detectaron algunas diferencias, en el sitio Carbón urbano dominaron bloques y guijones, mientras que en los arroyos Esquel y las Minas se observaron elementos de menor granulometría (guijón, guijarro y arena) (Tabla 5). 
Tabla 5. Valores medios de profundidad, ancho mojado, velocidad y caudal \pm 1 desvío estándar $(n=4)$, sustrato dominante y porcentaje de arena y sedimentos finos, para los seis sitios (referencia y urbanos) de estudio en tres localidades del noroeste de la provincia del Chubut, Cordillera Patagónica (Argentina). Bl: bloque; Gui: guijón; Gja: guijarro y Gr: grava.

\begin{tabular}{|c|c|c|c|c|c|c|}
\hline & \multicolumn{2}{|c|}{ Esquel } & \multicolumn{2}{|c|}{ Las Minas } & \multicolumn{2}{|c|}{ Carbón } \\
\hline & $\mathbf{E U}$ & ED & LMU & LMD & $\mathbf{C U}$ & CD \\
\hline $\begin{array}{l}\text { Ancho del lecho seco } \\
\text { (m) }\end{array}$ & 10,8 & 10,5 & 5,0 & 9,0 & 10,5 & 23,5 \\
\hline $\begin{array}{l}\text { Ancho del lecho mojado } \\
\text { (m) }\end{array}$ & $3,2 \pm 1,3$ & $9,9 \pm 0,4$ & $3,9 \pm 1,9$ & $5,8 \pm 2,2$ & $8,7 \pm 0,7$ & $18,8 \pm 3,7$ \\
\hline $\begin{array}{l}\text { Profundidad media } \\
\quad(\mathrm{cm})\end{array}$ & $20 \pm 10$ & 30 & $20 \pm 10$ & $10 \pm 10$ & $30 \pm 10$ & $30 \pm 10$ \\
\hline $\begin{array}{l}\text { Veloc. de la corriente } \\
\left(\mathrm{m} \cdot \mathrm{s}^{-1}\right)\end{array}$ & $0,9 \pm 0,2$ & $0,9 \pm 0,3$ & $0,8 \pm 0,4$ & $1,0 \pm 0,6$ & $0,8 \pm 0,2$ & $0,8 \pm 0,2$ \\
\hline $\begin{array}{l}\text { Caudal } \\
\qquad\left(\mathrm{m}^{3} \cdot \mathrm{s}^{-1}\right)\end{array}$ & $0,5 \pm 0,4$ & $2,5 \pm 1,3$ & $0,7 \pm 0,4$ & $1,2 \pm 1,6$ & $1,9 \pm 0,9$ & $4,8 \pm 2,9$ \\
\hline Sustrato dominante & $\mathrm{Bl} / \mathrm{Gui}$ & Gja/Gra & Bl/Gui & Gui/Gja & $\mathrm{Bl} / \mathrm{Gui}$ & $\mathrm{Bl} / \mathrm{Gui}$ \\
\hline $\begin{array}{l}\% \text { Arena y sedimentos } \\
\text { finos }\end{array}$ & 10 & 20 & 10 & 5 & 10 & 10 \\
\hline
\end{tabular}

Los valores medios de temperatura del agua estuvieron comprendidos entre 8,1 y $11,3{ }^{\circ} \mathrm{C}$ en los sitios CU y LMD respectivamente, siendo la media menor en los sitios de referencia EU y LMU respecto a sitios urbanos. No obstante estas diferencias no fueron significativas en ninguno de los casos (ANOVA, Kruskal-Wallis, p>0,05). Los valores de $\mathrm{pH}$ no presentaron importantes variaciones entre los sitios siendo en todos los casos circumneutrales ( 7). Los valores medios de conductividad del agua estuvieron comprendidos entre 50 y $100 \mu \mathrm{S}_{20} \mathrm{~cm}^{-1}$, en todos los sitios muestreados con excepción de ED, dónde el valor medio $\left(313 \mu \mathrm{S}_{20} \mathrm{~cm}^{-1}\right)$ fue significativamente superior al del sitio de referencia, EU (ANOVA, Kruskal-Wallis, p<0,005) (Figura 36).

Los valores medios de total de sólidos en suspensión estuvieron comprendidos entre 2,1 y $27 \mathrm{mg} . \mathrm{I}^{-1}$, en los sitios CU y LMD, respectivamente (Figura 37). Por otra parte los valores medios de turbidez variaron entre 4,3 y 82,5 mg. $\mathrm{l}^{-1}$, en los sitios CU y ED respectivamente (Figura 37). Los valores de nutrientes (amonio, nitratos-nitritos y fósforo reactivo soluble) en el sitio ED fueron significativamente mayores al del sitio de referencia EU (ANOVA, Kruskal-Wallis, p<0,005) (Figura 37). 

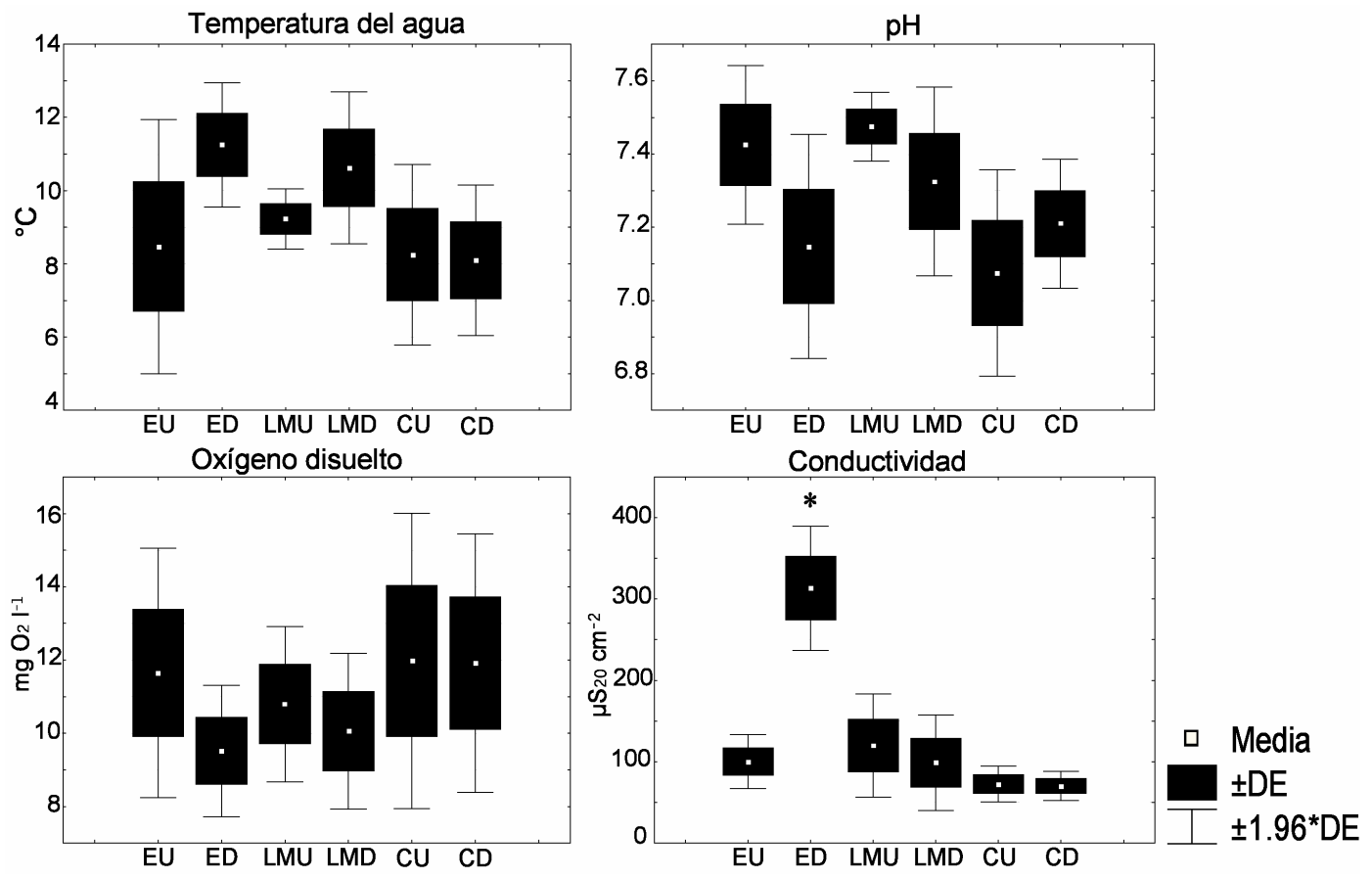

Figura 36. Temperatura, $\mathrm{pH}$, oxígeno disuelto y conductividad para los seis sitios (referencia y urbanos) de estudio en tres localidades de la cordillera patagónica (Argentina).*= ANOVA, Kruskal-Wallis, $\mathrm{p}<0,005 . n=4$.

Por otra parte, en los sitios LMD y CD, no hubo diferencias significativas de estos valores con respecto a los sitios de referencia. El sitio LMD, durante el mes de septiembre fue objeto de un evento de dragado importante lo que incrementó el arrastre de sedimentos en columna de agua (Figura 38), como consecuencia el valor de TSS fue considerablemente más alto que el registrado en otros meses para el mismo sitio (Figura 36). 

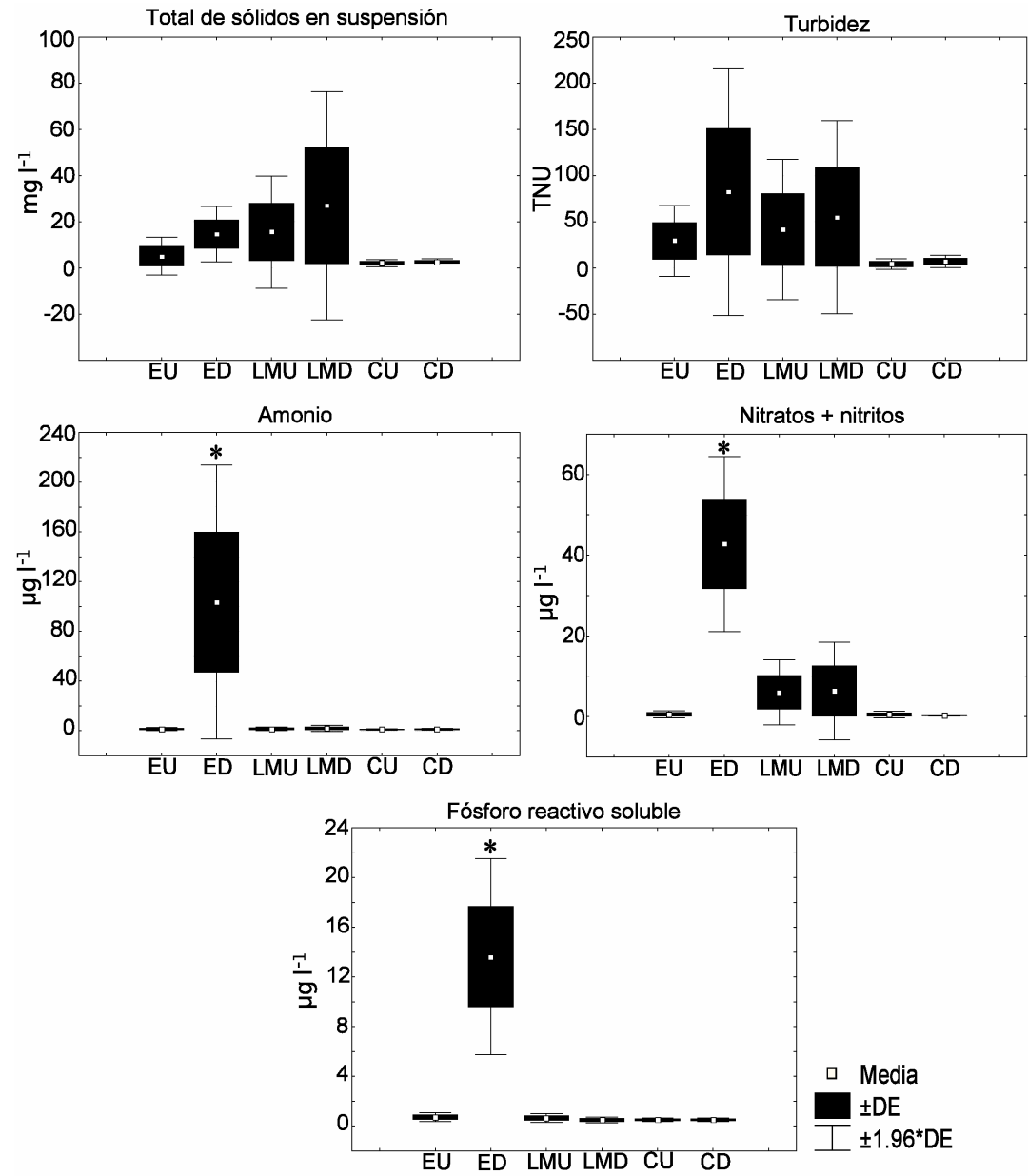

Figura 37. Total de sólidos en suspensión, turbidez, amonio, nitratos y fósforo reactivo soluble, para los seis sitios (referencia y urbanos) de estudio en tres localidades de la cordillera patagónica (Argentina). ${ }^{*}=$ ANOVA, test de Tukey, $\mathrm{p}<0,001 . n=4$.

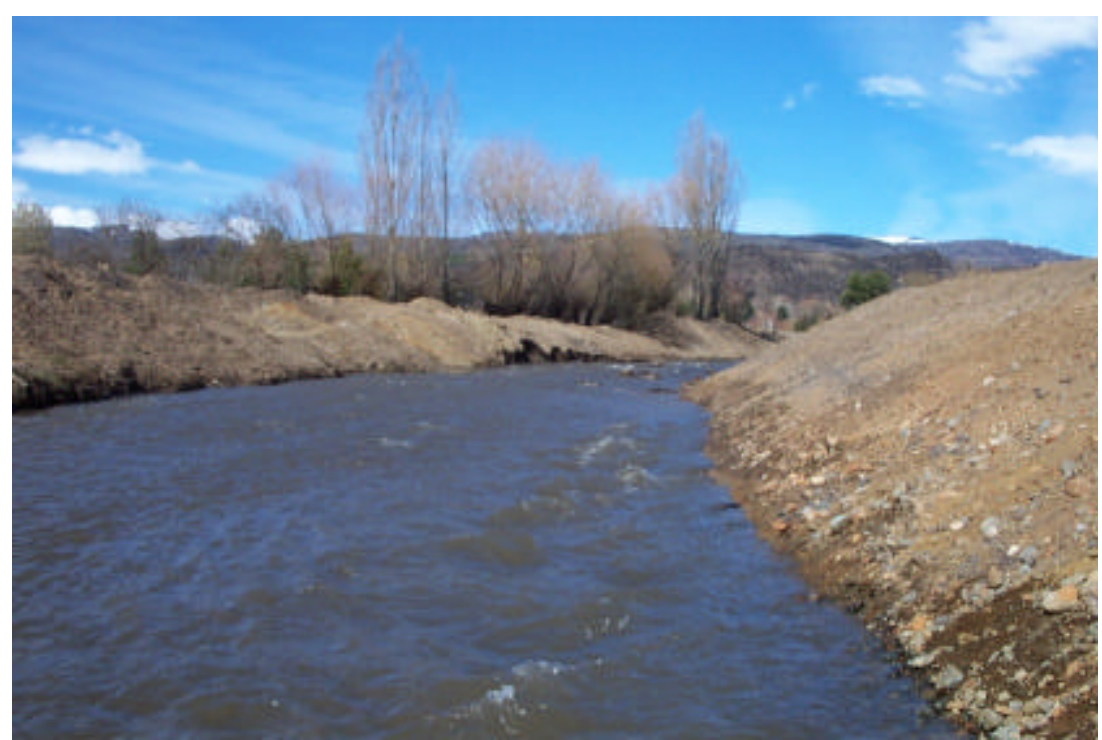

Figura 38. Tramo de estudio en el sitio Las Minas urbano, aguas abajo de la localidad de Cholila, se aprecia el arrastre severo de sedimentos en suspensión ocasionado por las actividades de dragado, durante el mes de septiembre de 2005. 


\subsubsection{Análisis de la materia orgánica}

Las fracciones de materia orgánica dominantes en los sitios relevados fueron algas filamentosas (LMD), otros (ED y $\mathrm{CU}$ ) y hojarasca fragmentada (EU). Los mayores valores de MOPB (suma de todas las fracciones de origen alóctono) fueron registradas en los sitios CU y $\operatorname{ED}(87,3$ y 76,5 \%, respectivamente). La contribución de material leñoso por sitio alcanzó un valor de 19,2 \% en el sitio CD, en el resto de los sitios no alcanzó el valor de $12 \%$. La fracción algas filamentosas fue mayor en los sitios urbanos con respecto a sus correspondientes sitios de referencia, mientras que una tendencia opuesta se observó para las briófitas y la hojarasca entera, fracciones que presentaron mayores valores en los sitios de referencia (Tabla 6).

Tabla 6. Distribución de materia orgánica autóctona y alóctona, y de la clorofila $a$ epilítica. Abundancia relativa (\%) de las fracciones de materia orgánica dominantes y MOPB, como la suma de todas las fracciones de origen alóctono, en los seis sitios de muestreo, noroeste de la provincia de Chubut, Cordillera Patagónica, durante el período de estudio (mayo 2005 - marzo 2006). Los valores corresponden a medias anuales \pm desvío estándar, $n=24$. Los valores de clorofila $a$ epilítica corresponden a datos del mes de febrero 2006.

\begin{tabular}{|c|c|c|c|c|c|c|}
\hline & \multicolumn{2}{|c|}{ Esquel } & \multicolumn{2}{|c|}{ Las Minas } & \multicolumn{2}{|c|}{ Carbón } \\
\hline & $\mathbf{E U}$ & ED & LMU & LMD & $\mathbf{C U}$ & CD \\
\hline \multicolumn{7}{|l|}{ Fracción autóctona } \\
\hline Algas filamentosas & $15,6 \pm 25,3$ & $22,6 \pm 24,3$ & $18,2 \pm 30$ & $27,6 \pm 30,1$ & $0,9 \pm 1,3$ & $14,2 \pm 18,2$ \\
\hline $\begin{array}{l}\text { Algas } \\
\text { mucilaginosas }\end{array}$ & $7 \pm 12$ & 0 & $12,7 \pm 21$ & 0 & $5,4 \pm 11$ & $7,3 \pm 14,6$ \\
\hline Briófitas & $5,5 \pm 8$ & $0,8 \pm 1,7$ & $1,9 \pm 2,3$ & $1,8 \pm 3,4$ & $6,7 \pm 1,6$ & $2,9 \pm 3,4$ \\
\hline \multicolumn{7}{|l|}{ Fracción alóctona } \\
\hline Hojarasca entera & $14 \pm 19,8$ & $11,7 \pm 20,1$ & $18,9 \pm 15,7$ & $16,6 \pm 23,5$ & $15,1 \pm 13,4$ & $9,4 \pm 4,4$ \\
\hline H. fragmentada & $32,3 \pm 31$ & $8,3 \pm 5,1$ & $12,1 \pm 5$ & $11,2 \pm 6,8$ & $15,7 \pm 7,6$ & $17,3 \pm 8,3$ \\
\hline Material leñoso & $9,2 \pm 1,6$ & $5,2 \pm 5.9$ & $10 \pm 8$ & $9,1 \pm 5,3$ & $11,2 \pm 5,8$ & $19,2 \pm 20,9$ \\
\hline Frutos y semillas & $3,3 \pm 4$ & $16,3 \pm 28,7$ & $7,4 \pm 9,2$ & $5,7 \pm 6,1$ & $6,5 \pm 5,3$ & $2,5 \pm 4$ \\
\hline Otros & $12,7 \pm 3$ & $35 \pm 12,2$ & $18,1 \pm 11$ & $26,6 \pm 12,8$ & $38,8 \pm 16,7$ & $27,3 \pm 19,4$ \\
\hline MOPB & $71,6 \pm 59,2$ & $76,5 \pm 72,8$ & $66,7 \pm 48,8$ & $69,2 \pm 54,6$ & $87,3 \pm 48,8$ & $75,6 \pm 57,1$ \\
\hline \multicolumn{7}{|l|}{ Clorofila epilítica } \\
\hline Clorofila $a$ mg. $\mathrm{m}^{-2}$ & 4,52 & 3,65 & 3,46 & 4,18 & 9,33 & 5,63 \\
\hline
\end{tabular}

Los valores de clorofila $a$ epilítica se consignan en la tabla 6 , los mismos estuvieron comprendidos entre los 3,46 y 9,33 mg.m ${ }^{-2}$ correspondiendo los valores extremos al sitio LMU y CU, respectivamente. 


\subsubsection{Vegetación acuática}

Claramente el sitio que presentó la mayor diversidad de macrófitas fue ED, con ocho especies, comprendiendo emergentes, sumergidas y subemergentes. Por otra parte en los sitios EU y CD se identificaron únicamente especies vegetales acuáticas emergentes. Tanto en LMU, LMD como en CU, no hubo registros de especies vegetales acuáticas (Tabla 7). La emergente Verónica anagallis-acuatica fue la especie con mayor cantidad de registros.

Tabla 7. Lista de especies de plantas acuáticas sumergidas, subemergentes y emergentes registradas en cada uno de los seis sitios de estudio, en el noroeste de la provincia de Chubut, Cordillera Patagónica (Argentina), nr: sin registro de plantas acuáticas.

\begin{tabular}{|c|c|c|c|c|c|}
\hline \multicolumn{2}{|r|}{ Esquel } & \multicolumn{2}{|c|}{ Las Minas } & \multicolumn{2}{|r|}{ Carbón } \\
\hline$\overline{\mathbf{E U}}$ & ED & LMU & LMD & $\mathbf{C U}$ & CD \\
\hline $\begin{array}{l}\text { Emergentes } \\
\text { Veronica anagallis- } \\
\text { aquatica (berro de } \\
\text { agua) }\end{array}$ & $\begin{array}{l}\text { Sumergidas } \\
\text { Cladophora } \text { spp. } \\
\text { Myriophyllum quitense } \\
\text { Callitriche lechleri } \\
\text { Ranunculus sp. } \\
\text { Subemergentes } \\
\text { Mimulus glabratus (berro } \\
\text { dulce) } \\
\text { Emergentes } \\
\text { Veronica anagallis-aquatica } \\
\text { (berro de agua) } \\
\text { Eleocharis sp. } \\
\text { Juncus arcticus (junquillo) }\end{array}$ & $\mathrm{nr}$ & $\mathrm{nr}$ & $\mathrm{nr}$ & $\begin{array}{l}\text { Emergentes } \\
\text { Veronica anagallis- } \\
\text { aquatica (berro de } \\
\text { agua) } \\
\text { Juncus microcephalus } \\
\text { (junco) }\end{array}$ \\
\hline
\end{tabular}

\subsubsection{Caracterización del hábitat}

Tanto el índice QBRp como el HA presentaron valores más bajos en los sitios urbanos que en sus respectivos sitios de referencia. El menor valor de QBRp fue registrado en LMD (puntaje total 25,5; categoría: naranja, alteración fuerte, mala calidad) y el más alto en EU (puntaje total 66,5; categoría: amarillo, inicio de alteración importante, calidad intermedia) (Figura 39a). La mayoría de los sitios de uso urbano presentaron valores más bajos en los bloques 1 y 3 , el primero relacionado al grado de cobertura vegetal, y el segundo a la calidad de la misma. Con excepción del sitio EU, el bloque asociado con el grado de naturalidad del canal (bloque 4) presentó un menor apartamiento de su condición natural óptima esperable. 
En cuanto al índice de calidad de hábitat dentro del arroyo (HA), los valores estuvieron comprendidos entre 69 (ED) y 167 (CU), con juicios de calidad marginal y óptimo respectivamente (Figura 39b). En los sitios urbanizados, los apartados relacionados con la protección vegetal de ribera y el ancho de la franja buffer recibieron la menor calificación. Asimismo, respecto de este último apartado, también en los sitios de referencia fue el de calificación más baja, sin embargo superó la obtenida para los sitios urbanizados.
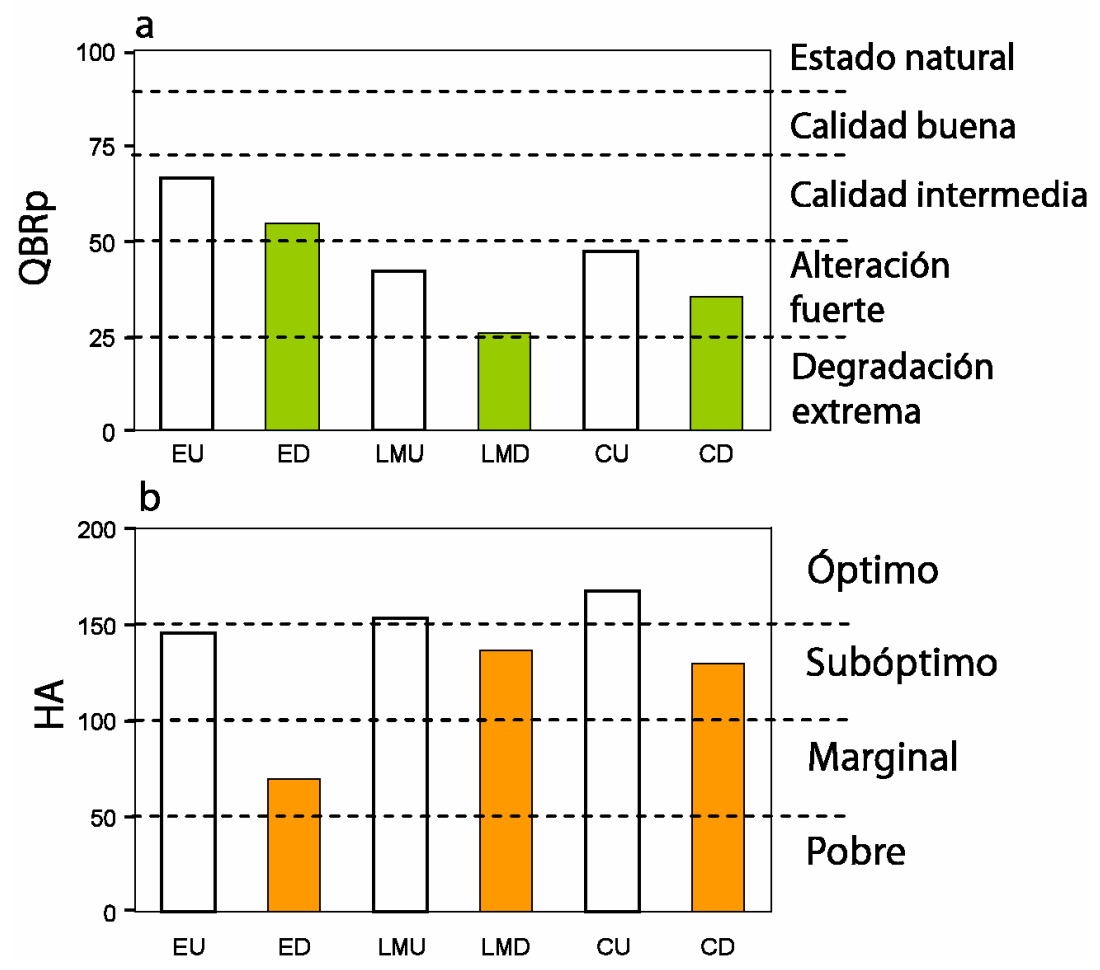

Figura 39: Valores totales del índice a. QBRp y b. HA, para los sitios de referencia (barras blancas) y urbanos (barras de color) en las localidades cordilleranas de Esquel, Cholila y Corcovado (noroeste de la provincia del Chubut, Patagonia, Argentina) (marzo 2006). Códigos de los sitios en Tabla 1.

\subsubsection{Composición de la comunidad de tricópteros}

La comunidad de tricópteros en los sitios urbanos, estuvo representada por un total de 20 taxa comprendidos en nueve familias (Ecnomidae, Glossosomatidae, Hydrobiosidae, Hydropsychidae, Hydroptilidae, Leptoceridae, Philorheithridae, Polycentropodidae y Sericostomatidae) (Tabla 8). Las mayores densidades fueron alcanzadas por $S$. annulicornis, Brachysetodes sp. y P. ovale. 
Tabla 8: Densidad media \pm 1 desvío estándar de las 20 especies de Trichoptera y valores medios anuales \pm 1 desvío estándar de densidad, riqueza taxonómica, diversidad ShannonWeaver y equitatividad de Pielou $(n=24)$, en los seis sitios de muestreo, en el noroeste de la provincia del Chubut, Cordillera Patagónica, durante el período de muestreo (mayo 2005 marzo 2006). COD: código asignado a cada especie para la figura 42.

\begin{tabular}{|c|c|c|c|c|c|c|c|}
\hline & \multirow{2}{*}{ COD } & \multicolumn{2}{|c|}{ Esquel } & \multicolumn{2}{|c|}{ Las Minas } & \multicolumn{2}{|c|}{ Carbón } \\
\hline & & $\overline{\mathbf{E U}}$ & $\overline{\text { ED }}$ & LMU & LMD & $\mathbf{C U}$ & CD \\
\hline \multicolumn{8}{|l|}{ Ecnomidae } \\
\hline Austrotinodes sp. 1 & $A u$ & 0 & 0 & 0 & $0,46 \pm 0,9$ & $0,92 \pm 1,8$ & 0 \\
\hline \multicolumn{8}{|l|}{ Glossosomatidae } \\
\hline Mastigoptila longicornuta & $M l$ & 0 & 0 & 0 & 0 & $1,4 \pm 2,8$ & $1,8 \pm 3,7$ \\
\hline \multicolumn{8}{|l|}{ Hydrobiosidae } \\
\hline Atopsyche sp. & At & 0 & 0 & 0 & 0 & $0,46 \pm 0,9$ & 0 \\
\hline Cailloma pumida & $C p$ & $0,46 \pm 0,9$ & 0 & $7,4 \pm 7,5$ & $6 \pm 12$ & $7,4 \pm 10,1$ & $14,8 \pm 17,5$ \\
\hline Neoatopsyche brevispina & $N b$ & $17,1 \pm 31,8$ & 0 & $9,7 \pm 8,3$ & 0 & $43,4 \pm 50,4$ & $27,3 \pm 41,8$ \\
\hline Neoatopsyche unispina & $U n$ & 0 & 0 & 0 & $13 \pm 20,2$ & 0 & $10,6 \pm 18,8$ \\
\hline $\begin{array}{l}\text { Neopsilochorema } \\
\text { tricarinatum }\end{array}$ & $N t$ & $0,46 \pm 0,9$ & 0 & 0 & $0,46 \pm 0,9$ & $14,8 \pm 12,6$ & $16,2 \pm 25,1$ \\
\hline Reochorema tenuispinum & $R t$ & $0,46 \pm 0,9$ & 0 & 0 & $0,46 \pm 0,9$ & 0 & 0 \\
\hline \multicolumn{8}{|l|}{ Hydropsychidae } \\
\hline Smicridea sp. 1 & Sspl & 0 & 0 & $0,46 \pm 0,9$ & 0 & 0 & 0 \\
\hline Smicridea annulicornis & $S a$ & $20,8 \pm 38$ & 0 & $81,6 \pm 88,4$ & $17,1 \pm 30,5$ & $417 \pm 401$ & $1035 \pm 1323$ \\
\hline Smicridea dithyra & $S d$ & $1,85 \pm 3,7$ & 0 & 0 & 0 & 0 & $85,1 \pm 170,2$ \\
\hline Smicridea frequens & $S f$ & 0 & 0 & 0 & $4,16 \pm 4,8$ & $0,46 \pm 0,9$ & $82,8 \pm 150,8$ \\
\hline \multicolumn{8}{|l|}{ Hydroptilidae } \\
\hline Metrichia patagonica & $M p$ & 0 & 0 & $1,87 \pm 0,4$ & $1,4 \pm 1,8$ & 0 & 0 \\
\hline Oxyethira bidentata & $O b$ & 0 & 0 & 0 & $0,9 \pm 1,85$ & $0,46 \pm 0,9$ & 0 \\
\hline \multicolumn{8}{|l|}{ Leptoceridae } \\
\hline Brachysetodes sp. & Bsp & $41,6 \pm 74,9$ & 0 & $106,4 \pm 97,3$ & $5 \pm 4,6$ & $162 \pm 141,6$ & $34,2 \pm 19,2$ \\
\hline Hudsonema flaminii & $H f$ & $16,6 \pm 33$ & 0 & $217,8 \pm 260$ & $3,23 \pm 5,3$ & $18,5 \pm 35,8$ & $1,85 \pm 2,6$ \\
\hline \multicolumn{8}{|l|}{ Philorheithridae } \\
\hline Psilopsyche molinai & $P m$ & 0 & 0 & 0 & 0 & $6 \pm 9,7$ & 0 \\
\hline \multicolumn{8}{|l|}{ Polycentropodidae } \\
\hline Polycentropus sp. & $P y$ & $0,46 \pm 0,9$ & 0 & 0 & 0 & 0 & 0 \\
\hline \multicolumn{8}{|l|}{ Sericostomatidae } \\
\hline Myotrichia murina & $M m$ & 0 & 0 & $1,38 \pm 1,8$ & 0 & 0 & 0 \\
\hline Parasericostoma ovale & Po & 0 & 0 & 0 & $0,92 \pm 1,8$ & $136,4 \pm 76$ & $753,4 \pm 881$ \\
\hline
\end{tabular}


Tabla 8. Continuación.

\begin{tabular}{lcccccc}
\hline & \multirow{2}{*}{ COD } & \multicolumn{2}{c}{ Esquel } & \multicolumn{2}{c}{ Las Minas } & \multicolumn{2}{c}{ Carbón } \\
\cline { 2 - 7 } & EU & ED & LMU & LMD & CU & CD \\
\hline Densidad & $99,9 \pm 177,8$ & 0 & $427 \pm 333,6$ & $53,2 \pm 47,3$ & $809,4 \pm 508$ & $2064 \pm 2202$ \\
Riqueza total acumulada & 9 & 0 & 8 & 12 & 13 & 11 \\
Diversidad & $0,8 \pm 0,57$ & 0 & $1,05 \pm 3,55$ & $1,13 \pm 0,33$ & $1,14 \pm 0,32$ & $1,1 \pm 0,12$ \\
Equitatividad & $0,61 \pm 0,4$ & 0 & $0,62 \pm 0,23$ & $0,73 \pm 0,19$ & $0,57 \pm 0,18$ & $0,53 \pm 0.1$ \\
\hline
\end{tabular}

La mayor densidad de tricópteros se observó en el sitio $\mathrm{CD}$, en la ciudad de Corcovado, en los meses de mayo y marzo con 4520 y 3326 ind. $\mathrm{m}^{-2}$, respectivamente, siendo las especies responsables de estos valores $S$. annulicornis y $P$. ovale. En el sitio ED, aguas abajo de la ciudad de Esquel, no se registró ningún individuo durante todo el estudio (Figura 40a).

Con respecto a la riqueza taxonómica, el mayor valor correspondió al sitio CU en mayo con 6,16 especies de tricópteros (Figura 40b). Con excepción del arroyo Carbón en los meses de diciembre y marzo, los valores de riqueza taxonómica media fueros mayores en los sitios de referencia, con respecto a los urbanos (Figura 40b).

La diversidad Shannon-Weaver presentó una variación entre 0 y 1,54 bits. El menor valor se registró en los sitios ED (todos los meses) EU (diciembre), mientras que el máximo se observó en CU marzo (Figura 40c). Debido a la ausencia total de tricópteros la equitatividad fue 0 bits en ED (todos los meses) y en EU (diciembre). El máximo valor (0,93 bits) fue registrado en LMU septiembre (figura 40d). 


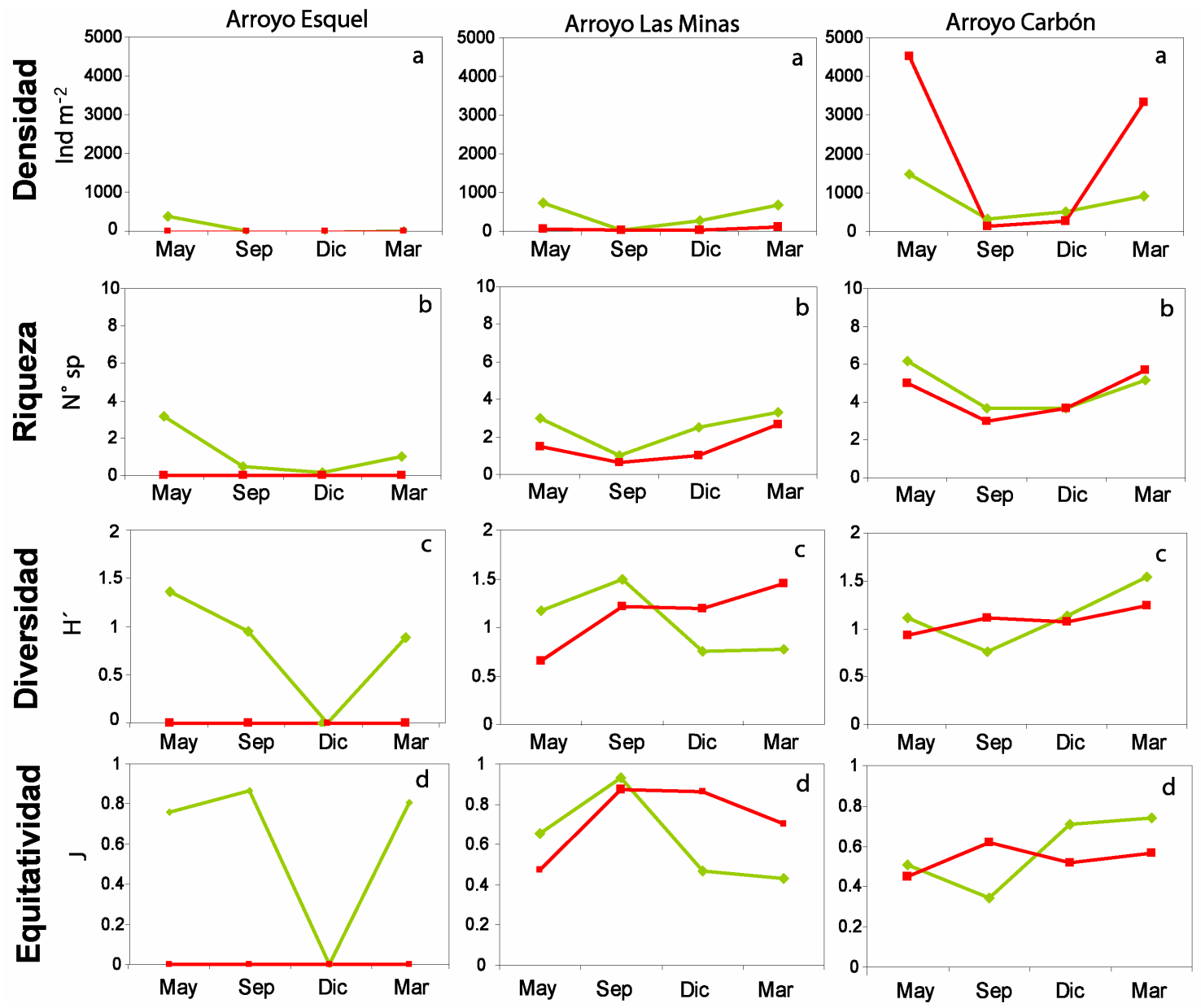

Figura 40. a. Densidad (ind. $\mathrm{m}^{-2}$ ), b. riqueza taxonómica media, c. Diversidad Shannon-Weaver y d. equitatividad de Pielou, para los sitios urbanos (línea roja) y los de referencia (línea verde) en tres localidades del noroeste de la provincia del Chubut, Cordillera Patagónica (Argentina), en cuatro meses del año, durante el período de muestreo. Valores medios de tres réplicas tomadas en rápidos y tres en pozones $(n=6)$.

\subsubsection{Estructura funcional de la comunidad de tricópteros}

Los grupos funcionales dominantes en los sitios de muestreo fueron desmenuzadores (EU y LMU) y colectores-filtradores (CU, CD y LMD). También se registró una importante presencia de predadores particularmente en el sitio LMD. En los dos sitios urbanos, LMD y CD, se registró un aumento de la proporción de colectores-filtradores en relación a sus sitios de referencia (Figura 41). Asimismo en el sitio LMD se observó una disminución marcada en la proporción de desmenuzadores (LMU 77 \% a LMD 17 $\%)$. 
EU
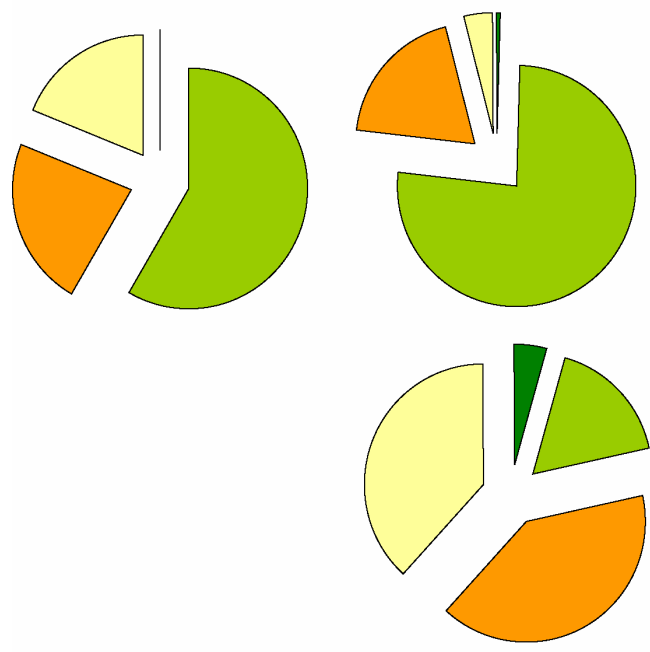

LMD
CU
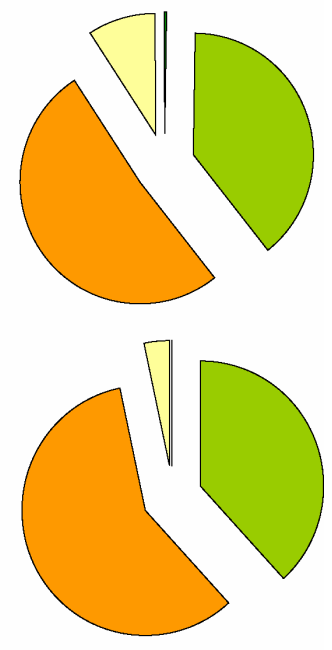

CD $\square$ Raspadores

Desmenuzadores
Colectores-filtradores

Predadores

Figura 41. Proporción (\% abundancia) de los principales grupos funcionales en los sitios urbanos y de referencia en tres localidades del noroeste de la provincia del Chubut, Cordillera Patagónica (Argentina), durante el período de muestreo (mayo 2005-marzo 2006) $(n=24)$. El sitio ED no presentó individuos del orden.

\subsubsection{Distribución temporal de tricópteros en relación a las principales variables}

\section{ambientales}

El análisis de redundancias (RDA) de las especies de tricópteros de los sitios urbanos y de referencia y las principales variables físico-químicas y fracciones de materia orgánica se presenta en la figura 42. Se incluyeron en el ordenamiento las variables que presentaron valores de los factores inflación menores a 10 (Tabla 9). Las variables que se correlacionaron significativamente con el eje 1 fueron: amonio, total de sólidos en suspensión, conductividad, profundidad y algas filamentosas. Las variables que se correlacionaron significativamente con el eje 2 fueron: ancho del lecho mojado, oxígeno disuelto, algas filamentosas y las fracciones de materia orgánica otros y materia orgánica particulada béntica (Tabla 9).

El RDA 1 estuvo explicado por las variables asociadas con los efectos de las urbanizaciones esto es: el amonio, la conductividad, el total de sólidos en suspensión y las algas filamentosas, se incrementaron significativamente hacia los valores negativos del eje 1 (Figura 42). El ancho, el oxígeno disuelto, las algas filamentosas y las fracciones de materia orgánica “otros” y materia orgánica particulada béntica (MOPB) correlacionaron negativamente con el eje 2 . 
Tabla 9. Autovalores del análisis de redundancia, test de Montecarlo y significación. TSS: total de sólidos en suspensión; MOPB: materia orgánica particulada béntica. Análisis realizado entre las comunidades de tricópteros y las variables ambientales en ríos de tres localidades de la Cordillera patagónica (Argentina), durante el período de muestreo (mayo 2005-marzo 2006). Los valores en negrita corresponden a correlaciones significativas con el eje.

\begin{tabular}{lcc}
\hline & RDA 1 & RDA 2 \\
\hline Autovalores & 0,48 & 0,10 \\
Correlaciones especie-ambiente & 0.94 & 0.74 \\
Porcentaje acumulado de la varianza de las & 48,2 & 57,8 \\
especies explicada & & \\
Correlación con los ejes: & & \\
Amonio & $\mathbf{- 0 , 5 2}$ & $\mathbf{- 0 , 3 8}$ \\
TSS & $\mathbf{- 0 , 3 5}$ & $-0,17$ \\
Conductividad & $\mathbf{- 0 , 6}$ & $-0,04$ \\
Ancho mojado & $\mathbf{0 , 4 4}$ & $\mathbf{- 0 , 6 5}$ \\
Profundidad & $\mathbf{0 , 3 1}$ & $-0,25$ \\
Oxígeno Disuelto & $-0,1$ & $\mathbf{- 0 , 3 1}$ \\
Algas Filamentosas & $\mathbf{- 0 , 3 2}$ & $\mathbf{- 0 , 3 2}$ \\
Otros & $-0,01$ & $\mathbf{- 0 , 4}$ \\
MOPB & $-0,005$ & 0,16 \\
\hline Test de Montecarlo & & \\
Para el primer eje: $\mathrm{F}=13,032, \mathrm{p}<0.0001$ & & \\
Para todos los ejes: $\mathrm{F}=3,334, \mathrm{p}<0.0001$ & & \\
\hline
\end{tabular}

En la figura 42 se representan las especies de Trichoptera simultáneamente con las variables ambientales con mayor valor predictivo sobre su densidad. Las especies asociadas a los ambientes con mayor profundidad, ancho y altos valores de la fracción orgánica "otros" fueron S. frequens, S. dithyra, N. tricarinatum, P. ovale, M. longicornuta, Atopsyche sp (cuadrante inferior derecho). Mientras que Polycentropus sp., M. patagonica, Smicridea sp. 1, R. tenuispinum aumentaron en densidad en los sitios más someros esto es, de menor profundidad y ancho, y los meses de menor caudal (diciembre y marzo). 


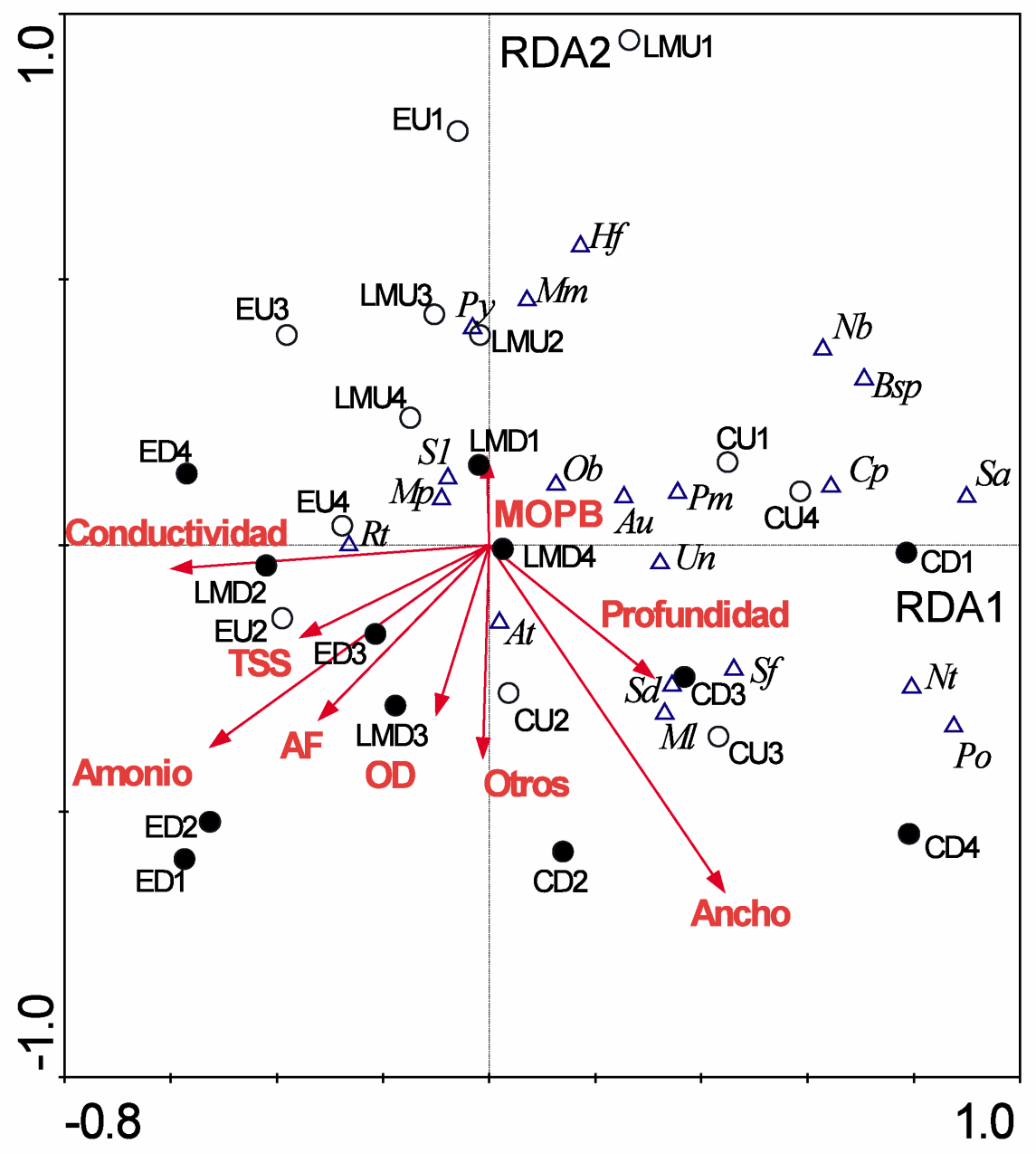

Figura 42. Análisis RDA, triplot mostrando la distribución las especies del Orden Trichoptera y sitios de estudio en relación a las variables ambientales. TSS: total de sólidos en suspensión; OD: oxígeno disuelto; AF: algas filamentosas; MOPB: materia orgánica particulada béntica. Código de referencia de las especies en Tabla 8. Los sitios de referencia se indican con círculos abiertos, los sitios urbanos se indican con círculos rellenos. Los números corresponden a las fechas de muestreo (1: mayo; 2: septiembre; 3: diciembre y 4: marzo).

Las especies ubicadas en el cuadrante superior derecho: H. flaminii, M. murina, $N$. brevispina, Brachysetodes sp., C. pumida, S. annulicornis, P. molinai, Austrotinodes sp. y $O$. bidentata, se asociaron a sitios que exhibieron valores bajos de amonio, TSS y conductividad. Por el contrario no se registró ninguna especie (ED1, ED2, ED3) o la densidad y la riqueza fueron muy bajas (LMD2, EU2) en los sitios o momentos del año donde estas variables aumentaron en extremo (cuadrante inferior izquierdo). 


\subsection{Usos de la tierra asociados a prácticas silvopastoriles.}

\subsubsection{Descriptores de la cuenca}

Los sitios seleccionados para este estudio (Figura 43), presentaron un rango de elevación entre los 361 y 820 msnm (Tabla 1).

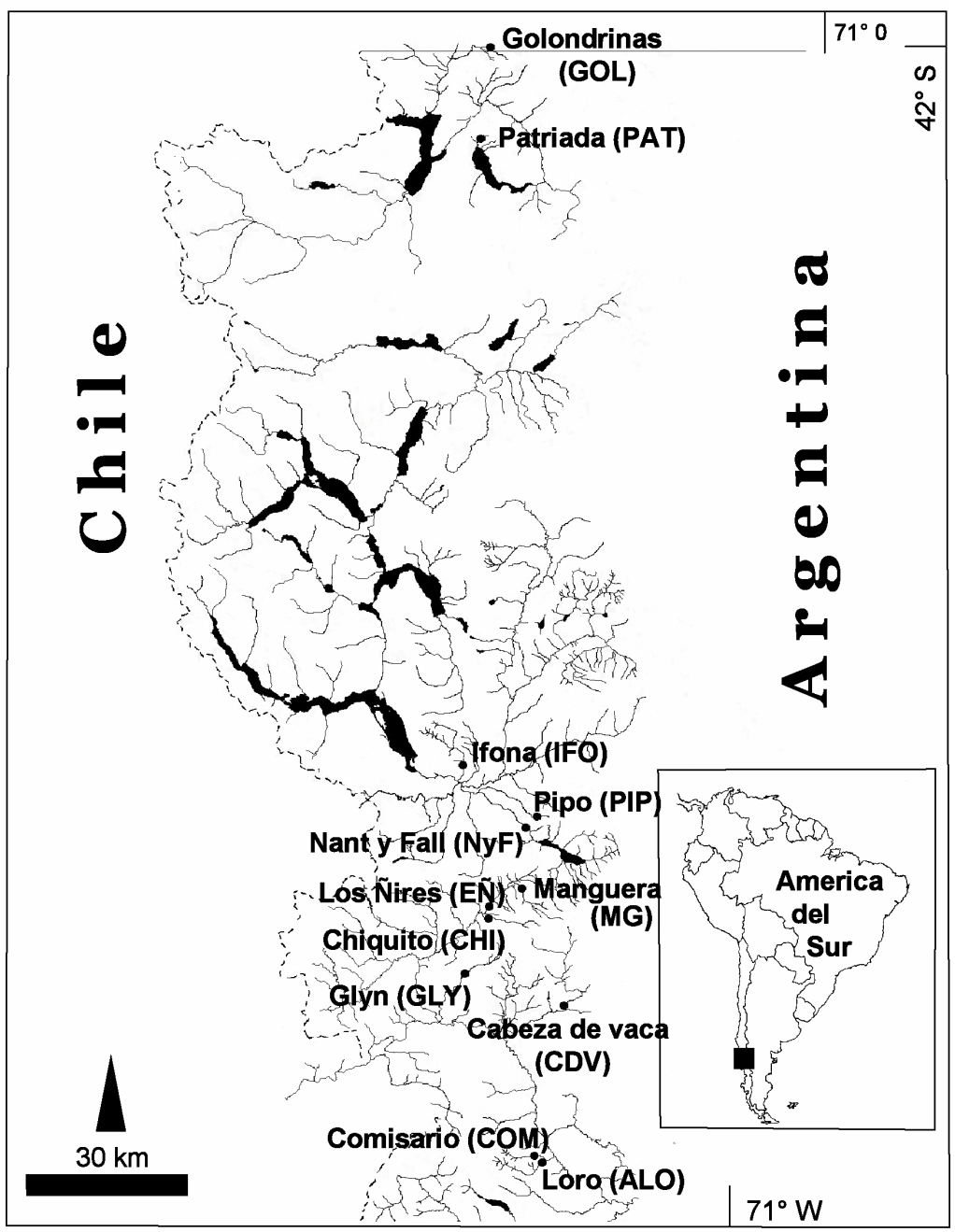

Figura 43. Mapa del área de estudio mostrando los doce sitios seleccionados, noroeste de la provincia del Chubut, Patagonia, Argentina. Códigos de cada sitio entre paréntesis.

\subsubsection{Descriptores ambientales del tramo}

Los valores medios de temperatura del agua estuvieron comprendidos entre 3,63 (ALO, bosque nativo) y $10,4{ }^{\circ} \mathrm{C}$ ( $\mathrm{NyF}$, pasturas). Los sitios de bosque nativo con mayor canopia presentaron los valores más bajos de temperatura probablemente por efecto de sombreo, mientras que los sitios abiertos con menor cobertura de vegetación ribereña como las pasturas alcanzaron mayores valores (Tabla 10). La temperatura media del agua fue significativamente menor en los sitios de bosque nativo, respecto de los demás 
usos (BÑ < BM, PAS, PIN; Mann-Whitney U-test $p=0,049)$. Asimismo, el ancho del canal fue mayor en los sitios de pasturas, particularmente en el arroyo Nant y Fall que presentó 21,1 m en el tramo estudiado. En la mayoría de los sitios, el sustrato estuvo compuesto principalmente por bloques, guijones y guijarros, no obstante, en algunos casos la proporción de elementos de granulometría pequeña (arena, grava) fue mayor al $30 \%$ como es el caso de EÑ (pasturas), GOL, PAT (pinares) y PIP (bosque manejado) (Tabla 10).

$\mathrm{El} \mathrm{pH}$ en todos los casos fue circumneutral, con un rango comprendido entre 7,07 y 7,60. Los valores medios de conductividad estuvieron comprendidos entre 29,25 y $128,25 \mu \mathrm{S}_{20} . \mathrm{cm}^{-1}$, en los sitios COM y GOL, respectivamente. Los mayores valores de oxígeno disuelto se registraron en los sitios de bosque nativo (12,76 a 15,05 mg. $\left.\mathrm{l}^{-1}\right)$, mientras que el sitio NyF (pasturas), presentó el menor valor medio anual de esta variable $\left(8,8 \mathrm{mg} \cdot \mathrm{l}^{-1}\right)$. Los sitios $\mathrm{NyF}$ y PAT presentaron los valores más bajos de turbidez (4,25 TNU), mientras que el en el sitio GOL el valor registrado fue considerablemente más alto (72,5 TNU). Los valores medios de TSS estuvieron comprendidos entre 0,75 y 9,24 mg. $\mathrm{l}^{-1}$, siendo estos valores hallados en los sitios COM (bosque nativo) y PIP (bosque nativo manejado), respectivamente. Algunos valores extremos de esta variable se detectaron en los sitios PIP (bosque manejado) con un máximo de 33,9 mg. $\mathrm{l}^{-1}$ y MG (pasturas) 16,1 mg. $\mathrm{l}^{-1}$ ambos durante el verano (Tabla $10)$.

Los valores de nutrientes estuvieron comprendidos dentro de los rangos esperados para ambientes cordilleranos de Patagonia. Es así que el mínimo y máximo de amonio varió entre 0,78 y $1,99 \mu \mathrm{g} .1^{-1}$ (sitios GOL y PIP respectivamente). Asimismo, los valores máximos y mínimos de nitratos-nitritos hallados fueron 0,07 (IFO y CHI) y $0,73 \mu \mathrm{g} .1^{-1}$ (PAT) respectivamente. El menor valor de fósforo reactivo soluble se registró en el sitio GOL $\left(0,28 \mu \mathrm{g} .1^{-1}\right)$, mientras que el mayor fue hallado en $\operatorname{PIP}\left(1,26 \mu \mathrm{g} \cdot \mathrm{l}^{-1}\right)$. 
Tabla 10. Caracterización fisicoquímica de los 12 sitios de estudio del noroeste de la provincia de Chubut, Cordillera Patagónica (Argentina) durante el año de estudio (mayo 2005-marzo 2006). Los valores corresponden a la media anual $n=4, \pm 1$ desvío estándar. Bl: bloque, Gui: guijón, Gja: guijarro, Gr: grava, Sf: sedimentos finos. Códigos de los sitios en Tabla 1.

\begin{tabular}{|c|c|c|c|c|c|c|c|c|c|c|c|c|}
\hline & \multicolumn{3}{|c|}{ Pasturas } & \multicolumn{3}{|c|}{ Pinar } & \multicolumn{3}{|c|}{ Bosque manejado } & \multicolumn{3}{|c|}{ Bosque nativo } \\
\hline & NYF & $\mathbf{E N}$ & MG & GOL & PAT & IFO & CDV & PIP & GLY & COM & ALO & CHI \\
\hline $\begin{array}{l}\text { Temp. del agua } \\
\left({ }^{\circ} \mathbf{C}\right)\end{array}$ & $10,4 \pm 2,7$ & $7 \pm 2,6$ & $7,1 \pm 1,4$ & $7,7 \pm 1,5$ & $7,7 \pm 1,1$ & $8,8 \pm 2,6$ & $6,5 \pm 2,4$ & $7,2 \pm 3,2$ & $7,4 \pm 2,2$ & $4,4 \pm 2,1$ & $3,6 \pm 1,8$ & $5,4 \pm 1,9$ \\
\hline $\begin{array}{l}\text { Ancho mojado } \\
\quad(\mathrm{m})\end{array}$ & $21,1 \pm 3$ & $6,92 \pm 3,4$ & $5,8 \pm 0,7$ & $2,2 \pm 0,5$ & $1,17 \pm 0,05$ & $8,7 \pm 0,5$ & $7,9 \pm 3$ & $1,45 \pm 0,5$ & $4,22 \pm 0,8$ & $8,4 \pm 0,6$ & $3,73 \pm 0,3$ & $1,85 \pm 0,5$ \\
\hline $\begin{array}{l}\text { Ancho seco } \\
\text { (m) }\end{array}$ & 31,5 & 22,5 & 14,2 & 4,2 & 1,8 & 10,5 & 8,25 & 2,3 & 5,7 & 9 & 4 & 3,5 \\
\hline $\begin{array}{l}\text { Profundidad } \\
\quad(\mathrm{cm})\end{array}$ & $25,4 \pm 5,8$ & $26,7 \pm 5,4$ & $16,7 \pm 4$ & $18,8 \pm 5,4$ & $9,7 \pm 2,1$ & $37,7 \pm 4$ & $23,4 \pm 3,3$ & $9,3 \pm 3,6$ & $20,4 \pm 7,9$ & $30,4 \pm 4,4$ & $26,7 \pm 4,2$ & $17 \pm 5,9$ \\
\hline $\begin{array}{c}\text { Velocidad } \\
\quad\left(\mathbf{m . s}^{-1}\right)\end{array}$ & $0,82 \pm 0,1$ & $1,08 \pm 0,4$ & $0,92 \pm 0,4$ & $0,5 \pm 0,4$ & $0,33 \pm 0,1$ & $0,9 \pm 0,1$ & $1,1 \pm 0,2$ & $0,27 \pm 0,2$ & $1,06 \pm 0,5$ & $1,10 \pm 0,5$ & $1,04 \pm 0,2$ & $0,63 \pm 0,5$ \\
\hline $\begin{array}{l}\text { Caudal } \\
\qquad\left(\mathbf{m}^{3} \cdot \mathbf{s}^{-1}\right)\end{array}$ & $4,6 \pm 2,5$ & $2,05 \pm 1,3$ & $1 \pm 0,8$ & $0,2 \pm 0,2$ & 0,04 & $3,03 \pm 0,6$ & $1,9 \pm 0,9$ & $0,04 \pm 0,04$ & $1,15 \pm 1,1$ & $2,82 \pm 1,3$ & $1,03 \pm 0,3$ & $0,23 \pm 0,2$ \\
\hline Sustrato & Gr/Gui & $\mathrm{Sf} / \mathrm{Gr}$ & $\mathrm{Bl} / \mathrm{Gui}$ & Gui/Sf & $\mathrm{Gr} / \mathrm{Sf}$ & Bl/Gui & Gui/Gr & $\mathrm{Gr} / \mathrm{Sf}$ & Gja/Gui & Bl/Gui & Bl/Gui & Gui/Gja \\
\hline $\begin{array}{l}\% \text { Arena y } \\
\text { sedimentos finos }\end{array}$ & 15 & 40 & 5 & 30 & 35 & 5 & 15 & 35 & 15 & 5 & 5 & 10 \\
\hline pH & $7,6 \pm 0,4$ & $7,2 \pm 0,4$ & $7,4 \pm 0,4$ & $7,1 \pm 0,4$ & $7,2 \pm 0,4$ & $7,2 \pm 0,3$ & $7,3 \pm 0,1$ & $7,3 \pm 0,3$ & $7,2 \pm 0,1$ & $7,2 \pm 0,2$ & $7,3 \pm 0,2$ & $7,2 \pm 0,2$ \\
\hline $\begin{array}{l}\text { Conductividad } \\
\left(\mu \mathbf{S}_{20} \mathrm{~cm}^{-1}\right)\end{array}$ & $114 \pm 2,7$ & $83 \pm 24,1$ & $65 \pm 21,6$ & $128,2 \pm 7,1$ & $71,7 \pm 5,9$ & $36,5 \pm 5,2$ & $50 \pm 14$ & $56,7 \pm 16$ & $77,2 \pm 18,1$ & $29,2 \pm 2,9$ & $25,7 \pm 2,9$ & $50 \pm 36$ \\
\hline
\end{tabular}


Tabla 10. Continuación.

\begin{tabular}{|c|c|c|c|c|c|c|c|c|c|c|c|c|}
\hline & \multicolumn{3}{|c|}{ Pasturas } & \multicolumn{3}{|c|}{ Pinar } & \multicolumn{3}{|c|}{ Bosque manejado } & \multicolumn{3}{|c|}{ Bosque nativo } \\
\hline & NYF & $\mathbf{E N}$ & MG & GOL & PAT & IFO & CDV & PIP & GLY & COM & ALO & CHI \\
\hline $\begin{array}{l}\text { Oxigeno Disuelto } \\
\left(\mathrm{mg} . \mathrm{I}^{-1}\right)\end{array}$ & $8,8 \pm 1,6$ & $12,3 \pm 2,2$ & $12,3 \pm 1,9$ & $11,6 \pm 1,5$ & $11,7 \pm 1,6$ & $11,4 \pm 3,3$ & $11,2 \pm 1,6$ & $12,7 \pm 4,5$ & $12,4 \pm 3,7$ & $14,4 \pm 3,3$ & $15 \pm 3,4$ & $12,8 \pm 1,3$ \\
\hline $\begin{array}{c}\text { Turbidez } \\
\text { (TNU) }\end{array}$ & $4,2 \pm 3,8$ & $16,2 \pm 12,3$ & $8,5 \pm 12,4$ & $72,5 \pm 114$ & $4,2 \pm 2,2$ & $24,5 \pm 32$ & $10 \pm 14,8$ & $5 \pm 10$ & $10,2 \pm 17,9$ & $37 \pm 72$ & $4,7 \pm 8,2$ & $49,7 \pm 95$ \\
\hline $\begin{array}{l}\text { Amonio } \\
\qquad\left(\mu \mathrm{g} . \mathrm{I}^{-1}\right)\end{array}$ & $1 \pm 0,5$ & $1,4 \pm 1$ & $1 \pm 0,8$ & $0,8 \pm 0,7$ & $1 \pm 0,6$ & $1,1 \pm 0,6$ & $1 \pm 0,5$ & $2 \pm 1,6$ & $0,9 \pm 0,8$ & $0,8 \pm 0,7$ & $0,9 \pm 0,6$ & $1,8 \pm 1,5$ \\
\hline $\begin{array}{l}\text { Nitratos + Nitritos } \\
\quad\left(\mu \mathrm{g} . \mathrm{I}^{-1}\right)\end{array}$ & $0,2 \pm 0,2$ & $0,1 \pm 0,04$ & $0,2 \pm 0,3$ & $0,5 \pm 0,4$ & $0,7 \pm 0,6$ & $0,07 \pm 0,1$ & $0,2 \pm 0,1$ & $0,1 \pm 0,04$ & $0,3 \pm 0,2$ & $0,4 \pm 0,8$ & $0,1 \pm 0,1$ & $0,1 \pm 0,06$ \\
\hline $\begin{array}{l}\text { Fósforo reactivo } \\
\text { soluble } \\
\qquad\left(\mu \mathrm{g} . \mathrm{I}^{-1}\right)\end{array}$ & $0,3 \pm 0,05$ & $0,9 \pm 0,5$ & $0,8 \pm 0,6$ & $0,3 \pm 0,1$ & $0,6 \pm 0,4$ & $0,6 \pm 0,5$ & $0,6 \pm 0,2$ & $1,3 \pm 1$ & $0,4 \pm 0,2$ & $0,4 \pm 0,2$ & $0,3 \pm 0,2$ & $1 \pm 0,6$ \\
\hline $\begin{array}{l}\text { Total de sólidos en } \\
\text { suspensión } \\
\left(\mathrm{mg} . \mathrm{I}^{-1}\right)\end{array}$ & $2,7 \pm 0,8$ & $8 \pm 5,6$ & $5,1 \pm 7,3$ & $1 \pm 0,6$ & $2,8 \pm 2,4$ & $2,6 \pm 1$ & $2,4 \pm 1,9$ & $9,2 \pm 16,4$ & $1,1 \pm 0,6$ & $0,7 \pm 0,6$ & $1,1 \pm 1,9$ & $4,05 \pm 1,9$ \\
\hline
\end{tabular}




\subsubsection{Clorofila epilítica}

Los valores medios de clorofila $a$ epilítica, por uso, variaron entre 6,02 y 9,18 $\mathrm{mg} \cdot \mathrm{m}^{-2}$, para uso pasturas y bosque nativo respectivamente, sin embargo no se registraron diferencias significativas (Kruskall-Wallis, $p>0,05$ ) entre estos valores para los distintos usos durante el mes de marzo (Figura 44).

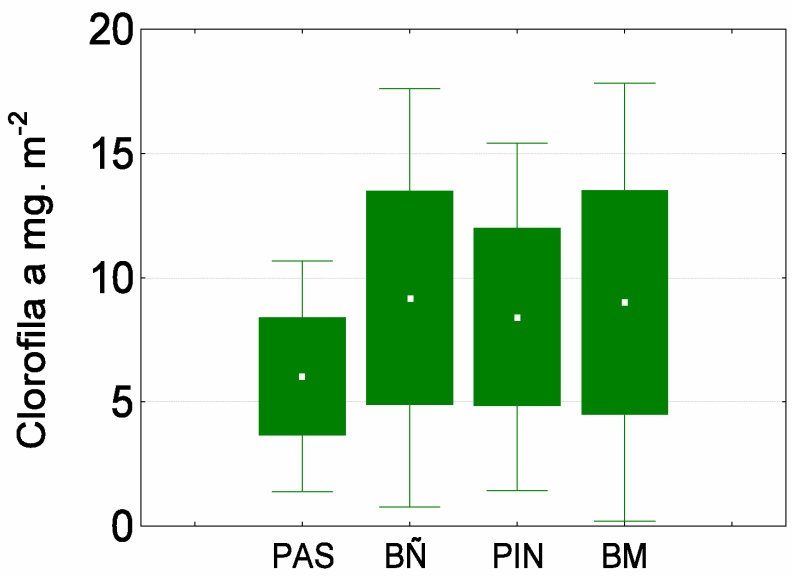

Figura 44: Valores medios de clorofila $a\left(\mathrm{mg} \cdot \mathrm{m}^{-2}\right)$ en los distintos usos silvopastoriles y de referencia $n=3$, durante el período de muestreo de marzo 2006. Cuadrados claros: media, barras: máximo y mínimo, cajas: intercuartiles (25-75\%).

\subsubsection{Distribución de la materia orgánica}

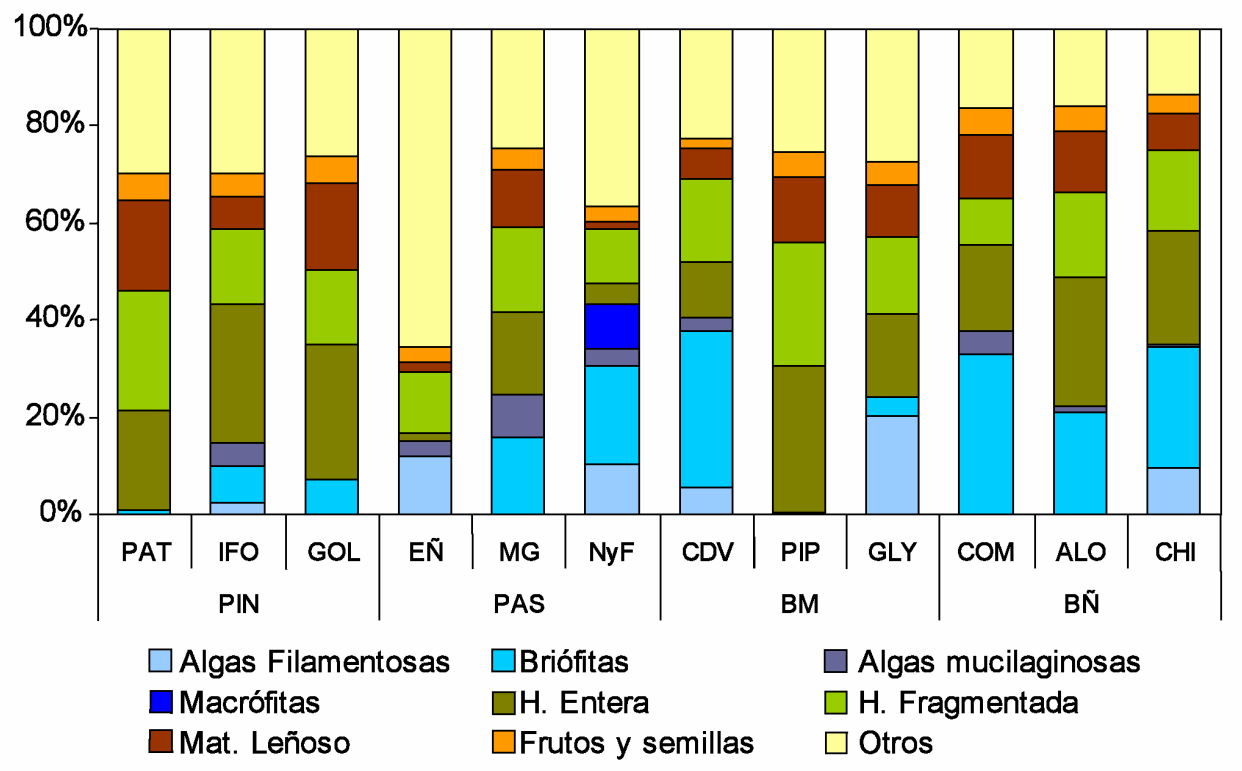

Figura 45. Distribución de detrito orgánico autóctono y alóctono en los 12 sitios de estudio por uso de la tierra, valores promedio de cuatro muestreos. Noroeste de la provincia del Chubut, Cordillera Patagónica (mayo 2005-marzo 2006). H: hojarasca. Mat: material.

Con respecto a la materia orgánica béntica se obtuvieron nueve clases, cuatro de ellas correspondientes a materia orgánica autóctona (algas filamentosas, algas mucilaginosas, 
briófitas y macrófitas) y cinco a fracciones de material alóctono (hojarasca entera, hojarasca fragmentada, material leñoso, frutos y semillas y fragmentos muy pequeños). Los valores más altos de briófitas se registraron en los sitios CDV (bosque manejado), COM, ALO y CHI (bosque de ñire). Las macrófitas sólo se encontraron representadas en el sitio $\mathrm{NyF}$ (pasturas), mientras que las algas filamentosas sólo se registraron en los sitios IFO, EÑ, NyF, CDV, GLY y CHI. Con respecto a las fracciones de materia orgánica alóctona, la hojarasca entera, junto con la fragmentada tuvieron buena participación en la mayoría de los sitios, exceptuando EÑ , dónde la fracción dominante de material alóctono fue la de fragmentos muy pequeños. En relación al material leñoso y a la fracción frutos y semillas, se observó poca variación en sus proporciones en los sitios estudiados (Figura 45).

\subsubsection{Ordenamiento de los sitios en base a las características ambientales}

Un análisis exploratorio realizado a través de un Análisis de Componentes Principales (ACP), permitió observar las principales diferencias entre los sitios con respecto a los parámetros ambientales registrados. El primer eje explicó el 67,4 \% de la varianza y estuvo determinado por las variables briófitas, MOPB, PRS y TSS. El segundo eje capturó el 16,8 \% de la varianza y estuvo explicado por las variables oxígeno disuelto, otros, ancho, velocidad, conductividad y nitratos. Hacia el extremo negativo del ACP1 se agruparon los sitios que presentaron mayor velocidad de corriente y presencia de briófitas, mientras que hacia sus valores positivos se agruparon sitios de menor magnitud del curso de agua, con menor velocidad de corriente, alta retención de materia orgánica particulada béntica (MOPB), valores máximos de fósforo reactivo soluble y total de sólidos en suspensión. En el extremo positivo del ACP2 se agruparon sitios de cauces más anchos, con alta contribución de la fracción otros y altos valores de conductividad, mientras que hacia los valores negativos se agruparon los sitios que tuvieron alto contenido de oxígeno disuelto y valores máximos de nitratos y nitritos (Figura 46). 


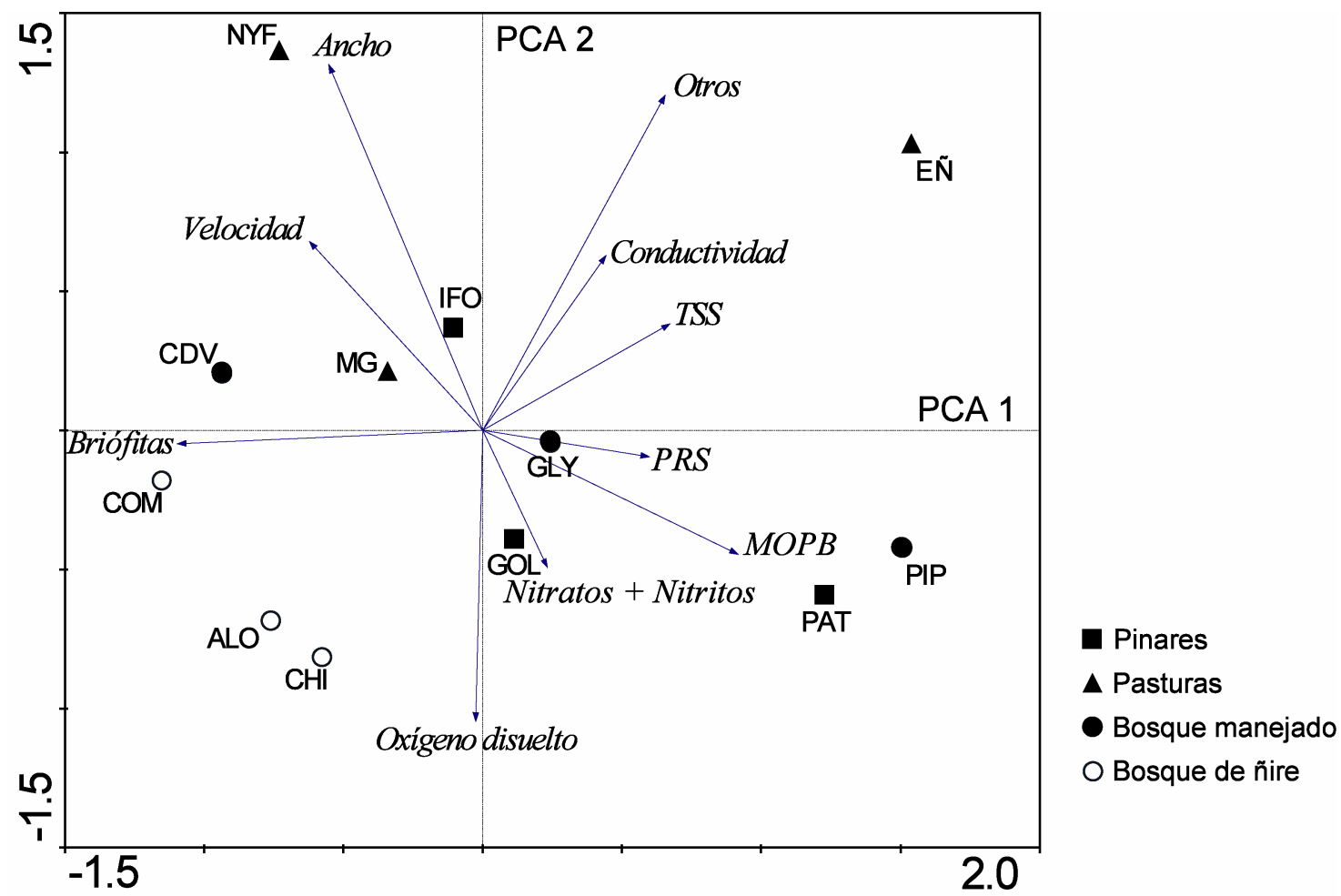

Figura 46. Representación de los dos primeros ejes del Análisis de Componentes Principales (ACP), mostrando la distribución de los sitios de estudio en relación a las principales variables ambientales, durante el período de estudio (mayo 2005-marzo 2006), en el noroeste de la provincia de Chubut, Patagonia, Argentina. Los códigos de los sitios se consignan en la Tabla 1 y los símbolos que identifican los usos se detallan en la figura. TSS: total de sólidos en suspensión; PRS: fósforo reactivo soluble; MOPB: materia orgánica particulada béntica.

De acuerdo a estas características ambientales se reconocieron dos grupos principales de sitios. Los tres sitios testigo de bosque de ñire sin manejar (ALO, COM, $\mathrm{CHI}$ ) fueron agrupados juntos en el cuadrante inferior izquierdo esto puso de manifiesto cierta certidumbre en la selección de los sitios de referencia. Por otra parte en el cuadrante inferior derecho se agruparon los sitios GLY, PIP (bosque manejado) y PAT y GOL (pinares) que presentaron los mayores valores de nitratos + nitritos y fósforo reactivo soluble, y gran cantidad de materia orgánica particulada béntica. En contraposición los sitios NYF, MG (pasturas), CDV (bosque manejado) e IFO (pinar), que presentaron condiciones de alta velocidad y menor retención de materia orgánica se ubicaron hacia el lado positivo del ACP2 (Figura 46).

\subsubsection{Vegetación acuática}

Se registraron un total de 17 especies de plantas acuáticas (Tabla 11), siendo pasturas el uso que exhibió mayor cantidad de especies, por el contrario en los sitios ubicados en 
pinares no se colectó ninguna especie. Las briófitas estuvieron presentes en los usos bosque manejado y bosque nativo. En general las especies sumergidas y emergentes estuvieron presentes en los sitios pasturas, bosque manejado y bosque nativo. En los sitios localizados en bosque nativo no hubo presencia de especies subemergentes. Las juncáceas Juncus arcticus así como $V$. anagallis-aquatica (berro de agua) y $V$. serpyllifolia tuvieron una buena representación, tanto en los sitios de pasturas como en los de bosque manejado.

Tabla 11. Lista de especies de plantas acuáticas sumergidas, subemergentes y emergentes registradas en los doce sitios de estudio de acuerdo a cada uno de los tipo de uso de la tierra, en el noroeste de la provincia de Chubut, Cordillera Patagónica (Argentina). Mes de diciembre.

\begin{tabular}{llll}
\hline Pinares & Pasturas & Bosque manejado & Bosque nativo \\
\hline $\mathrm{nr}$ & Sumergidas & Sumergidas & Sumergidas \\
& Cladophora sp. & Briofitas & Briofitas \\
Callitriche lechleri & C. lechleri & Ranunculus sp. \\
Ranunculus flagelliformis & R. hydrophilus & \\
Lilaeopsis macloviana & & Emergentes \\
& Subemergentes & J. arcticus \\
Subemergentes & M. glabratus & \\
Mimulus glabratus & & \\
Limosella australis & Emergentes & \\
& V. serpyllifolia & \\
Emergentes & V. anagallis-aquatica & \\
Veronica anagallis- & E. pseudoalbibracteata & \\
aquatica & & \\
V. serpyllifolia & & \\
Juncus arcticus & & \\
J. burkartii & & \\
J. diemii & & \\
J. microcephalus & & \\
Eleocharis albibracteata & & \\
E. melanostachys & & \\
& & \\
& &
\end{tabular}

\subsubsection{Caracterización del hábitat}

De acuerdo al QBRp, los sitios seleccionados para este estudio presentaron distintas calidades que variaron desde las categorías "alteración fuerte" hasta "estado natural", sin embargo ningún sitio se ubicó por su puntaje en la categoría "degradación extrema" (0-25 puntos). La calificación más baja se asignó a los sitios de pasturas, dos de ellos presentaron calidad intermedia (NyF y EN) y el tercero (MG), con mayor impacto correspondió a la categoría "alteración fuerte". Los arroyos en pinares presentaron una “calidad intermedia", al igual que los sitios CDV y PIP (bosque manejado). Estos sitios, 
en los que la puntuación fue baja, mostraron sus menores calificaciones en el apartado 3, referido a la calidad de la cubierta vegetal. Este resultado se debió a la falta de especies arbóreas autóctonas, e incluso a la presencia de especies exóticas tanto aisladas como formando comunidades. Este fue el caso de los sauces (Salix fragilis) en los sitios LN y CDV y de las coníferas exóticas en los sitios de pinares. Asimismo los tres sitios correspondientes al uso pastoril también presentaron una baja puntuación en el apartado 2, referido a la estructura de la cubierta. Por otra parte el sitio GLY y los tres sitios en bosque nativo sin impacto correspondieron a la categoría estado natural, con el máximo valor posible en el sitio ALO (Figura 47a). En estos casos la buena cobertura de especies arbóreas como también la presencia de un sotobosque bien desarrollado, y una buena representación de las especies nativas en ambos estratos (ñire, coihue, ciprés de la cordillera, laura, chaurilla y calafate) contribuyeron a determinar las calificaciones obtenidas para estos puntos de muestreo.

Con respecto al índice de calidad de hábitat (HA), tanto los sitios de bosque nativo como los pinares, presentaron una condición óptima. Mientras que las calificaciones más bajas fueron registradas para el sitio EÑ (pasturas) que presentó una calidad de hábitat marginal, dos de las pasturas (MG y NyF) y los tres sitios de bosque manejado, con condiciones de hábitat subóptimas (Figura 47b). Las bajas calificaciones obtenidas por los sitios de pasturas se debieron principalmente a una baja cobertura de sustrato disponible epifaunal (apartado 1), deficiente protección de ribera (apartado 9) y ausencia o escasa zona de amortiguación (apartado 10). En los sitios de pasturas la zona de protección de bosque de ribera no superó los 3 metros de ancho, con un alto grado de fragmentación. En cuanto al sustrato disponible epifaunal, los lechos de estos cursos de agua presentaron muy poca heterogeneidad, carentes de ramas o troncos y con bajo porcentaje de sustratos tipo bloques y guijones. Por el contrario en los sitios con puntajes altos, en el lecho se encontró una gran variedad de sustratos incluyendo briófitas y algas epilíticas, ramas y troncos que proporcionaron una mayor diversidad ambiental y oportunidad de colonización para la fauna béntica. En estos últimos sitios se detectó la totalidad de las combinaciones de flujo/profundidad. 

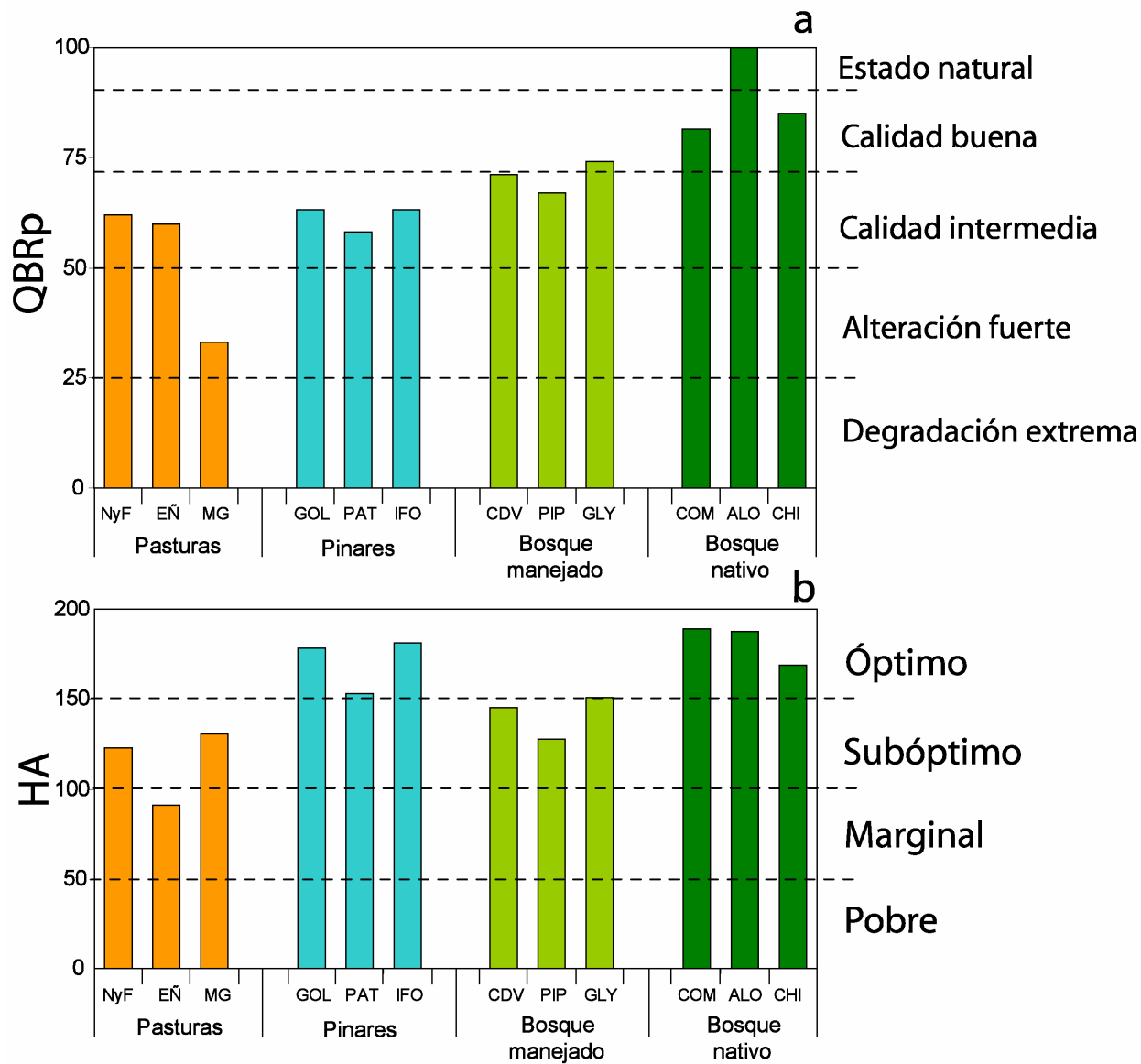

Figura 47: Valores totales del índice a) QBRp y b) HA, para los doce sitios de muestro agrupados según el tipo de uso de la tierra (pasturas, pinares, bosque manejado y bosque nativo) en el noroeste de la provincia del Chubut, Cordillera Patagónica (Argentina), datos de diciembre de 2006.

\subsubsection{Composición de la comunidad de tricópteros}

La comunidad de tricópteros estuvo representada por un total de 36 taxa, comprendidos en trece familias (Calamoceratidae, Ecnomidae, Glossosomatidae, Helicophidae, Hydrobiosidae, Hydropsychidae, Hydroptilidae, Leptoceridae, Limnephilidae, Philopotamidae, Philorheithridae, Polycentropodidae y Sericostomatidae) (Tabla 12). La familia mejor representada fue Hydrobiosidae con ocho taxa, correspondientes a seis géneros.

Siete de los taxa documentados tuvieron una aparición esporádica, cuatro de ellos Nectopsyche sp., O. bidentata, A. hirsutus y una especie no determinada de perteneciente a la familia Philorheithridae, fueron colectados en sólo dos sitios, y tres (Phylloicus sp., M. griseum, R. lobuliferum) presentaron sólo un registro y una densidad media anual inferior a los 4 ind. $\mathrm{m}^{-2}$. 
El sericostomátido, $P$. ovale fue la especie que presentó mayor densidad siendo la media de 2500 ind. $\mathrm{m}^{-2}$ en NyF (pastura), seguida de S. annulicornis (Hydropsychidae) con un valor de 995 ind. ${ }^{-2}$ en EN (pastura) y Brachysetodes sp. (Leptoceridae) con 416 ind. $\mathrm{m}^{-2}$ en PIP (bosque manejado). Un rasgo notorio fue que en los tres sitios de pastura (EÑ, MG, NyF) el colector-filtrador S. annulicornis, superó la media anual de 250 ind. $\mathrm{m}^{-2}$.

La especie $P$. cristatum se registró únicamente en sitios de bosque nativo, mientras que las dos especies representantes de la familia endémica Helicophidae ( $A$. valgiformis y E. aequispina) junto con M. neotropicalis (Hydroptilidae) se colectaron sólo en los usos de pinares y bosque nativo.

El menor valor de densidad promedio anual fue registrado para el pinar IFO (131 ind. $\mathrm{m}^{-2}$ ), mientras que el mayor se observó en el sitio NyF (pastura) (3305 ind. $\mathrm{m}^{-2}$ ), seguido de LÑ (1034 ind. $\mathrm{m}^{-2}$ ) siendo las especies responsables de estos valores $P$. ovale, S. annulicornis y S. frequens en el caso de NyF, S. annulicornis en EÑ (Tabla 12). Los menores valores de riqueza taxonómica se registraron en los sitios MG e IFO con 7 y 8 especies, respectivamente. Por otra parte, la mayor riqueza taxonómica fue observada en el sitio de bosque nativo $\mathrm{CHI}$, con 22 taxa pertenecientes al orden, comprendiendo el 61 $\%$ de las especies relevadas en todo el estudio.

Los valores de diversidad media anual de Shannon-Weaver, estuvieron comprendidos entre 0,32 (pasturas, EÑ) y 1,75 bits (pinares, GOL) y la equitatividad varió entre 0,31 y 0,8, para los sitios NyF (pasturas) y ALO (bosque de ñire), respectivamente. Los mayores valores absolutos de diversidad fueron registrados en el sitio GOL por ejemplo durante el mes de septiembre (1,93 bits), y en los meses de mayo y diciembre (1,73 y 1,76 bits respectivamente) (Tabla 12$)$. 
Tabla 12. Densidad media anual $(n=24) \pm$ desvío estándar de las 36 especies de Trichoptera y valores de densidad, riqueza taxonómica, diversidad Shannon-Weaver y equitatividad de Pielou en los 12 sitios de muestreo en el noroeste de la Cordillera Patagónica, durante el período de muestreo (mayo 2005 - marzo 2006).

\begin{tabular}{|c|c|c|c|c|c|c|c|c|c|c|c|c|}
\hline & \multicolumn{3}{|c|}{ Pasturas } & \multicolumn{3}{|c|}{ Pinares } & \multicolumn{3}{|c|}{ Bosque manejado } & \multicolumn{3}{|c|}{ Bosque nativo } \\
\hline & NyF & $\mathbf{E N}$ & MG & GOL & PAT & IFO & CDV & PIP & GLY & COM & ALO & $\mathrm{CHI}$ \\
\hline \multicolumn{13}{|l|}{ Calamoceratidae } \\
\hline Phylloicus sp. & 0 & 0 & 0 & $0,5 \pm 0,9$ & 0 & 0 & 0 & 0 & 0 & 0 & 0 & 0 \\
\hline \multicolumn{13}{|l|}{ Ecnomidae } \\
\hline Austrotinodes sp. & 0 & 0 & 0 & $3,7 \pm 5,2$ & $4,2 \pm 4,9$ & 0 & 0 & 0 & 0 & 0 & 0 & 0 \\
\hline \multicolumn{13}{|l|}{ Glossosomatidae } \\
\hline Mastigoptila sp. & 0 & 0 & $45,3 \pm 60,7$ & 0 & $0,9 \pm 1,8$ & 0 & 0 & 0 & 0 & $207,66 \pm 190,7$ & $76,78 \pm 111,7$ & $63,4 \pm 80,6$ \\
\hline M. longicornuta & $11,1 \pm 15,3$ & 0 & $1,4 \pm 1,8$ & 0 & 0 & 0 & 0 & $32,4 \pm 57,5$ & 0 & 0 & 0 & $5,09 \pm 10,1$ \\
\hline \multicolumn{13}{|l|}{ Helicophidae } \\
\hline Austrocentrus valgiformis & 0 & 0 & 0 & $69,8 \pm 72,3$ & 0 & $1,4 \pm 2,8$ & 0 & 0 & 0 & $8,33 \pm 16,6$ & $15,73 \pm 2,4$ & $7,86 \pm 6,1$ \\
\hline Eosericostoma aequispina & 0 & 0 & 0 & $0,9 \pm 1,8$ & $23,1 \pm 28,4$ & 0 & 0 & 0 & 0 & 0 & 0 & $11,1 \pm 11,2$ \\
\hline \multicolumn{13}{|l|}{ Hydrobiosidae } \\
\hline Atopsyche sp. & 0 & 0 & 0 & 0 & 0 & 0 & $0,46 \pm 0,9$ & 0 & 0 & 0 & 0 & $0,93 \pm 1,8$ \\
\hline Cailloma pumida & $5,1 \pm 9$ & $0,5 \pm 0,9$ & $6 \pm 5,1$ & 0 & 0 & 0 & $1,85 \pm 2,6$ & 0 & $19,9 \pm 24,5$ & 0 & 0 & $1,85 \pm 1,5$ \\
\hline Metachorema griseum & $3,2 \pm 6,5$ & 0 & 0 & 0 & 0 & 0 & 0 & 0 & 0 & 0 & 0 & 0 \\
\hline Neoatopsyche brevispina & $31 \pm 31,3$ & $8,3 \pm 12,2$ & 0 & $14,3 \pm 9,2$ & 0 & $0,9 \pm 1,8$ & $28,21 \pm 32,6$ & $2,31 \pm 4,63$ & $3,24 \pm 6,5$ & $3,24 \pm 3,8$ & 0 & $12 \pm 21,6$ \\
\hline Neoatopsyche unispina & $11,1 \pm 7,8$ & $1,4 \pm 2,9$ & 0 & $5,5 \pm 10$ & 0 & 0 & $20,81 \pm 33,1$ & $1,39 \pm 1,7$ & $72,6 \pm 78,7$ & 0 & 0 & 0 \\
\hline $\begin{array}{l}\text { Neopsilochorema } \\
\text { tricarinatum }\end{array}$ & $4,2 \pm 2,8$ & $4,6 \pm 7$ & 0 & $2,8 \pm 2,4$ & $0,9 \pm 1,8$ & 0 & $18,5 \pm 17,6$ & $25,44 \pm 15,6$ & $6,48 \pm 10,5$ & 0 & $12,95 \pm 14,4$ & $5,09 \pm 6,4$ \\
\hline Reochorema lobuliferum & 0 & 0 & 0 & 0 & 0 & 0 & $0,46 \pm 0,9$ & 0 & 0 & 0 & 0 & 0 \\
\hline Reochorema tenuispinum & 0 & $1,8 \pm 3,7$ & 0 & $7,4 \pm 12,5$ & 0 & 0 & 0 & $22,6 \pm 23,3$ & $14,8 \pm 27,2$ & $0,46 \pm 0,9$ & $6,01 \pm 7,3$ & $9,25 \pm 8,1$ \\
\hline
\end{tabular}


Tabla 12. Continuación.

\begin{tabular}{|c|c|c|c|c|c|c|c|c|c|c|c|c|}
\hline & \multicolumn{3}{|c|}{ Pasturas } & \multicolumn{3}{|c|}{ Pinares } & \multicolumn{3}{|c|}{ Bosque manejado } & \multicolumn{3}{|c|}{ Bosque de Nire } \\
\hline & NyF & $\mathbf{E N}$ & MG & GOL & PAT & IFO & CDV & PIP & GLY & COM & ALO & CHI \\
\hline \multicolumn{13}{|l|}{ Hydropsychidae } \\
\hline Smicridea sp. 2 & 0 & 0 & $1,8 \pm 3,7$ & $47,2 \pm 94,3$ & $164,2 \pm 82,2$ & 0 & 0 & 0 & 0 & $95,28 \pm 79,6$ & $53,19 \pm 55,2$ & 0 \\
\hline Smicridea annulicornis & $438,9 \pm 450$ & $995,7 \pm 1225,7$ & $275,6 \pm 271,3$ & 0 & 0 & $0,5 \pm 0,9$ & $189,63 \pm 222,7$ & $0,46 \pm 0,9$ & $190,5 \pm 215,6$ & 0 & 0 & $6,48 \pm 12,9$ \\
\hline Smicridea dithyra & 0 & 0 & 0 & $6,5 \pm 13$ & $6,9 \pm 13,9$ & 0 & 0 & 0 & 0 & $1,39 \pm 2,7$ & 0 & 0 \\
\hline Smicridea frequens & $172 \pm 243,1$ & 0 & 0 & $10,2 \pm 16,9$ & $51,8 \pm 103,6$ & 0 & $9,25 \pm 18,5$ & 0 & $3,7 \pm 6,2$ & 0 & $4,63 \pm 5,3$ & 0 \\
\hline \multicolumn{13}{|l|}{ Hydroptilidae } \\
\hline Metrichia neotropicalis & 0 & 0 & 0 & 0 & 0 & $2,8 \pm 3,2$ & 0 & 0 & 0 & $10,64 \pm 15,7$ & $1,39 \pm 2,8$ & $37,93 \pm 69,8$ \\
\hline Metrichia patagonica & 0 & 0 & 0 & $17,1 \pm 34,2$ & 0 & 0 & $1,39 \pm 1,8$ & 0 & 0 & $2,78 \pm 5,5$ & 0 & $19,89 \pm 39,8$ \\
\hline Oxyethira bidentata & $1,8 \pm 3,7$ & 0 & 0 & 0 & 0 & 0 & 0 & 0 & $0,46 \pm 0,9$ & 0 & 0 & 0 \\
\hline \multicolumn{13}{|l|}{ Leptoceridae } \\
\hline Brachysetodes sp. & 0 & $1,4 \pm 1,7$ & $34,2 \pm 29,8$ & $88,8 \pm 140$ & $60,6 \pm 98$ & $106,4 \pm 124,7$ & 0 & $416,71 \pm 630$ & $145,7 \pm 136,5$ & $12,03 \pm 11,9$ & $33,3 \pm 55,9$ & 0 \\
\hline Brachysetodes quadrifidus & $96,6 \pm 121,6$ & 0 & 0 & 0 & 0 & 0 & $190,5 \pm 247,9$ & 0 & 0 & 0 & 0 & $335 \pm 230$ \\
\hline Hudsonema flaminii & $18 \pm 24,8$ & $1,4 \pm 2,8$ & 0 & $2,3 \pm 4,6$ & 0 & 0 & $49,03 \pm 39,2$ & 0 & $1,85 \pm 2,14$ & 0 & 0 & $6,94 \pm 13,8$ \\
\hline Nectopsyche sp. & 0 & $0,9 \pm 1,8$ & 0 & 0 & $0,9 \pm 1,8$ & 0 & 0 & 0 & 0 & 0 & 0 & 0,00 \\
\hline Triplectides sp. & 0 & 0 & 0 & 0 & $7,4 \pm 12,5$ & 0 & $1,85 \pm 1,5$ & 0 & 0 & 0 & 0 & $2,78 \pm 4,40$ \\
\hline \multicolumn{13}{|l|}{ Limnephilidae } \\
\hline Austrocosmoecus hirsutus & 0 & 0 & 0 & 0 & 0 & 0 & 0 & 0 & 0 & 0 & $0,93 \pm 1,8$ & $0,93 \pm 1,85$ \\
\hline Monocosmoecus sp. & 0 & 0 & 0 & 0 & 0 & 0 & 0 & 0 & $0,46 \pm 0,9$ & 0 & $0,46 \pm 0,9$ & $1,85 \pm 3,70$ \\
\hline Verger sp. & $3,2 \pm 5,3$ & 0 & 0 & 0 & 0 & $0,5 \pm 0,9$ & $0,46 \pm 0,9$ & $0,46 \pm 0,93$ & 0 & 0 & $0,46 \pm 0,9$ & $1,39 \pm 2,78$ \\
\hline \multicolumn{13}{|l|}{ Philopotamidae } \\
\hline Sortosa sp. & 0 & 0 & 0 & $4,2 \pm 8,3$ & $40,2 \pm 66,5$ & 0 & 0 & 0 & 0 & 0 & $0,46 \pm 0,9$ & 0 \\
\hline
\end{tabular}


Tabla 12. Continuación.

\begin{tabular}{|c|c|c|c|c|c|c|c|c|c|c|c|c|}
\hline & \multicolumn{3}{|c|}{ Pasturas } & \multicolumn{3}{|c|}{ Pinares } & \multicolumn{3}{|c|}{ Bosque manejado } & \multicolumn{3}{|c|}{ Bosque de Nire } \\
\hline & NyF & $\mathbf{E N}$ & MG & GOL & PAT & IFO & CDV & PIP & GLY & COM & ALO & CHI \\
\hline \multicolumn{13}{|l|}{ Philorheithridae } \\
\hline Philorheithridae sp. & 0 & 0 & 0 & $3,7 \pm 5,2$ & 0 & $0,9 \pm 1,8$ & 0 & 0 & 0 & 0 & 0 & 0 \\
\hline Psilopsyche molinai & 0 & $16,6 \pm 18,5$ & 0 & 0 & 0 & 0 & 0 & 0 & $1,85 \pm 2,6$ & 0 & 0 & $1,85 \pm 2,62$ \\
\hline \multicolumn{13}{|l|}{ Policentropodidae } \\
\hline Polycentropus sp. & 0 & 0 & 0 & $34,4 \pm 57,2$ & $1,8 \pm 2,6$ & 0 & $0,46 \pm 0,9$ & $84,64 \pm 81,1$ & $9,7 \pm 15,9$ & 0 & 0 & $2,78 \pm 3,54$ \\
\hline \multicolumn{13}{|l|}{ Sericostomatidae } \\
\hline Myotrichia murina & 0 & 0 & $5,5 \pm 6,4$ & $59,7 \pm 50,1$ & $289,5 \pm 145,3$ & 0 & 0 & $160,95 \pm 219$ & $0,93 \pm 1,1$ & $0,46 \pm 0,9$ & 0 & $383 \pm 113$ \\
\hline Parasericostoma cristatum & 0 & 0 & 0 & 0 & 0 & 0 & 0 & 0 & 0 & $2,31 \pm 4,6$ & $64,29 \pm 47,2$ & $1,39 \pm 1,77$ \\
\hline Parasericostoma ovale & $2509 \pm 977,27$ & $1,4 \pm 2,8$ & 0 & 0 & 0 & $18 \pm 27,6$ & $6,94 \pm 7,7$ & 0 & 0 & 0,00 & 0 & 0,00 \\
\hline Densidad & $3305 \pm 1396$ & $1034 \pm 1264$ & $370 \pm 247$ & $379 \pm 302$ & $652 \pm 263$ & $131 \pm 153$ & $519 \pm 270$ & $747 \pm 1006$ & $472 \pm 355$ & $344 \pm 213$ & $270 \pm 251$ & $919 \pm 364$ \\
\hline Riqueza & 13 & 11 & 7 & 18 & 13 & 8 & 15 & 10 & 14 & 11 & 13 & 22 \\
\hline Diversidad ( $\left.\mathbf{H}^{\prime}\right)$ & $0,71 \pm 0,33$ & $0,32 \pm 0,23$ & $0,86 \pm 0,5$ & $1,75 \pm 0,14$ & $1,19 \pm 0,32$ & $0,56 \pm 0,03$ & $1,17 \pm 0,35$ & $1,4 \pm 0,17$ & $1,07 \pm 0,48$ & $1,02 \pm 0,28$ & $1,55 \pm 0,15$ & $1,31 \pm 0,22$ \\
\hline Equitatividad & $0,31 \pm 0,15$ & $0,37 \pm 0,41$ & $0,51 \pm 0,27$ & $0,76 \pm 0,05$ & $0,6 \pm 0,11$ & $0,53 \pm 0,2$ & $0,53 \pm 0,14$ & $0,72 \pm 0,09$ & $0,58 \pm 0,27$ & $0,62 \pm 0,22$ & $0,8 \pm 0,08$ & $0,52 \pm 0,08$ \\
\hline
\end{tabular}


En relación al comportamiento de los distintos descriptores de la comunidad de tricópteros por uso de la tierra se observó que la densidad en sitios de pasturas fue mayor que la registrada en los demás usos (Figura 48a). Sin embargo esta diferencia fue significativa sólo entre pasturas y pinares (Mann Whitney U-test, p<0,05). De la misma manera los valores diversidad Shannon-Weaver, tanto como de Equitatividad, fueron significativamente menores en los sitios de pasturas con respecto a los restantes tres usos (Figura 48 c y d). Si bien se observó un gradiente de disminución de la riqueza en función del aumento en intensidad del uso de la tierra, esto es la riqueza en pasturas fue menor que la observada en pinares, y la de ambas menor que la de bosque manejado las diferencias no fueron significativas (Mann-Whitney U-test, $\mathrm{p}<0,05$ ) (Figura 48b).
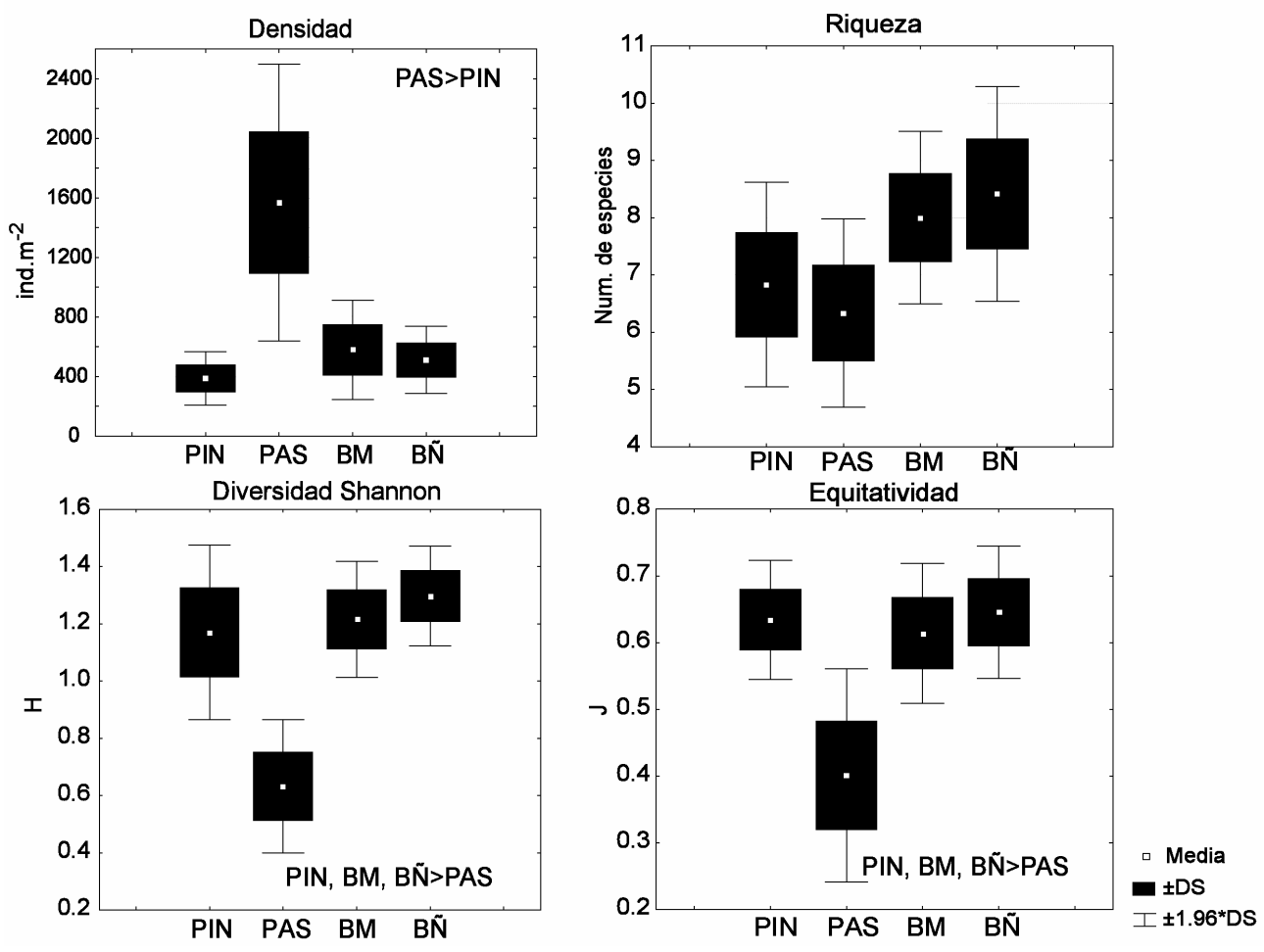

Figura 48. a. Densidad (ind. $\mathrm{m}^{-2}$ ), b. riqueza taxonómica media, c. Diversidad Shannon-Weaver y d. equitatividad de Pielou, para los 12 sitios de muestreo en el noroeste de la provincia del Chubut, Cordillera Patagónica (Argentina), valores medios de cuatro meses del año, durante el período de muestreo (mayo 2005 - marzo 2006). DS: desvío estándar. Las diferencias significativas se indican en cada figura (Mann-Whitney U-test, $\mathrm{p}<0,05$ ).

\subsubsection{Estructura funcional de la comunidad de tricópteros}

De la totalidad de la comunidad de tricópteros encontrada en los sitios sometidos a usos silvopastoriles (Tabla 12), 10 especies pertenecieron al grupo funcional desmenuzador, 
9 de ellas fueron predadoras, 6 raspadoras, 5 colectoras-filtradoras, 1 perforadora de algas y 1 colectora-recolectora.

En los sitios localizados en pinares, los desmenuzadores contribuyeron con una proporción relativa de 45 a $95 \%$ del total de la comunidad, mayormente M. murina y Brachysetodes sp. Por otra parte en los sitios localizados en pasturas, los grupos funcionales dominantes fueron colectores-filtradores, de las especies $S$. frequens y $S$. annulicornis, en el caso de MG y EÑ (73 y $96 \%$, respectivamente), mientras que en NyF, la comunidad estuvo dominada por desmenuzadores $(82 \%)$, donde $P$. ovale (Sericostomatidae) fue la especie con mayor densidad (promedio anual superior a 2500 ind. $\mathrm{m}^{-2}$ ) (Figura 49).

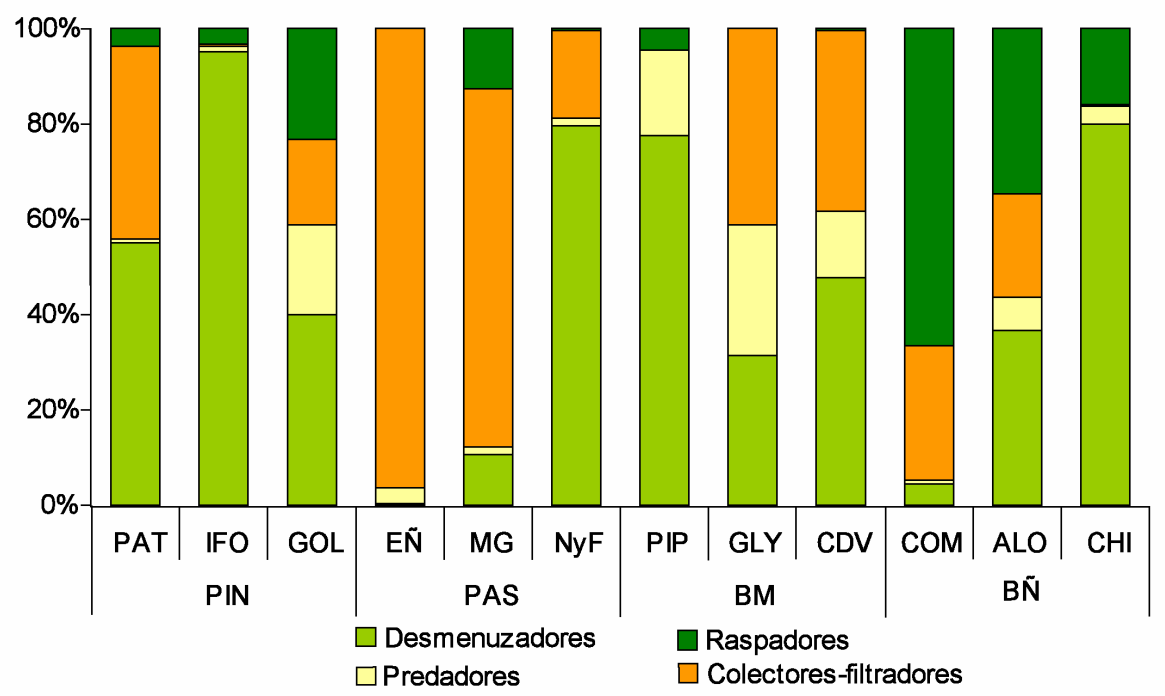

Figura 49. Estructura trófica de los 12 sitios de muestreo, en el noroeste de la provincia del Chubut, Cordillera Patagónica (Argentina), valores medios de cuatro meses del año, durante el período de muestreo (mayo 2005-marzo 2006). Datos correspondientes a densidad de tricópteros.

En los sitios de bosque manejado, los desmenuzadores dominaron (PIP) o codominaron junto con colectores-filtradores (GLY y CDV), sin embargo en los tres sitios los predadores conformaron una importante fracción de la comunidad de tricópteros en relación al resto de los usos representando entre 13,6 y 27,2 \% de la comunidad total de Tricópteros. Estos altos porcentajes se atribuyen fundamentalmente a especies de la familia Hydrobiosidae en los sitios GLY y CDV, siendo las más importantes en densidad las del género Neoatopsyche, $N$. unispina en el primer caso y $N$. brevispina en el segundo. Mientras que en el sitio PIP, se encontró que la especie 
predadora dominante fue Polycentropus sp., que apareció junto con otros hidrobiósidos (Figura 49).

Con respecto a los arroyos de referencia, el grupo funcional dominante fue el de los raspadores en COM, mientras que los desmenuzadores predominaron en ALO y $\mathrm{CHI}$, con 36,7 y $80 \%$, respectivamente, que se deben principalmente a $P$. cristatum en el caso de ALO y B. quadrifidus y M. murina en el CHI. Sin embargo, tanto en ALO como en CHI, también se registró una importante contribución de raspadores (13 y 32 $\%$, respectivamente). Las especies raspadoras Mastigoptila sp. (Glossosomatidae), A. valgiformis (Helicophidae) y M. neotropicalis (Hydroptilidae) fueron las de mayor importancia en estos sitios, sin embargo la primera fue la más importante en términos de densidad (Figura 49).
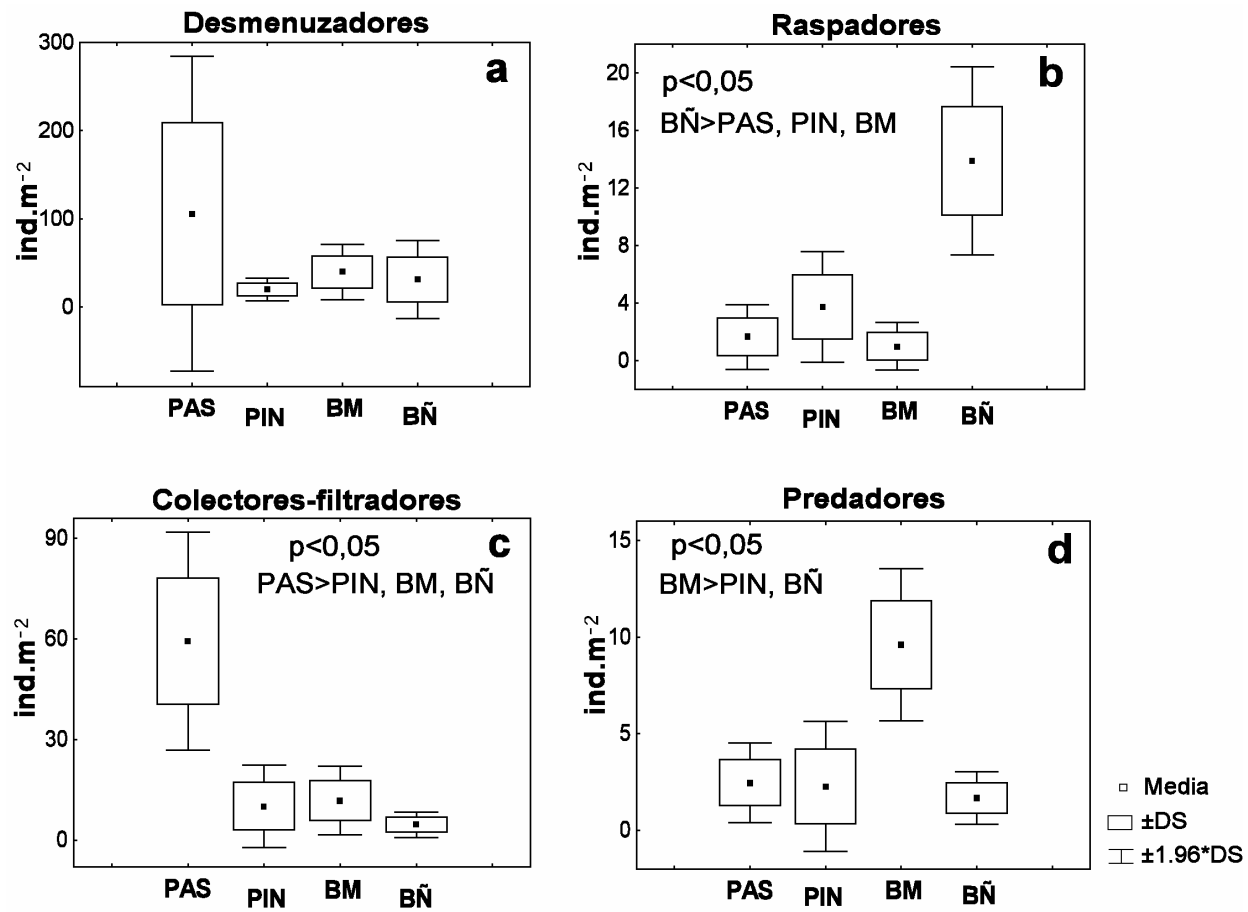

Figura 50. Densidad (ind. $\mathrm{m}^{-2}$ ) de los cuatro grupos funcionales dominantes distribuidos en los cuatro usos de la tierra, a lo largo del período de estudio (mayo 2005 - marzo 2006). Las diferencias significativas en los valores entre cada tipo de uso se indican en los gráficos (MannWhitney U-test, p<0,05) DS: desvío estándar.

En relación a la distribución de los grupos funcionales, no se registraron diferencias significativas en la densidad de especies desmenuzadoras según el uso de la tierra (Figura 50a). Sin embargo en los grupos raspadores, colectores-filtradores y predadores si se detectaron diferencias significativas. Los raspadores presentaron una mayor densidad en bosque de ñire con respecto a los restantes usos (Mann-Whitney U- 
test $\mathrm{p}<0,05)$ (Figura 50b). La densidad media de colectores-filtradores fue significativamente mayor en pasturas que en pinares, bosque manejado y bosque de ñire (Mann-Whitney U-test $\mathrm{p}<0,05$ ) (Figura 50c), mientras que los predadores presentaron su mayor densidad en sitios de bosque manejado, en comparación con los usos pinares y bosque de ñire (Mann-Whitney U-test p<0,05) (Figura 50d).

\subsubsection{Relaciones estacionales especie-ambiente}

Los dos primeros ejes del ordenamiento realizado mediante el Análisis de Correspondencias Canónicas (CCA) explicaron 42,2 \% de la varianza de la relación especies-ambiente. Los valores de correlación especie ambiente fueron de 0,88 para el primer eje y 0,96 para el segundo. De acuerdo al test de Montecarlo el ordenamiento obtenido tanto para el primer eje como para los cuatro ejes en su conjunto fue significativo ( $\mathrm{p}<0,001$, Tabla 13).

El ordenamiento de los sitios y las variables ambientales, dado por los dos primeros ejes se presenta en la Figura 51. Las variables ambientales utilizadas para producir el CCA se presentan en la tabla 13. Las variables que se correlacionaron con el primer eje fueron: temperatura del agua, $\mathrm{pH}$, conductividad, oxígeno disuelto y la presencia de algas filamentosas. Por otra parte las variables que se correlacionaron con el segundo eje fueron: velocidad, descarga, altitud, porcentaje de arena y nitratos.

Los sitios y momentos estacionales con menores valores de temperatura del agua, proporción de arena, conductividad, total de sólidos en suspensión, y altos valores de oxígeno disuelto y presencia de briófitas, se ubicaron en el cuadrante superior izquierdo. Este grupo comprendió a todos los sitios de bosque de ñire de referencia con excepción del sitio CHI con los muestreos de septiembre y marzo ligeramente desplazados hacia el cuadrante izquierdo inferior. Asimismo el sitio MG (pasturas) y el sitio IFO (meses de mayo, diciembre y marzo) quedaron localizados en el mismo cuadrante.

Los sitios ubicados a mayor altura, con mayores valores de velocidad, caudal y $\mathrm{pH}$, y caracterizados por briófitas, algas mucilaginosas y algas filamentosas se ordenaron en el cuadrante superior derecho. En el mismo se agruparon los sitios NyF, CDV, el sitio IFO (muestreo de septiembre), y los sitios EN y GLY (muestreo de diciembre).

El gradiente de uso de la tierra quedó claramente definido por el CCA2 esto es, hacia el extremo negativo del CCA 2 se agruparon los sitios de pinar PAT y GOL, los 
sitios de bosque manejado PIP y GLY (este último exceptuando el muestreo de diciembre) asociados a altos valores de nitratos, materia orgánica particulada béntica, porcentaje de arena y fósforo reactivo soluble.

Tabla 13. Autovalores del análisis de correspondencias canónicas (CCA), test de Montecarlo y significación. Análisis realizado entre las comunidades de tricópteros y las variables ambientales de los doce ríos del noroeste de la provincia del Chubut, Cordillera Patagónica (Argentina) sometidos a distintos tipos de uso (pasturas, pinares, bosque manejado y bosque nativo), durante el período de muestreo (mayo 2005-marzo 2006). Los valores en negrita destacan las correlaciones significativas con el eje.

\begin{tabular}{lcc}
\hline & CCA1 & CCA2 \\
\hline Autovalores & 0.397 & 0.278 \\
Correlaciones especie-ambiente & 0.88 & 0.96 \\
Porcentaje acumulado de la varianza de la relación & 24.8 & 42.2 \\
especies-ambiente & & \\
\hline Correlación con los ejes: & & \\
\hline Nitratos & 0.27 & $\mathbf{- 0 . 3 8}$ \\
Fósforo reactivo soluble & -0.03 & -0.21 \\
Temperatura del agua & $\mathbf{0 . 6 0}$ & $\mathbf{- 0 . 4 5}$ \\
Velocidad & 0.29 & $\mathbf{0 . 6 3}$ \\
Caudal & $\mathbf{0 . 6 0}$ & $\mathbf{0 . 6 5}$ \\
Conductividad & $\mathbf{0 . 4 5}$ & -0.32 \\
Oxígeno disuelto & $\mathbf{- 0 . 4 8}$ & 0.07 \\
Total de sólidos suspendidos & 0.22 & -0.10 \\
pH & $\mathbf{0 . 4 1}$ & 0.12 \\
Altitud & 0.14 & $\mathbf{0 . 5 4}$ \\
Porcentaje de arena & 0.17 & $\mathbf{- 0 . 8 8}$ \\
Algas filamentosas & $\mathbf{0 . 5 2}$ & 0.04 \\
Algas mucilaginosas & 0.17 & 0.34 \\
Briófitas & 0.09 & $\mathbf{0 . 6 9}$ \\
Materia orgánica particulada béntica & $\mathbf{- 0 . 3 9}$ & $\mathbf{- 0 . 4 6}$ \\
\hline Test de Montecarlo & & \\
Para el primer eje: F = 4.328, p<0.001 & & \\
Para todos los ejes: F $=1.968, \mathrm{p}<0.001$ & \\
\hline & & \\
\hline
\end{tabular}


En el lado derecho del cuadrante inferior se localizó el sitio EÑ (uso pastura), con excepción del muestreo de diciembre. Este sitio mostró altos valores de conductividad, mayor porcentaje de arena en su lecho, mayores valores de temperatura, y total de sólidos en suspensión pero además menores valores de oxígeno disuelto. Similarmente el sitio GLY (uso bosque manejado) en dos momentos de muestreo (septiembre y marzo) quedó ubicado en el cuadrante inferior derecho.

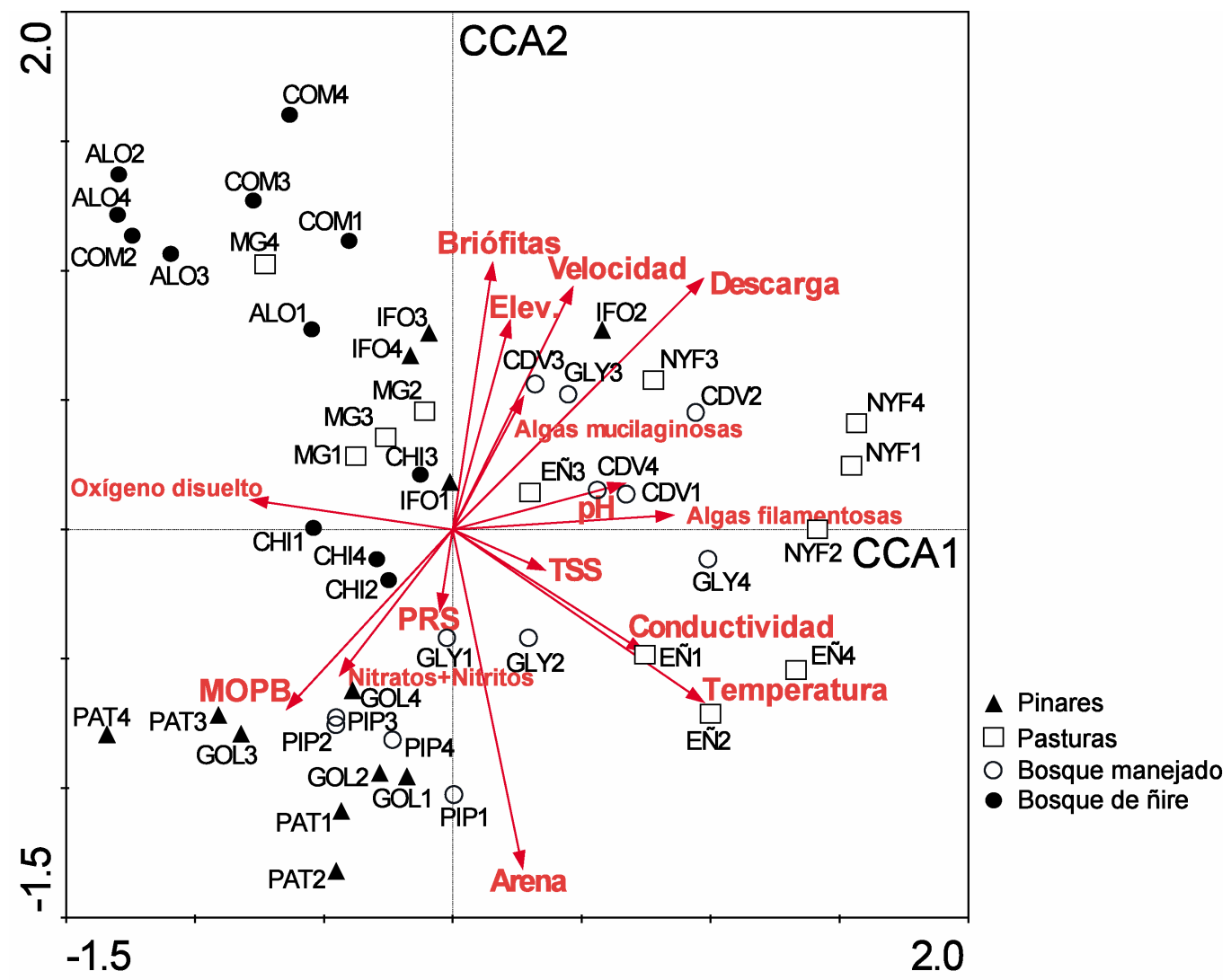

Figura 51. Ordenamiento según el Análisis de Correspondencias Canónicas de los 12 sitios de estudio en sus cuatro períodos de muestreo en el noroeste de la provincia del Chubut, Cordillera Patagónica, y las variables ambientales. TSS: total de sólidos en suspensión; PRS: fósforo reactivo soluble; MOPB: materia orgánica particulada béntica; Elev.: elevación. Los códigos de los sitios se encuentran en la Tabla 1, y los números junto al código de cada sitio corresponden a 1: mayo 2005; 2: septiembre 2005; 3: diciembre 2005 y 4: marzo 2006. Los símbolos que identifican los usos se detallan en la figura.

En la figura 52 se representan las especies en el hiperespacio definido por las variables ambientales, el diagrama presenta las asociaciones de especies que caracterizaron los distintos tipos de usos. En el cuadrante superior izquierdo se ubicaron las especies P. cristatum, Mastigoptila sp., M. neotropicalis, A. hirsutus, Smicridea sp. 2, A. valgiformis y Monocosmoecus sp., que caracterizaron los sitios de bosque nativo de referencia, bien oxigenados y con menores temperaturas. Por otra 
parte el grupo de especies determinado por $P$. ovale, $M$. griseum, $O$. bidentata, $H$. flaminii, B. quadrifidus, R. lobuliferum, S. annulicornis, C. pumida y Verger sp., dominaron los sitios pastoreados ( $\mathrm{NyF}$ y $\mathrm{CDV}$, principalmente), que a su vez presentaron mayores valores de caudal y velocidad de la corriente, y presencia de diversos tipos de algas mucilaginosas y filamentosas.

Otro de los ensambles estuvo conformado por R. tenuispina, Philorheithridae sp., Triplectides sp., M. murina, E. aequispina, S. dithyra, Nectopsyche sp., Sortosa sp., Polycentropus sp., Austrotinodes sp. y Phylloicus sp., que aumentaron en densidad en los sitios de menor caudal y velocidad, y un alto contenido de materia orgánica particulada béntica como por ejemplo los sitios de pinares PAT y GOL y el sitio de bosque manejado PIP.

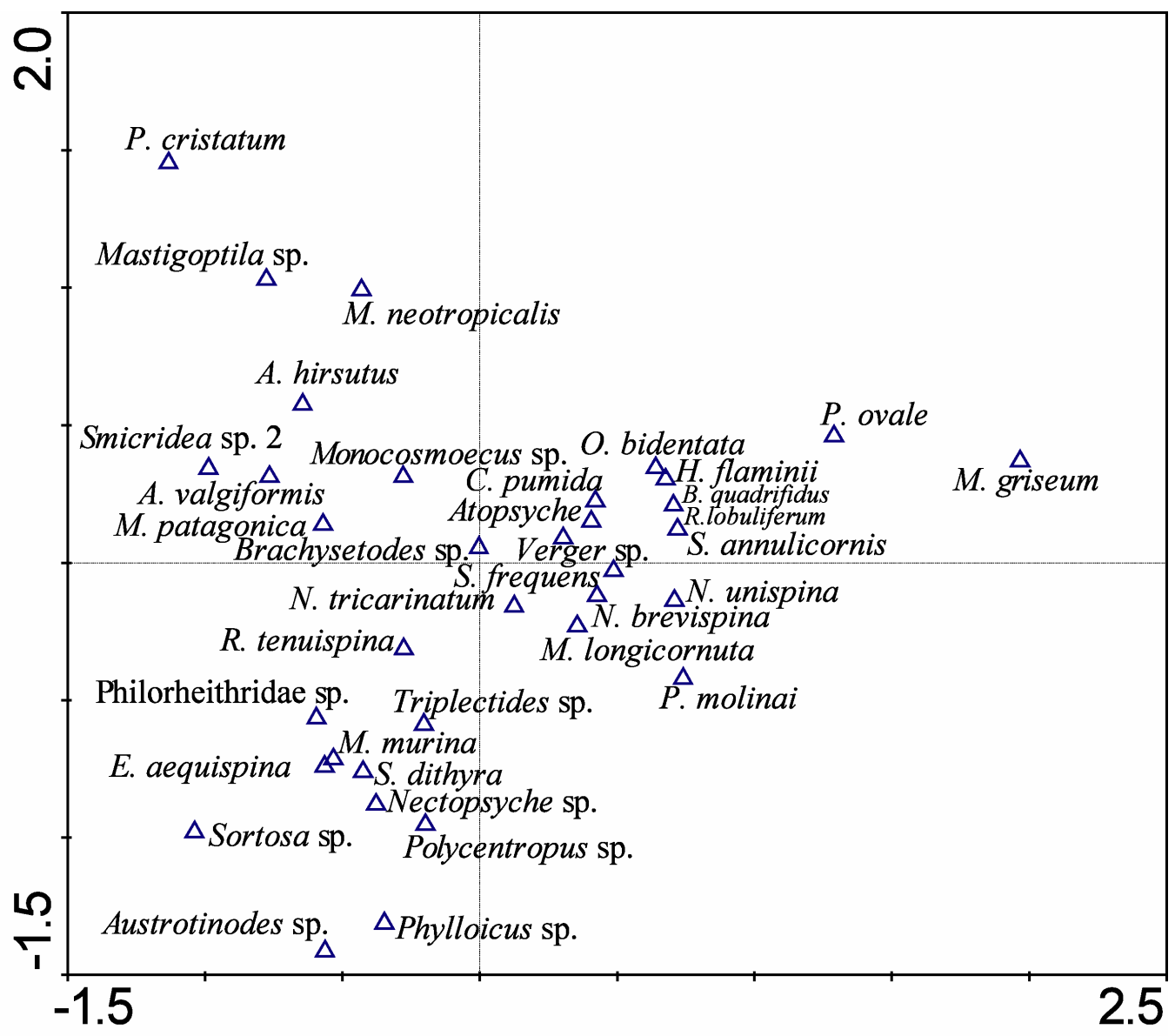

Figura 52. Ordenamiento de las especies de Trichoptera colectadas en los 12 sitios de la Cordillera Patagónica (noroeste de Chubut, Argentina), según el Análisis de Correspondencias Canónicas. 


\subsubsection{Atributos de la comunidad de tricópteros a escala de hábitat}

El análisis realizado a escala de mesohabitat permitió evidenciar una disminución tanto en densidad como en riqueza específica de tricópteros en los pozones con respecto a la encontrada en los rápidos (Figura 53). Sin embargo estas diferencias sólo fueron significativas para la densidad en los sitios sometidos al uso bosque manejado. Es decir los rápidos sostuvieron mayor densidad de tricópteros respecto a pozones en los sitios bosque manejado (Mann-Whitney U-test, $p<0.049$ ).
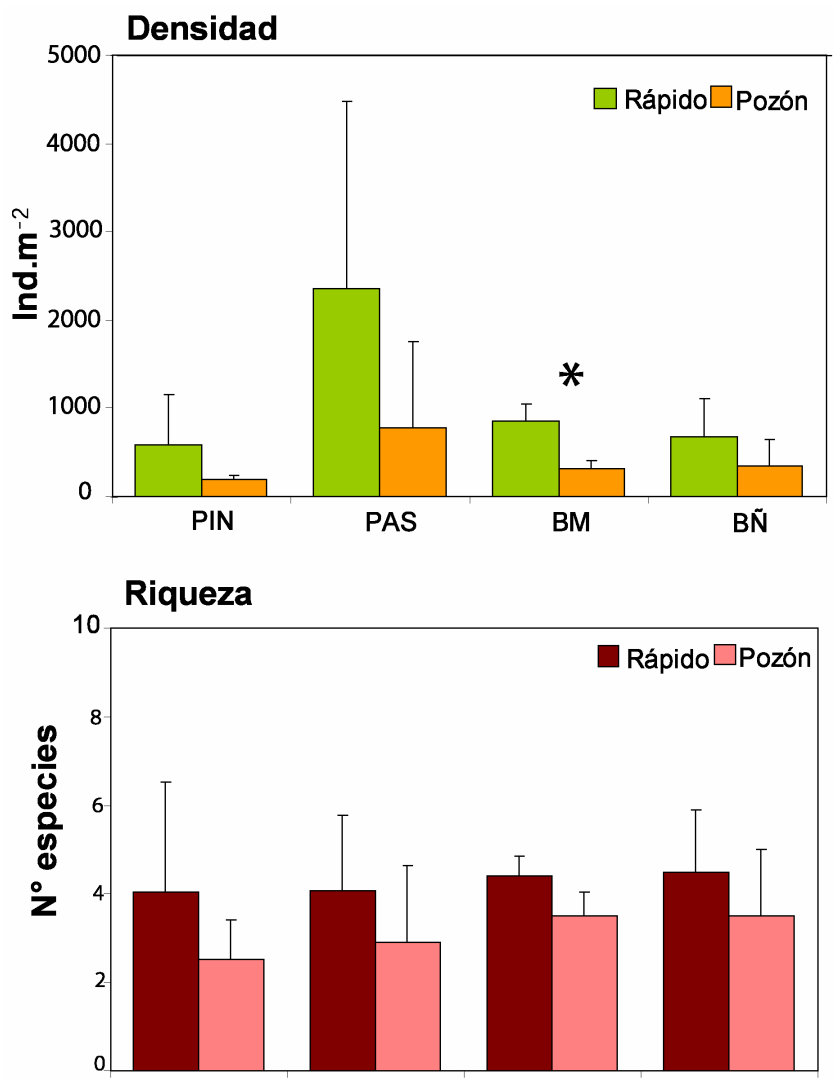

Figura 53. Densidad (ind. $\mathrm{m}^{-2}$ ) y riqueza taxonómica, en los hábitats de pozón y rápido según el tipo de uso de la tierra, durante el período de muestreo (mayo 2005 - marzo 2006) en los 12 sitios, noroeste de la provincia del Chubut, Patagonia Argentina $(n=36)$. *: $p<0.049$, MannWhitney U-test. 


\subsection{Comunidades de tricópteros y uso de la tierra a una escala de paisaje}

En la Tabla 14 se detallan las coordenadas geográficas y la altitud de los 18 sitios seleccionados para este estudio. Se consignan además los porcentajes de cada cuenca ocupados por los distintos tipos de usos de la tierra (bosque nativo, bosque exótico, pasturas-mallines, áreas urbanas, altas cumbres-lagos). La altitud de los sitios de muestreo varió entre 361 y 820 msnm para los sitios GOL y ALO respectivamente. El área de la cuenca de drenaje de cada río estudiado estuvo comprendida entre $1,8 \mathrm{Km}^{2}$ correspondiente al arroyo Patriada (PAT), y $299 \mathrm{Km}^{2}$ sitio ED sobre el arroyo Esquel. Sin embargo varias cuencas presentaron áreas inferiores a los $10 \mathrm{~km}^{2}$ (Tabla 14) como por ejemplo GOL, PAT, PIP y ALO.

Con excepción de la cuenca del arroyo Esquel cuyo valor de cobertura fue de 11 $\%$ y el arroyo el Loro con valores de $43,7 \%$, todas las cuencas tuvieron buena cobertura de bosque nativo, siendo en todos los casos superiores al 62,8\%. Esto es esperable para el nivel de actividad económica y actividades extractivas que reviste la región. En el caso del arroyo Loro, el resto de la cuenca correspondió a la presencia de altas cumbres naturalmente carentes de vegetación.

Los sitios seleccionados como uso bosque exótico presentaron coberturas de plantaciones de pinos de entre $3,1 \%$ en Ifona y 7,3 \% en Patriada. Si bien podría considerarse un porcentaje bajo con respecto al total de la cuenca, todos los tramos de río correspondientes a este tipo de uso atravesaron segmentos de entre 500 a 1500 metros lineales de bosques implantados. Los sitios EU, ED, CU, CD y NyF, tuvieron presencia de bosques de especies exóticas, todos en porcentajes inferiores a $6 \%$ y además localizados en áreas alejadas a los cursos de agua estudiados. Las áreas cubiertas por pasturas y mallines presentaron máximos en ED (18,7\%), seguido de EN $(8 \%)$. Otros sitios que presentaron conversión de bosque a pasturas fueron ED, LMU, LMD, CU, CD, NyF, EÑ, MG y CDV (Tabla 14).

Se obtuvieron regresiones significativas únicamente para las variables dependientes riqueza taxonómica de Trichoptera y diversidad Shannon-Weaver, en relación a ciertos tipos de cobertura o uso del suelo (Figura 54). El $32 \%$ de la varianza de la riqueza taxonómica fue explicada por el porcentaje de áreas urbanas, esto es la riqueza disminuyó significativamente con el incremento de las áreas urbanas en la cuenca $\left(r^{2}=0,33 ; p=0,01\right)$. Similarmente, el $35 \%$ de la variación de la diversidad 
específica de Shannon-Weaver fue explicado por la variable porcentaje de áreas urbanas en la cuenca $\left(r^{2}=0,35 ; \mathrm{p}<0,01\right)$. Un mejor ajuste de estos modelos se obtuvo al utilizar la variable independiente porcentaje de pasturas en la cuenca y la variable dependiente $\mathrm{H}^{\prime}$, este modelo explicó $56 \%$ de la variación de la diversidad. Asimismo, junto con el aumento del incremento en cobertura de pasturas también se observó una disminución significativa de la riqueza taxonómica $\left(r^{2}=0,28 ; p<0,02\right)$ (Figura 54).

En relación a lo descripto y de la observación de la figura 54 se destaca que ante una cobertura de uso urbano de entre 8 a $10 \%$ hubo una dramática disminución de la riqueza y la diversidad de tricópteros. Similarmente en cuencas con más de $8 \%$ de conversión a pasturas se observó una disminución de 60 \% de los valores de riqueza y $78 \%$ de la diversidad.

Se obtuvo un modelo significativo que relacionó positivamente la riqueza taxonómica de tricópteros y el incremento de la superficie de la cuenca cubierta por bosque nativo $\left(\mathrm{r}^{2}=0,33 ; \mathrm{p}<0,01\right)$ (Figura 54). La tendencia observada fue que una pérdida de $40 \%$ de bosque nativo se tradujo en una disminución de $35 \%$ de la riqueza taxonómica de tricópteros. 
Tabla 14. Descriptores de la cuenca de cada uno de los 18 sitios seleccionados para el estudio, en el noroeste del Chubut. Patagonia. Argentina.

\begin{tabular}{|c|c|c|c|c|c|c|c|c|c|c|c|c|c|c|c|c|c|c|}
\hline & \multicolumn{2}{|c|}{ Esquel } & \multicolumn{2}{|c|}{ Las Minas } & \multicolumn{2}{|c|}{ Carbón } & \multicolumn{3}{|c|}{ Pasturas } & \multicolumn{3}{|c|}{ Pinares } & \multicolumn{3}{|c|}{ Bosque manejado } & \multicolumn{3}{|c|}{ Bosque nativo } \\
\hline & $\mathbf{E U}$ & ED & LMU & LMD & $\mathbf{C U}$ & CD & NyF & $\mathbf{E \tilde { N }}$ & MG & GOL & PAT & IFO & CDV & PIP & GLY & COM & ALO & CHI \\
\hline Altitud (msnm) & 721 & 491 & 573 & 555 & 384 & 403 & 690 & 667 & 699 & 361 & 495 & 368 & 699 & 728 & 615 & 770 & 820 & 670 \\
\hline $\begin{array}{l}\text { Área de la } \\
\text { cuenca }\left(\mathrm{km}^{2}\right)\end{array}$ & 22,9 & 299 & 35 & 35,5 & 80,9 & 110 & 161,8 & 102,9 & 20,6 & 5,7 & 1,8 & 35,5 & 88,7 & 2,2 & 21,7 & 21,8 & 8,2 & 11,1 \\
\hline$\%$ Bosque nativo & 11,3 & 11,0 & 93,1 & 92,3 & 97,0 & 96,6 & 69,7 & 81 & 76 & 63 & 79,1 & 69,5 & 90,4 & 99 & 98,8 & 62,8 & 43,7 & 97,1 \\
\hline $\begin{array}{l}\% \text { Bosque } \\
\text { exótico }\end{array}$ & 0,7 & 5,6 & 0 & 0 & 1,4 & 1,1 & 0,2 & 0 & 0 & 5,3 & 7,3 & 3,1 & 0 & 0 & 0 & 0 & 0 & 0 \\
\hline $\begin{array}{l}\% \text { Pasturas } \\
\text { mallines }\end{array}$ & 0 & 18,7 & 1,3 & 1,3 & 1,4 & 1,5 & 4,4 & 8 & $<1$ & 0 & 0 & 0 & 2,8 & 0 & 0 & 0 & 0 & 0 \\
\hline \% Áreas urbanas & 0 & 9,0 & 0 & 0,7 & 0,2 & 0,4 & 0 & 0 & 0 & 0 & 0 & 0 & 0 & 0 & 0 & 0 & 0 & 0 \\
\hline $\begin{array}{l}\% \text { Altas cumbres } \\
\text { y lagos }\end{array}$ & 88,0 & 55,7 & 5,6 & 5,7 & 0 & 0,4 & 25,7 & 11 & 23 & 31,7 & 13,6 & 27,4 & 6,8 & 1 & 1,2 & 37,2 & 56,3 & 2,9 \\
\hline
\end{tabular}



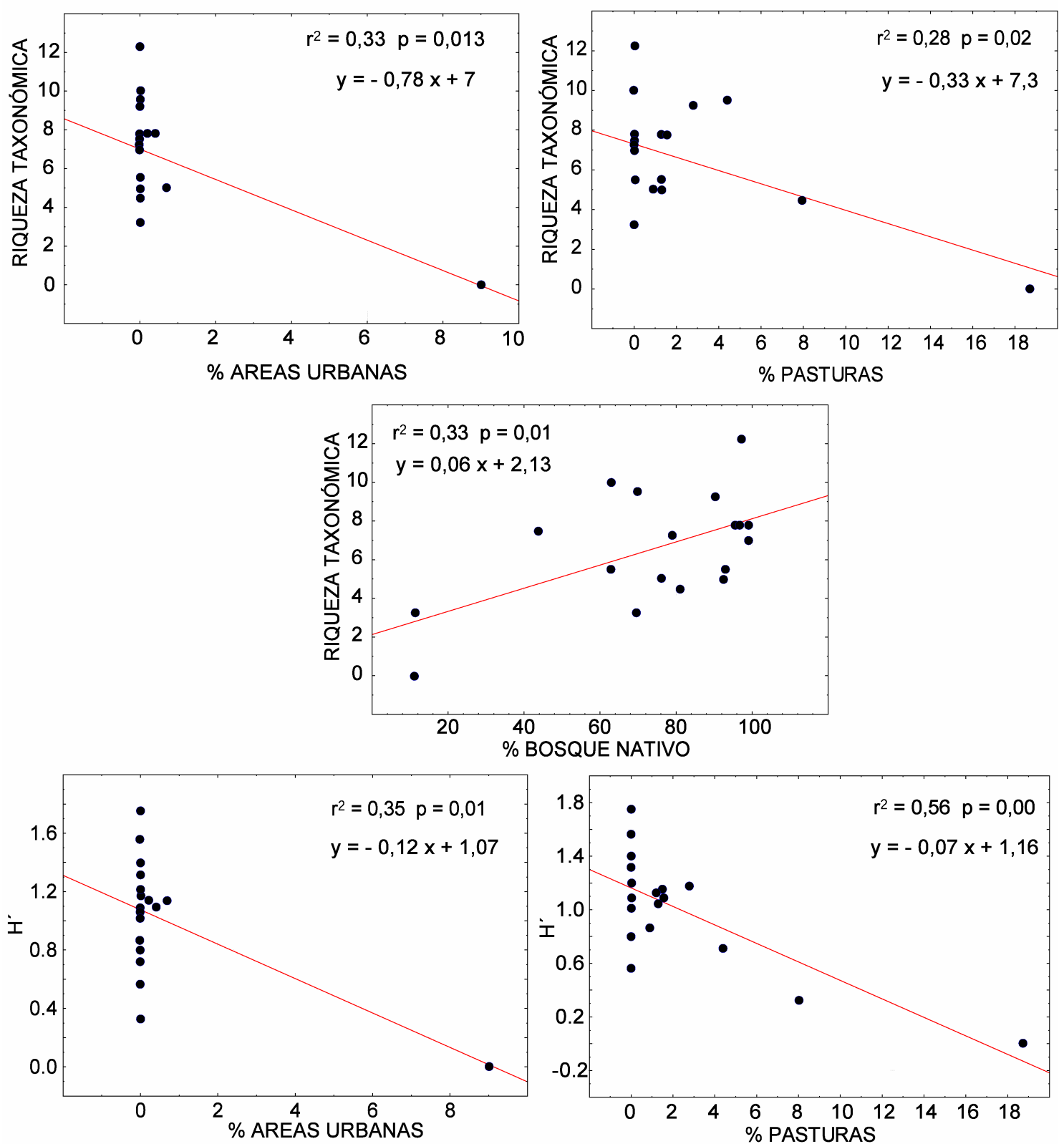

Figura 54. Regresiones lineales simples entre porcentaje de áreas urbanas, pasturas y bosque nativo (variables independientes) y la riqueza y diversidad de tricópteros. Datos correspondientes a las medias anuales de cada sitio, $n=18$. En cada recuadro se presentan los valores de $\mathrm{r}^{2}$ y la función ajustada a cada set de datos. Durante el período de estudio (mayo 2005 - marzo 2006), en el noroeste de la provincia del Chubut, Cordillera Patagónica, Argentina. 


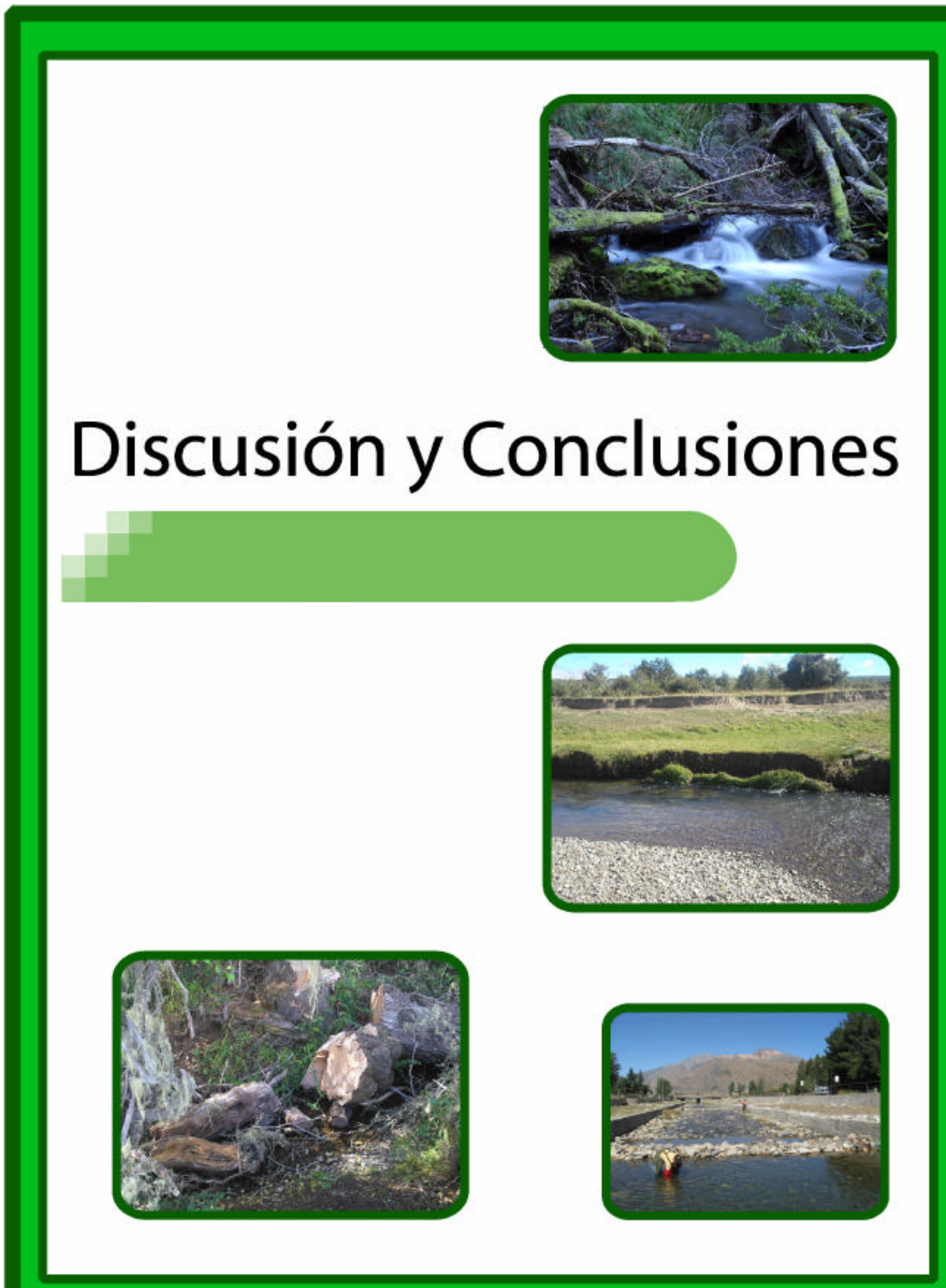




\section{DISCUSIÓN}

\section{Análisis de la biocenosis}

En el presente estudio se registraron un total de 37 taxa correspondientes a 26 géneros y 13 familias de Trichoptera. Esta riqueza es comparable a la reportada por Sganga (2011) (42 taxa, 12 familias), para ríos de la selva tropical misionera. Sin embargo es significativamente mayor a la documentada en otros estudios de nuestro país, como es el de Mangeaud (1996), quien encontró 22 especies pertenecientes a 10 familias del orden en un estudio llevado a cabo en la región semiárida del gran Chaco, por otra parte, en un río regulado de San Luis, Vallania et al. (1998) reconocieron 10 especies de tricópteros pertenecientes a 10 familias.

Existen también estudios en regiones naturalmente más diversas que reportan una mayor cantidad de especies, como es el caso del relevamiento realizado por Angrisano y Sganga (2007), en el Parque Nacional El Palmar, dónde se registraron 51 especies y 7 familias. Las autoras trabajaron colectando adultos lo que indudablemente mejoró el nivel de resolución taxonómica y además incorporó más ambientes y biotopos (lagunas, esteros) no contemplados en el presente estudio.

Asimismo los trabajos sobre tricópteros llevados a cabo previamente en la región Patagónica, son abundantes, pero indican riquezas mucho menores. Miserendino (2001), documentó 17 taxa en un relevamiento realizado en una transecta de $1000 \mathrm{~km}$ en la cordillera patagónica, y 10 taxa en el estudio estacional de zonación altitudinal del sistema Esquel-Percy (Miserendino, 1999). Por otra parte, Miserendino y Brand (2007), reconocieron 15 taxa comprendidos en siete familias para la cuenca alta, media y baja del Río Chubut. La mayor riqueza documentada en este estudio puede deberse a diversos factores, principalmente el gran número de cuencas hídricas relevadas y al esfuerzo de muestreo sobre una gran diversidad de ambientes en una amplia región geográfica, razones que pueden haber contribuido significativamente a ampliar la cantidad de registros. Sin embargo es innegable que al presente hay un mayor conocimiento de los estadios preimaginales de Trichoptera y se cuenta con claves más completas y actualizadas (Angrisano \& Sganga 2009).

Según Flint (1983), en la región Neotropical, el orden se subdivide en dos grupos faunísticos: el Brasilero y el Chileno. Mientras que el grupo Brasilero se encuentra distribuido, desde el sur de Méjico, América Central, Antillas, hasta la 
porción tropical y subtropical de América del Sur, el grupo Chileno abarca sur de Chile y sudoeste de Argentina, desde Río Negro hacia el sur. La fauna característica del grupo Chileno es altamente endémica y se encuentra estrechamente relacionada con la existente en las regiones de Australia y Nueva Zelanda, con la que comparte varias familias que están ausentes en el resto de América del Sur: Philorheithridae, Tasimiidae, Kokiriidae, Helicophidae y Stenopsychidae (de Moor \& Ivanov 2008).

Como resultado de este estudio se logró la asociación de los estadíos larva y adulto de Psilopsyche molinai (Philorheithridae) (Angrisano \& Brand, en preparación), y se amplió la distribución de varias especies del orden a la provincia de Chubut (Brand 2009). Entre ellas Austrocentrus valgiformis (Helicophidae), antes citada hasta la provincia de Neuquén (Flint 1997); Cailloma rotunda (Hydrobiosidae), citada únicamente para la provincia de Tierra del Fuego (Flint 1974); Metachorema griseum (Hydrobiosidae) relevada en la provincia de Neuquén (Bravo \& Angrisano 2003) y Parasericostoma cristatum (Sericostomatidae) documentada para las provincias de Neuquén y Río Negro (Valverde \& Albariño 1999). Además de ampliar la distribución geográfica de los taxa relevados, la presente tesis proporciona una completa caracterización ambiental de los biotopos donde las especies fueron encontradas. Sin embargo se debe continuar con los trabajos orientados a la identificación específica o descripción de taxones que hasta el momento no pudieron ser correctamente asignados, tal es el caso de Phylloicus, sp., Austrotinodes sp., Mastigoptila sp., Atopsyche sp., Smicridea sp. 1 y Smicridea sp. 2, Brachysetodes sp., Nectopsyche sp., Triplectides sp., Monocosmoecus sp., Verger sp., Sortosa sp., una especie no determinada de la familia Philorheithridae y Polycentropus sp. En tal sentido si bien en los últimos años se ha avanzado en el conocimiento de la fauna de la región aún se requiere de recursos para mejorar el estado del arte, posiblemente aunando esfuerzos entre sistemáticos y ecólogos lo que mejorará la calidad de los trabajos y de los inventarios (Miserendino 2005b).

Las larvas de Trichoptera constituyen un elemento importante en el flujo de energía y en la dinámica de nutrientes de los ambientes acuáticos, dada su amplia diversidad de adaptaciones tróficas (Reynaga 2009; Reynaga \& Rueda Martín 2010), sin embargo, es escasa la información disponible respecto a los hábitos alimentarios de los estadíos larvales de este grupo en la región Neotropical. El presente trabajo provee la primera descripción del hábito alimentario de algunas especies de Trichoptera. Las especies de hidrobiósidos, serían predadores, y B. quadrifidus y Monocosmoecus sp. 
desmenuzadores estrictos, dado que la aparición de otros ítems en la dieta se dio en muy baja proporción. El análisis de contenido estomacal para M. longicornuta, N. brevispina, N. tricarinatum, S. annulicornis, S. frequens, B. quadrifidus, Monocosmoecus sp. у $P$. ovale, coincide con las observaciones de otros autores para especies cogenéricas (Reynaga 2009; Reynaga \& Martín 2010). Reynaga (2009) encontró que la mayoría de los taxa analizados consumieron más de un ítem alimenticio, y registró presencia de MOPF, esto es coincidente con lo hallado para las dos especies del género Smicridea y para $M$. longicornuta y $P$. ovale del presente estudio. En línea con estas observaciones Tomanova et al. (2006) sugieren que un determinado taxón podría comportarse o poseer más de una estrategia funcional dependiendo del las circunstancias ambientales y el recurso disponible.

\section{Uso Urbano}

En relación a los descriptores morfológicos de los tramos estudiados en la mayoría de los sitios se observaron mayores magnitudes (ancho del cauce) en los sitios urbanos respecto a los de referencia. Además se evidenció una disminución en la granulometría del sustrato, desde bloques y guijones a sustratos dominados por guijón, guijarro y arena, con una mayor participación de sedimentos finos. Las modificaciones hidráulicas realizadas comúnmente en los cursos de agua urbanos conllevan este tipo de alteraciones en la morfología y el tamaño de los sedimentos (Finkenbine et al. 2000; Pizzuto et al. 2000). Estas prácticas alteran seriamente el hábitat físico reduciendo la heterogeneidad ambiental, lo que se refleja en una matriz de hábitats menos compleja y menos natural en los cursos de agua urbanos (Cortelezzi 2009; Davies et al. 2010). Paul y Meyer (2001) advierten que el aumento en el aporte de sedimentos en cuencas urbanas ha propiciado la transformación de ríos meandrosos con una morfología compleja en cursos de agua rectilíneos, canalizados. Las rectificaciones de los cauces aumentan la pendiente y la velocidad de la corriente especialmente cuando la obra de realineamiento se lleva a cabo con el objeto de incrementar la eficiencia del canal para transportar sedimentos.

En este estudio los tramos de ríos urbanos presentaron cambios significativos en las variables fisicoquímicas, sin embargo la magnitud de los cambios fue diferente en cada sitio estudiado dependiendo de las características particulares. Esto es, el tamaño de las urbanizaciones fue diferente (Cholila: 2.190 habitantes, Esquel: 30.977 habitantes 
y Corcovado: 1.848 habitantes), como así también la dimensión de los arroyos que las atraviesan, en términos de caudal, profundidad, etc. Si bien los cambios en los valores medios de temperatura del agua no fueron significativos estadísticamente, se observó un marcado aumento en los sitios impactados en Las Minas y Esquel, posiblemente por efecto de la remoción de la vegetación de ribera. Otros investigadores (Suren 2000; Pickett et al. 2001) también mencionan que el efecto de "isla" (las superficies de concreto se calientan y entregan ese calor a los arroyos) y el aumento de las superficies impermeables de las ciudades producen un cambio en el régimen térmico de los cursos de agua urbanos.

Por otro lado como producto de acciones puntuales durante el período de aguas altas en la ciudad de Cholila se observaron valores extremos de sólidos en suspensión. En esta oportunidad el cauce fue objeto de actividades de realineamiento y dragado. Ryan (1991) anticipa que los aportes continuos de sedimentos pueden tener efectos dramáticos en este tipo de ecosistemas, y sobre todo en las comunidades de invertebrados bentónicos de ríos urbanos. Las fuentes de estos sólidos son diversas (e.g. construcción de rutas y caminos, erosión de márgenes) y los pulsos de sedimentación suelen ser más intensos en regiones en las cuales las urbanizaciones se encuentran en la etapa inicial de su desarrollo. En el caso de Cholila la urbanización tiene predominio de calles de ripio con escasa pavimentación. En este tipo urbanizaciones rurales durante las épocas de intensas lluvias son frecuentes los incrementos en los sólidos en suspensión a través de la escorrentía superficial (Williamson 1993; Suren 2000).

Sin duda Esquel es la urbanización que presenta los cambios más pronunciados en las condiciones ambientales. La concentración de los nutrientes: amonio, nitratos y fósforo reactivo soluble, fue significativamente mayor en el tramo urbano respecto al de referencia, mientras que en los sitios Las minas abajo y Carbón abajo, no se observaron valores extremos. Si bien la ciudad de Esquel cuenta con una planta de tratamiento de líquidos cloacales, durante el presente estudio el funcionamiento de la misma resultó insuficiente para el tratamiento de los efluentes cloacales como se evidencia en los niveles de nutrientes. Adicionalmente en trabajos previos se ha documentado contaminación originada por fuentes difusas en el tramo urbano y post-urbano del arroyo Esquel (Miserendino 1995; Miserendino et al. 2008). Asimismo, si bien la contribución del Valle Chico, tributario del Arroyo Esquel, en los valores de conductividad y nutrientes no es despreciable no alcanzaría a explicar los incrementos en los valores registrados en el sitio Esquel abajo, tal como fuera documentado por 
Miserendino y Pizzolón (2000) y más recientemente en el trabajo de García Sotillo (2011). El aumento en la demanda biológica de oxígeno, la conductividad, los sólidos en suspensión, el amonio en los cursos de agua urbanizados depende de la eficacia del tratamiento de las aguas residuales pero también puede estar relacionada con la escorrentía superficial de fuentes difusas de contaminación (Lenat \& Crawford 1994; Latimer \& Quinn 1998; Faulkner et al. 2000).

Estudios previos a la construcción de la planta de tratamiento de líquidos cloacales (Miserendino 1995; Miserendino \& Pizzolón 2000), documentaron que de acuerdo a valores de demanda biológica de oxígeno y oxígeno disuelto, el arroyo Esquel presentaba una polución moderada. Si bien en el presente estudio se esperaba una recuperación en la calidad del agua con respecto a los valores de los parámetros fisicoquímicos previos a la puesta en funcionamiento de la planta de tratamiento de efluentes cloacales, no se registró una mejora en este sentido. Además de las ineficiencias en el sistema y los aportes no puntuales discutidos anteriormente debe mencionarse que la ciudad prácticamente duplicó su tamaño en los últimos diez años (censo 1990: 17.000 habitantes; 2000: 30.977 habitantes) (Miserendino et al. 2008). Esto sobrepasa la capacidad de funcionamiento de la planta debido a que por razones presupuestarias no se hallaban completas las ampliaciones de los módulos de carrizo las que se que se efectivizaron durante 2009-2010.

El manejo de los cursos de agua mediante actividades tales como dragado, regulación del caudal, abstracción de agua, entre otros, implica cambios directos o indirectos del hábitat (Riley 1998; Armitage \& Cannan 1999). La información concerniente a la composición y distribución de hábitats es crucial para comprender la magnitud del impacto producido por los cambios físicos en los cursos de agua (Armitage \& Cannan 1999). Los índices de valoración de hábitat fueron diseñados con el objeto de permitir una visión concreta del estado físico del sitio para establecer más objetivamente la calidad ecológica. Una mayor heterogeneidad y diversidad de hábitats probablemente sostendrá una biota más diversa (Giller \& Malmqvist 1998; Smith \& Smith 2000; Allan \& Castillo 2007). El índice propuesto por Barbour y colaboradores (1999) y que fue utilizado en el presente estudio resultó apropiado para realizar una evaluación rápida y cualitativa. Esto es, los sitios urbanos relevados presentaron en todos los casos una menor calidad de hábitat que sus respectivos sitios de referencia, siendo el sitio ED el que exhibió la categoría más baja. 
El sitio Esquel de referencia presentó ciertos signos de alteración (categoría: subóptimo) lo que no es sorprendente dado que varios autores se han encontrado con la dificultad de localizar sitios de referencia inalterados (Suárez et al. 2002; Munne et al. 2003). En relación a este problema, Bulleri et al. (2007) recomiendan elegir sitios no afectados por el tipo de impacto que uno desea evaluar, siguiendo la pauta de encontrar las mejores condiciones posibles.

La aplicación del índice QBRp reflejó adecuadamente el nivel de degradación de los corredores ribereños en los tramos urbanos, los que en todos los casos presentaron menor calidad respecto a los de referencia. No obstante, ninguno de los sitios evaluados en este estudio fue asignado a la calidad más baja (degradación extrema). La mejor condición fue hallada para los sitios Esquel de referencia y urbano (calidad intermedia), en ellos la vegetación ribereña presentó una mejor cobertura y estructuración, y las modificaciones del cauce no fueron tan severas. La pérdida de la vegetación ribereña, así como el reemplazo de especies arbóreas y arbustivas nativas por exóticas, principalmente Salix spp., significó una disminución importante en la calidad en los sitios estudiados. Estas parecen ser las intervenciones humanas más frecuentes asociadas a las urbanizaciones de la cordillera en Patagonia (Macchi 2007; Kutschker et al. 2009; Miserendino \& Brand 2009).

Los tricópteros estuvieron ausentes en el tramo urbano del arroyo Esquel. Este sitio presentó las peores condiciones ambientales en términos de calidad de hábitat y niveles de nutrientes, respecto del resto de los sitios estudiados. Esta situación ya fue advertida en trabajos previos realizados en el mismo sitio antes de la construcción de la planta de tratamiento (Miserendino 1995, 1999), y en los sucesivos reportes técnicos elaborados inmediatamente después de la puesta en marcha de la misma en el año 2001, donde toda la fauna sensible estuvo ausente (EPT) (Pizzolón et al. 2002). Está ampliamente documentado que el aporte continuo de nutrientes (nitrógeno y fósforo) puede acelerar los procesos de eutrofización (Strobl et al. 2006) o tener efectos letales en la biota, como es el caso del amonio, ocasionando fallas osmoregulatorias (Rosenberg \& Resh 1993; Suren 2000). Macchi (2007) reportó, para el arroyo Pocahullo (Neuquén), una ausencia total de tricópteros en un tramo localizado en áreas periurbanas sometidas a intensa contaminación orgánica, en respuesta a una drástica disminución en los valores de oxígeno y al incremento de la materia orgánica y la conductividad. Asimismo, en distintos trabajos llevados a cabo en ríos urbanos de ambientes serranos de Córdoba, Tucumán y San Luis se documenta una fuerte 
disminución de tricópteros hasta su desaparición, en tramos con extrema polución orgánica (aumento en el total de sólidos en suspensión, conductividad, entre otros) (Gualdoni et al. 1994 a,b; Vallania et al. 1996; Fernández et al. 2002).

La participación de los tricópteros en los sitios urbanizados de los arroyos Las Minas y Carbón fue importante en la dimensión temporal, en todas las oportunidades el hidropsíquido $S$. annulicornis se encontró bien representado. Varias especies de esta familia parecen presentar una tolerancia moderada a una mala calidad en las condiciones ambientales (Mackay \& Wiggins 1979; Dohet 2002; Bonada et al. 2004; Chakona et al. 2009). Bonada et al. (2004) observaron que algunos miembros de esta familia pueden tolerar la presencia de altas concentraciones de cloro, sulfatos, amonio, fosfatos y sólidos en suspensión.

Si bien no se documentaron cambios importantes de composición en la comunidad de tricópteros entre el sitio de referencia y el urbano en el arroyo Las Minas, fue notoria la disminución en densidad de los leptocéridos y la desaparición de $N$. brevispina. Consistentemente con estas observaciones Bonada et al. (2004) reportaron una alta sensibilidad en especies de Leptoceridae al incremento de sólidos en suspensión. Sumado a esto en el tramo urbano de Las Minas se observaron diferencias evidentes en la estructura funcional de la comunidad de tricópteros, lo cual es consistente con lo encontrado por otros autores (Díaz Villanueva et al. 2010). Esto es, un aumento significativo en la proporción de colectores-filtradores simultáneamente con la disminución de los desmenuzadores. Esto podría ser una consecuencia de un menor aporte de hojarasca y material proveniente de los bosques de ribera y un predominio de material sestónico transportado por la columna de agua. Sin embargo, en este trabajo no se registraron cambios sustanciales en el material detrítico alóctono grueso y fino entre el sitio de referencia y el urbano. Masi y Miserendino (2009) en una evaluación cuantitativa de detrito orgánico detectaron una marcada disminución de hojarasca entera (0.50 a 0 g.m $\mathrm{m}^{-2}$ ) y un aumento en la MOPF (3.02 a 5.80 g.m ${ }^{-2}$ ) para el sitio Las Minas urbano respecto al de referencia. Es probable que el método utilizado en este trabajo para estimar las fracciones de detrito (semicuantitativo) no fuera lo suficientemente preciso para evidenciar estos cambios.

El presente estudio demostró una mejora sustancial en las condiciones ambientales y en la comunidad de tricópteros (12 especies registradas) en el sitio LMD en relación a las observaciones realizadas por Pizzolón et al. (1997), antes de la construcción de la planta de tratamiento de efluentes cloacales de la ciudad de Cholila. 
Durante el período en el que se llevó a cabo ese estudio, los residuos orgánicos eran vertidos directamente al curso de agua sin ningún tratamiento. En dicha oportunidad los autores no registraron ninguna especie de Trichoptera en el tramo urbanizado (mismo sitio de colecta que el presente estudio).

En coincidencia con lo observado por varios investigadores (Castela et al. 2008) las urbanizaciones produjeron cambios en los descriptores morfológicos a escala de tramo, en las variables fisicoquímicas y en los índices de la calidad ambiental. Estos apartamientos de calidad del agua y del hábitat respecto al de referencia se tradujeron en cambios de composición y estructura trófica en las comunidades de tricópteros. El gradiente de perturbaciones detectadas en los ríos estudiados se correspondió con lo siguiente: las mejores condiciones ambientales se detectaron en una urbanización pequeña, casi rural como es el caso de Corcovado atravesada por un río de gran caudal, en comparación con los otros ríos analizados, que mostró pocas modificaciones en sus características ambientales y en su biota. En una situación intermedia, la ciudad de Cholila con alteraciones principalmente físicas (pérdida de hábitat, de vegetación ribereña y síntomas de sedimentación) con un efecto moderado sobre la comunidad. En una situación extrema, la ciudad de Esquel con una disminución marcada de la calidad del agua (carga elevada de nutrientes, incremento de la conductividad, etc.) que produjo la extinción local de la comunidad de Trichoptera.

\section{Uso silvopastoriles}

En los sitios sometidos a prácticas silvopastoriles, hubo pocas diferencias significativas en las variables físicas y químicas observadas en los distintos usos, con respecto a los sitios de referencia. En este sentido, la temperatura del agua fue significativamente menor en los sitios de bosque nativo respecto de los usos silvopastoriles. Esto evidenció que la reducción en la canopia ribereña como consecuencia de las distintas prácticas ya sea por podas selectivas, así como clareos más extensos, afectó el régimen térmico de los ríos. Baillie et al. (2005) documentaron en arroyos drenando bosques con áreas clareadas de hasta $25 \%$ de la cuenca, un marcado incremento en los niveles de luz incidente lo que produjo un aumento significativo en las temperaturas medias del agua. Similarmente, Kedzierski y Smock (2001) reportaron importantes diferencias en la temperatura del agua en estudios comparativos de arroyos en áreas forestadas y deforestadas. Los altos valores de temperatura pueden repercutir en las condiciones 
fisicoquímicas, como por ejemplo los niveles de oxígeno en columna de agua y las tasas de procesamiento de la materia orgánica (Rutherford et al. 1997; Baillie et al. 2005). Más aún, los cambios en el régimen térmico pueden producir modificaciones en los patrones de distribución de ciertas especies de insectos acuáticos por ejemplo de aquellas especies estenotérmicas (Quinn et al. 1994; Cox \& Rutherford 2000), lo que es un rasgo común de varias especies endémicas de cordillera patagónica.

Si bien los valores de oxígeno disuelto documentados en los sitios seleccionados para este estudio no presentaron diferencias significativas entre usos, en los tramos de bosque nativo se registraron los mayores valores, mientras que los observados en pasturas y pinares fueron los más bajos. Esta variable puede haber sido afectada por diversos factores, entre ellos por un aumento en la temperatura del agua, como también por las altas tasas de respiración originadas en la descomposición del material orgánico fino depositado en el sustrato (Collier \& Bowman 2003). En coincidencia con estas observaciones, Baillie et al. (2005) documentaron reducciones importantes en el oxígeno disuelto en sitios con importante acumulación de acículas de pino en el lecho.

Otro de los efectos graves del uso pastoril y de la extracción de madera del bosque es la erosión de las márgenes, causada por la disminución de la vegetación del corredor ribereño, lo que se agrava en el primer caso por los efectos de pisoteo de ganado. Ésta situación fue evidente en muchos de los tramos estudiados, en los que se observó un incremento en el sedimento fino del lecho, aunque la situación más extrema se reportó en el sitio Estancia Los Ñires. Quinn et al. (1997), fundamentan que las prácticas extensivas con ilimitado acceso del ganado a los cursos de agua pueden acelerar la erosión de las riberas, disturbar el lecho e incrementar el aporte de sedimentos finos. Esto puede producir severas alteraciones en la biota principalmente por la acción abrasiva del sedimento al ser transportado por la corriente (Davies-Colley et al. 1992; Zimmermann \& Death 2002), pero también debido a la colmatación por sedimento fino sobre el sustrato, que reduce la disponibilidad de hábitat para las especies de macroinvertebrados bentónicos (Quinn 2000; Gualdoni et al. 2009; Song et al. 2009).

Consecuentemente, el índice de calidad de hábitat evidenció un fuerte impacto en las condiciones físicas de los tramos pastoreados, que presentaron las peores calificaciones (alteración fuerte a calidad intermedia), demostrando que la pérdida de hábitat apropiado para las comunidades bentónicas es uno de los principales efectos 
asociados a la cría de ganado sobre los cursos de agua (Quinn et al. 1993; Townsend et al. 2003; Allan 2004).

Las calificaciones del QBRp obtenidas por los tramos de pasturas reflejaron la baja calidad de la vegetación ribereña, estos sitios fueron asignados a las categorías: subóptimo y marginal. La baja cobertura, la pobre estructura de la cubierta vegetal sumada a la presencia de especies exóticas (Salix spp.) fueron uno de los principales efectos evidenciados por este índice. Diversos autores argumentan que debido al grado de sombreo y la poca profundidad que presentan, los arroyos de mediano a bajo orden son muy vulnerables a los cambios en la cobertura ribereña, al incremento de los sedimentos finos y al ingreso de los nutrientes (Davies-Colley \& Quinn 1998; Richardson \& Danehy 2007).

Se ha documentado un aumento en la densidad de macroinvertebrados en sitios con uso pastoril (Allen 1959; Quinn 2000), debido principalmente a un incremento en la producción primaria. Asimismo, la disminución en la riqueza, especialmente de los taxa sensibles también es un fenómeno ampliamente extendido (Chakona et al. 2009). La desaparición de especies intolerantes puede relacionarse con el cambio en el régimen térmico (Rutherford et al. 1997; Cox \& Rutherford 2000), la falta de vegetación ribereña (Collier et al. 1997) y los cambios en la composición granulométrica del sustrato (Quinn et al. 1998; Quinn 2000).

Contrariamente a lo esperado, en el presente estudio no se detectaron apartamientos significativos en los niveles de nitratos, fósforo reactivo soluble, ni de amonio, con respecto a los valores de los sitios de referencia. Esto contrasta con lo reportado en diversos trabajos en tramos afectados por prácticas agrícologanaderas (Jones \& Smock 1991; Smith et al. 1993; Song et al. 2009) en los que se observó un incremento en los nutrientes, principalmente nitrógeno y fósforo, proveniente de las excretas del ganado. Los autores observaron un aumento significativo de la producción primaria lo que repercutió en los niveles tróficos superiores, esto es, se incrementó la densidad y la biomasa de los invertebrados (Quinn 2000; Niyogi et al. 2007). Es posible que debido a la modalidad del uso ganadero primariamente extensivo (Estadística ganadera anual, DGAG 2006) de los sitios abordados en el presente estudio no se hayan observado niveles altos en los valores de nutrientes. Sin embargo la alta densidad de tricópteros registrada en estos sitios podría estar indicando un aumento en la productividad de estos sistemas en respuesta al incremento de algún recurso trófico (Song et al. 2009). Si bien la riqueza no fue significativamente diferente, la media fue 
menor en los sitios de pasturas con respecto al resto de los usos. La falta de significación estadística para estas variables podría deberse en el presente diseño a las diferencias de condiciones entre ríos seleccionados para el uso pastura (por ej. vegetación nativa remanente, manejo del rodeo, dragados esporádicos, etc.) las que fueron mayores a las esperadas y esto se tradujo en desvíos importantes.

Los ensambles de tricópteros en ríos de pasturas estuvieron caracterizados por los siguientes taxa: Parasericostoma ovale, Metachorema griseum, Oxyethira bidentata, Hudsonema flaminii, Brachysetodes quadrifidus, Rheochorema lobuliferum, Smicridea annulicornis, Cailloma pumida y Verger sp. En concordancia con lo observado para $O$. bidentata, la especie cogenérica Oxyethira albiceps, ha sido fuertemente asociada a condiciones de baja calidad del agua y hábitats empobrecidos de pasturas (Quinn 2000) al igual que otros hidroptílidos (Bonada et al. 2004; Chakona et al. 2009). Asimismo es conocida la tolerancia de ciertas especies del género Smicridea a pobres condiciones ambientales (Mackay \& Wiggins 1979; Dohet 2002). En un estudio previo, Miserendino \& Pizzolón (2004) anticiparon que S. annulicornis fue una especie dominante en términos de densidad y biomasa en ríos cordilleranos con uso ganadero. Blinn y Ruiter (2006), encuentran que especies norteamericanas de Smicridea serían capaces de tolerar más de $50 \%$ de colmatación del sustrato con sedimentos finos.

Los cambios más notorios en la comunidad de tricópteros ocurrieron en términos de diversidad y equitatividad, las que fueron significativamente menores en las pasturas que en los restantes usos. En efecto, la estructura de la comunidad de Trichoptera en los arroyos de pasturas cambió. En los sitios Manguera y Estancia Los Nires, el colectorfiltrador Smicridea annulicornis representó el grueso de la comunidad. Probablemente este fenómeno estaría relacionado con el incremento de material particulado fino sestónico incorporado por la escorrentía superficial desde los terrenos adyacentes al curso de agua (Allan et al. 1997; Sieh et al. 2003; Utz et al. 2009). En el sitio Nant y Fall se observó codominancia de desmenuzadores (Parasericostoma ovale) y colectores-filtradores (Smicridea annulicornis y S. frequens) coincidentemente en un estudio realizado dos años después, Brand y Miserendino (2011 b) reportan la misma relación de predominio en este sitio. Asimismo el estudio destacó que la producción secundaria anual de estas especies fue diez veces mayor a la registrada en un ambiente de cabecera de bosque nativo, entre otros debido a una amplia oferta de recursos tróficos y a una significativa heterogeneidad ambiental. 
Según Chakona et al. (2009) el uso agrícologanadero representa el mayor impacto para la biota acuática luego de las urbanizaciones. Los arroyos impactados por este tipo de uso presentan comunidades de macroinvertebrados poco diversas y dominadas por especies ubicuas tolerantes a condiciones de polución persistentes (Allan 2004). El presente trabajo mostró coincidencias con estas observaciones dado que las modificaciones producidas por el uso pasturas si bien no fueron graves se vieron claramente reflejadas en la comunidad de tricópteros. Los atributos comunitarios diversidad, equitatividad, y estructura funcional fueron los indicadores más apropiados para evidenciar la calidad ecológica y del agua en este tipo de uso.

Las consecuencias del manejo forestal sobre los cursos de agua dependen del tipo de actividades extractivas que se lleven a cabo y de la intensidad de las mismas (Harding et al. 2000; Collier \& Bowman 2003; Death et al. 2003). Al igual que durante el desarrollo pastoril, el aumento de la temperatura del agua en respuesta a una mayor incidencia de luz solar es uno de los fenómenos asociados al clareo del bosque (Baillie et al. 2005). Asimismo se observa una disminución en los niveles de oxígeno disuelto en estos ríos como consecuencia de la incorporación excesiva de detrito orgánico durante las actividades de poda y raleo. Excepto por una mayor temperatura en los sitios de bosque manejado respecto al bosque nativo, el presente estudio no mostró mayores diferencias en las características fisicoquímicas (ej. oxígeno, nutrientes). Sin embargo, los índices de calidad de hábitat y de bosque de ribera evidenciaron síntomas de alteración en la granulometría del sustrato, disminución de la disponibilidad de hábitat del lecho y pérdida de la estabilidad de las márgenes.

El sitio Pipo presentó cambios dramáticos en las condiciones ambientales, esto es se observó una importante deposición de arena y sedimento fino ocasionada por la obstrucción del cauce por los restos vegetales descartados durante las tareas de extracción de madera (ramas y hojarasca). Tal como es documentado por Kutschker et al. (2009), es muy común la disposición del material de descarte en el cauce de los arroyos en vez de su adecuada remoción y quema como indican las ordenanzas de la Dirección General de Bosques y Parques. Estas acciones evitarían tanto la acumulación excesiva de material en el lecho, la alteración en las características hidráulicas, la disrupción de la secuencia de rápidos y pozones, así como también la colmatación de sedimentos en las áreas deposicionales.

Si bien por disposiciones legales en la región cordillerana debe respetarse la franja de protección ribereña, las intervenciones en todos los sitios de bosque manejado 
afectaron ejemplares de la zona de amortiguación. Thompson (2001) postula que los efectos de estas prácticas pueden atenuarse excluyendo del manejo al corredor de ribereño.

El incremento de la producción primaria como consecuencia de las actividades de clareo que promueven una mayor incidencia de radiación lumínica, ha sido ampliamente documentado (Collier et al. 1997; Hetrick et al. 1998; Fuchs et al. 2003; Mallory \& Richardson 2005), sin embargo este efecto no fue observado en los sitios seleccionados para este estudio, dado que tanto los valores de clorofila perifítica como la presencia de briófitas y algas filamentosas fue similar a la hallada en los sitios de referencia. Estos resultados coinciden con las observaciones de Melody y Richardson (2007), quienes afirman que la variabilidad encontrada en los niveles de perifiton puede atribuirse a las técnicas de poda y raleo utilizadas (como por ejemplo tala rasa versus poda selectiva) que tendrían distintos efectos en los ambientes acuáticos.

Varios estudios reportan elevada densidad o biomasa de macroinvertebrados en sitios de bosque manejado luego del clareo de la vegetación ribereña, en respuesta al incremento en la producción primaria (Anderson 1992; Fuchs et al. 2003). Los resultados observados en este estudio no revelaron ninguna modificación en términos de densidad, riqueza, diversidad o equitatividad entre los sitios de bosque manejado y de referencia. Sin embargo, los valores presentados corresponden únicamente a los tricópteros y es probable que este mecanismo opere a nivel de la comunidad de macroinvertebrados. Con respecto a la estructura funcional en los tramos de bosque manejado, se observó una codominancia de colectores filtradores y desmenuzadores, excepto en el caso del sitio Pipo, donde la comunidad estuvo dominada por desmenuzadores. Como se describió anteriormente en este sitio hubo abundante material de descarte de las podas, depositado en el cauce lo que explicaría este patrón. Asimismo, la densidad de predadores fue significativamente mayor en los sitios de bosque manejado que en el resto de los usos. Algunos autores documentan un aumento en la densidad de ciertos grupos de macroinvertebrados, como quironómidos y oligoquetos, luego de las actividades de poda y clareo (Baillie et al. 2005; Miserendino \& Masi 2010). Probablemente en este caso, el aumento en el número de predadores esté relacionado con una mayor densidad de las especies presa.

De acuerdo a las características ambientales y a los atributos de la comunidad de tricópteros, los sitios con poda selectiva para extracción de leña presentaron más semejanzas con el bosque nativo de referencia que con el uso pastura. Sin embargo fue 
evidente que las prácticas que se llevaron a cabo inmediatamente después de las actividades de extracción (ej. disposición de residuos de cortas) modificaron la calidad del hábitat, la cantidad de detrito y la estructura trófica.

En la región patagónica es común que las actividades de extracción de madera y clareo del bosque se encuentren asociadas al uso ganadero y esto puede afectar la recuperación del bosque, debido al efecto de pisoteo y ramoneo de renovales (Raffaele et al. 2008). Es posible que algunos de los patrones observados en esta tesis reflejaran esta superposición de usos. Será conveniente en un futuro realizar comparaciones en áreas con y sin exclusión de ganado.

De acuerdo a lo observado la comunidad de tricópteros no presentó diferencias en los sitios de pinar respecto al bosque de referencia tanto en términos de densidad, riqueza y diversidad. Esto difiere de lo documentado para ríos neozelandeses en estudios de adultos muestreados con diversas artes de captura, los que mostraron menor abundancia y riqueza de tricópteros en pinares respecto del bosque nativo (Collier \& Smith 1995; Collier et al. 1997). Por el contrario, Chakona et al. (2009) encontraron similitudes en la riqueza de las comunidades de Trichoptera entre sitios de bosque nativo y exótico en respuesta a las apropiadas condiciones del hábitat tanto de los arroyos como del bosque adyacente. Indudablemente hay ciertas funciones ecológicas que los bosques ribereños exóticos siguen cumpliendo como por ejemplo el sombreo, el aporte de ramas que favorece la diversidad de hábitats dentro arroyo, y la oferta de sitios de oviposición y refugio. Sin embargo se ha observado que los cambios en el tipo de vegetación (nativa por exótica) podrían alterar los microclimas del bosque ribereño, o bien la disponibilidad de refugio para los estadíos adultos incrementando la presión de predación (Jackson 1988; Sweeney 1993; Baas \& Mennen 1996). Se ha demostrado que los cambios en la calidad del detrito alóctono pueden afectar la estructura trófica de los arroyos cordilleranos patagónicos debido a que las hojas de Nothofagus pumilio (lenga) demoran menos tiempo que las acículas de pino en ser acondicionadas por acción de hongos y bacterias (Albariño \& Balseiro 2002). No obstante, en los sitios visitados en el presente estudio no se detectó una disminución en la abundancia relativa de los desmenuzadores sobre el resto de los grupos funcionales. Más aún, en los sitios de pinares Brachysetodes sp., Hudsonema flaminii, Triplectides sp. y Nectopsyche sp. (Leptoceridae) y Myotrichia murina y Parasericostoma ovale (Sericostomatidae) todos del gremio desmenuzadores, contribuyeron con más del $40 \%$ de la comunidad lo que sugeriría cierta plasticidad en la utilización de los recursos tróficos. En coincidencia con 
esto Albariño y Valverde (1999) demostraron en estudios experimentales, que las larvas del sericostomátido Parasericostoma cristatum consumieron eficientemente acículas de Pinus ponderosa en arroyos de la cordillera Patagónica. Sin embargo, Miserendino y Masi (2010) encontraron una disminución significativa en la riqueza taxonómica de los desmenuzadores en los sitios de pinar respecto al bosque nativo cuando consideraron toda la comunidad de macroinvertebrados bentónicos. Miserendino y Pizzolón (2004) detectaron diferencias en grupos funcionales en sitios forestados con otra especie exótica altamente invasiva de las áreas de ribera (Salix fragilis), respecto de las vegetadas con Nothofagus, en ríos de montaña. Esto pone de manifiesto la complejidad de las interacciones que existen en estos ecosistemas y sugiere la conveniencia de utilizar la comunidad de macroinvertebrados completa en la evaluación de ciertos usos. Serán necesarios más estudios ya sea de campo o experimentales para profundizar estas líneas de investigación y lograr una mejor comprensión de estas interacciones.

Las asociaciones de tricópteros de sitios de bosque nativo de referencia estuvieron caracterizadas por P. cristatum, Mastigoptila sp., Metrichia neotropicalis, A. hirsutus, Smicridea sp. 2, Monocosmoecus sp. y Austrocentrus valgiformis. Este ensamble de especies sería el propio de sitios prístinos con calidad del agua óptima, es decir bajas temperaturas, altas concentraciones de oxígeno disuelto, máxima transparencia, sin pulsos de sedimentación y baja conductividad. Como fuera evidenciado por los índices de calidad de hábitat y de vegetación ribereña, estos tramos presentaron las mejores condiciones esperables. La mayor riqueza específica fue registrada en el sitio de referencia CHI. Esto coincide con lo observado para el mismo sitio en un estudio anual donde Brand y Miserendino (2011c) reportaron 17 especies de Trichoptera.

En los sitios de bosque nativo el grupo funcional raspadores fue significativamente mayor en términos de densidad respecto del resto de los usos, sugiriendo que este es un rasgo que se perdería ante disturbios antrópicos. Las especies de tricópteros raspadores Mastigoptila sp., $M$. neotropicalis y A. valgiformis disminuyeron fuertemente en los usos pastura, bosque manejado y pinar, estas estarían asociadas a las briófitas que tuvieron fuerte presencia en el bosque nativo. En este sentido Masi y Miserendino (2009), documentaron que la biomasa de briófitas fue significativamente mayor en el bosque nativo que en pasturas, indicando que las actividades vinculadas al uso de la tierra pueden producir cambios en los recursos 
energéticos disponibles para las comunidades bénticas, en coincidencia con documentado por Riley et al. (2003) para ríos neozelandeses.

\section{Funciones de los corredores ribereños}

En este trabajo fue evidente que la ausencia del corredor de ribera se tradujo en diferencias significativas de la temperatura del agua. Además, el Análisis de Correspondencias Canónicas reveló que la mayoría de los ríos de pinares y de bosque manejado estuvieron caracterizados por importantes cantidades de materia orgánica particulada béntica (MOPB) a diferencia de los sitios de pastura. Esto es, en los ríos que atravesaron ambientes boscosos fue significativo el aporte de material alóctono. Un estudio comparativo sobre material detrítico llevado a cabo en verano reveló que la MOPB fue mayor en sitios forestados, ya sea con especies nativas como de exóticas (pino) respecto de pasturas siendo además la biomasa de madera y material fragmentado mayor en los sitios de ñire con y sin intervención (Masi \& Miserendino 2009). Lo que sugiere que las interacciones entre el río y su entorno en los ambientes cordilleranos son muchas y pueden tener consecuencias en la biota y en las tramas tróficas. De hecho la composición, los atributos estructurales y funcionales de las comunidades de Trichoptera de los sitios de pasturas fueron significativamente diferentes a las exhibidas por los sitios boscosos con y sin manejo. La integridad y buena salud del bosque ribereño se tradujo en un mejoramiento de las condiciones dentro del arroyo y permitió un desarrollo de comunidades diversas de tricópteros, lo que coincide con lo observado en otras regiones (Castela et al. 2008; Song et al. 2009).

En recientes estudios (Vondracek et al. 2005; Arnaiz et al. 2010) se ha demostrado que la composición y diversidad de macroinvertebrados puede verse notablemente mejorada con la conservación de la vegetación ribereña y que los parches de vegetación aún con algún grado de discontinuidad podrían mitigar los efectos del uso pastoril sobre la biota acuática (Scarsbrook \& Halliday 1999) y esto ha sido extrapolado a ambientes de meseta patagónica con alto estatus de desertificación (Miserendino 2004). Más aún, Storey y Cowley (1997) demostraron que la composición de la comunidad de macroinvertebrados en tramos pastoreados se aproximó a la de los sitios de referencia hasta una distancia de hasta $600 \mathrm{~m}$ aguas abajo de la interfase bosquepastura. 
Una de las pautas de manejo sugeridas para conservar la calidad del agua de los ambientes sometidos a usos agrícologanaderos es la reforestación de la zona de ribera en bloques de 10 a 20 metros de ancho (Collier 1995; Naiman et al. 2005; Richardson \& Danehy 2007; Richardson 2008; Song et al. 2009; Wasson et al. 2010). Un corredor ribereño de 20 metros de ancho o de hasta cuatro veces el ancho del cauce mojado es el recomendado como método estandarizado, para lograr una reducción en el aporte de nutrientes y materia orgánica transportados por la escorrentía superficial (Vought et al. 1994; Wallace et al. 1995). Esto ha sido recientemente incorporado a las normativas de manejo del bosque de lenga y ñire por la DGBP del Chubut. Se ha observado que esto minimiza el ingreso de malezas y mantiene muchas de las funciones ecosistémicas (Parkyn et al. 2003).

En vista de los resultados presentados en este trabajo de tesis y dada su profunda influencia en el mantenimiento de la calidad del ecosistema dentro del arroyo sería recomendable prestar especial atención a los bosques de amortiguación ribereña en ambientes lóticos de cabecera. Sobre todo teniendo en cuenta que inciden en las condiciones ecológicas aún de los tramos aguas abajo.

\section{Tricópteros y uso de la tierra a una escala de paisaje}

Las actividades antropogénicas a una escala de cuenca se traducen en el deterioro de la integridad biótica de los ríos y en consecuencia de las comunidades de macroinvertebrados bentónicos que los habitan (Allan 2004; Vondracek et al. 2005). Aunque las urbanizaciones producen los impactos más severos en las comunidades acuáticas (Allan 2004; Poff et al. 2006), el uso agrícologanadero afecta la forma y función de estos ecosistemas derivando en la pérdida de la biota (Sutherland et al. 2002; Donohue et al. 2006), especialmente de aquellas especies endémicas (Harding et al. 1997). Por lo tanto un manejo adecuado a escala de cuenca atendiendo las realidades de cada región mejoraría la calidad ecológica y conservación de los recursos acuáticos (Lussier et al. 2008).

En el presente estudio se encontró que tanto la riqueza de especies de Trichoptera como la diversidad de esta comunidad se vieron influenciadas por la cobertura de distintos tipos de uso de la cuenca. Esto es, ante un aumento de la superficie de áreas urbanizadas y de pasturas se produjo una disminución significativa en el número de taxa y en la diversidad de Trichoptera. Los valores umbrales detectados 
tanto para la cobertura de usos urbanos como para las pasturas indicarían que entre 8 y $10 \%$ del área de la cuenca convertida a estos usos producirían una disminución significativa en los valores de riqueza y diversidad de tricópteros. Estos resultados coinciden plenamente con lo reportado por Paul y Meyer (2001) para cuencas urbanizadas de América del Norte, en las cuales 10 y $15 \%$ del área de la cuenca urbanizada produjeron dramáticos cambios en distintos atributos de la comunidad de macroinvertebrados bentónicos. Por otra parte Lussier et al. (2008), en arroyos de Rhode Island, documentaron un notorio cambio desde una fauna sensible hacia una más tolerante con el incremento de las áreas urbanas. Asimismo, Maloney y Feminella (2006) encontraron un valor umbral de $10 \%$ correspondiente a coberturas de superficies impermeables en la cuenca a partir del cual se produjeron alteraciones significativas en las comunidades de macroinvertebrados, principalmente una disminución de los grupos sensibles (EPT), y de los valores de los índices bióticos.

La relación significativa y positiva entre la riqueza de Trichoptera y el incremento de cobertura de bosque nativo en la cuenca es totalmente consistente con lo reportado por Death y Collier (2010) para ambientes neozelandeses. Los autores encontraron para la comunidad biótica en general, que los valores de los índices bióticos (MCI y QMCI), el porcentaje de individuos del grupo EPT, y el número de taxa EPT, entre otras variables, se incrementaron con el aumento de la cobertura de bosque nativo en la cuenca, siendo esta variable un modelador de las condiciones ecológicas en esos cursos de agua. Un comportamiento similar fue documentado para ríos estadounidenses en los trabajos de Sponseller et al. (2001), Strayer et al. (2003) y Sweeney et al. (2004), entre otros. En la mayoría de estos casos se estimó que ante una pérdida de 40 a $60 \%$ de la vegetación nativa de la cuenca la declinación de la diversidad de macroinvertebrados fue drástica. Asimismo, Black et al. (2004), demostraron que el número total de taxa disminuiría rápidamente por debajo del 70 a $80 \%$ de cobertura boscosa en la cuenca. La tendencia observada en los modelos obtenidos en este estudio para las cuencas estudiadas de la cordillera patagónica, fue que una pérdida de $40 \%$ de bosque nativo se tradujo en una declinación del $35 \%$ de la riqueza taxonómica de tricópteros.

Por otra parte, no se encontró ninguna relación significativa entre la estructura funcional de la comunidad de Trichoptera en los ríos seleccionados y los porcentajes de cobertura de los distintos usos. Death y Collier (2010) tampoco hallaron relación entre la composición funcional de la comunidad béntica y el incremento de cobertura boscosa 
en la cuenca. Probablemente, la vegetación inmediatamente adyacente al cuerpo de agua incida en la estructura trófica de la comunidad (Collier et al. 1997; Kiffney et al. 2003). Sin embargo, Compin y Cereghino (2007) afirman que los distintos tipos de uso a nivel de cuenca, resultaron óptimos para explicar los cambios en los patrones de grupos funcionales observados en ambientes del sudoeste de Francia.

Los modelos predictivos presentados en este trabajo son modelos exploratorios que resultaron en su mayoría consistentes con lo documentado por diversos autores para otras regiones del mundo. Sería importante, sin embargo expandir este tipo de estudios hacia otras cuencas patagónicas contemplando diversas biozonas e incorporando un mayor número de sitios en el desarrollo de los modelos. 


\section{CONCLUSIONES}

La comunidad de Trichoptera encontrada en el presente estudio fue rica y diversa. Se registraron 37 especies, agrupadas en 26 géneros y 13 familias, lo que es mayor a lo documentado en estudios previos en la Patagonia. Asimismo se amplia la distribución de cuatro especies y logrando asociar la larva y el adulto de Psilopsyche molinai (Philorheithridae). Sin embargo se recomienda continuar con los trabajos orientados a la identificación específica o descripción de taxones que hasta el momento no pudieron ser correctamente asignados.

Los resultados obtenidos en el presente trabajo evidencian los cambios producidos por distintas actividades antrópicas tanto a nivel de corredor ribereño como a nivel de cuenca.

Entre los impactos más severos sobre las comunidades de tricópteros se encuentra el producido por las urbanizaciones. Estos sitios presentan homogeneización del sustrato, falta de cobertura ribereña, incremento del total de sólidos en suspensión y modificación del lecho y las márgenes como las más importantes causas de deterioro físico. Por otra parte la incorporación de nutrientes al curso de agua tanto por fuentes puntuales como por las difusas determina una fuerte polución química (respecto de los valores esperables en la región) documentada en el tramo correspondiente a la ciudad de Esquel, estas condiciones resultan en la extinción local de las especies del orden Trichoptera. En la ciudad de Cholila los disturbios fueron principalmente físicos (dragado con incremento de TSS), lo que determinó cambios de la estructura trófica de la comunidad.

Con respecto a los usos silvopastoriles, los sitios de pasturas presentan la degradación más importante en términos de características físicas, sin un incremento en los valores de nutrientes respecto a los otros usos. Estas modificaciones se traducen en cambios de la comunidad de tricópteros siendo la densidad, la diversidad y la equitatividad los estimadores más sensibles.

La densidad de los distintos grupos funcionales por uso silvopastoril refleja cambios en la calidad de cada uno de los usos. En este sentido, las pasturas se 
caracterizaron por un significativo aumento en la participación de los colectoresfiltradores posiblemente como resultado de un mayor aporte de material fino proveniente del lixiviado y escorrentía superficial de la cuenca.

El Análisis de Componentes Principales permitió realizar una diferenciación clara entre los sitios de bosque nativo de referencia respecto del resto de los usos en base a las características ambientales. En este sentido la temperatura media fue significativamente menor que en el resto de los usos y los valores de los índices de calidad de hábitat y calidad de bosque de ribera alcanzaron los valores óptimos en estos sitios.

Los sitios de bosque nativo de referencia presentan significativamente más cantidad de raspadores con respecto a los otros usos, sugiriendo que los cambios ambientales que resultan de las prácticas silvopastoriles podrían disminuir la presencia de los raspadores en las cuencas de cabecera.

La asociación típica de tricópteros de los sitios de bosque de referencia estuvo compuesta por Parasericostoma cristatum, Mastigoptila sp., Metrichia neotropicalis, Austrocosmoecus hirsutus, Smicridea sp. 2, Monocosmoecus sp. y Austrocentrus valgiformis. Este grupo de taxa sensibles caracterizaría los ensambles de tricópteros de los sitios sin polución química ni degradación física en ambientes cordilleranos patagónicos.

Los ensambles de tricópteros típicos de pasturas estuvieron constituidos por: Parasericostoma ovale, Metachorema griseum, Oxyethira bidentata, Hudsonema flaminii, Brachysetodes quadrifidus, Reochorema lobuliferum, Smicridea annulicornis, Cailloma pumida y Verger sp. Estos fueron frecuentes y abundantes en los ambientes sometidos a uso ganadero.

El análisis de la comunidad de Trichoptera ya sea de los atributos comunitarios o funcionales no permitió evidenciar efectos negativos de las plantaciones de pino. Ciertas especies de tricópteros desmenuzadores presentarían plasticidad trófica los que permitiría consumir acículas de pino. Sin embargo es recomendable analizar en un futuro otros posibles efectos de las plantaciones de coníferas exóticas sobre distintos 
aspectos de la estructura trófica y evaluar el posible efecto sobre los estadíos de pupas y adultos. Asimismo, futuros estudios deberían evaluar a fondo los efectos de la presencia de otras especies exóticas en los bosques de ribera como por ejemplo Salix fragilis.

Se encontró una relación negativa entre riqueza taxonómica y diversidad de tricópteros y el área de la cuenca urbanizada y convertida a pasturas, mientras que la relación fue positiva entre la riqueza taxonómica y el porcentaje de la cuenca cubierto de bosque nativo. Asimismo, se reconoce un valor umbral de 8-10\% a partir del cual se evidencia una pérdida significativa en la riqueza y diversidad de esta comunidad, lo que coincide ampliamente con lo documentado en diversos trabajos para el hemisferio norte y el hemisferio sur.

Sería recomendable que se continúe con la utilización de estas herramientas de información geográfica en futuros trabajos que profundicen el análisis de estas relaciones incorporando otras cuencas patagónicas de diversas biozonas que incluyan un mayor número de sitios en el desarrollo de los modelos.

Los resultados del presente estudio ponen en evidencia los efectos favorables del mantenimiento de la vegetación ribereña sobre las condiciones ambientales y el funcionamiento de los ríos de cabecera patagónicos, de acuerdo a las observaciones registradas en los ríos Nant y Fall, Glyn, Cabeza de vaca. Aún cuando se halla presente en parches, puede atenuar los efectos del desarrollo pastoril y de las actividades de extracción de madera del bosque. Los efectos del sombreo, el aporte de material orgánico para las larvas, el hábitat adecuado para los adultos y la mayor estabilidad de las riberas serían los beneficios más importantes que aporta un corredor ribereño sano.

A raíz de las prácticas extractivas en el bosque se observa un manejo inapropiado de la vegetación de ribera (sitio Pipo) con talas que afectan especímenes del corredor ribereño y una disposición inadecuada del material de descarte. Esto se traduce en una disminución en la calidad del hábitat dentro del arroyo y cambios marcados en la estructura trófica.

Como resultado de un enfoque integral, es posible detectar que los cambios más significativos en ecosistemas lóticos que incluirían características físicas, químicas, 
condición del hábitat, de la ribera y comunidad de Trichoptera, se produjeron en los sitios urbanos, un estado intermedio se encontró en usos pasturas, seguido de bosque manejado y bosque de pino. Los sitios de bosque nativo presentan la mayor integridad ecológica con las mejores condiciones ambientales, en los cuales se encuentra una comunidad de tricópteros rica, diversificada y con mayor cantidad de representantes endémicos.

En un escenario de expansión acelerada de las áreas urbanas en la Patagonia, se vislumbran problemas en el manejo cursos de agua y en el tratamiento de los residuos cloacales producidos por las urbanizaciones. En principio las prácticas de canalización y dragado de cursos de agua son muy frecuentes en los ambientes urbanos, y se traducen una degradación seria de la calidad del hábitat lo que repercute directamente en la biota acuática. Por otra parte debido a la falta de previsión en el crecimiento poblacional fallas en la planificación urbana a la que se suman cuestiones económicas, las plantas de tratamiento pueden resultar insuficientes.

En relación al manejo del bosque para colecta de leña se observaron ineficiencias en el control sobre las prácticas extractivas en el bosque de ñire. Es decir que las normas establecidas para la protección del bosque de ribera no se respetaron efectivamente.

Las prácticas involucradas en los usos de la tierra y la manera que afectan la integridad y la conservación de los ecosistemas acuáticos de la Patagonia se destacan como problemas emergentes. El presente trabajo resalta la vulnerabilidad de la estos ambientes frente a los disturbios antrópicos y el rol de las comunidades de Trichoptera en los ecosistemas de cabecera patagónicos. 


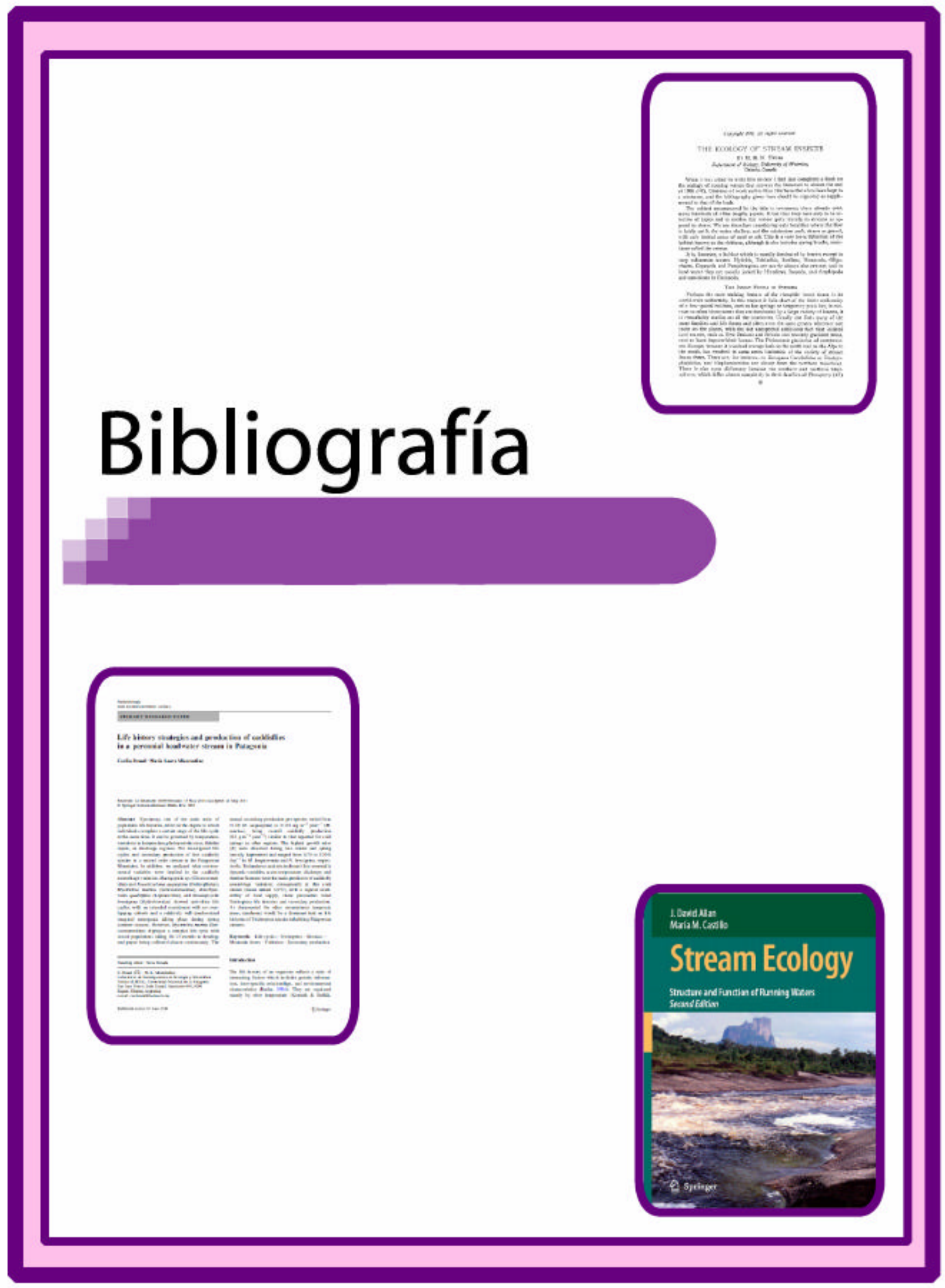




\section{BIBLIOGRAFIA}

Albariño, R.J. \& E.G. Balseiro. 2002. Leaf litter breakdown in Patagonian streams: native versus exotic trees and the effect of invertebrate size. Aquatic Conservation: Marine and Freshwater Ecosystems. 12: 181-192.

Albariño, R.J. \& A.C. Valverde. 1999. Hábito alimentario del estado larval de Parasericostoma cristatum (Trichoptera: Sericostomatidae). Revista de la Sociedad Entomológica Argentina. 57 (1-4): 131-135.

Allan, J.D. 2004. Influence of land use and landscape setting on the ecological status of rivers. Limnetica. 23 (3-4): 187-198.

Allan, J.D. \& M.M. Castillo. 2007. Stream Ecology. Structure and function of running waters. Editor Series Springer. Dordrecht, Netherlands. 436.

Allan, J.D., D.L. Erickson \& J. Fay. 1997. The influence on catchment land use on stream integrity across multiple spatial scales. Freshwater Biology. 37: 149-161.

Allen, K.R. 1959. Effect of land development on stream bottom faunas. Proceedings of the New Zealand Ecological Society. p. 7

Anderson, N.H. 1992. Influence of disturbance on insect communities in Pacific Northwest streams. Hydrobiologia. 248: 79-92.

Angrisano, E.B. 1995 a. Insecta Trichoptera. En: Lopretto, E. y Tell, G. (eds). Ecosistemas de Aguas Continentales. Metodologías para su estudio. 3. Ediciones Sur. pp 1199-1237.

Angrisano, E.B. 1995 b. Contribución para el conocimiento de las Oxyethira Neotropicales (Trichoptera, Hydroptilidae). Physis. 50 (118-119): 27-35.

Angrisano, E.B. 1997. Contribution to the knowledge of the larvae of Hydrobiosidae. I. Neopsilochorema tricarinatum and Australochorema rectispinum. Proceedings of the $7^{\text {th }}$ International Symposium on Trichoptera, 15-17.

Angrisano, E.B. \& P.G. Korob. 2001. Trichoptera. En: Fernández, H.R. \& E. Domínguez (eds). Guía para la determinación de los Artrópodos Bentónicos Sudamericanos. Editorial Universitaria de Tucumán. Tucumán. Argentina, 55-92.

Angrisano, E.B. \& J.V. Sganga. 2005. Contribution to the knowledge of the genus Metrichia Ross from Argentina (Trichoptera: Hydroptilidae: Ochrotrichiini). Aquatic Insects. 27 (2): 113-123. 
Angrisano, E.B. \& J.V. Sganga. 2007. Guía para la identificación de los tricópteros (Insecta) del Parque Nacional El Palmar (Entre Ríos, Republica Argentina). Natura Neotropicalis. 38 (1-2): 1-55.

Angrisano, E.B. \& J.V. Sganga. 2009. Trichoptera. En: Domínguez, E. \& H.R. Fernández (eds). Macroinvertebrados bentónicos sudamericanos: sistemática y biología. $1^{\mathrm{a}}$ edición. Fundación Miguel Lillo. Tucumán. Argentina, 255-307.

APHA. 1980. Standard Methods for the Examination of Water and Wastewater. American Public Health Association, Washington, D.C., USA. 1134 pp.

APHA. 1999. Standard Methods for the Examination of Water and Wastewater. American Public Health Association, Hanover, MD, USA. 1325 pp.

APHA - AWWA - WPCF. 1989. Standard methods for the Examination of Water and Wastewater. Clesceri, I.S., A.F. Greenberg \& R.R. Trussell (Eds). 17 edición. Baltimore, Maryland.

Armitage, P.D. \& C.E. Cannan. 1999. Annual changes in summer patterns of mesohabitat distribution and associated macroinvertebrates assemblages. Hydrological Processes. 14: 3161-3179.

Armitage, P.D., D. Moss, J.F. Wright \& M.T. Furse. 1983. The performance of a new biological water quality score system based on macroinvertebrates over a wide range of unpolluted running water sites. Water Research. 17: 333-347.

Arnaiz, O.L., A.L. Wilson, R.J. Watts \& M.M. Stevens. 2010. Influence of riparian condition on aquatic macroinvertebrate communities in an agricultural catchment in south-eastern Australia. Ecological Research. 26 (1): 123-131.

Baas, S.F.J. \& J.B.T. Mennen. 1996. Aspects of microclimate in contrasting land use, and the light climate along stream continua in New Zealand. Niwa Report REC602. 45 pp.

Baillie, B.R., K.J. Collier \& J. Nagels. 2005. Effects of forest harvesting and woody debris removal on two Northland streams, New Zealand. New Zealand Journal of Marine and Freshwater Research. 39: 1-15.

Baillie, B.R. \& T.R. Davies. 2002. Influence of large woody debris on channel morphology in native forest and pine plantation streams in the Nelson region, New Zealand. New Zealand Journal of Marine and Freshwater Research. 36: 763-774.

Ballesteros Navia, Y.V., M.D.C. Zúñiga De Cardoso \& A.M. Rojas De Hernández. 1997. Distribution and structure of the order Trichoptera in Various 
drainages of the Cauca River basin, Colombia, and their relationship to the water quality. Proceedings of the $8^{\text {th }}$ International Symposium on Trichoptera, 19-23.

Barbour, M.T., J. Gerritsen, B.D. Snyder \& J.B. Stribling. 1999. Rapid bioassessment protocols for use in streams and wadeable rivers: periphyton, benthic macroinvertebrates and fish. U.S. Environmental Protection Agency; Office of Water. Washington, D.C. 339 pp.

Barbour, M.T. \& J.B. Stribling. 1991. Use of habitat assessment in evaluating the biological integrity of stream communities. En: Gibson, G. (ed.). Biological criteria: Research and regulation. Proceedings of a symposium. Office of Water, U.S. Environmental Protection Agency. Washington, D.C. EPA-440-5-91-005. Arlington.

Barbour, M.T. \& J.B. Stribling. 1994. A technique for assessing stream habitat structure. En: Conference proceedings, Riparian ecosystems in the humid U.S.: Functions, values and management. National Association of Conservation Districts, Washington D.C. Atlanta, Georgia, 156-178.

Barringer, T.H., R.G. Reiser \& C.V. Price. 1994. Potential effects of development on flow characteristics of two New Jersey streams. Water Resource Bulletin. 30: 283-295.

Bauer, G. 2010. Calidad del agua en el río Percy inferior en relación con las características naturales y de uso del suelo de la cuenca. Tesis de Licenciatura. Universidad Nacional de la Patagonia "San Juan Bosco". 58 pp.

Black, R.W., M.D. Munn \& R.W. Plotnikoff. 2004. Using macroinvertebrates to identify biota-land cover optima at multiple scales in the pacific northwest. Journal of the North American Benthological Society. 23: 340-362.

Blakely, T.J. \& J.S. Harding. 2005. Longitudinal patterns in benthic communities in an urban stream under restoration. New Zealand Journal of Marine and Freshwater Research. 39: 17-28.

Blinn, D.W. \& D.E. Ruiter. 2006. Tolerance values of stream caddisflies (Trichoptera) in the lower Colorado River Basin, USA. The Southwestern Naturalist. 51 (3): $326-337$.

Bonada, N., C. Zamora-Muñoz, M. Rieradevall \& N. Prat. 2004. Ecological profiles of caddisfly larvae in Mediterranean streams: implications for bioassessment methods. Environmental Pollution. 132: 509-521.

Brand, C. 2009. Nuevas citas de Trichoptera para la Patagonia Argentina. Revista de la Sociedad Entomológica Argentina. 68 (1-2): 223-226. 
Brand, C. \& M.L. Miserendino. 2011 a. Characterizing Trichoptera trophic structure in rivers under contrasting land use in Patagonia, Argentina. Zoosymposia. Proceedings of $13^{\text {th }}$ International Symposium on Trichoptera. 5: 29-40.

Brand, C. \& M.L. Miserendino. 2011 b. Life cycle phenology, secondary production, and trophic guilds of caddisfly species in a lake-outlet stream of Patagonia. Limnologica. doi:10.1016/j.limno.2011.09.004.

Brand, C. \& M.L. Miserendino. 2011 c. Life history strategies and production of caddisflies in a perennial headwater stream in Patagonia. Hydrobiologia. 673 (1): $137-151$.

Bravo, W.R. \& E.B. Angrisano. 2003. Contribution to the knowledge of the pre-imaginal stages of Neotropical Hydrobiosidae (Trichoptera): Metachorema griseum Schmid. Aquatic Insects. 25 (3): 203-209.

Bravo, W.R. \& E.B. Angrisano. 2004. Descripción de los estados preimaginales de cuatro géneros de Hydrobiosidae (Trichoptera) Neotropicales. Revista de la Sociedad Entomológica Argentina. 61 (3-4): 97-105.

Brookes, A. 1988. Channelized rivers: perspectives for environmental management. John Wiley \& Sons. Chichester. 326 pp.

Brunton, M.N. 1985. The effects of suspensoids on fish. Hydrobiologia. 125: 221-242.

Bulleri, F., A.J. Underwood \& L. Benedetti-Chiecchi. 2007. The assessment and interpretation of ecological impacts in human-dominated environments. Environmental Conservation. 34 (3): 181-182.

Camargo, J.A., A. Alonso \& M. De La Puente. 2004. Multimetric assessment of nutrient enrichment in impounded rivers based on benthic macroinvertebrates. Environmental Monitoring and Assessment. 96: 233-249.

Carabelli, F. \& R. Scoz. 2008. Human-Induced Alterations in Native Forests of Patagonia, Argentina. En: Lafortezza, R., J. Chen, G. Sanesi y T. R. Crow (eds). Patterns and Processes in Forest Landscapes. Springer Science, 89-105.

Carrascosa, V. \& A. Munné. 2000. Qualificació dels boscos de ribera Andorrans. Adaptació de l'índex QBR als rius d'alta muntanya. Hábitats. 1: 4-13.

Castela, J., V. Ferreira \& M.A.S. Graca. 2008. Evaluation of stream ecological integrity using litter decomposition and benthic invertebrates. Environmental Pollution. 153: 440-449. 
Chakona, A., C. Phiri \& J.A. Day. 2009. Potential for Trichoptera communities as biological indicators of morphological degradation in riverine systems. Hydrobiologia. 621: 155-167.

Chessman, B.C. 1995. Rapid assessment of rivers using macroinvertebrates: a procedure based on habitat-specific sampling, family level identification and a biotic index. Australian Joumal of Ecology. 20: 122-129.

Collier, K.J. 1995. Environmental factors affecting the taxonomic composition of aquatic macroinvertebrate communities in lowland waterways of Northland, New Zealand. New Zealand Journal of Marine and Freshwater Research. 29: 453-465.

Collier, K.J. \& E.J. Bowman. 2003. Role of wood in pumice-bed streams I: impacts of post-harvest management on water quality, habitat and benthic invertebrates. Forest Ecology and Management. 177: 243-259.

Collier, K.J. \& J.M. Quinn. 2003. Land-use influences macroinvertebrates community response following a pulse disturbance. Freshwater Biology. 48: 1462-1481.

Collier, K.J. \& B.J. Smith. 1995. Sticky trapping of adult mayflies, stoneflies and caddisflies alongside three contrasting streams near Hamilton, New Zealand. New Zealand Natural Sciences. 22: 1-9.

Collier, K.J., B.J. Smith \& B.R. Baillie. 1997. Summer light-trap catches of adult Trichoptera in hill-country catchments of contrasting land use, Waikato, New Zealand. New Zealand Journal of Marine and Freshwater Research. 37: 623-634.

Collier, K.J., B.J. Smith, J.M. Quinn, M.R. Scarsbrook, N.J. Halliday, G.F. Crocker \& S.M. Parkyn. 2000. Biodiversity of stream invertebrate faunas in a Waikato hill-country catchment in relation to land use. New Zealand Entomology. 23: 922.

Collier, K.J., R.J. Wilcock \& A.S. Meredith. 1998. Influence of substrate type and physico-chemical conditions on macroinvertebrate faunas and biotic indices of some lowland Waikato, New Zealand streams. New Zealand Journal of Marine and Freshwater Research. 32: 1-19.

Compin, A. \& R. Céréghino. 2007. Spatial patterns of macroinvertebrate functional feeding groups in streams in relation to physical and land-cover in southwestern France. Landscape Ecology. 22: 1215-1225.

Corigliano, M. del C. 1999. Índices bióticos: Aplicaciones y alcances. Revista de la Sociedad Entomológica Argentina. 58 (1-2): 193-201. 
Coronato, F.R. \& H.F. Del Valle. 1988. Caracterización hídrica de las cuencas hidrográficas de la provincia del Chubut. Series Cenpat-Conicet. Puerto Madryn. Chubut. Argentina. 183 pp.

Correa, M.O. 1978-1999. Flora Patagónica. Tomo VIII: parte I, II, III, IVa, IVb, V y VIII. Colección científica del INTA. Buenos Aires.

Cortelezzi, A. 2009. Hábitats funcionales y macroinvertebrados en cauces modificados de arroyos de llanura: impacto sobre la calidad ecológica. Tesis Doctoral. Universidad Nacional de La Plata. XI+158 pp.

Cox, T.J. \& J.C. Rutherford. 2000. Thermal tolerances of two stream invertebrates exposed to diurnally varying temperature. New Zealand Journal of Marine and Freshwater Research. 34: 203-208.

Cummins, K.W. 1972. What is a river? Zoological description. En: River, Ecology and Man. Oglesby R.T., C.A. Carlson \& J.A. McCann (eds.). Academic Press, Inc. New York and London, 33-52.

Cummins, K.W. \& M.J. Klug. 1979. Feeding Ecology of Streams Invertebrates. Annual Review of Ecology and Systematics. 10: 147-172.

Davies-Colley, R.J., C.W. Hickey, J.M. Quinn \& P.A. Ryan. 1992. Effects of clay discharges on streams. 1. Optical properties and epilithon. Hydrobiologia. 248: 215-234.

Davies-Colley, R.J. \& J.M. Quinn. 1998. Stream lighting in five regions of the North Island, New Zealand: control by channel size and riparian vegetation. New Zealand Journal of Marine and Freshwater Research. 32: 591-605.

Davies, P.J., I.A. Wright, S.J. Findlay, O.J. Jonasson \& S. Burgin. 2010. Impact of urban development on aquatic macroinvertebrates in south eastern Australia: degradation of in-stream habitats and comparison with non-urban streams. Aquatic Ecology. 44 (4): 685-700.

de Moor, F.C. 1999. The use of Trichoptera to assess biodiversity and conservation status of South African river systems. Proceedings of the $9^{\text {th }}$ International Symposium on Trichoptera. Chiang Mai, China, 237-244.

de Moor, F.C. 2007. Regional biogeographical differences in Trichoptera diversity in South Africa: Observed patterns and processes. Proceedings of the $12^{\text {th }}$ International Symposium on Trichoptera. Mexico. Bueno-Soria, J., R. Barba-Álvarez \& B. Armitage (eds). The Caddis Press, 211-218. 
de Moor, F.C. \& V.D. Ivanov. 2008. Global diversity of caddisflies (Trichoptera: Insecta) in freshwater. Hydrobiologia. 595: 393-407.

Death, R.G., B.R. Baillie \& P. Fransen. 2003. Effect of Pinus radiata logging on stream invertebrate communities in Hawke's Bay, New Zealand. New Zealand Journal of Marine and Freshwater Research. 37: 507-520.

Death, R.G. \& K.J. Collier. 2010. Measuring stream macroinvertebrate responses to gradients of vegetation cover: when is enough enough? Freshwater Biology. 55: 1447-1464.

DGAG. Dirección General de Agricultura y Ganadería de la Provincia del Chubut. 2006. Estadística ganadera anual. http://organismos.chubut.gov.ar/dgag/2006/ 11/16/estadistica-ganadera-anual-2006/

Díaz Villanueva, V., L. Buria \& R.J. Albariño. 2010. Primary consumers and resources: annual variation in two contrasting reaches of a Patagonian mountain stream. Annales de Limnologie - International Journal of Limnology. 46: 1-8.

Dimitri, M.J. 1977. Pequeña flora ilustrada de los Parques Nacionales AndinoPatagónicos. Separata de Anales de Parques Nacionales, Tomo XXIII. Servicio Nacional de Parques Nacionales. 122 pp.

Dohet, A. 2002. Are caddisflies an ideal group for the biological assessment of water quality in streams? Proceedings of the $10^{\text {th }}$ International Symposium on Trichoptera. Nova Suppl. Ent., Keltern, 507-520.

Domínguez, E. \& H.R. Fernández. 1998. Calidad de los ríos de la cuenca del Salí (Tucumán Argentina) medida por un índice biótico. Serie conservación de la naturaleza. Tomo II. Fundación Miguel Lillo Tucumán. Universidad Nacional de Tucumán. Tucumán.

Donohue, I., M.L. Mcgarrigle \& P. Mills. 2006. Linking catchment characteristics and water chemistry with the ecological status of Irish rivers. Water Research. 40: 91-98.

Dunne, T. \& L.B. Leopold. 1978. Water in Environmental Planning. Freeman. New York. 818 pp.

Faulkner, H., V. Edmonds-Brown \& A. Green. 2000. Problems of quality designation in diffusely populated urban streams - the case of Pymme's Brook, North London. Environmental Pollution. 109: 91-107. 
Fernández, H.R., F. Romero, M.B. Vete, V. Manzo, C. Nieto \& M. Orce. 2002. Evaluación de tres índices bióticos en un río subtropical de montaña (TucumánArgentina). Limnetica. 21 (1-2): 1-13.

Finkenbine, J.K., D.S. Atwater \& D.S. Mavinic. 2000. Stream health after urbanization. Journal of American Water Resources Association. 36: 1149-1160.

Flint, O.S. Jr. 1973. Studies of Neotropical Caddisflies, XVI: the genus Austrotinodes (Trichoptera: Psychomyiidae). Proceedings of the Biological Society of Washington. 86 (11): 127-142.

Flint, O.S. Jr. 1974. Studies of Neotropical Caddisflies, XIX: The genus Cailloma (Trichoptera: Rhyacophilidae). Proceedings of the Biological Society of Washington. 87 (41): 473-484.

Flint, O.S. Jr. 1983. Studies of Neotropical Caddisflies, XXXIII: New Species from Austral South America (Trichoptera). Smithsonian Contributions to Zoology. 377: 1-100.

Flint, O.S. Jr. 1997. Studies of Neotropical Caddisflies, LIV: the Patagonian genus Austrocentrus, with the description of its immature stages (Trichoptera: Helicophidae). Proceedings of the $8^{\text {th }}$ International Symposium on Trichoptera. Ohio Biological Survey, 99-108.

Flint, O.S. Jr., R.H. Holzenthal \& S.C. Harris. 1999. Catalog of the Neotropical Caddisflies (Insecta: Trichoptera). Ohio Biological Survey. Columbus, Ohio. IV + 239 pp.

Friberg, N. \& M.J. Winterbourn. 1997. Effects of native and exotic forest on benthic stream biota in New Zealand: a colonization study. Marine and Freshwater Research. 48: 267-275.

Fuchs, S.A., S.G. Hinch \& E. Mellina. 2003. Effects of streamside logging on stream macroinvertebrate communities and habitat in the sub-boreal forests of British Columbia, Canada. Canadian Journal of Forest Research. 33: 1408-1415.

García, A., B. Villeneuve \& J.G. Wasson. 2006. Large scale evaluations of pressures. En: Solimini, A.G., A.C. Cardoso \& Heiskanen, A.S. (eds). Indicators and Methods for Water Framework Directive Ecological Status Assessment. Linkages Between Chemical and Biological Quality of Surface Waters. Office for official Publications of the European Communities. Luxembourg, 213-225. 
García Sotillo, F. 2011. Efectos de la cloración de efluentes cloacales tratados sobre la calidad de agua de ambientes lóticos naturales. Tesis de Licenciatura. Universidad Nacional de la Patagonia "San Juan Bosco". 63 pp.

Giller, P.S. \& B. Malmqvist. 1998. The Biology of Streams and Rivers. Primera edición. Biology of Habitats. Oxford University Press. Oxford. 296 pp.

Gombeer, S.C., D. Knapen \& L. Bervoets. 2011. The influence of different spatial-scale variables on caddisfly assemblages in Flemish lowland streams. Ecological Entomology. 36: 355-368.

González Del Tánago, M. \& M. Antón. 1998. Plan forestal de la Comunidad de Madrid. Subprograma de ríos y riberas. E.T.S. Ingenieros de Montes. Madrid.

González Del Tánago, M. \& M. Antón. 2000. Aplicación del índice QBR para estimar la calidad ambiental de las riberas de los principales ríos de la comunidad de Madrid. Resúmenes del X Congreso de la Asociación Española de Limnología y II Congreso Ibérico de Limnología. Valencia, España.

Gordon, N.D., T.A. Mcmahon, B.L. Finlayson, C.J. Gippel \& R.J. Nathan. 2004. Stream Hydrology. An Introduction for Ecologists. $2^{\text {nd }}$ edition. John Wiley \& Sons Ltd. Sussex, England. 429 pp.

Graf, W., J. Murphy, J. Dahl, C. Zamora-Muñoz \& M.J. López-Rodríguez. 2008. Trichoptera. Distribution and Ecological Preferences of European Freshwater Organisms. Pensoft Publishers. Sofia, Bulgaria. 388 pp.

Graynoth, E. 1979. Effects of logging on stream environments and faunas in Nelson. New Zealand Journal of Marine and Freshwater Research. 13: 79-109.

Gualdoni, C.M., M.F. Boccolini, A.M. Oberto, R.E. Principe, G.B. Raffaini \& M. del C. Corigliano. 2009. Potential habitats versus functional habitats in a lowland braided river (Córdoba, Argentina). Annales de Limnologie - International Journal of Limnology. 45: 69-78.

Gualdoni, C.M. \& M. del C. Corigliano. 1991. El ajuste de un índice biótico para uso regional. Revista de la Universidad Nacional de Río Cuarto. 11: 65-80.

Gualdoni, C.M., A.M. Oberto \& G.B. Raffaini. 1994a. Evaluación de la calidad biológica de los ambientes lóticos de la subcuenca del Río Ctalamochita (Tercero) (Córdoba, Argentina). Revista de la Universidad Nacional de Río Cuarto. 14 (1): $65-80$. 
Gualdoni, C.M., A.M. Oberto \& G.B. Raffaini. 1994b. La aplicación de índices bióticos en la subcuenca del río Concharava (Cuarto) (Córdoba, Argentina). Revista de la Universidad Nacional de Río Cuarto. 14 (1): 39-53.

Haggerty, S.M., D.P. Batzer \& C.R. Jackson. 2002. Macroinvertebrate assemblages in perennial headwater streams of the Coastal Mountain range of Washington, U.S.A. Hydrobiologia. 479: 143-154.

Hall, M.J., P. Closs \& R.H. Riley. 2001. Relationships between land-use and stream invertebrate community structure in a South Island, New Zealand, coastal stream catchment. New Zealand Journal of Marine and Freshwater Research. 35: 591-603.

Harding, J.S., J.M. Quinn \& C.W. Hickey. 2000. Effects of mining and production forestry. En: Collier, K.J. \& M.J. Winterbourn (eds). New Zealand stream invertebrates: ecology and implications for management. Limnological Society. Christchurch, New Zealand, 230-259.

Harding, J.S. \& M.J. Winterbourn. 1995. Effects of contrasting land use on physico-chemical conditions and benthic assemblages of streams in a Canterbury (South Island, New Zealand) river system. New Zealand Journal of Marine and Freshwater Research. 29: 479-492.

Harding, J.S., M.J. Winterbourn \& W. Mc Diffet. 1997. Stream faunas and ecoregions in the South Island, New Zealand: do they correspond? Archiv für Hydrobiologie. 140: 289-307.

Hellawell, J.M. 1978. Biological surveillance of rivers. Medmenham \& Stevenage, Water Research Centre. U.K. XII + 331 pp.

Hellawell, J.M. 1986. Biological Indicators of Freshwater Pollution and Environmental Management. Editor Series Elsevier. London. 546 pp.

Herbst, G.N. 1980. Effects of burial on food value and consumption of leaf detritus by aquatic invertebrates in a lowland forest stream. Oikos. 35: 411-424.

Hering, D., A. Schmidt-Kloiber, J. Murphy, S. Lüke, C. Zamora-Muñoz, M.J. López-Rodríguez, T. Huber \& W. Graf. 2009. Potential impact of climate change on aquatic insects: A sensitivity analysis for European caddisflies (Trichoptera) based on distribution patterns and ecological preferences. Aquatic Sciences. 71: 3-14.

Hetrick, N.J., M.A. Brusven, T.C. Bjornn, R.M. Keith \& W.R. Meehan. 1998. Effects of canopy removal on invertebrates and diet of juvenile Coho salmon in a small stream in southeast Alaska. Transactions of the American Fisheries Society. 127: 876-888. 
Hickey, C.W. 2000. Ecotoxicology: laboratory and field approaches. En: Collier, K.J. \& M.J. Winterbourn (eds). New Zealand streams invertebrates: ecology and implications for management. New Zealand Limnological Society. Christchurch, 313343.

Holzenthal, R.H., R.J. Blahnik, A.L. Prather \& K.M. Kjer. 2007. Order Trichoptera Kirby, 1813 (Insecta), Caddisflies. Zootaxa. 1668: 639-698.

Holzenthal, R.W. 1986a. Studies in Neotropical Leptoceridae (Trichoptera), IV: a revision of Brachysetodes Schmid. Transactions of the American Entomological Society. 111: 407-440.

Holzenthal, R.W. 1986b. Studies in Neotropical Leptoceridae (Trichoptera), VI: Immature Stages of Hudsonema flaminii (Navás) and the Evolution and Historical Biogeography of Hudsoneminii (Triplectidinae). Proceedings of the Entomological Society of Washington. 88 (2): 268-279.

Hynes, H.B.N. 1970. The ecology of stream insects. Annual Reviews of Entomology. 15: 25-42.

Johnson, R.K., M.T. Furse, D. Hering \& L. Sandin. 2007. Ecological relationships between stream communities and spatial scale: implications for designing catchment level monitoring programmes. Freshwater Biology. 52: 939-958.

Kedzierski, W.M. \& L.A. Smock. 2001. Effects of logging on macroinvertebrate production in a sand-bottomed, low gradient stream. Freshwater Biology. 46: 821-833.

Kiffney, P.M., J.S. Richardson \& J.P. Bull. 2003. Responses of periphyton and insects to experimental manipulation of riparian buffer width along forest streams. Journal of Applied Ecology. 40: 1060-1076.

Kutschker, A., C. Brand \& M.L. Miserendino. 2009. Evaluación de la calidad de los bosques de ribera en ríos del NO del Chubut sometidos a distintos usos de la tierra. Ecología Austral. 19: 19-34.

Jackson, J. 1988. Diel emergency and longevity of selected adult aquatic insects from a Sonoran desert stream. The American Midland Naturalist. 119: 344-352.

Jones, J.B. \& L.A. Smock. 1991. Transport and retention of particulate organic matter in two low-gradient streams. Journal of the North American Benthological Society. 10: 115-126. 
Latimer, J.S. \& J.G. Quinn. 1998. Aliphatic petroleum and biogenic hydrocarbons entering Narragansett Bay from tributaries under dry weather conditions. Estuaries. 21: 91-107.

Lenat, D.R. \& J.K. Crawford. 1994. Effects of land use on water quality and aquatic biota of three North Carolina Piedemont streams. Hydrobiologia. 294: 185-199.

Lopretto, E. \& G. Tell. 1995. Ecosistemas de Aguas Continentales. Metodologías para su estudio. Tomos I, II y III. Ediciones Sur. 1401 pp.

Ludwig, J.A. \& J.F. Reynolds. 1988. Statistical Ecology. Editor Series Wiley Interscience. 333 pp.

Lussier, S.M., S.N. Da Silva, M. Charpentier, J.F. Heltshe, S.M. Cormier, D.J. Klemm, M. Chintala \& S. Jayaraman. 2008. The influence of suburban land use on habitat and biotic integrity of coastal Rhode Island streams. Environmental Monitoring and Assessment. 139 (1-3): 119-136.

Macchi, P.A. 2007. Tesis de Licenciatura. Calidad del agua en ecosistemas fluviales utilizando macroinvertebrados bentónicos. Universidad Nacional del Comahue. 79 pp.

Mackay, R.J. \& G.B. Wiggins. 1979. Ecological diversity in Trichoptera. Annual Review of Entomology. 24: 185-208.

Mallory, M.A. \& J.S. Richardson. 2005. Complex interactions of light, nutrients and consumer density in a stream periphyton-grazer (tailed frog tadpoles) system. Journal of Animal Ecology. 74: 1020-1028.

Maloney, K.O. \& J.W. Feminella. 2006. Evaluation of single- and multi-metric benthic macroinvertebrate indicators of catchment disturbance over time at the Fort Benning Military Installation, Georgia, USA. Ecological Indicators. 6: 469-484.

Mangeaud, A. 1996. Trichopterans in a River of the Gran Chaco, Argentina. Studies on Neotropical Fauna and Environment. 31: 152-155.

Mangeaud, A. 1999. Efectos de fuentes de contaminación puntual sobre las comunidades de insectos bentónicos en la cuenca del Suquía (Córdoba). Revista de la Sociedad Entomológica Argentina. 58 (1-2): 218-222.

Marchese, M. \& I. Ezcurra De Drago. 2006. Bentos como Indicadores de Condiciones Tróficas del Río Paraná Medio. En: Tundisi, J.G., T. Matsumura-Tundisi \& C.S. Galli (eds). Eutrofização na América do Sul: Causas, Conseqüências e Tecnologias de Gerenciamento e Controle. São Carlos, 339-362. 
Masi, C.I. \& M.L. Miserendino. 2009. Usos de la tierra y distribución de la materia orgánica particulada béntica en ríos de montaña (Patagonia, Argentina). Ecología Austral. 19: 185-196.

Mason, C.F. 1991. Biology of freshwater pollution. Longman Scientific and Technical. New York. 614 pp.

Mayack, D.T., J.H. Thorp \& M. Cothran. 1989. Effects of burial and floodplain retention on stream processing of allochtonous litter. Oikos. 54: 378-388.

Melody, K.J. \& J.S. Richardson. 2007. Riparian forest harvesting and its influence on benthic communities of small streams of sub-boreal British Columbia. Canadian Journal of Forest Research. 37: 907-918.

Merritt, R.W. \& K.W. Cummins. 1996. An Introduction to the Aquatic Insects of North America. $3^{\text {ra }}$ Edición. Kendall/Hunt publishing Company. Dubuque, Iowa, USA. $862 \mathrm{pp}$.

Merritt, R.W., K.W. Cummins \& M.P. Berg. 2008. An Introduction to the Aquatic Insects of North America. $4^{\text {ta }}$ Edición. Kendall/Hunt Publishing Company. Dubuque, Iowa, Usa. 1158 pp.

Milne, M. 1938. The "metamorphotype method" in Trichoptera. Journal of the New York Entomological Society. 46: 435-437.

Miserendino, M.L. 1995. Composición y distribución del macrozoobentos de un sistema lótico andino-patagónico. Ecología Austral. 5: 133-142.

Miserendino, M.L. 1999. Distribución altitudinal de especies de Trichoptera en un sistema fluvial en Patagonia. Ecología Austral. 9: 28-34.

Miserendino, M.L. 2001. Macroinvertebrate assemblages in Andean Patagonian Rivers and streams: environmental relationships. Hydrobiologia. 444: 147158.

Miserendino, M.L. 2004. Effects of landscape and desertification on the macroinvertebrate assemblages of rivers in Andean Patagonia. Archiv für Hydrobiologie. 159 (2): 185-209.

Miserendino, M.L. 2005a. Interacciones bosque río implicaciones para los ecosistemas acuáticos. Patagonia Forestal. XI (4): 14-17.

Miserendino, M.L. 2005b. Usos de la tierra y comunidades de insectos acuáticos en ríos de Patagonia, los "sistemáticos" problemas con que nos encontramos los ecólogos. Resúmenes del VI Congreso Argentino de Entomología. San Miguel de Tucumán, 54. 
Miserendino, M.L. 2007. Macroinvertebrate functional organization and water quality in a large arid river from Patagonia (Argentina). International Journal of Limnology. 43 (3): 133-145.

Miserendino, M.L. \& C. Brand. 2007. Trichoptera assemblages and environmental features in a large arid Patagonian river. Fundamental and Applied Limnology. 169 (4): 307-318.

Miserendino, M.L. \& C. Brand. 2009. Environmental effects of urbanization on streams and rivers in Patagonia (Argentina): the use of macroinvertebrates in monitoring. En: Daniels, J.A. (ed). Advances in Environmental Research. Nova Science Publishers, Inc. New York, 1-38.

Miserendino, M.L., C. Brand \& C.Y. Di Prinzio. 2008. Assessing urban impacts on water quality, benthic communities and fish in streams of the Andes Mountains, Patagonia (Argentina). Water Air and Soil Pollution. 194 (1-4): 91-110.

Miserendino, M.L., R. Casaux, M. Archangelsky, C.Y. Di Prinzio, C. Brand \& A.M. Kutschker. 2011. Assessing land-use effects on water quality, in-stream habitat, riparian ecosystems and biodiversity in Patagonian northwest streams. Science of the Total Environment. 409: 612-624.

Miserendino, M.L. \& C.I. Masi. 2010. The effects of land use on environmental features and functional organization of macroinvertebrate communities in Patagonian low order streams. Ecological Indicators. 10: 311-319.

Miserendino, M.L. \& L. Pizzolón. 1992. Un índice biótico de calidad de aguas corrientes para la región Andino-Patagónica. Segundo Congreso Latinoamericano de Ecología. Caxambú, Minais Gerais, Brasil, 39-40.

Miserendino, M.L. \& L. Pizzolón. 1999. Rapid assessment of river water quality using macroinvertebrates: a family level biotic index for the Patagonic Andean zone. Acta Limnologica Brasiliensia. 11: 137-148.

Miserendino, M.L. \& L. Pizzolón. 2000. Macroinvertebrates of a fluvial system in Patagonia: altitudinal zonation and functional structure. Archiv für Hydrobiologie. 150: 55-83.

Miserendino, M.L. \& L. Pizzolón. 2003. Distribution of macroinvertebrate assemblages in the Azul-Quemquemtreu river basin, Patagonia, Argentina. New Zealand Journal of Marine and Freshwater Research. 37 (3): 525-539. 
Miserendino, M.L. \& L. Pizzolón. 2004. Interactive effects of basin features and land-use change on macroinvertebrate communities of headwater streams in the Patagonian Andes. River Research and Applications. 20: 967-983.

Mol, J.H. \& P.E. Ouboter. 2004. Downstream effects of erosion from smallscale gold mining on the in stream habitat and fish community of a small neotropical rainforest stream. Conservation Biology. 18: 201-214.

Munné, A., N. Prat, C. Solá, N. Bonada \& M. Rieradevall. 2003. A simple field method for assessing the ecological quality of riparian habitat in rivers and streams: QBR index. Aquatic Conservation: Marine and Freshwater Ecosystems. 13: 147-163.

Mykrä, H., J. Heino \& T. Muotka. 2007. Scale related components of stream macroinvertebrate assemblage variation. Global Ecology \& Biogeography. 16: 149-159.

Naiman, R.J., H. Décamps \& M.E. Mcclain. 2005. Riparia: Ecology, Conservation and Management of Streamside Communities. Elsevier Academic Press. San Diego. 430 pp.

Niyogi, D.K., M. Koren, C.J. Arbuckle \& C.R. Townsend. 2007. Stream communities along a catchment land use gradient: subsidy-stress responses to pastoral development. Environmental Management. 39: 213-225.

Palmer, C., J. O’Keefe \& A. Palmer. 1993. Macroinvertebrate functional feeding groups in the middle and lower reaches of the Buffalo River eastern Cape, South Africa. II Functional Morphology and Behaviour. Freshwater Biology. 29: 455462.

Parkyn, S.M., R.J. Davies-Colley, N.J. Halliday, K.J. Costley \& G.F. Croker. 2003. Planted riparian buffer zones in New Zealand: do they live up to expectations? Restoration Ecology. 11: 436-447.

Paruelo, J.M., A. Beltrán, E. Jobbágy, O.E. Sala \& O.E. Golluscio. 1998. The climate of Patagonia: general patterns and controls on biotic processes. Ecología Austral. 8: 85-101.

Paul, M.J. \& J.L. Meyer. 2001. Streams in the Urban Landscape. Annual Review of Ecology and Systematics. 32: 333-365.

Pautasso, M. \& D. Fontaneto. 2008. A test of the species-people correlation for stream macroinvertebrates in European countries. Ecological Applications. 18: 18421849 . 
Pavé, P.J. \& M. Marchese. 2005. Invertebrados bentónicos como indicadores de la calidad del agua en ríos urbanos (Paraná-Entre Ríos, Argentina). Ecología Austral. 15 (2): 183-197

Pickett, S.T.A., M.L. Cadenasso, J.M. Grove, C.H. Nilon \& R.V. Pouyat. 2001. Urban ecological systems: linking terrestrial ecological, physical, and socioeconomic components of metropolitan areas. Annual Review of Ecology and Systematics. 32: 127-157.

Pizzolón, L., M.L. Miserendino, L. Arias \& R. Benedetti. 1997. Impacto de las descargas cloacales de Cholila sobre el arroyo Las Minas. Ingeniería Sanitaria y Ambiental. 31: 56-58.

Pizzolón, L., M.L. Miserendino \& G. Alday. 2002. Informe Final Proyecto "Control de la calidad del agua en la cuenca del Río Percy". Solicitado por Cooperativa 16 de Octubre. 63 pp.

Pizzuto, J.E., W.C. Hession \& M. Mcbride. 2000. Comparing gravel-bed rivers in paired urban and rural catchments of southeastern Pennsylvania. Geology. 28: 79-82.

Poff, N.L., B.P. Bledsoe \& C.O. Cuhaciyan. 2006. Hydrologic variation with land use across the contiguous United States: geomorphic and ecological consequences for stream ecosystems. Geomorphology. 79: 264-285.

Prat, N. 1997. La problemática de la conservación de los ríos españoles como ecosistemas. Ecosistemas. 20-21: 42-47.

Prat, N., A. Munné, C. Solá, N. Bonada \& M. Rieradevall. 1999. Perspectivas en la utilización de los insectos acuáticos como bioindicadores del estado ecológico de los ríos. Aplicación a los ríos mediterráneos. Revista de la Sociedad Entomológica Argentina. 58: 181-192.

Quinn, J.M. 2000. Effects of pastoral development. En: Collier, K.J. \& M.J. Winterbourn (eds). New Zealand stream invertebrates: ecology and implications for management. New Zealand Limnological Society. Christchurch, 208-229.

Quinn, J.M., G.L. Steele, C.W. Hickey \& M.L. Vickers. 1994. Upper thermal tolerances of twelve New Zealand stream invertebrate species. New Zealand Journal of Marine and Freshwater Research. 28: 391-397.

Quinn, J.M., A.B. Cooper, R.J. Davies-Colley, J.C. Rutherford \& R.B. Williamson. 1997. Land use effects on habitat, water quality, periphyton, and benthic 
invertebrates in Waikato, New Zealand, hill-country streams. New Zealand Journal of Marine and Freshwater Research. 31: 579-597.

Quinn, J.M., A.B. Cooper \& R.B. Williamson. 1993. Riparian zones as buffer strips: a New Zealand perspective. En: Bunn, S.E. et al. (eds). Ecology and Management of riparian zones in Australia. Marcoola, Queensland, 53-87.

Quinn, J.M., M. Stroud, B. Thorrold, A. Mcgowan \& K.J. Collier. 1998. Hill-farming effects on stream water quality and possible solutions. En: Quinn, J.M. \& B.S. Thorrold (eds). Hill-country stream management: proceedings of a workshop, April 1998. NIWA. Whatawhata Research centre, Waikato, 32-33.

Quintero, A. \& A.M. Rojas De Hernández. 1990. Aspectos bioecológicos del orden Trichoptera y su relación con la calidad del agua. Revista Colombiana de Ecología. 13: 26-28.

Raffaele, E., T. Kitzberger \& T.T. Veblen. 2008. Efectos del ganado sobre la regeneración del bosque después de la floración de Chusquea culeou: experimentos que podemos hacer cada 60 años. Libro de Resúmenes de las las Jornadas de Ciencias Naturales en la Patagonia. Biodiversidad y Conservación. Esquel. Chubut, 78.

Reynaga, M.C. 2009. Hábitos alimentarios de larvas de Trichoptera (Insecta) de una cuenca subtropical. Ecología Austral. 19: 207-214.

Reynaga, M.C. \& P. Rueda Martín. 2010. Trophic analysis of two species of Atopsyche (Trichoptera: Hydrobiosidae). Limnologica. 40: 61-66.

Richardson, J.S. 2008. Aquatic arthropods and forestry: effects of large scale land use on aquatic systems in Nearctic temperate regions. Canadian Entomology. 140: 495-509.

Richardson, J.S. \& R.J. Danehy. 2007. A Synthesis of the Ecology of Headwater Streams and their Riparian Zones in Temperate Forests. Forest Science. 53 (2): 131-147.

Richardson, J.S. \& R.M. Thompson. 2009. Setting conservation targets for freshwater ecosystems in forested catchments. En: Villard, M.A. \& B.G. Jonsson (eds). Setting Conservation Targets for Managed Forest Landscapes. Cambridge University Press. Cambridge, 244-262.

Riley, A.C. 1998. Restoring streams in cities: a guide for planners, policymakers, and citizens. Island Press. Washington, D.C. XXII + 425 pp. 
Riley, R., C.R. Towsend, D.K. Niyogi, C.A. Arbuckle \& K.A. Peacock. 2003. Headwater stream response to grassland agricultural development in New Zealand. New Zealand Journal of Marine and Freshwater Research. 37: 389-403.

Rodrígues Capítulo, A., M. Tangorra \& C. Ocón. 2001. Use of benthic macroinvertebrates to assess the biological status of Pampean streams in Argentina. Aquatic Ecology. 35: 109-119.

Rosenberg, D.M. \& V.H. Resh. 1993. Introduction to freshwater biomonitoring and benthic macroinvertebrates. En: Rosenberg, D.M. \& V.H. Resh (eds). Freshwater biomonitoring and benthic macroinvertebrates. Chapman \& Hall. London, 1-9.

Roy, A.H., A.D. Rosemond, M.J. Paul, D.S. Leigh \& J.B. Wallace. 2003. Stream macroinvertebrate response to catchment urbanization (Georgia, U.S.A.). Freshwater Biology. 48: 329-346.

Rutherford, J.C., S. Blackett, C. Blackett, L. Saito \& R.J. Davies-Colley. 1997. Predicting the effects of shade on water temperature in small streams. New Zealand Journal of Marine and Freshwater Research. 31: 707-721.

Ryan, P.A. 1991. Environmental effects of sediment on New Zealand streams: a review. New Zealand Journal of Marine and Freshwater Research. 25: 207-221.

Sabater, F., B. A., E. Marti, I. Muñoz, A. Romani, J. Wray \& S. Sabater. 2000. Effects of riparian vegetation removal on nutrient retention in a Mediterranean stream. Journal of the North American Benthological Society. 19 (4): 609-620.

Scarsbrook, M.R. \& N.J. Halliday. 1999. Transition from pasture to native forest land use along stream continua: effects on stream ecosystems and implications for restoration. New Zealand Journal of Marine and Freshwater Research. 33: 293-310.

Sganga, J.V. 2011. Variabilidad espacial y estructura de las comunidades de Trichoptera (Insecta) en arroyos del Parque Provincial Salto Encantado del Valle del Cuñá-Pirú (Misiones, Argentina). Tesis Doctoral. Universidad de Buenos Aires. 169 pp.

Sganga, J.V. \& M.S. Fontanarrosa. 2006. Contribution to the knowledge of the preimaginal stages of the genus Smicridea McLachlan in South America (Trichoptera: Hydropsychidae: Smicrideinae). Zootaxa. 1258: 1-15.

Sieh, S.H., J.V. Ward \& B.C. Kondratieff. 2003. Longitudinal changes in macroinvertebrate production in a stream affected by urban and agricultural activities. Archiv für Hydrobiologie. 157: 483-503. 
Sirombra, M.G., O.M. Grimolizzi \& A.M. Frenzel. 2006. Riberas de cursos de agua y calidad ecológica: una herramienta informática. XXII Reunión Argentina de Ecología, Córdoba, 214.

Smith, R.L. \& T.M. Smith. 2000. Elements of Ecology. $4^{\text {ta }}$ Edición. Adison Wesley Longman, Inc. 567 pp.

Smith, R.D., R.C. Sidle, P.E. Porter \& J.R. Noel. 1993. Effects of experimental removal of woody debris on the channel morphology of a forest, gravel bed stream. Journal of Hydrology. 152: 153-178.

Sokal, R.R. \& F.J. Rohlf. 1995. Biometry. $3^{\text {ra }}$ Edición. W.H. Freeman and Company. New York. 887 pp.

Song, M.Y., F. Lepieur, A. Thomas, S. Lek-Ang, T. Chon \& S. Lek. 2009. Impact of agricultural land use on aquatic insect assemblages in the Garonne river catchment (SW France). Aquatic Ecology. 43: 999-1009.

Sponseller, R.A., E.F. Benfield \& H.M. Valett. 2001. Relationships between land use, spatial scale and stream macroinvertebrate communities. Freshwater Biology. 46: $1409-1424$.

Stark, J.D. 1985. A macroinvertebrate community index of water quality for stony streams. Water \& soil miscellaneous publication. National Water and Soil Conservation Authority. Wellington. 83: 273-303.

Stark, J.D. 1993. Performance of the Macroinvertebrate Community Index: effects of sampling method, sample replication, water depth, current velocity, and substratum on index values. New Zealand Journal of Marine and Freshwater Research. 27: 463-478.

Stark, J.D. 1998. SQMCI: a biotic index for freshwater macroinvertebrate coded abundance data. New Zealand Journal of Marine and Freshwater Research. 32: $55-66$.

Storey, R.G. \& D.R. Cowley. 1997. Recovery of three New Zealand rural streams as they pass through native forest remnants. Hydrobiologia. 353: 63-76.

Strahler, H.N. 1957. Quantitative analysis of watershed geomorphology. Transactions - American Geophysical Union. 33: 913-920.

Strayer, D.L., R.E. Beighley, L.C. Thompson, S. Brooks, C. Nilsson, G. Pinay \& R. Naiman. 2003. Effects of land cover on stream ecosystems: roles of empirical models and scaling issues. Ecosystems. 6: 407-423. 
Strobl, R.O., P.D. Robillard, R.D. Shannon, R.L. Day \& A.J. Mcdonnell. 2006. A Water Quality Monitoring Network Design Methodology for the Selection of Critical Sampling Points: Part I. Environmental Monitoring and Assessment. 112: 137158.

Suárez, M.L. \& M.R. Vidal-Abarca. 2000. Aplicación del índice de calidad del bosque de ribera QBR (Munné et al., 1998) a los cauces fluviales de la Cuenca del río Segura. Tecnología del Agua. 201: 33-45.

Suárez, M.L., M.R. Vidal-Abarca, M.D.M. Sánchez-Montoya, J. AlbaTercedor, M. Álvarez, J. Avilés, N. Bonada, J. Casas, P. Jáimez-Cuéllar, A. Munné, I. Pardo, N. Prat, M. Rieradevall, M.J. Salinas, M. Toro \& S. Vivas. 2002. Las riberas de los ríos mediterráneos y su calidad: el uso del índice QBR. Limnetica. 21 (34): $135-148$.

Suren, A.M. 2000. Effects of urbanization. En: Collier, K.J. \& M.J. Winterbourn (eds). New Zealand Stream Invertebrates: Ecology and Implications for Management. New Zealand Limnological Society. Hamilton, 260-288.

Sutherland, A.B., J.L. Meyer \& E.P. Gardiner. 2002. Effects of land cover on sediment regime and fish assemblage structure in four southern Appalachian streams. Freshwater Biology. 47: 1791-1805.

Sweeney, B.W. 1984. Factors influencing life-history patterns of aquatic insects. En: Resh, V.H. \& D.M. Rosenberg (eds). The ecology of aquatic insects. Praeger. New York, 56-100.

Sweeney, B.W. 1993. Effects of streamside vegetation on macroinvertebrate communities of White Clay Creek in eastern North America. Proceedings of the Academy of Natural Sciences of Philadelphia. 144: 291-340.

Sweeney, B.W., T.L. Bott, J.K. Jackson, L.A. Kaplan, J.D. Newbold, L.J. Standley, W.C. Hession \& R.J. Horwitz. 2004. Riparian deforestation, stream narrowing, and loss of stream ecosystem services. Proceedings of the National Academy of Sciences of the United States of American Midland Naturalist. 101: 14132-14137.

Sykora, J.L., M. Koryak \& J.M. Fowles. 1997. Adult Trichoptera as indicators of water quality in the Upper Ohio River Drainage Basin. Proceedings of the $7^{\text {th }}$ International Symposium on Trichoptera. Ohio Biological Survey, 441-444.

Tell, G., I. Izaguirre \& R. Quintana. 1997. Flora y fauna patagónicas. Ediciones Caleuche. Argentina. 175 pp. 
ter Braak, C.J.F. 1986. Canonical correspondence analysis: a new eigenvector technique for multivariate direct gradient analysis. Ecology. 67: 1167-1179.

ter Braak, C.J.F. \& P. Smilauer. 1998. CANOCO Reference manual and User's guide to Canoco for Windows: software for Canonical Community Ordination (version 4). Editor Series Microcomputer power. Ithaca, New York, Usa. 352 pp.

ter Braak, C.J.F. \& P. Smilauer. 1999. CANOCO for Windows (version 4.02) a FORTRAN program for canonical community ordination. Centre for biometry. Wageningen, The Netherlands.

Tomanova, S., E. Goitia \& J. Helesic. 2006. Trophic levels and functional feeding groups of macroinvertebrates in neotropical streams. Hydrobiologia. 556: 251264.

Thompson, R.M. 2001. Tesis Doctoral. Effects of exotic pine forestry on stream community attributes. University of Otago.

Townsend, C.R., S. Dolédec, R. Norris, K.A. Peacock \& C.A. Arbuckle. 2003. The influence of scale and geography on relationships between stream community composition and landscape variables: description and prediction. Freshwater Biology. 48: 768-785.

Utz, R.M., R.H. Hildebrand \& D.M. Boward. 2009. Identifying regional differences in threshold responses of aquatic invertebrates to land cover gradients. Ecological Indicators. 9: 556-567.

Vallania, A., P.A. Garelis, M.A. Tripole \& M.A. Gil. 1996. Un índice biótico para las Sierras de San Luis. Revista de la Universidad Nacional de Río Cuarto. 16 (2): 129-136.

Vallania, A., A.I. Medina \& M.E. Sosa. 1998. Estructura de la comunidad de Trichoptera en un arroyo regulado de la provincia de San Luis, Argentina. Revista de la Sociedad Entomológica Argentina. 57 (1-4): 7-11.

Valverde, A.C. 1996. Descripción de los estados preimaginales y de los segmentos genitales de Polycentropus joergenseni Ulmer, 1909 (Trichoptera: Polycentropodidae). Revista Brasileña de Entomologia. 40 (1): 65-70.

Valverde, A.C. \& R.J. Albariño. 1999. Descripción de los estados inmaduros de Myotrichia murina y Parasericostoma cristatum (Trichoptera: Sericostomatidae). Revista de la Sociedad Entomológica Argentina. 58 (3-4): 11-16. 
Valverde, A.C. \& M.L. Miserendino. 1997. Los estados inmaduros de Parasericostoma ovale (Trichoptera: Sericostomatidae). Revista de la Sociedad Entomológica Argentina. 56 (1-4): 33-37.

Valverde, A.C. \& M.L. Miserendino. 1998. Aportes al conocimiento de los estados preimaginales de Mastigoptila longicornuta (Trichoptera: Glossosomatidae). Revista de la Sociedad Entomológica Argentina. 57 (1-4): 49-55.

Voelz, N.J. \& J.V. Ward. 1990. Macroinvertebrate responses along a complex regulated stream environmental gradient. Regulated Rivers: Research \& Management. 5: 365-374.

Vondracek, B., K.L. Blann, C.B. Cox, J.A. Nerbonne, K.G. Mumford \& B.A. Nerbonne. 2005. Land use, spatial scale and stream ecosystems: lessons from an agricultural region. Ecological Applications. 36: 775-791.

Vought, L.B., J. Dahl, C.L. Pedersen \& J.O. Lacoursiére. 1994. Nutrient retention in riparian ecotones. Ambio. 23: 343-348.

Wallace, J.B. \& J.R. Webster. 1996. The Role of Macroinvertebrates in Stream Ecosystem Function. Annual Review of Entomology. 41: 115-139.

Wallace, J.B., M.R. Whiles, S. Eggert, T.F. Cuffney \& G.H. Lugthart. 1995. Long-term dynamics of coarse particulate organic matter in 3 Appalachian Mountain streams. Journal of the North American Benthological Society. 14: 217-232.

Walling, D.E. \& D. Fang. 2003. Recent trends in the suspended sediment loads of the world's rivers. Global Planet Change. 39: 111-126.

Wantzen, K.M. 1998. Siltation effects on benthic communities in first order streams in Mato Grosso, Brazil. Verhandlungen Internationale Vereinigung für Limnologie. 26: 1155-1159.

Wantzen, K.M. 2006. Physical pollution: effects of gully erosion on benthic invertebrates in a tropical clear-water stream. Aquatic Conservation: Marine and Freshwater Ecosystems. 16: 733-749.

Ward, J.V. 1985. Thermal characteristics of running waters. Hydrobiologia. 125: $31-46$.

Ward, J.V. 1989. The four dimensional nature of lotic ecosystems. Journal of the North American Benthological Society. 8: 2-8.

Ward, J.V. 1992. Aquatic insect ecology. John Wiley \& Sons, Inc. New YorkLondon. 438 pp. 
Waringer, J. \& W. Graf. 2002. Trichoptera communities as a tool for assessing the ecological integrity of Danubian floodplains in Lower Austria. Proceedings of the $10^{\text {th }}$ International Symposium on Trichoptera. Nova Suppl. Ent., Keltern, 617-625.

Wasson, J.G., B. Villeneuve, A. Lital, J. Murray-Bligh, M. Dobiasova, S. Bacikova, H. Timm, H. Pella, N. Mengin \& A. Chandesris. 2010. Large-scale relationships between basin and riparian land cover and the ecological status of European rivers. Freshwater Biology. 55: 1465-1482.

Webster, J.R. \& E.F. Benefield. 1986. Vascular plant breakdown in freshwater ecosystems. Annual Review of Ecology and Systematics. 17: 567-594.

Weijters, M.J., J.H. Janse, R. Alkemade \& J.T.A. Verhoeven. 2009. Quantifying the effect of catchment land use and water nutrient concentrations on freshwater river and stream biodiversity. Aquatic Conservation: Marine and Freshwater Ecosystems. 19: 104-112.

Wetzel, R.G. \& G.E. Likens. 1991. Limnological analysis. $2^{\text {da }}$ Edición. Springer-Verlang. New York. 370 pp.

Wiberg-Larsen, P., K.P. Brodersen, S. Birkholm, P.N. Gron \& J. Skriver. 2000. Species richness and assemblage structure of Trichoptera in Danish streams. Freshwater Biology. 43: 633-647.

Wiggins, G.B. 1998. Larvae of the North American Caddisfly Genera (Trichoptera). $2^{\text {da }}$ Edición. Unversity of Toronto Press Toronto. Canada. 457 pp.

Wiggins, G.B. 2004. Caddisflies. The Underwater Architects. $1^{\text {ra }}$ Edición. University of Toronto Press Inc. Toronto. Canada. 292 pp.

Wilding, T.K. 1996. Effects of urban development on small stream ecosystems of Auckland, and the influence of riparian vegetation. MSc. Thesis, University of Auckland. Auckland, New Zealand. 116 pp.

Williamson, R.B. 1993. Urban Runoff data book. Water Quality Centre Publication 20. NIWA. Hamilton. 51 pp.

Winget, R.N. \& F.A. Magnum. 1979. Aquatic ecosystem inventory. Macroinvertebrates analysis, biotic condition index: integrated biological, physical and chemical stream parameters for management. U.S. Department of Agriculture. Intermountain Region Spec. Forest. Serv. Rep. 51 pp.

Winterbourn, M.J. 1981. The use of aquatic invertebrates in studies of stream water quality. Water \& Soil Publication. 22: 5-16. 
Brand, C. 2012 Comunidades de Trichoptera en ríos patagónicos sometidos a diferentes usos de la tierra

Zimmermann, E.M. \& R.G. Death. 2002. Effect of substrate stability and canopy cover on stream invertebrate communities. New Zealand Journal of Marine and Freshwater Research. 36: 537-545. 


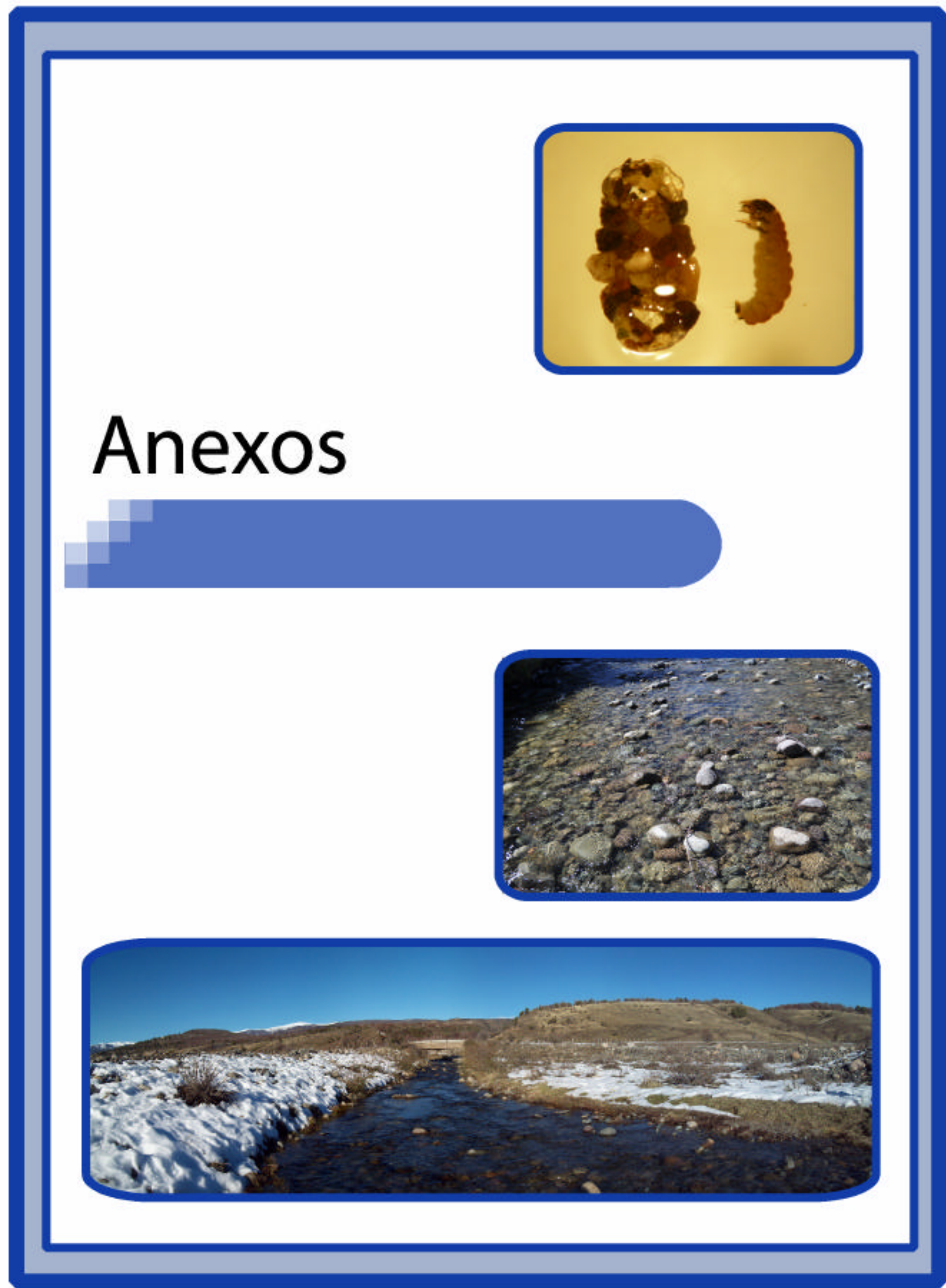




\section{ANEXOS}

10.1 Anexo I. Planilla de campo QBRp (Kutschker et al. 2009) Calificación de la zona de ribera de los ecosistemas fluviales. Índice QBRp

Estación:

Fecha:

Grado de cubierta de la zona de ribera. Puntuación entre 0 y 25

\begin{tabular}{|c|l|}
\hline \multicolumn{2}{|l|}{ Puntuación } \\
\hline 20 & $>80 \%$ de cubierta vegetal de la zona de ribera (las plantes anuales no se contabilizan) \\
\hline 15 & $50-80 \%$ de cubierta vegetal de la zona de ribera \\
\hline 10 & $10-50 \%$ de cubierta vegetal de la zona de ribera \\
\hline 5 & $<10 \%$ de cubierta vegetal de la zona de ribera \\
\hline+5 & si la conectividad entre el bosque de ribera y el ecosistema forestal adyacente es total \\
+2 & si la conectividad entre el bosque de ribera y el ecosistema forestal adyacente es superior al $50 \%$ \\
\hline-2 & si la conectividad entre el bosque de ribera y el ecosistema forestal adyacente es entre el 25 y $50 \%$ \\
-5 & si la conectividad entre el bosque de ribera y el ecosistema forestal adyacente es inferior al $25 \%$ \\
\hline
\end{tabular}

Estructura de la cubierta (se contabiliza toda la zona de ribera). Puntuación entre 0 y 25

\begin{tabular}{|c|c|}
\hline \multicolumn{2}{|c|}{ Puntuación } \\
\hline 18 & cobertura de árboles superior al $75 \%$ \\
\hline 15 & $\begin{array}{l}\text { cobertura de árboles entre el } 50 \text { y } 75 \% \text { o cobertura de árboles entre el } 25 \text { y } 50 \% \text { y en el resto de la } \\
\text { cubierta los arbustos superan el } 25 \%\end{array}$ \\
\hline 10 & cobertura de árboles inferior al $50 \%$ y el resto de la cubierta con arbustos entre 10 y $25 \%$ \\
\hline 5 & sin árboles y arbustos por debajo del $10 \%$ \\
\hline $\begin{array}{l}+5 \\
+2 \\
+2\end{array}$ & $\begin{array}{l}\text { si en la orilla la concentración de helófitos o arbustos es superior al } 50 \% \\
\text { si en la orilla la concentración de helófitos o arbustos es entre } 25 \text { y } 50 \% \\
\text { si los árboles tienen un sotobosque arbustivo }\end{array}$ \\
\hline $\begin{array}{l}-2 \\
-2 \\
-5\end{array}$ & $\begin{array}{l}\text { si hay una distribución regular (linealidad) en los pies de los árboles y el sotobosque es }>50 \% \\
\text { si los árboles y arbustos se distribuyen en manchas, sin una continuidad } \\
\text { si hay una distribución regular (linealidad) en los pies de los árboles y el sotobosque es }<50 \%\end{array}$ \\
\hline
\end{tabular}

Calidad de la cubierta (depende del tipo morfológico de la zona de ribera y del orden lótico*). Puntuación entre 0 y 25

\begin{tabular}{|c|c|c|c|}
\hline \multicolumn{4}{|c|}{ Puntuación } \\
\hline 15 & \multicolumn{3}{|l|}{ número óptimo de especies arbóreas autóctonas } \\
\hline 10 & \multicolumn{3}{|l|}{ número de especies de árboles autóctonos inferior al óptimo } \\
\hline 5 & \multicolumn{3}{|l|}{ sin especies de árboles autóctonos } \\
\hline $\begin{array}{l}+5 \\
+2.5\end{array}$ & \multicolumn{3}{|c|}{$\begin{array}{l}\text { si la comunidad forma una franja longitudinal continua adyacente al canal fluvial en más del } 75 \% \text { de } \\
\text { la longitud del tramo } \\
\text { si la comunidad forma una franja longitudinal continua adyacente al canal fluvial entre el } 50 \text { y } 75 \% \\
\text { de la longitud del tramo }\end{array}$} \\
\hline & Tipo 1 & Tipo 2 & Tipo 3 \\
\hline+5 & Si el número diferente de especies de arbustos es & +3 & +4 \\
\hline $\begin{array}{c}-2.5 \\
-5\end{array}$ & $\begin{array}{l}\text { si hay alguna sp. de árbol y/o arbusto alóctono aislada } \\
\text { si hay sp. de árboles y/o arbustos alóctonos formando comunidades }\end{array}$ & & \\
\hline
\end{tabular}

Grado de naturalidad del canal fluvial. Puntuación entre 0 y 25

\begin{tabular}{|c|l|}
\hline \multicolumn{2}{|l|}{ Puntuación } \\
\hline 25 & el canal del río no ha estado modificado \\
\hline 20 & modificaciones de las terrazas adyacentes sin reducción del canal \\
\hline 15 & modificaciones de las terrazas adyacentes al lecho del río con reducción del canal \\
\hline 10 & signos de alteración y estructuras que modifican el canal \\
\hline 5 & estructuras transversales \\
\hline 0 & río canalizado en la totalidad del tramo \\
\hline
\end{tabular}


* Determinación del tipo morfológico de la zona de ribera (apartado 3)

Sumar el tipo de desnivel de la orilla derecha e izquierda, y sumar o restar según los otros 2 apartados.

Tipos de desnivel de la zona riparia
Vertical/cóncavo (pendiente $>75^{\circ}$ ), con una
altura no superable por las máximas avenidas

altura no superable por las máximas avenidas

Igual pero con un pequeño talud o orilla

inundable periódicamente (avenidas ordinarias)
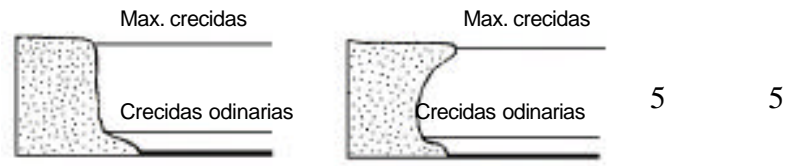

Pendiente entre el 45 y $75^{\circ}$, escalado o no. La pendiente se cuenta con el ángulo entre la horizontal y la recta entre la orilla y el último punto de la ribera. $\mathrm{S}$ a $>\mathrm{S}$ b
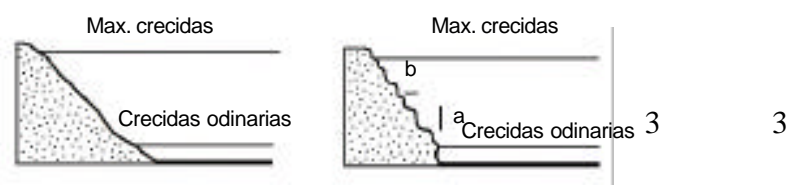

Pendiente entre el 20 y $45^{\circ}$, escalonado o no. $\mathrm{S}$ a $<\mathrm{S} \mathrm{b}$
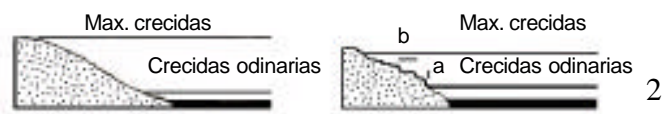

Pendiente $<20^{\circ}$, ribera uniforme y llana.

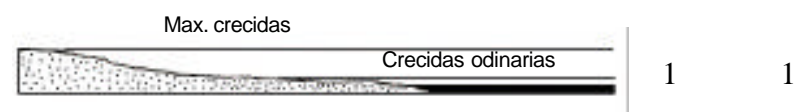

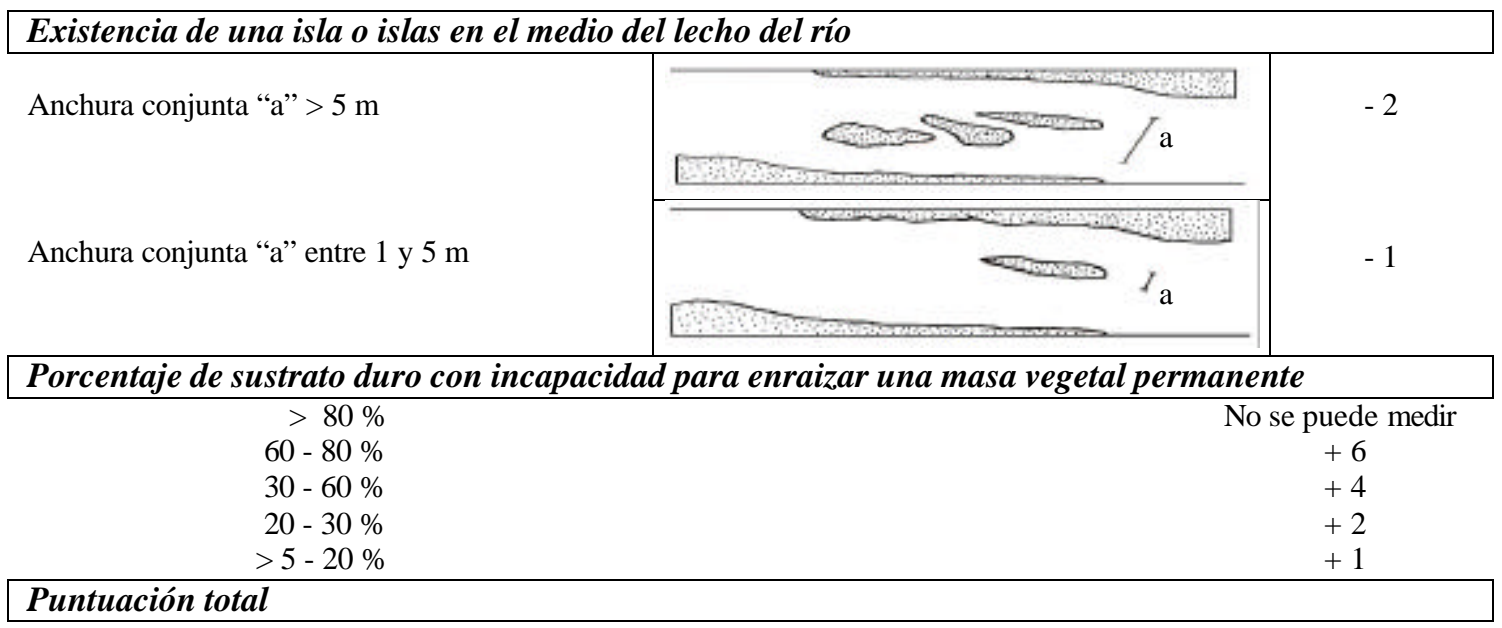

\section{Tipo morfológico según la puntuación}

\begin{tabular}{|c|c|l|}
\hline$>8$ & Tipo 1 & Riberas con una potencialidad intermedia para soportar una zona vegetada \\
\hline 5 y 8 & Tipo 2 & Riberas cerradas \\
\hline$<5$ & Tipo 3 & Riberas extensas \\
\hline
\end{tabular}

Número óptimo de especies arbóreas según tipo morfológico y orden lótico

\begin{tabular}{|c|c|c|c|}
\cline { 2 - 4 } \multicolumn{1}{c|}{} & \multicolumn{3}{c|}{ Orden lótico } \\
\hline Tipo morfológico & Bajo & Medio & Alto \\
\hline 1 & $1-2$ & 2 & $>2$ \\
\hline 2 & $1-2$ & 3 & $>3$ \\
\hline 3 & $1-2$ & $>3$ & $=4$ \\
\hline
\end{tabular}


Brand, C. 2012 Comunidades de Trichoptera en ríos patagónicos sometidos a diferentes usos de la tierra

Los rangos de calidad según el índice QBRp son:

\begin{tabular}{|l|c|c|}
\hline \multicolumn{1}{|c|}{ Nivel de calidad } & QBRp & Color representativo \\
\hline $\begin{array}{l}\text { Bosque de ribera sin alteraciones, calidad muy buena, estado } \\
\text { natural }\end{array}$ & $>90$ & Azul \\
\hline Bosque ligeramente perturbado, calidad buena & $>70-90$ & Verde \\
\hline Inicio de alteración importante, calidad intermedia & $>50-70$ & Amarillo \\
\hline Alteración fuerte, mala calidad & $>25-50$ & Naranja \\
\hline Degradación extrema, calidad pésima & $=25$ & Rojo \\
\hline
\end{tabular}


10.2. Anexo II. Planilla de campo HA (Traducción de Barbour et al. 1999).

\begin{tabular}{|c|c|c|c|c|c|c|c|c|c|c|c|c|c|c|c|c|c|c|c|c|}
\hline \multirow[b]{3}{*}{$\begin{array}{l}\text { PARAMETRO } 1 \\
\text { Cobertura de } \\
\text { sustrato } \\
\text { disponible para } \\
\text { ser colonizado } \\
\text { por la fauna }\end{array}$} & \multicolumn{20}{|c|}{ Ranking } \\
\hline & \multicolumn{5}{|c|}{ OPTIMO } & \multicolumn{5}{|c|}{ SUBOPTIMO } & \multicolumn{5}{|c|}{ MARGINAL } & \multicolumn{5}{|c|}{ POBRE } \\
\hline & \multicolumn{5}{|c|}{$\begin{array}{l}\text { Más del } 70 \% \text { del } \\
\text { sustrato colonizable: } \\
\text { mezcla de ramas, } \\
\text { troncos sumergidos, } \\
\text { bancos socavados, } \\
\text { rocas u otros hábitats } \\
\text { estables que permitan } \\
\text { una completa } \\
\text { colonización (troncos } \\
\text { y ramas que NO son } \\
\text { nuevos y NO están } \\
\text { derivando) }\end{array}$} & \multicolumn{5}{|c|}{$\begin{array}{l}\text { 40-70\% colonizable. } \\
\text { Mezcla de hábitats } \\
\text { estables, útiles para } \\
\text { colonización, hábitat } \\
\text { adecuado para el } \\
\text { mantenimiento de } \\
\text { poblaciones. } \\
\text { Presencia de } \\
\text { sustratos adicionales } \\
\text { (troncos o ramas } \\
\text { nuevas) aún no } \\
\text { preparados para } \\
\text { colonización. }\end{array}$} & \multicolumn{5}{|c|}{$\begin{array}{l}20-40 \% \\
\text { colonizable. } \\
\text { Mezcla de } \\
\text { hábitats estables. } \\
\text { Frecuentemente } \\
\text { sustrato } \\
\text { disturbado o } \\
\text { removido. }\end{array}$} & \multicolumn{5}{|c|}{$\begin{array}{l}\text { Menos del 20\% } \\
\text { de hábitats } \\
\text { estables, } \\
\text { pérdida de } \\
\text { hábitat } \\
\text { evidente, } \\
\text { sustrato } \\
\text { inestable o } \\
\text { perdido. }\end{array}$} \\
\hline PUNTAJE & 0 & 19 & 18 & & 16 & 15 & 14 & 13 & 12 & 11 & 10 & & 8 & & 6 & & & & & \\
\hline
\end{tabular}

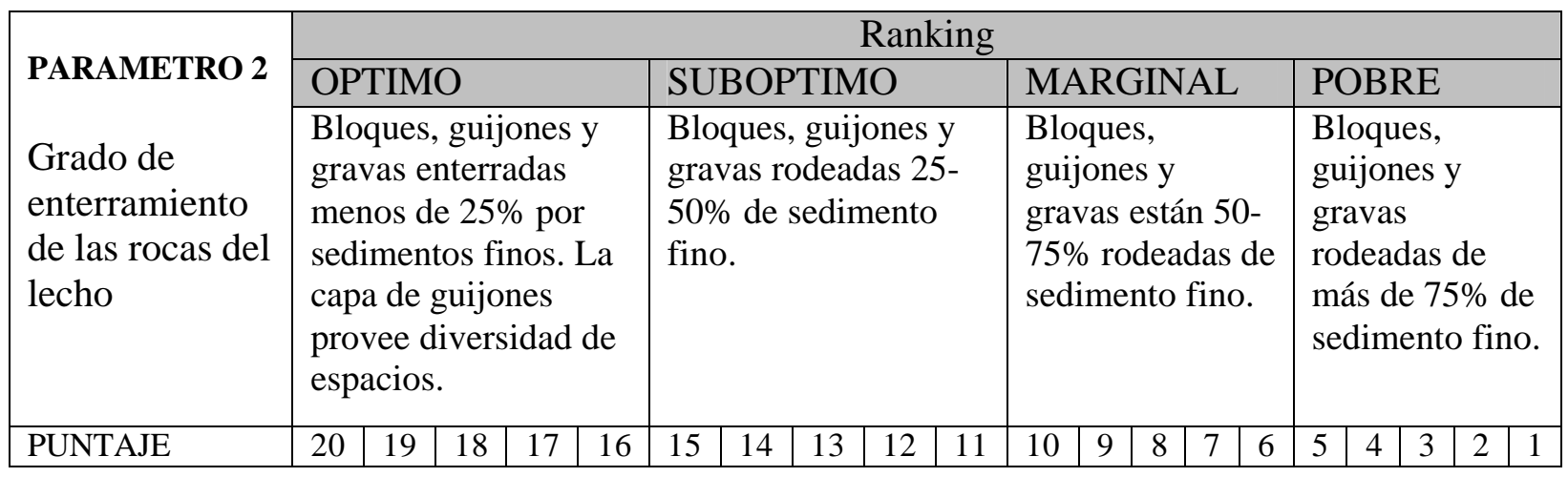

\begin{tabular}{|c|c|c|c|c|c|c|c|c|c|c|c|c|c|c|c|c|c|c|c|c|}
\hline \multirow{3}{*}{$\begin{array}{l}\text { PARAMETRO } 3 \\
\text { Régimen de } \\
\text { velocidad/ } \\
\text { profundidad }\end{array}$} & \multicolumn{20}{|c|}{ Ranking } \\
\hline & \multicolumn{5}{|c|}{ OPTIMO } & \multicolumn{5}{|c|}{ SUBOPTIMO } & \multicolumn{5}{|c|}{ MARGINAL } & \multicolumn{5}{|c|}{ POBRE } \\
\hline & \multicolumn{5}{|c|}{$\begin{array}{l}4 \text { combinaciones. } \\
\text { (lento/profundo, } \\
\text { lento/superficial, } \\
\text { rápido/profundo y } \\
\text { rápido/superficial) }\end{array}$} & \multicolumn{5}{|c|}{$\begin{array}{l}\text { Sólo } 3 \text { regimenes. } \\
\text { (si se perdió } \\
\text { rápido/superficial, } \\
\text { poner el menor } \\
\text { puntaje). }\end{array}$} & \multicolumn{5}{|c|}{$\begin{array}{l}2 \text { regimenes. } \\
\text { (si se perdió } \\
\text { rápido/superficial } \\
\text { o } \\
\text { lento/superficial, } \\
\text { poner el menor } \\
\text { puntaje). }\end{array}$} & \multicolumn{5}{|c|}{$\begin{array}{l}\text { Dominado por } \\
\text { un solo régimen } \\
\text { (usualmente es } \\
\text { lento/profundo). }\end{array}$} \\
\hline PUNTAJE & 20 & 19 & 18 & 17 & 16 & 15 & 14 & 13 & 12 & 11 & 10 & 9 & 8 & 7 & 6 & 5 & 4 & 3 & 2 & 1 \\
\hline
\end{tabular}




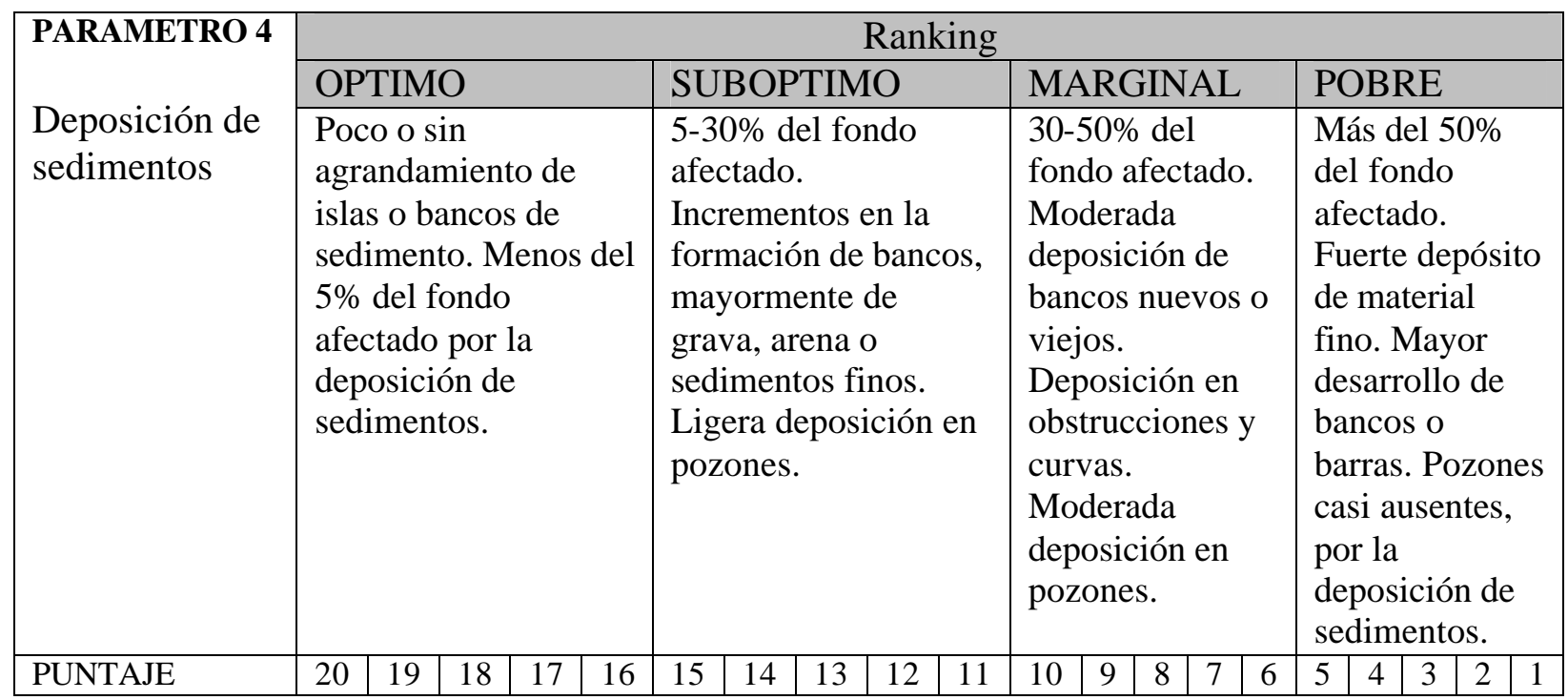

\begin{tabular}{|c|c|c|c|c|}
\hline \multirow[b]{2}{*}{ PARAMETRO 5} & \multicolumn{4}{|c|}{ Ranking } \\
\hline & OPTIMO & SUBOPTIMO & MARGINAL & POBRE \\
\hline $\begin{array}{l}\text { Estatus del } \\
\text { flujo del agua } \\
\text { en el cauce }\end{array}$ & $\begin{array}{l}\text { El agua alcanza la } \\
\text { base de ambas riberas } \\
\text { y hay mínima } \\
\text { cantidad de sustrato } \\
\text { expuesto (no } \\
\text { mojado). }\end{array}$ & $\begin{array}{l}\text { El agua llena más del } \\
75 \% \text { del cauce } \\
\text { disponible, o menos } \\
\text { del } 25 \% \text { del sustrato } \\
\text { expuesto. }\end{array}$ & $\begin{array}{l}\text { El agua llena 25- } \\
75 \% \text { del cauce } \\
\text { disponible y el } \\
\text { sustrato en áreas } \\
\text { de rápidos está } \\
\text { expuesto. }\end{array}$ & $\begin{array}{l}\text { Muy poco agua } \\
\text { en el canal y } \\
\text { mayormente en } \\
\text { pozones } \\
\text { estancados. }\end{array}$ \\
\hline $\mathrm{PUN}^{\prime}$ & \begin{tabular}{|l|l|l|l|l|}
20 & 19 & 18 & 17 & 16
\end{tabular} & \begin{tabular}{l|l|l|l}
15 & 14 & 13 & 12 \\
\end{tabular} & \begin{tabular}{|l|l|l|l|l|}
10 & 9 & 8 & 7 & 6 \\
\end{tabular} & \begin{tabular}{l|l|l|l}
5 & 4 & 3 & 2 \\
\end{tabular} \\
\hline
\end{tabular}

\begin{tabular}{|c|c|c|c|c|}
\hline \multirow[b]{2}{*}{ PARAMETRO 6} & \multicolumn{4}{|c|}{ Ranking } \\
\hline & OPTIMO & SUBOPTIMO & MARGINAL & POBRE \\
\hline $\begin{array}{l}\text { Alteraciones } \\
\text { del canal }\end{array}$ & $\begin{array}{l}\text { Canalizaciones o } \\
\text { dragados ausentes o } \\
\text { mínimos, arroyo con } \\
\text { un patrón normal. }\end{array}$ & $\begin{array}{l}\text { Alguna canalización } \\
\text { presente, usualmente } \\
\text { en áreas de } \\
\text { estribaciones de } \\
\text { puentes, evidencia de } \\
\text { canalización pasada } \\
\text { (dragado mayor a } 20 \\
\text { años) pero no } \\
\text { reciente. }\end{array}$ & $\begin{array}{l}\text { La canalización } \\
\text { puede ser } \\
\text { extensa, } \\
\text { terraplenes de } \\
\text { las estructuras } \\
\text { de orilla } \\
\text { presentes sobre } \\
\text { ambos bancos } \\
40-80 \% \text { del } \\
\text { tramo del río } \\
\text { canalizado y } \\
\text { roto. }\end{array}$ & $\begin{array}{l}\text { Bancos de la } \\
\text { orilla con } \\
\text { gaviones o } \\
\text { cemento, más } \\
\text { del } 80 \% \text { del } \\
\text { tramo de } \\
\text { arroyo } \\
\text { canalizado. } \\
\text { Hábitat del } \\
\text { lecho muy } \\
\text { alterado o } \\
\text { enteramente } \\
\text { removido. }\end{array}$ \\
\hline PUNTAJE & \begin{tabular}{|l|l|l|l|l}
20 & 19 & 18 & 17 & 16 \\
\end{tabular} & \begin{tabular}{|l|l|l|l|l|}
15 & 14 & 13 & 12 & 11
\end{tabular} & \begin{tabular}{|l|l|l|l|}
10 & 9 & 8 & 7 \\
\end{tabular} & \begin{tabular}{l|l|l|l|l|}
5 & 4 & 3 & 2 & 1 \\
\end{tabular} \\
\hline
\end{tabular}




\begin{tabular}{|c|c|c|c|c|c|c|c|c|c|c|c|c|c|c|}
\hline \multirow{3}{*}{$\begin{array}{l}\text { PARAMETRO } 7 \\
\text { Frecuencia de } \\
\text { rápidos o } \\
\text { curvas } \\
\text { (meandros) }\end{array}$} & \multicolumn{14}{|c|}{ Ranking } \\
\hline & \multicolumn{3}{|c|}{ OPTIMO } & \multicolumn{4}{|c|}{ SUBOPTIMO } & \multicolumn{3}{|c|}{ MARGINAL } & \multicolumn{4}{|c|}{ POBRE } \\
\hline & \multicolumn{3}{|c|}{$\begin{array}{l}\text { Rápidos frecuentes, } \\
\text { distancia entre rápidos } \\
\text { dividida por el ancho } \\
\text { mayor 7:1 (gralmente } \\
5 \text { a 7), gran variedad } \\
\text { de hábitats. } \\
\text { Importante presencia } \\
\text { de obstrucciones y } \\
\text { bloques naturales. }\end{array}$} & \multicolumn{4}{|c|}{$\begin{array}{l}\text { Ocurrencia de rápidos } \\
\text { infrecuente, distancia } \\
\text { entre rápidos dividida } \\
\text { por el ancho de la } \\
\text { corriente entre } 7 \text { y } 15 .\end{array}$} & \multicolumn{3}{|c|}{$\begin{array}{l}\text { Rápidos y curvas } \\
\text { ocasionales, la } \\
\text { forma del fondo } \\
\text { provee algo de } \\
\text { hábitat, distancia } \\
\text { entre rápidos } \\
\text { dividida por el } \\
\text { ancho del río } \\
\text { entre } 15 \text { y } 25 \text {. }\end{array}$} & \multicolumn{4}{|c|}{$\begin{array}{l}\text { Corriente } \\
\text { “chata”o con } \\
\text { rápidos } \\
\text { superficiales, } \\
\text { pobreza de } \\
\text { hábitats, } \\
\text { distancia entre } \\
\text { rápidos } \\
\text { dividida por el } \\
\text { ancho del río } \\
>25 \text {. }\end{array}$} \\
\hline PUNTAJE & \begin{tabular}{l|l}
20 & 19 \\
\end{tabular} & 18 & \begin{tabular}{l|l}
17 & 16 \\
\end{tabular} & 15 & 14 & 13 & \begin{tabular}{|l|l|}
12 & 11 \\
\end{tabular} & \begin{tabular}{l|l}
10 & 9 \\
\end{tabular} & 8 & \begin{tabular}{|l|l|}
7 & 6 \\
\end{tabular} & \begin{tabular}{|l|l|}
5 & 4 \\
\end{tabular} & 3 & 2 & 1 \\
\hline \multirow{3}{*}{$\begin{array}{l}\text { PARAMETRO } 8 \\
\text { Estabilidad de la } \\
\text { ribera (cada } \\
\text { ribera por } \\
\text { separado) }\end{array}$} & \multicolumn{14}{|c|}{ Ranking } \\
\hline & \multicolumn{3}{|c|}{ OPTIMO } & \multicolumn{4}{|c|}{ SUBOPTIMO } & \multicolumn{3}{|c|}{ MARGINAL } & \multicolumn{4}{|c|}{ POBRE } \\
\hline & \multicolumn{3}{|c|}{$\begin{array}{l}\text { Riberas estables, } \\
\text { evidencia de erosión } \\
\text { o fallas en la ribera } \\
\text { ausentes o mínimas. } \\
\text { Bajo potencial para } \\
\text { futuros problemas. } \\
\text { Menos del 5\% de la } \\
\text { ribera afectada. }\end{array}$} & \multicolumn{4}{|c|}{$\begin{array}{l}\text { Moderadamente } \\
\text { estables, áreas } \\
\text { erosionadas pequeñas } \\
\text { e infrecuentes, } \\
\text { mayormente en } \\
\text { retroceso. 5-30\% de la } \\
\text { ribera erosionada. }\end{array}$} & \multicolumn{3}{|c|}{$\begin{array}{l}\text { Moderadamente } \\
\text { inestable, 30- } \\
60 \% \text { del banco } \\
\text { con áreas } \\
\text { erosionadas, } \\
\text { erosión potencial } \\
\text { alta durante } \\
\text { crecidas. }\end{array}$} & \multicolumn{4}{|c|}{$\begin{array}{l}\text { Inestable, áreas } \\
\text { erosionadas o } \\
\text { desnudas } \\
\text { frecuentes, en } \\
\text { secciones rectas y } \\
\text { meandros. } \\
\text { Desprendimiento } \\
\text { de ribera. } 60- \\
100 \% \text { de la ribera } \\
\text { con signos de } \\
\text { erosión. }\end{array}$} \\
\hline PUNTAJE & 10 & & 9 & & 8 & 7 & 6 & 5 & 4 & 3 & 2 & & 1 & 0 \\
\hline PUNTAJE & 10 & & 9 & & 8 & 7 & 6 & 5 & 4 & 3 & 2 & & 1 & 0 \\
\hline
\end{tabular}

\begin{tabular}{|c|c|c|c|c|c|c|c|c|c|c|c|}
\hline \multirow[b]{3}{*}{$\begin{array}{l}\text { PARAMETRO } 9 \\
\text { Protección } \\
\text { vegetal (cada } \\
\text { ribera por } \\
\text { separado) }\end{array}$} & \multicolumn{11}{|c|}{ Ranking } \\
\hline & \multicolumn{2}{|c|}{ OPTIMO } & \multicolumn{3}{|c|}{ SUBOPTIMO } & \multicolumn{3}{|c|}{ MARGINAL } & \multicolumn{3}{|c|}{ POBRE } \\
\hline & \multicolumn{2}{|c|}{$\begin{array}{l}\text { Más del } 90 \% \text { de la } \\
\text { ribera y la zona } \\
\text { ribereña inmediata } \\
\text { cubierta de } \\
\text { vegetación nativa } \\
\text { (árboles, arbustos, } \\
\text { macrófitas, } \\
\text { herbáceas). Mínimas } \\
\text { alteraciones por } \\
\text { pastoreo o } \\
\text { movimiento de } \\
\text { animales. Casi todas } \\
\text { las plantas pueden } \\
\text { crecer naturalmente. }\end{array}$} & \multicolumn{3}{|c|}{$\begin{array}{l}70-90 \% \text { de las } \\
\text { superficies de la ribera } \\
\text { y la zona ribereña } \\
\text { inmediata cubierta de } \\
\text { vegetación nativa, un } \\
\text { estrato no } \\
\text { representado. } \\
\text { Disrupciones evidentes } \\
\text { pero no afectan el } \\
\text { potencial crecimiento } \\
\text { de las plantas al menos } \\
\text { en gran extensión, } \\
\text { herbáceas con más de } \\
\text { la mitad de su altura } \\
\text { potencial. }\end{array}$} & \multicolumn{3}{|c|}{$\begin{array}{l}50-70 \% \text { de las } \\
\text { superficies de } \\
\text { ribera cubiertas } \\
\text { con vegetación, } \\
\text { disrupciones } \\
\text { obvias, } \\
\text { vegetación en } \\
\text { parches, } \\
\text { herbáceas con } \\
\text { menos de la } \\
\text { mitad de su altura } \\
\text { potencial. }\end{array}$} & \multicolumn{3}{|c|}{$\begin{array}{l}\text { Menos del } 50 \% \text { de } \\
\text { las superficies de } \\
\text { la ribera cubiertas } \\
\text { con vegetación. } \\
\text { Vegetación de las } \\
\text { márgenes muy } \\
\text { alterada, la } \\
\text { vegetación ha sido } \\
\text { removida hasta } 5 \\
\text { cm o menos en } \\
\text { promedio de } \\
\text { altura. }\end{array}$} \\
\hline PUNTAJE & 10 & 9 & 8 & 7 & 6 & 5 & 4 & 3 & 2 & 1 & 0 \\
\hline PUNTAJE & 10 & 9 & 8 & 7 & 6 & 5 & 4 & 3 & 2 & 1 & 0 \\
\hline
\end{tabular}




\begin{tabular}{|c|c|c|c|c|c|c|c|c|c|c|c|}
\hline \multirow[b]{3}{*}{$\begin{array}{l}\text { PARAMETRO } 10 \\
\text { Ancho de la } \\
\text { zona de } \\
\text { vegetación } \\
\text { ribereña (cada } \\
\text { ribera por } \\
\text { separado) }\end{array}$} & \multicolumn{11}{|c|}{ Ranking } \\
\hline & \multicolumn{2}{|c|}{ OPTIMO } & \multicolumn{3}{|c|}{ SUBOPTIMO } & \multicolumn{3}{|c|}{ MARGINAL } & \multicolumn{3}{|c|}{ POBRE } \\
\hline & \multicolumn{2}{|c|}{$\begin{array}{l}\text { Ancho de la zona } \\
\text { ribereña }>18 \mathrm{~m} . \\
\text { Sin impacto de } \\
\text { actividades humanas } \\
\text { (estacionamiento, } \\
\text { rutas de grava, talado, } \\
\text { céspedes, } \\
\text { sembradíos). }\end{array}$} & \multicolumn{3}{|c|}{$\begin{array}{l}\text { Ancho de la zona } \\
\text { ribereña } 12-18 \mathrm{~m} . \\
\text { Mínimo impacto de } \\
\text { actividades humanas. }\end{array}$} & \multicolumn{3}{|c|}{$\begin{array}{l}\text { Ancho de la zona } \\
\text { ribereña 6-12 m. } \\
\text { Con impacto en } \\
\text { la zona por } \\
\text { actividades } \\
\text { humanas. }\end{array}$} & \multicolumn{3}{|c|}{$\begin{array}{l}\text { Zona ribereña de } \\
\text { menos de } 6 \mathrm{~m} . \\
\text { Poco remanente. }\end{array}$} \\
\hline PUNTAJE & 10 & 9 & 8 & 7 & 6 & 5 & 4 & 3 & 2 & 1 & 0 \\
\hline PUNTAJE & 10 & 9 & 8 & 7 & 6 & 5 & 4 & 3 & 2 & 1 & 0 \\
\hline
\end{tabular}

